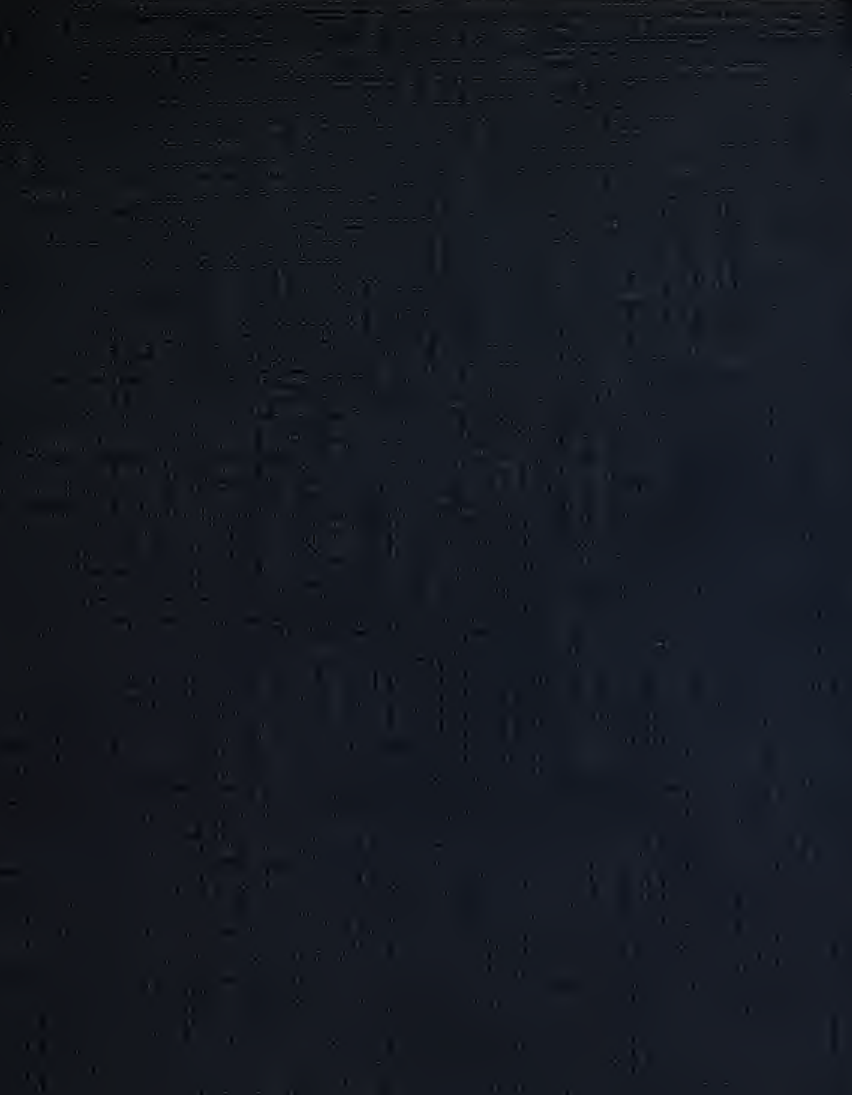


LIBRARY UNIVERSITY OF CALIFORNIA IRVINE
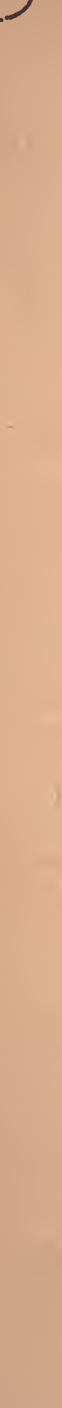


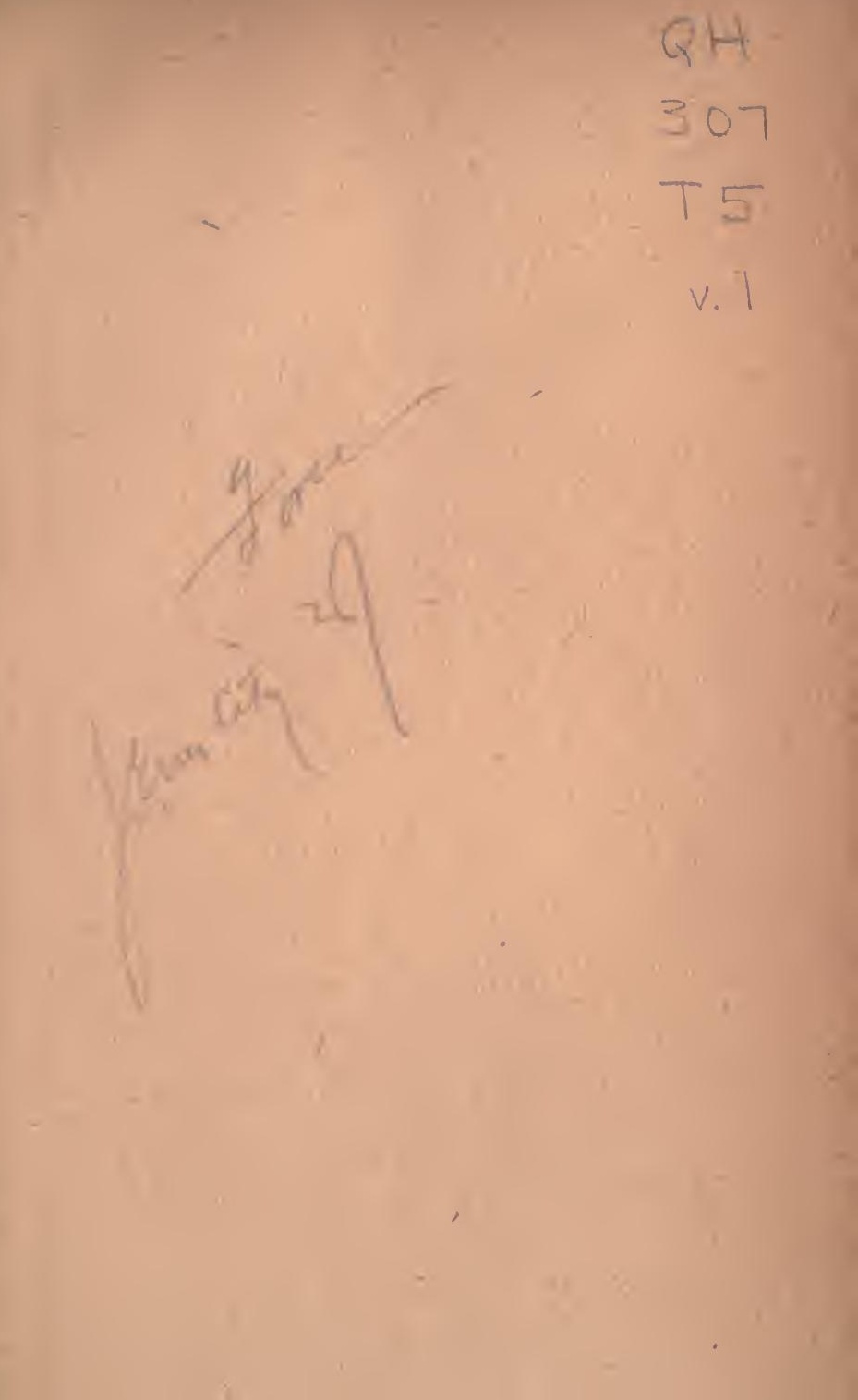


(1)

$+1$

I

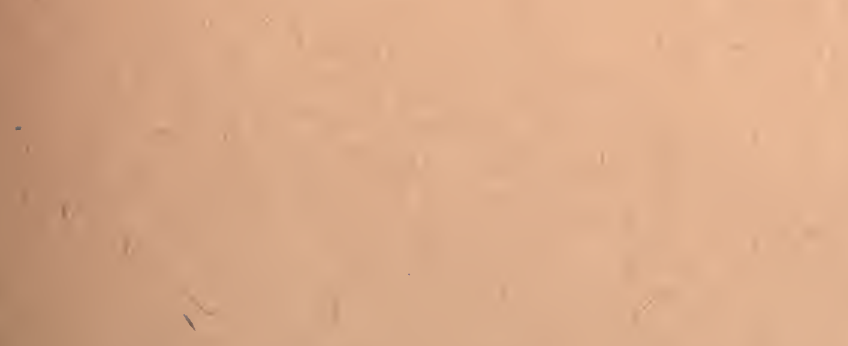

8

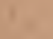




\section{THE SYSTEM OF ANIMATE NATURE}

THE GIFFORD LECTURES DELIVERED IN

THE UNIVERSITY OF ST. ANDREWS

IN THE YEARS 1915 AND 1916

BY

J. AR'THUR 'THOMSON, M.A., LL.D.

Professor of Natural History in the University of Aberdeen

IN TWO VOLUMES

VoL. I

NEW YORK

HENRY HOLT AND COMPANY 
Copyrient, 1920

BY

HENRY HOLT AND COMPANY

Che Qumn \& 3 Toben Company

BOOK MANUFACTURERS RAHWAY NEW JERSEY 
GRATEFULLY INSCRIBED TO

MY TBACHER, COLLEAGUR, AND FRIEND,

PROFESSOR PATRICK GEDDES 
"All depends on keeping the eye steadily fixed on the facts of nature and so receiving their images simply as they are. For God forbid that we should give out a dream of our imagination for a pattern of the world: rather may He graciously grant us to write an apocalypse or true vision of the footsteps of the Creator imprinted on His creatures."

Bacon

"This I dare affirm in knowledge of Nature, that a little natural philosophy, and the first entrance into it, doth dispose the opinion to atheism, but on the other side, much natural philosophy and wading deep into it, will bring about men's minds to religion."

BACON 


\section{PREFACE}

IT was evidently the desire of the founder of the Gifford Lectureships in the Scottish Universities that each lecturer should, from his own special studies and in his own way, endeavour to make some contribution that would help others in considering the highest questions that Man can ask: What kind of world is this in which wo live-a universe or a multiverse? How has it eome to be as it is? Does it give any hint of a purpose? What is Man's place in Nature? To what extent does our knowledge of Nature conform with our conception of God?

Lord Gifford contemplated the possibility of very varied answers to these and similar questions; he thought it possible that some of them might be held to be unanswerable; his one stipulation was for reverent study.

Under provisions so liberal, no apology need be mado for a contribution which is scientific rather than philosophical, being in the main confined to the biological outlook. Whatever be our philosophical interpretation or our religious conviction, we must admit the desirability of having more than a passing acquaintance with the system of things of which our everyday life is in some measure part. The idea of Nature as a temptress leading man's soul astray has long since disappeared, and most of us turn to Nature with expectancy, varying with our temperament and experience. If the world we call "outer" be in any sense God's creation, will it not reveal to us something of Him? If it be our chief end to glorify God, should we not put ourselves in the way 
of intellectually enjoying the works of His hands? If Nature is expressing a thought, may we not try to spell this out by patient observation? Even if we have no philosophieal or religious preconceptions of this sort, we are likely to understand our own life better by inquiring into the order of things in which we are immersed, sometimes, perhaps, almost submerged.

The aim of this study of Animate Nature is to state the general results of biological inquiry which must be taken account of if we are to think of organic Nature as a whole and in relation to the rest of our experience. Both among careful thinkers and careless passers-by views of organic Nature are held, in regard, for instance, to the organism as mechanism, tho determinism of heredity, the struggle for existence, which seem to the author to bo lacking in accuracy or in adequacy, which therefore tend to involve unnecessary difficulties in systematisation and perhaps gratuitous confusion in conduct. It has been declared by some that the world of life is "a dismal cockpit", that in the behaviour of living creatures mind is a negligible quantity, that the study of heredity must leave us fatalistic, and that evolution is largely "a chapter of accidents". Such views engender what may be called natural irreligion, and it is the object of this course to show that such views are scientifically untenable.

Nature doubtless presents many puzzling features, but care must be taken to make sure that what seem to be unconformabilities are not due to the inadequacy of our knowledge. While trying to keep wishes from fathering thoughts, we have been led in our study to see that the general results of Biology, when stated with accuracy, are not out of line with transcendental conclusions reached along other paths,-conclusions which different minds express in different forms. 
It looks as if Nature were much more conformable than is often supposed to religious interpretation, but we have not seen it to be our duty to justify the ways of God to man. We have tried to keep as close as possible to the facts of the case, leaving philosophical and religious inferences for those who are better qualified to draw them.

Our endeavour to present the scientific view of Animate Nature has often led only to a disappointing balancing of alternative formulations, for science abounds in open questions; it has also involved considerable noise of facts throughout the lectures, for there is no other way of getting beyond mere opinions. But it will be understood that the appeal to facts is not exactly for their own sake, as in a course of lectures on deseriptive Biology, but as a basis for those distinetive biologieal and psycho-biological concepts of organism, behaviour, development, heredity, evolution, and so on, which must be included in a philosophical view of Nature.

It would be ungracious not to use this opportunity of thanking many friends in St. Andrews and Dundee-especially Principal Sir John Herkless and Principal John Yule Mackay-from whom I received much kindness while delivering theso lectures.

UNIVERSITY OF ABERDEEN,

May, 1919. 



\title{
CONTENTS
}

\author{
PART I. \\ THE REALM OF ORGANISMS AS IT IS.
}

\section{LEECTORE 1.}

THE UNFATHOMED UNIVERSE AND THE AIM OF SCIENCE

8 1. Man's Early ()utlook on Nature, 3-\$2. Growing Recognition of a Scientific (Mrder, 4-8 3. Aims of Science, 88. Limitations of Natural Knowledge, 13-85. The Function of Feeling in our View of Nature, 25-86. Towarda a Philosophical Interpretation of Nature, 34-87. Science and Religion, 39.

\section{LECTURE II.}

THE REALM OF ORGANISMS CONTRASTED WITH THE DOMAIN OF THL INORGANIC . . . . . .

81. Things and Living Creatures, 49-82. The Characteristic Features of the Realm of (Organisms, 50-83. A Multitude of Individualities, yet a Systema Natura, 5184. Abundance and Insurgence of Life, 53-85. Struggle and Sifting, 56-\$6. A System of Inter-related Lives, 58\$7. The Prevalence of Adaptations, 59-8 8. The Pervasiveness of Beauty, 62-\$9. The Other Side of the Picture, 63810. Resemblances between the Realm of Organisms and the Domain of the Inorganic, 63-\$11. Contrasts between the Realm of Organisms and the Domain of the Inorganie, 71-8 12. The Suitability of the Inorganic to be the Basis and Environment of the Organic, 73.

\section{LECTURE III.}

THE CRITERIA OF LIVINGNESS

8 1. Living and Not-living, 79-8ీ 2. The Essential Characteristics of Living Urganisms, 80-\$3. Persiatence of a Complex Specific Metabolism and of a Corresponding Specific Organisation, 81-84. The Capacity of Growth, Reproduction, and Development, 9I-\&5. Effective Behaviour, Registration of Experience, and Variability, 97. 


\section{LECTURE IV.}

\$1. Is Organism More than Mechanism?, 107-8 2. Chemical and Physical Laws Apply to (Mrganisms, 110-\$3. Some 1)ifficulties in the Application of Physical and Chemical Formulæ to Organisms, 113- 84 . Criticism of Mechanistic Deseriptions of Everyday Functions, 117- $\$ 5$. Criticism of Mechanistic Descriptions of Animal Behaviour, 122-\$6. Difficulty of Applying Mechanistic Formulx to Development, 126- 7 . Dilliculty of Applying Mechanistic Formula to Urganic Evolution, $131-\$ 8$. Answers to Criticisms, 135.

\section{LECTURE $\nabla$.}

\section{THE UNIQUENESS OF LIFE'}

$\S 1$. The Inadequacy of a Mechanistic Description of Organisms Is a Negative (onclusion, $143-\$ 2$. The Problem: Vitalism or Mechanism, or Neither?, 144-\$3. Are Organisms Unique in Virtue of their Complexity?, 147-\$4. Have Organisms a Monopoly of Some Peculiar Energy or Energies?, 149$\$ 5$. Is there a Non-perceptual Vital Ageney resident in Organisms and Operative in distinctively Vital Activities?, 153-\$6. Descriptive or Methodological Vitalism: the 'Biological'View, 159-\$7. Spcculative, 163-\$8. Retrospeet, 166 $-\$$ !). Why Cannot the Controversy between Mechanistic and Vitalistic Theory be Ended?, 169.

\section{LECTURE $\nabla I$.}

ANIMAL BEHAVIOUR .

\$1. What Is Behaviour?, 175-\$2. Diverse Views as to Animal Behaviour, $177-\$ 3$. Activities of Unicellular ()rganisms, $179-\$ 4$. Spceial Case of Shell-building among Arenaceous Foraminifera, $185-\$ 5$. leflex Actions, 186- $\$ 6$. Tropisms, 192- $\$ 7$. Non-intelligent Experimentation, 195\$ 8. Instinetive Behaviour, $198-\$ 9$. Theories of Instinct, $203-\$ 10$. Evidence of Intelligent Behaviour, $211-\$ 11$. Secondary Simplifications of Behaviour, 215-\$ 12. Rational Conduet, 217- $\$ 13$. General Impressions of Animal Behaviour, 217.

\section{LECTURE $\nabla I I$.}

\section{THE PROBLEM OF BODY AND MIND . . . . . .}

\& 1. The Approach to the Problem, 227-\$2. What Must Be Recognised from the Biological Side, 230-\$3. What Must Be Recognised from the Humanist Side, 234-8 4 . Various Theories of the Relation of 'Mind' and 'Body', 236- $\$ 5$. Monistic Speculation along the Line of the Double-Aspect or Correlation Theory, 251 . 


\section{LECTURE VIII.}

8. A Synoptic View of Animate Nature Must Include the Fact of the Pervasiveness of Beauty, 259-82. General Char. acteristics of the Esthetic Emotion, 260-83. Beauty a General Quality of Animate Nature, 261-\$4. Theoretical Ubjections to the Thesis, 261-\$5. Cuncreto Ubjections, 2658. F. Factors in Nisthetic Delight, 267-\$7. Aspects of Beauty in Animate Nature, 271-88. Biological Significance of Beauty to the Beautiful Animals themselves, 275-\$!). Beauty of Animal Artitice, 278-8 10. Evolution of Aisthetic Emotion, $279-811$. The Signifeance of the Pervasive Beauty
of Animate Nature, 282.

\section{LECTURE IX.}

THE ISSUES OF LHFE .

81. The Tacties of Animate Natur', $289-82$. The Twofold Business of Life, $291-83$. The Struggle for Existence, 2938. Correction of Some Misconceptions of the Struggle for Existence, $301-\$ 5$. The Welfare of the Species, 305- $\$ 6$. As regards Warfare, 308.

\section{LECTORE I.}

\section{ADAPTIVENESS AND PURPOSIVENESS}

8 1. Animate Nature Abounds in Adaptations, 319-8 2 Their ()rigin neither by Design nor Mechanical, 325- 8 . Is There 'Purpose" in the Inorganic Domain?, 330-84 Purposefulness and Purposiveness in Human Behaviour, 33185. Purposiveness and Purposefulness in Animal Behaviour, $335-86$. The l'urposelikeness of the Urdinary Functioning of the Body is Covered ly the Concept of Adaptation, 3417. Provisional Conclusion and Anticipation, 343. 



\section{PART I.}

\section{THE REALM OF ORGANISMS AS IT IS.}





\section{LECTURE I.}

THE UNFATHOMED UNIVERSE AND THE AIM OF SCIENCE. 



\section{LECTURE I.}

\section{THE UNFATHOMED UNIVERSE AND THE AII OF SCIENCE.}

§1. Man's Early Outlook on Nature. §2. Growing Recognition of a Scientific Order. §3. Aims of Science. §4. Limitations of Natural Knowledge. §5. The Function of Feeling in our View of Nature. §6. Towards a Philosophical Interpretation of Nature. \$7. Science and Religion.

\section{$\S$ 1. Man's Early Outlook on-Nature.}

Is early days men must have looked somewhat distractedly and uncomprehendingly on the erowded world without, discerning only glimpses of order amid the big booming confusion. There is a ring of truth in the fine description Eschylus gave, that-“ "first, beholding they beheld in vain, and, hearing, heard not, but like shapes in dreams, mixed all things wildly down the tedious time, nor knew to build a house against the sun with wicketed sides, nor any wood-work knew, but lived like silly ants, beneath the ground, in hollow eaves unsunned. There came to them no steadfast sign of winter, nor of spring flower-perfumed, nor of summer full of fruit, but blindly and lawlessly they did all things."

Poincaré speaks of the days before Man learned from the stars that there was a reign of law. "Isolated amidst a nature where everything was a mystery to him, terrified at each unexpected manifestation of incomprehensible forces, he was incapable of seeing in the conduct of the universe anything but caprice" (1913, p. 290). So large were 
the seas of ignorance, so many the straits, that there was as yet no discernment of the coherent continents of knowledge.

Gradually, however, Man came to himself and grew in knowledge of the empirical order of Nature. It was a great step when he first recognised the year with its object-lesson of recurrent scquences-a basis from which to observe other practically important uniformities. What a momentous beginning the Chaldxans made who first discerned that the multitude of the stars was " not a confused crowd wandering at random, but rather a disciplined army"! It was a working knowledge of natural processes, rather than an understanding of them, that was in the first instance built up, and it was correlated, on the one hand, with a still very imperfect mastery of the forces of Nature, and, on the other, with a belief in magic and in the possession of things by spirits-imaginative constructions which are perhaps analogous, as Prof. W. E. Ritter suggests, to the materialism and animism of later days.

\section{§ 2. Growing Recognition of a Scientific Order.}

The empirical order was gradually replaced by a scientific order. Some practical need pressed a question home; imagination found a clue; measurement or some other form of accurate registration furnished reliable data; a regularity of sequence was discovered and tested; a law was formulated. Especially after the foundation-laying work of Galileo, did the scientific reconstruction of the physical world proceed apace. There was a period of the discovery of the 'Forces of Nature' and of the 'Laws of Nature', and a growing clearness. "God said, Let Newton be, and there was light." 
The scientific order has grown like an organism. Its methods have become more penetrating; improvements in instruments (such as telescope and microscope, spectroseope and radioscope) have almost meant new senses. Its standard of accuracy has been raised, many residual phenomena and minute discrepancies, previously neglected, have pointed the way to discoveries, as in the case of Argon. Its concepts have been periodically thrown into the crucible of criticism, and come out clcarer, or not at all. Thus force, instead of being a power inherent in substances, became a measure of the rate of transference of energy, and heat became a mode of motion. Large bodies of facts which used to be regarded as beyond science, the weather and dreams for instance, have become amenable to scientific treatment.

The progress of science wrought inevitable changes in man's outlook. The work of Copernicus and Galileo shattered the geocentric theory, which made our Earth the centre of the solar system, and subsequent discoveries showed what a small corner of the universe our whole system occupies. Not that we estimate man's kingdom in furlongs! The great discoverers in astronomy, physics, and chemistry revealed more and more clearly the reign of law in the inorganic world. No room was left for guidance or control other than there is in the nature of things themselves; no room was left for interventions or influxes; and the idea that physical events were immediately ordered " by the hand of God" in relation to human interests disappeared like a dream. There came indeed to be an exaggeration of the omnipotence of the Laws of Nature-man's formulations of observed uniformities of sequence, which, although they evidently approximate to reality, cannot be invested with 
absolutism. Yet the old order ehanged, giving place to a new-the whole inorganic world was more and more completely and consistently analysed in terms of dynamics.

In regard to the realm of organisms also the outlook ehanged. The filiations of living ereatures were diseovered and the special creationists retreated before the erolutionists. It was shown that the living body is the theatre of many chemical and physical operations in a line with those of the inorganic domain. The chains of physiological events that make up everyday functions and behaviour were disclosed. Plants and animals were brought under the reign of law. The fitnesses or adaptations which seemed to speak so eloquently of a direct Designer were shown to be the outcome of long-continued processes of varying and sifting. And when Man's zoological place in Nature was recognised, the a anthropocentric theory saw the beginning of its end. Even for those who continue to maintain, rightly we think, that organism is more than mechanism, that organic evolution is not a mechanical process, that thinking, feeling, and willing are activities that count, that man transeends his ancestry, and that it is not only legitimatc but necessary to regard the cosmic process in the light of its outcomethe whole aspect of the world has changed.

But experience is the only limit to the application of scientific methods, and a new psychology began to accompany the new physiology, rather at the risk of its own life, to be sure, because of its partner's appetite. The outlook was changed by the disclosure of the close interdependence of what is conveniently called ' mind' and what is conveniently called 'body', by increased knowledge of the individual development and racial evolution of mental powers or modes of behaviour, by a disclosure of a certain 


\section{THE UNFATHOMED UNIVERSE}

amount of common ground between man and beast, by an analysis of obligatory modes of activity which we call reflexes and tropisms, and so on. Thus science has extended its claims.

With the advance of natural knowledge-at times very slowly, and again by leaps and bounds-has come an increased control of Nature which is as rich in promise as in achievement. We have recalled the picture Aschylus gave of our ancestors-living in caves, fearful of wild beasts, often dying of hunger or of poison, without wood-work or metals, without fire, without foresight, and unable to think of the general well-being. What a contrast between that picture and our life to-day. For nowadays the serpent that bites Man's heel is in nine cases out of ten microscopic; year by year Man increases his mastery over the physical forces; he coins wealth out of the thin air; he annihilates distance with his shrewd devices; he makes the ether carry his messages; he is extending his rule to the heavens; and he is making experiments on the control of life itself. In the so-called purely physical domain, at least, his dreams have more than come true.

After a long period during which science consisted of numerous discrete bodies of knowledge, largely related to the practical control of Nature, there began to be concentration into a system, a sort of cosmology. Science entered upon a new and purely theoretical rôle of giving man a composite picture of the world and its processes. This is increasingly impressive, the more we realise it-which means hard work. After a long ascent we get a new view, æsthetieally magnificent, intellectually a revelation of connectedness. But, fine as it is, the scientific picture has satisfied very few thinkers of distinction, the chief reason being 
that the contributions which each science makes are always partial views, reached by processes of abstraction, by focussing attention on certain aspects of things. Pooling the results of the several sciences does not of itself result even in a scientific system, for that requires correlation. Still less does it result in a philosophic system. This will be clearer if the aims of science are discriminated.

\section{$\S$ 3. Aims of Science.}

Science expresses a quite specific endeavour to get phenomena under intellectual control, so that we can think of them economically and clearly in relation to the rest of our science, and so that we can use them as a basis for secure prediction and effective action. Knowledge is foresight, and foresight is power. The direct motives of seience are, in the main, intellectual curiosity, a self-preservative dislike of obscurities, a desire for unity and continuity in outlook. Often, in particular cases, the immediate motive may have been utilitarian-a desire for mastery; but the great majority of important practical discoveries have behind them a long labour of theoretical research pursued for its own sake.

That the chief end of science is descriptive formulation has probably been clear to keen analytic minds since the time of Galileo, especially to the great discoverers in astronomy, mechanics, and dynamics. But as a definitely stated conception, corrective of misunderstandings, the view of science as essentially descriptive began to make itself felt about the beginning of the last quarter of the nineteenth century, and may be associated with the names of Kirchhoff and Mach. It was in 1876 that Kirchhoff defined the task of mechanics as that of "describing completely and in 
the simplest manner the motions which take place in $\mathrm{Na}$ ture". Widening this a little, wo may say that the aim of science is to describe natural phenomena and occurrences as exactly as possible, as simply as possible, as completely as possible, as consistently as possible, and always in terms which are communicable and verifiable. This is a very different rôle from that of solving the riddles of the universe, and it is well expressed in what Newton said in regard to the law of gravitation. "So far I have accounted for the phenomena presented to us by the heavens and the sea by means of the force of gravity, but I have as yet assigned no cause to this gravity... I havo not been able to deduce from phenomena the raison d'être of the properties of gravity and I have not set up hypotheses" (Newton, Philosophia naturalis Principia Mathematica. 1687).

"We must confess," said Prof. J. H. Poynting (1900, p. 616), "that physical laws have greatly fallen off in dignity. No long time ago they were quite commonly described as the Fixed Laws of Nature, and were supposed sufficient in themselves to govern the universe. Now we can only assign to them the humble rank of mere descriptions, often erroneous, of similarities which we believe wo have observed. . . A law of nature explains nothing, it has no governing power, it is but a descriptive formula which the careless have sometimes personified." It used to be said that "the laws of Nature are the thoughts of God"; now we say that they are the investigator's formulæ summing up regularities of recurrence.

This view of the function of science must be accepted as expressing at least part of the truth, for who should know better what they are aiming at than the great discoverers themselves? But is it not necessary to make certain reserva- 
tions? (a) First, instead of explaining an event by showing that it obeys a law of Nature, the modern investigator is content to say that it is fully described or represented in such and such a formula, that it can be included in this or that typical case. As Aristotle said, from a great number of experiences one general conception is formed which will embrace all similar cases. There is unification under a common law. As Clifford says, "A truo explanation refers ihe previously unknown to the known." It assimilates the less known to the better known. But we must not overlook the preliminary analysis and reduction to a common denominator which made it possible to bring an apparent incommensurable into a series, and to recognise unity and continuity of process. Equations may not be explanations, but the analytic descriptions given by exact science are very different from the pictorial descriptions of everyday life. There is sometimes a mock modesty in the declaration of the scientific inquirer that he is describing not explaining; and there is deceptiveness in his formulation, if he reaches his simplification by violence, by a jugglery which coerces to a common denominator such fractions of reality as motion and emotion which are radically incommensurable.

(b) Second, there are laws of Nature such as Gravitation, which sum up uniformities in terms largely independent of hypothetical constructions. These must be distinguished from summations in terms of what Rankine called "conceptions of a conjectural order" which image the intimate nature of things and processes. Ohm's laws remain, whatever be our view of electrical energy. Mendel's law remains, whatever be our views as to what are called 'fac tors' in inheritance. As long as we consider moving bodies in bulk within sensible distances of the earth, the law of 
gravitation holds absolutely, and states without hypothesis how the motions of the bodies and the earth are mutually affected. But if we proceed, with Le Sage or some other, to a theory of gravitation, we enter a realm of imaginative construction. We work with concepts which are, no doubt, ingenious, well-thought-out, consistent, and useful; but how far they correspond to, or are representative of objective entities is a question to be carefully considered. Sometimes the concepts that are effectively worked with are obviously mere symbols; thus no one supposes that carbon atoms aro really like their quite useful quadrumanous diagrammatic representations in books on chemistry. The difficulty is in regard to subtler symbols or concepts, which work so well that wo inevitably come to think of them as objective actualities. And it may be that what was at first an imaginative thought-economising symbol, part of a system of intellectual shorthand, will be actually verified in Nature. Thus many physicists now speak confidently and convineingly of the 'reality' of the atom. When it is legitimate to speak of a scientific symbol as real is a matter for the experts only, as is plain enough from their disagreement. Thus the ether was declared by Lord Kelvin to be the greatest certainty in physies, while we find the upholders of the Principle of Relativity declaring that the Victorian ether and the Victorian matter must both go. Similarly in biological problems, such as those centred in inheritance, there is divergence of opinion as to the objectivity of 'biophores', 'determinants', 'factors', and 'genes', though these are very useful in formulating conclusions and prompting further questions.

(c) Third, it has to be remembered that the descriptive formulx are more than summations of the routine of in- 
dividual experience (a view which would lead us near the impasse of solipsism), for they are verifiable by all normally constituted minds, and that they must have a close correspondence with the actualities of Nature sinee the predictions based on them are fulfilled. We continually risk our lives on the closeness of this correspondence. That we are not betrayed proves, not that the coneepts or intellectual counters used in representation are like the real things, or are even the only usable concepts, but that the uniformities which the concepts are used to detect and to represent are real.

Speaking of the electrical theory of matter, the late Prof. J. H. Poynting said: "The ehief value of such hypothesis lies, not in its objective truth, but in its success in accounting for, in co-ordinating, what we actually observe, and in predicting results which are afterwards verified. It is to be regarded as a 'working model' which gives the same results as the actual atom, though, it may be, by quite different machinery." While adhering to this view, let us, however, safeguard it by recognising that the validity of the working model depends on its verifiability, and on its correspondence with actualities. As Hertz said, the quality of scientific symbols is such that their intellectually necessary consequences correspond to occurrences. For certain purposes the view that the sun goes round the earth is just as effective as the conclusion that the earth goes round the sun. We can rise at dawn with equal punctuality on either hypothesis. But beyond a short radius the former will lead us hopelessly wrong, while the latter never will.

(d) Fourthly, it is interesting to notice that Bacon did not include historia naturalis in his encyclopædia of the sciences, probably because it remained too concretely de- 
scriptive and did not admit of formulation in terms of abstract concepts, as astronomy, for instance, does. Yet there is in natural history a kind of description which is just as essential in its own place as is mechanical or dynamical description-namely, historical deseription. We would not buy a horse on the strength of a description in terms of the dynamics of particles, partly because we could not go far in the way of checking its accuracy, but mainly because of our shrewd conviction that the essential thing is to know what we can about the horse's history. Similarly, our science of the horse must include not only its whole architecture from skull to blood crystals, not only the consensus of its active parts from brain to phagocytes, but also its character and its individual and racial becoming. Even within the sciences of the inorganic, when dealing, for instance, with the geological interpretation of scenery or the establishment of the solar system, the description must be genetic or historical. It is an interesting point that, just about the time when Physics began to proclaim emphatically that its office was to describe not to explain, Natural History in Darwin's hands passed emphatically from description to historical explanation.

\section{$\S$ 4. Limitations of Natural Knowledge.}

Science makes so many permanent discoveries, which are never contradicted though often transcended, that she acquires an assured confidence which has only been equalled by that of Theology. For this very reason it is useful that she should be ever examining herself. One of the famous balance-sheets was that made by $\mathrm{Du}$ Bois-Reymond in his lectures on the Seven Riddles of the Universe and on the Limits of Natural Knowledge. $\mathrm{He}$ confessed that the 
science of his day could not offer any explanation of the origin of life, the apparent purposiveness of Nature, and the origin of language; but he did not hold that these enigmas were insoluble. On the other hand, as to the essence of matter and energy, the origin of motion, the fact of sensation, and the freedom of the will, his pronouncement was not only Ignoramus, but Ignorabimus. Similarly to-day, without ceasing for a moment to admire the splendour of scientific achievement, and the promise that there is of further conquests, we have to say many times Ignoramus, and perhaps it is no bad sign of the wholesomeness of modern science that it is acutely aware of its limitations-both intrinsic and extrinsic.

(a) To begin with, there is less forgetfulness of the fact that we know Nature only as it is mirrored in our minds. When we think of what science would have been if the stars had been always hidden in cloud, we realise that much has depended on the stimuli of the outer world; but the discernment of the cosmos has been within us, growing with our strength and hindered by our limitations. It is a familiar experience, for instance, that our immediate perceptual power increases at compound interest, the eye perceiving more and more as the mind is educated. Our concepts stimulate our perceptual powers to a higher degree of intensity.

(b) A large part of even the near at hand world is invisible, like the air. Much may escape all our senses, as the ultra-violet rays, which the ants feel, escape our eyes. It is said that there are living creatures, the Chlamydozoa, which lie just on the border-line of microscopic visibility; and beyond these minima sensibilia there may be organisms still smaller. An alien observer of the earth in 
early days might have complained of its azoic dullness, while the primitive Biococci were proliferating in billions beneath his feet. So to-day there may be forms of life and modes of energy around us which we do not know.

In any case, how different our world is from that of the man born blind; and what, asks John Burroughs, if we could go on opening one eye after another to the number of a dozen or so, and were able, he should have added, to correlate our impressions? What if we had three or more extra senses? How different our view of Animate Nature would have been if the microscope and the spectroscope, to name only two of our extraneous sense-organs, had not been invented! Apart from such imaginings we have many remarkable facts in regard to the cultivation of the senses that we have. The blind man knows every footstep in the village. In the opinion of some experts, there are considerable tracts of fallow ground in our brains, which may one day be tilled. How slow should Man be in supposing that ho has exhausted a subject! There are few who have even a calculus which will show them how far they have succeeded in discerning the more or less obvious inter-relations or 'aspects' of the object of their study. Warned by such errors as that of Comte, who declared that Man could never know anything as to the chemical composition of the heavenly bodies, we have learned to be cautious in not putting in 'full stops'. There is a large library now on the animals of the Deep Sea, yet it is not very long since a great naturalist declared that of the possible tenants of the Oceanic Abysses we could not hope to know anything unless some of them-if there were any-happened to tumble upwards to the superficial zones of reduced pressure. Science has reason to beware of saying "Non possumus". 
Yet, as a warning against finality in another direction, we must admit the vagueness that is apt to invest our knowledge of the past. In the perfectly exact sciences, we can sometimes work backwards with remarkable certainty to comets, eclipses, and the like; but in Biology how watchful we have to be lest we get entangled in the vicious circle of inventing a past from its continued life in the present, and then interpreting the present in terms of our invention.

(c) A reasonable humility of mind is also engendered by recognising how limited, after all, is our range of exact data. The late Professor Rowland, a distinguished physicist, writes $(1899$, p. 408$)$ : “In time we are limited by a few hundred or possibly thousand years. . . . In space we have exact knowledge limited to portions of our earth's surface and a mile or so below the surface, together with what little we can learn from looking through powerful telescopes into the space beyond. In temperature our knowledge extends from near the absolute zero to that of the sun, but exact knowledge is far more limited. In pressures we go from the Crookes vacuum, still containing myriads of flying atoms, to pressures limited by the strength of steel, but still very minute compared with the pressures at the centre of the earth and sun, where the hardest steel would flow like the most limpid water. In velocities we are limited to a few miles per second. In forces to possibly one hundred tons to the square inch. In mechanical rotations to a few hundred times a second." Perhaps some of these limits have been extended since Professor Rowland gave the address from which we have quoted, but that would not affect our point,-the importance of bearing in mind the limits of exact knowledge.

(d) Another limitation is involved in the very nature 
of scientific procedure, which makes headway by abstraction. Divide et impera is the scientific rule. The scientific description of Nature is made up of many partial views contributed by the several sciences. We have to confine our attention at a given time to certain aspects of a thing or process. We treat of the mass of a body as if we had the body under the influence of gravitation only, though we know that we cannot secure the entire absence of electrieal, magnetic, and other forces. Science works with perfect levers, with pure masses, 'ideal systems' in generalwhich we do not meet in everyday life.

In certain cases the abstracting is obvious and not dangerous; in other cases it escapes attention and leads to fallacy. We know that biologically we cannot abstract the trout from the stream; even for the purposes of analytical anatomy we must remember the environment, still more when dynamical relations are considered. This is obvious, but is it so obvious that a theory of animal behaviour which reduces all to 'forced movements' or tropisms is the outcome of "a process of abstraction which leaves out the eharacteristic features of the concrete fact to be explained ", the plasticity, the endeavour, the awareness of the organism?

(e) When we take the long and wide philosophical view of a subject, trying to see the phenomena or the process as a whole, the inevitable limitations of science must be borne in mind. If all Animate Nature is the outcome of a few Protists, we must see these in the light of the evolution as a whole. "The true nature of the antecedents, that is to say, of the apparent cause, is revealed only in the effeets" (Pringle-Pattison, 1917, p. 332); or should one not say the full nature? If wo believe that Tyndall's "matter" (British Association Address, Belfast, 1874), with its famous 
"promise and potency of all terrestrial life", is exhaustively described in terms of the dynamics of particles, then we cannot by any ingenuity evolve the conscious out of it; if on general grounds we feel bound to regard conscious life as evolved from Tyndall's " matter", then the reality of that "matter" could not be exhaustively described in terms of the dynamics of particles.

"All explanation of the higher by the lower is philosophically a hysteron-proteron. The antecedents assigned are not the causes of the consequents, for by antecedents the naturalistic theories mean the antecedents in abstraction from their consequents-the antecedents taken as they appear in themselves, or as we might suppose them to be if no such consequents had ever issued from them. So conceived, however, the antecedents (matter and energy, for example) have no real existence-they are mere entia rationis, abstract aspects of the concrete fact which we call the universe" (Pringle-Pattison, Man's Place in the Cosmos, pp. 11-12).

(f) The aim of science is not so much "to give an account of the whole matter", as used to be said, but rather to work out, patiently and piccemeal, a number of descriptions and formulations of diverse aspects, each for a certain purpose, by certain methods, in certain symbols. The chemist's account of a peacock's tail is an abstraction, and so is the physicist's, the biologist's, and the psychologist's. But even when all these results, reached by scientific abstraction, are pooled, we have not "an account of the whole matter"of "the positive full-orbed reality". That correlation often has to wait for genius. Moreover, the scientific synthesis, if it be achieved, requires to be assimilated with what the artist, the poet, and the genuine lover of birds may be able 


\section{THE UNFATHOMED UNIVERSE}

to tell us concerning the peacock's tail. Huxley's declaration that the advance of science is synonymous with description in materialistic symbols, assumed too readily that formulations which give Man a considerable power of prediction and a considerable degree of practical control are therefore theoretically exhaustive.

(g) But let us consider further limitations. We describe what goes on around us or within us in the simplest possible terms, but the fundamental concepts we use are notably in process of development. As Kirchhoff said, "It is thinkable that a description which to-day is the simplest that ean be given may in the further development of science be replaced by one still more simple." It is also thinkable, we may add, that some of our present-day formulations will turn out to be too simple, for abstraction often leads to fallacy. This at least is certain, that when we describe occurrences in terms of matter and energy, life and mind, or any similar grand concepts, we are working with what cannot be called self-explanatory. Every one of them is big with mystery, though some are in process of simplification. Much so-called 'explanation' is reducing unusual unintelligibility to order rather than to radical understanding. No achievement in science has been more satisfactory than the Law of Gravitation, but can any one tell what actuaily happens in the unseen universe when the apple falls in the orchard? In language which is a survival we still speak of the force of gravity, the force of attraction, and so on, but we know that forces as causes do not exist. The earth does not pull the stone, the stone gravitates to the earth. Some have proposed to speak of bodies 'tractating' and 'pellating' instead of saying that they attract or repel one another. But, as Professor Soddy says, "Why two bodies tractate or 
pellate is not known in a single instance, least of all perhaps in the oldest recognised case, gravitation" (Matter and Energy, pp. 111-12).

We know of over eighty elements and much about many of them, but do we know what being an element, like Mercury or Antimony, really means, or the import of their periodic classification? Great libraries are filled with our descriptions of the structure and activities of plants and animals, but do we know what livingness essentially is? We cannot define it at present in terms of anything else, we take it as 'given'. We cannot tell wherein consists the essential difference between the flight of a bird and the movement of a comet. How much, relatively speaking, is known of ' mind' and 'body', how little is known in regard to the relation between them, if there is a relation!

(h) We hear much of the achievements of science in tracing things back to their beginnings. That is the bistorical or genetic method, and it yields very interesting results. The present becomes more intelligible in the light of the past. But, when we get far back, how mysterious the beginnings become. How mysterious still, to tell the truth, are many of the big steps between the beginning and the end! In the inorganic sphere one collocation passes into another, usually without jolts. The course runs smoothly. But when we pass to organic evolution or even to individual development, we are almost driven back to a belief in magic! Who can tell even in the sketchiest fashion how a Silver Wyandotte was evolved from an Indian Jungle Fowl, or how stage gives rise to stage as the chick develops in three weeks from a minute transparent spot on the top of the yolk of an egg?

Matter has seemed to many easy-going minds a firm 
basis to start from, but what is matter, and what has been its history? Must there not have been a differentiation of various forms of matter, may there not have been a prematerial state of things, do we ever get to beginnings? This necessary limitation is well stated by Dr. Arthur Shipley:"No body of scientific doctrine succeeds in describing in terms of laws of succession more than some limited set of stages of a natural process; the whole process-if, indeed, it can be regarded as a whole-must for ever be beyond the reach of scientific grasp. The earliest stage to which science has succeeded in tracing back any part of a sequence of phenomena itself constitutes a new problem for science, and that without end. There is always an earlier stage and to an earliest we can never attain. The questions of origins concern the theologian, the metaphysician, perhaps the poet" (Schuster and Shipley, 1917, p. 276).

(i) Another limitation has to do with causal sequences. In ordinary scientific discourse, as Bergson points out, three different meanings of the term 'cause' are common. A cause may act by impelling (one billiard ball striking another), or by releasing (a spark exploding the gunpowder), or by unwinding (the relaxing of the spring turning the cylinder of a gramophone and having the melody as effect). Now "only in the first case, really, docs cause explain effect; in the others the effect is more or less given in advance, and the antecedent invoked is-in different degrees, of course-its occasion rather than its cause". (Creative Evolution, English Trans., p. 77).

In the domain of mechanics, in Gravitational Astronomy, we see the high-water mark of scientific description, in exactness and approximate completeness. There, with a clear intellectual conscience, we can proclaim, “causa æquat effec- 
tum"; for why, the resultant is just another form of the components. In the great majority of cases, however, where there is a qualitative change, we know that a given collocation of matter and energy gives rise to another, and does so uniformly, but we cannot tell why the resultant must be as it is and not otherwise. In the great majority of cases all that science can say is, "If this, then that"; and it is a very useful thing to be able to say.

Every one knows that oxygen and hydrogen will unite violently to form water, but all that we can say is that it is their nature to. Perhaps it may be explained as due to "the interplay between electricity and matter", and then we shall shift the pegs of our claim in the desert of ignorance.

We rub our eyes and say: "But surely it is the very business of Science to show how things happen, to explain occurrences." So in a sense it is, but as Professor Stout puts it, "What is really done is to show that a given result, often called an effect, is part of a continuous process which includes a known antecedent, often called the cause." Indeed, "the current scientific conception of a cause" is the " totality of the conditions in the presence of which an event occurs and in the alisence of any member of which it does not occur" (Taylor, 1909, p. 170).

(j) Finally there is a sense in which science, if not asymptotic, is bound for a long time to remain approximate. The Universe is still unfathomed.

(1) A scientific law formulates an observed routine in the order of nature, but sometimes it is only a provisional 'fit'. Residual phenomena emerge which lead to restatement. So Kepler improves on Copernicus, and Newton on Kepler.

(2) Even when the 'fit' of the formulation is more 
than approximate, extension or intensification of inquiry may show that it does not apply beyond certain limits. Thus the law of gravitation, which must be very near to perfect accuracy when applied to planetary distances, may not hold either for very minute molecular distances or for immense stellar distances.

(3) Even generalisations that work well and must bear a close correspondence to reality, since they afford a basis for effective prophecy, may require some modification, in their setting at least, in the light of some new fact or idea, of great magnitude. Thus Prof. Frederick Soddy writes: "It sounds incredible, but nevertheless it is true, that scienco up to the close of the nineteenth century had no suspicion even of the existence of the original sources of natural energy. . . The vista which has been opened up by these new discoveries [of the radio-active properties of some substances] is without parallel in the whole history of science" (Harper's Magazine, December, 1909, p. 53).

(4) We eannot pass over the caution suggested by the Michelson-Morley experiment, which showed that scientific observations cannot transcend the system in which they are immersed. In Prof. Wildon Carr's words, "It showed us that observers within a system of reference, in uniform movement of translation relatively to other systems, have no absolute standard by which they can determine their movement. There is no absolute ether, no absolute space, and no absolute time, by reference to which we can determine our movements" (1918, p. 21). And Prof. Max Planck writes of this new idea of the relativity of time: "With the revolution which it brings about in our conception of the physical universe, no other is comparable, in range 
and profundity, except that due to the introduction of the Copernican Astronomy."

(5) Finally, it may be useful to remember that, according to current and probably well-warranted scientific belief, there was once a time when what happened upon the earth might have been formulated in its immediacy with apparent exhaustiveness in terms of the dynamics of particles. But that cannot be said now. New aspects of reality have in the course of ages 'welled up' and required new sciences. We know, too, as we say, the ends of processes which in azoic days had only begun. And yet we are not sure that we know any ends (in the sense of goals), for the process continues. Science seems bound to be not only approximate but asymptotic, for its subject-matter continues to evolve.

One may have a more or less wholesome dislike of perpetual-motion mongers and their successors, but one resents scientific absolutism which will consider nothing that seems to infringe a law. For these laws, beyond those of mathematics, are not more than summations of experience in a certain limited here and now. The Uniformity of Nature which the legalists hold over us as a sacrosanct principle is a big assumption. For who shall define its tenure in a world of æonic flux?

We should remember, too, how thickly beset we are with unsolved problems of a less ultimate nature. What, for instance, is the commonest and most universal vital event? It is cell-division. And though the literature about it would fill a large library, we do not yet know the conditions of its occurrence or the forces at work in its accomplishment! When we succeed in stating a problem in a clear way it is gratuitous to speak of it as insoluble, but of the number of 
unsolved problems and of the way in which the solution of one raises another, every one is aware.

For the reasons we have indicated in this discussion and for others, there are many, in this age of extraordinarily rapid scientific discovery, who stand wondering before an unfathomed universe. We have made many charts, but there is still more sea. Perhaps one of the most hopeful signs at once of the progressireness of science and of its conformability with the humanities and philosophies is in its vivid realisation of its own limitations.

From the absence of a scientific answer to a scientific question, we do not dream of arguing, as has been often argued, that some other kind of answer, say thcological, must be true. We have to render to Cæsar the things that are Cæsar's; and there is no exchange betwcen scientific and transcendental coinage. But what we may usefully recognise is the self-imposed limitation of science, that it seeks, for certain purposes and by certain methods, to describe occurrences and processes in the simplest possible, universally verifiable terms, and that it does not pretend to exhaust their reality. This leads us to recognise the validity of feeling in an interpretation of Nature.

\section{§5. The Function of Feeling in our View of Nature.}

The world without has played a great part in the education of the human spirit. Its enigmas have quickened Man's intelligence; its practical problems have trained his will; Animate Nature in particular has been a school of feeling; the mother's face has been a factor in the evolution of personality (see Merz, 1916). In her manifold opportunities Nature has thus helped man to polish the mirror of his mind, and the process continues. Nature still supplies us with 
abundance of brain-stretching theoretical puzzles and we eagerly tackle them; there are more worlds to conquer and we do not let the sword sleep in our hand; but how does it stand with feeling? Nature is beautiful, gladdening, awesome, mysterious, wonderful, as ever, but do we feel it as our forefathers did?

What is this feeling for Nature? It may be a simple restfulness, such as Darwin once spoke of when for the moment he laid aside his questionings; it may be a keen æsthetic joy; it may be the thrill of a starry night; it may be the pleasure of seeing trust and affection in a dog's eyes; it may be the response our heart makes in spring when we hear the wild geese passing overhead on their northward migration, and know that another winter is over and gone; it may be that deep calls to deep, and we have a vicarious share in life's triumph over matter; it has often expressed itself in reverent worship; it may be an awed elation in finding ourselves part of so sublime a process as cosmic evolution. This element of feeling in our outlook on Nature is a satisfaction in itself, but our plea for allowing it to operate in our interpretation of Nature is that we get closer to some things through feeling than we do through science. Just as feeling contributes to our total appreciation of people, so of Nature. Through feeling we discern what science cannot get into focus. Not that any one dreams of mingling feeling with science or of attempting to eke out science with feeling, but to try to exclude feeling from our total view of Nature is to try to close one of the right-ofway paths to reality. Goethe went the length of saying: "Sympathy and enjoyment in what we see is in fact the only reality, and, from such reality, reality as a natural product follows. All else is vanity." 


\section{THE UNFATHOMED UNIVERSE}

In the preface to his Diversions of a Naturalist (1915, p. vi), Sir Ray Lankester, who has so greatly enriched Zoology, speaks in a very interesting way of the value of science in giving us prevision and control, but goes on to say: "Science commends itself to us as does Honesty and as does great Art and all fine thought and deed-not as a policy yielding material profits, but because it satisfies man's soul." This is very different from the old moan that increase of knowledge is increase of sorrow, and surely more wholesome, but we wonder if it is true. Is it science that satisfies man's soul, or is it the attendant feeling and imagining which the study of Nature evokes?

There have always been men of science, tough-minded by birth, to whom an enthusiasm for natural knowledge has been in itself enough, who have asked for no satisfaction from either faith or feeling; and the world owes much to their preoccupation. But this has not been true on the whole; the unsatisfyingness of an exclusively scientific view of Nature has been confessed age after age.

In the ages of the empirical order Man had his imaginative constructions of early magic and of early animism. These were attempts to eke out very imperfect understanding and very imperfect control of Nature, but they were also sops to feeling. The replacement of the empirical order by the scientific order was great gain. It meant a less beclouded intellectual sky and a greatly increased mastery of natural resources. But with the gain came loss, for the reconstructions of science are austere, not home-like to the human spirit. The creations of early days-the attractive elves as well as the repellent gnomes-were scattered by the growing light of science, save a few which found refuge and here and there still linger in the caverns of Man's mind. There is 
no doubt that the scientific method is antipodal to feeling, and that scientific methods and systems are almost hostile. So we tend to get further away from " an original relation to Nature", such as many children have, such as Emerson referred to when he said: "The earlier generations saw God face to face; we through their eyes. Why should not we also enjoy an original relation to Nature?"

It might be thought that the more science grows the more feeling should deepen. "All knowledge," Coleridge said, " begins and ends with wonder, but the first wonder is the child of ignorance, while the second wonder is the parent of adoration." Truly progressive science should enrich our feeling, for it gives to our vision depth, order, connectedness, and continuity, and makes the whole world more translucent and more full of meaning. But we have, after all, to admit that the light of science is as cold as it is clear. Keats was right in lamenting that the rainbow had never been quite the same, in spite of what Wordsworth said, since Newton looked at it with his discerning eye. No doubt that for any wonder Science dissipates, she gives us twain; but they are not the old homely wonders. No doubt, though Science is ever pushing the curtain back a little further, so that halfwonders disappear, the wonder remains. But the fundamental mysteriousness of Nature is cold comfort for the loss of the wonder of the rainbow and of the Northern Lights, of the flower in the crannied wall and of the way of the eagle in the air.

The fact is that it is rather the scientific mood than science that is opposed to feeling. For the eyes of the investigator have neither laughter nor tears. In the actual work of science, emotion is dangerous. For scientific purposes we must look out of one window only and with all possible con- 
centration. It has been said, though it is a dangerous halftruth, that the worst kind of comparative psychologist is the observer who is devoted to his animals.

Especially since Darwin's day, we have been learning in biology to see creatures in their spatial and temporal linkages, but it cannot be denied that the predominant method of science is analytic and deliberately abstract, whereas the tendency of feeling is always to see things whole -synoptically. As Goethe said, "these dissecting operations, ever and ever continued, produce likewise many a disadvantage; the living is indeed analysed into elements, but it cannot be brought together again out of them and animated ". Compared with the biologist's insight the shepherd's outlook is superficial, but unless the biologist can reconstruict and reanimate he has lost that view of things in their totality which the shepherd has. We may have a profound knowledge of the life-history of a creature and yet fail to get that imaginative vision which the authors of Animal Biographies have with less material made their own.

In the attempt to conserve what is reached through feeling, to which Man instinctively tries to hold firm, satisfaction has been sought in Nature-poetry, in symbolism, in Natural Theology, or in an idealisation of Nature in a religious halo. These avenues of satisfaction, these pathways to reality, for the two phrases mean much the same, remain happily open to many. To others, however, they are closed, partly because of the austerity of the scientific mood and partly because there is a lack of correlation. Thus much Naturepoetry is too like antiquarian or reminiscent architecture, evading the problem of idealising the present in offering us constructions whose beauty makes us forget for the time that they are anachronisms. Similarly, the spiritualisations 
offered by philosophy and by theology have often seemed unconvincing because imposed from without, instead of. arising in minds saturated with the actualities of the case. It goes without saying that there have been poets, philosophers, and theologians who have seized on the universal elements in Nature which are for all time. It is also obvious that Nature-poems may be literary treasures though they are no longer significant to us in our world-outlook. But what we want to get at is simply this: What counteractives or compensations may there be for those in whom the scientific mood is strong, in whom neither Nature-poem nor ancient Theodicy, neither philosophical idealisation nor fairy tale finds satisfactory organic response.

To conserve the feeling for Nature-at once a satisfaction and a clue-we may get what aid we sincercly can from Nature-poetry and other idealisations, we may give greater breadth and depth to our vision by more science, we may exercise ourselves in scientific reconstructions till the Dryad comes back into the tree, but all these are vanity unless we keep close to the concrete realities themselves, and receive with open minds the great primal impressions of immensity, flux, order, intricacy, and beauty, not refusing to be thrilled by what seemed to our more naïve predecessors to be immediately divine.

There is grandeur in the spectacle of the star-strewn sky, so apparently crowded, but there are thousands of worlds unseen for every one our unaided eyes can image, and yet the astronomers tell us that the emptiness of space is its most striking characteristic. We are staggered by the fact that when we look at $\alpha$ Centauri, which lies some ten billions of miles nearer to us than any other known star, we see it, not as it is to-night, but as it was four years ago. We have 
no mental picture of the remoteness of the sun, which is the earth's 'mother-country', but if the sun were represented in a model by a grain of sand one-hundredth of an inch in diameter, and the earth by a quite invisible speck one inch away, the nearest star would be represented on this scale by another grain of sand some four miles off. One knows indeed that size and distance are in a way the least important distinctions in the world, but just as men often lose their littleness in sojourning among the great mountains, so it is part of the significance of things to us that we belong to a system cast on big lines. We are citizens of no mean city.

No one supposes that we are divided into scientific, æsthetic, and other parts, and function in bits as it were; or that there is an antithesis, like good and evil, between science and feeling; or that there is any such thing as 'pure perception'. As a matter of fact, as Professor Ritter says, "We know-and-feel, all in one breath, whenever we respond in an unsophisticated, natural manner to contacts with men and things" (1911, p. 126). Decper science may deepen feeling, and deeper feeling may lead to deeper science. We are inclined to agree with Ritter that "we cannot interpret plant and animal life broadly and soundly either in technical science or in common intelligence unless the æsthetic side of our nature joins with the intellectual side in determining our attitude toward the beings we deal with." Progress is to be looked for in correlated, not dissociated development. There is no question of allowing feeling to influence our calculations or measurements, for the scientific accounts are open to public inspection and are fortunately audited with severity. But we need not think that the ark of science has such an unstable equilibrium that a touch of imaginative 
insight will upset it. There is no question, on the other hand, of admitting into our feeling for Nature any element that is incongruent with our intellectual experience. That way lies sentimentalism or worse. But we need not be too timorous in our anthropomorphism or afraid of exaggerating the wonder and subtlety of Nature. We cannot, for our life's sake, and for the sake of our philosophical reconstruction, afford to lose in scientific analysis what the poets and artists and the lovers of Nature all see. It is intuitively felt, rather than intellectually perceived, the vision of things as totalities, root and all, all in all; neither fancifully, nor mystically, but sympathetically in their wholeness. There is a deep wisdom in Wordsworth's remark in one of his Prefaces:- "Poetry is the breath and finer spirit of all knowledge; it is the impassioned expression which is in the countenance of all science."

To all those who remind us what "a dubious and varying oracle" feeling has proved to be in the past, we would answer, "But how often a wise counsellor!" In an exalted mood many have in the light of feeling made decisions from which the happiness of a lifetime flowed, and it was a wise man who declared that great ideas come from the heart. We mean by feeling in its finer expression the lamp which others have called intuition. It goes out if not tended, and if facts do not form part of its oil the flame will sputter. But it is a light in the region 'beyond science'. As M. Bergson writes, "Sur notre personnalité, sur notre liberté . . sur notre origine et peut-être aussi sur notre destinée, elle projette une lumière vacillante et faible, mais qui n'en perce pas moins l'obscurité de la nuit où nous laisse l'intelligence."

The words " The Unfathomed Universe", used in the title 
of this lecture, were suggested by Walt Whitman's wellknown line- " Prais'd be the fathomless universe, for life and joy, and for the objects and knowledge curious." Whitman assuredly strikes the right note-that of the joyous adventurer sailing into opulent seas unexplored. Wherever in the past he has sounded he has touched treasure, he looks forward to winning the secrets of deeps still unfathomed. Experience never disappointed surely warrants a feeling of expectancy, an impression of inexhaustible riches- " these immense meadows, these interminable rivers", horizon bo yond horizon, which are ours, here and now, to seek to appropriate.

The climax of intuition is mysticism, and those of us who do not practise it must not brush it hastily aside. Many mystics are precise and logical thinkers-though they explore a kingdom beyond science and logic. Some psychologists have suggested that in conditions of quiet or of exaltation, as in the presence of fine scenery, there may enter into the focus of consciousness some larger area of the unconscious mind than is usual in ordinary life. Others believe that the mystic is thrilled by extra-human influences. All that we plead for is a recognition of the fact that practical men and women of to-day.do still manage to get into an original relation with Nature. In his Candle of Vision (1918), A. E. writes:

"I draw attention to the mystery in common and obvions things, and ask that they be explained and not slurred over as if no explanation were necessary. I ask the doubters of my vision to penetrate a little into the mystery of their own thoughts and dreams before they cry out against me, who for many years travelled far and came upon lovely and inhabited regions to which I would also lead them. I know that my brain is a court where many living creatures throng, and I am never alone in it. You, too, can know that, 
if you heighten the imagination and intensify the will. The darkness in you will begin to glow, and you will see clearly, and you will know that what you thought was but a mosaic of memories is rather the froth of a gigantic ocean of life, breaking on the shores of matter, casting up its own flotsam to mingle with the life of the shores it breaks on."

And speaking of the concentration required in the habit of vision, he says: "It is an exercise this, a training for higher adventures of the soul: it is no light labour. The ploughman's cleaving the furrows is easier by far. Five minutes of this effort will at first leave us trembling as at the close of a laborious day."

Surely students of science should be the last to dogmatise as to the possibilities of this life of ours.

\section{§6. Towards a Philosophical Interpretation of Nature.}

As the scientific order transcends the empirical, it is transcended in turn by a philosophical order which aims at a harmonious interpretation of our experience as a whole. The essential change is often referred to as passing from the ' how' to the 'why', from analytic and historical description to interpretation, but there is also this difference that while science must keep feeling at an arm's length, philosophy seeks to give a view of the world that will satisfy the claims of feeling as well as those of the understanding. It is just our outlook on the whole of life, the world within as well as the world without, and it includes the assets of feeling as well as intellectual gains.

To illustrate concretely : biologists are easily satisfied with their outlook on animate nature if they are willing to leave out of account the fact of human personality at its best, or the fact of human society. We may define our biology 


\section{THE UNFATHOMED UNIVERSE}

so as to exclude them, - that is a question of method,- - but to think of leaving them out in our total interpretation of our experience is to allow the light that is in us to be darkened. Similarly, although there is great difference of opinion in regard to the philosophy of the beautiful, there is general agreement that our total outlook on Nature is to be distrusted if the fact of beauty has been ignored. Feeling is to be excluded from scientific investigation, but it must be allowed to operate in our philosophical synthesis. Perhaps we may say that feeling supplies the mortar in which are laid the stones contributed by Natural Science to the (synoptic) edifice which the genius of Philosophy is building.

There are several hopeful indications of an advance towards a philosophical order of Nature. The first is the increasing correlation of the sciences, which are parts of one endeavour to understand the order of Nature and Man's life in its midst. The sciences work into one another's hands in correlation, and this has always been fruitful, as is well illustrated by the transforming and vitalising of chemistry after it joined hands with physics. The scientific study of animal behaviour, still in the freshness of its youth, shows us the effectiveness of a combined attack-psychological and biological-on a difficult set of problems. The autonomy of biology is not inconsistent with its correlation-imperium in imperio-with chemistry and physies on the one hand and psychology and sociology on the other. While the sciences are separated off for the sake of clearness, because they pursue different methods, use different tools, and sum up in different kinds of formulæ, they work into one another's hands, and they are simply different modes of one rational inquiry. Their mutual influence is increased, not decreased, 
when each recognises its abstractness; and the hope of their leading on to a philosophical order is in proportion to the clearness with which it is recognised that a synthesis is not additive.

It is customary to speak of the unity of the sciences, and no doubt they are beginning to form a system or hierarchy, but the ideal of one science of Nature-the ideal of Descartes, of Hobbes, of Leibniz-is giving place to an ideal of correlation rather than of unity. There has been much profitable breaking down of artificial partitions, much fruitful co-operation of several sciences on one problem, many a useful discovery of a common denominator bringing apparently disconnected facts into comparable relationship, but the materialistic proposal to make physiology a branch of physics, and psychology a branch of physiology, has not been substantiated. Biology and Psychology remain autonomous, with categories of their own. Treating of the work of science, Prof. A. E. Dolbear writes: "By explanation is meant the presentation of the mechanical antecedents for a phenomenon in so complete a way that no supplementary or unknown factors are necessary." If that kind of explanation were feasible throughout, there would be one science of Nature, in terms of ideal motions, expressible in mathematical formulæ. But this is false simplicity; it does not really work. Thus, to take a clear case, in the higher reaches of animal behaviour, most biologists admit the necessity of invoking other than mechanical factors.

The second hopeful sign we have already referred to, the frank recognition on the part of science that it is not its rôle to solve the riddles of the universe. It remains more or less open to students of science to deny the feasibility of any solution and to doubt the value of any generalisations 


\section{THE UNFATHOMED UNIVERSE}

save those called scientific, but there has been perfect openness in the retreat from the position of world-interpretation. No longer should it be possible to ask, as the title of a not very ancient book does, "God or Natural Selection?", for that is opposing an interpretative concept to a descriptive formula, in short, trying to talk two languages at once.

The third hopeful sign, as it seems to an outsider, is a change on the part of Philosophy in its relations with Science. There is a growing recognition that Philosophy must use in her characteristically interpretative reconstruction all the general results of the sciences. The Procrustean attempt to force the facts of Nature to fit a premeditated abstract intellectual scheme is not more promising than the antipodal attempt to wring a philosophical system out of Nature alone. The reaction of Lotze from Schelling may serve as a diagrammatic illustration of what is now taking place in our midst; that philosophy is using the best that science can give, and is systematising that along with the other winnings of the developing human spirit.

Prof. A. E. Taylor gives (1909, p. 192) a luminous statement of the relation between science and philosophy:

"The work of the Philosophy of Nature and of Mind only begins where that of the experimental sciences leaves off. Its data are not particular facts, as directly amassed by experiment and observation, but the hypotheses used by experimental science for the co-ordination and description of these facts. And it examines these hypotheses, not with the object of modifying their structure so as to include new facts, or to include the old facts in a simpler form, but purely for the purpose of estimating their value as an account of ultimately real existence. Whether the hypotheses are adequate as implements for the calculation of natural processes is a question which Philosophy, when it understands its place, leaves entirely to the special sciences; whether they can claim to be more than useful formulæ for calculation, i.e., whether they give us knowledge 
of ultimate Reality, is a problem which can only be dealt with by the science which systematically analyses the meaning of reality, i.e., by Metaphysies. We may perhaps follow the usage of some recent writers in marking this difference of object by a difference in terminology, and say that the goal of experimental science is the description of facts, the goal of Metaphysics their interpretation. The difference of aim is, however, not ultimate. Description of facts, when once we cease to be content with such description as will subserve the purpose of calculation, and call for the description of the fact as it really is, of itself becomes metaphysical interpretation."

Along with the sympathetic interest that many modern philosophers (such as Ward, Royce, Pringle-Pattison, Stout, Taylor, Lovejoy, Bergson) have taken in the general results of science, there is benefit accruing to science through their expert criticism of scientific categories. For the mood and training of the scientific investigator is rarely such that it leads far in that direction. Some of the ablest scientific minds the world has known have betrayed in their would-be philosophical deliverances an extraordinary naïveté.

In thinking of the empirical, scientific, and philosophical orders as reconstructions of increasing completeness and, it is hoped, of increasing nearness to reality, it must be remembered that they co-exist in our midst like outcrops of strata of different epochs. Thus we have little more than empirical knowledge in regard to the variability of living creatures, or in regard to certain obscure diseases. In medical practice, stock-breeding, and engineering, empirical knowledge has often worked extraordinarily well. The explanation is sometimes diagnostic genius, sometimes remarkable development of perception in quite ordinary individuals. A patiently accumulated working knowledge often leads a shrewd man a long way without much science in the strict 
sense. Similarly there are many who have established for themselves scientific order over large areas, but have not sought to correlate it with other parts of their experience, thus failing of philosophical endeavour. And others who seek do not find. Similarly, many scholars who have a philosophy of history have neither a philosophy nor a science of Nature. It is to be recognised, then, that the empirical, the scientific, and the philosophical order co-exist in us and in our midst.

Another note may be permitted. It has often been pointed out that progress in intellectual construction is correlated with mastery of environing conditions. As compared with the early working knowledge, the scientific order meant increased control of Nature, and as science has grown our mastery has widened and deepened. We have only to think of the successive harnessings of wind, water, steam, and electricity. Preventive medicine and hygiene, the arts of agriculture and breeding are good instances of the passage from control of the inorganic to the control of organisms. When we look around and see how much men suffer from a partiality of view that is remediable and from philosophies which are discreditable, is it too much to hope that the growing philosophical order is going to lead us to an increased control of the higher issues of life-an aid which Religion will be unwise to refuse?

\section{§7. Science and Religion.}

Science is frankly cmpirical in method and aim; it seeks to discover the laws of concrete being and becoming, and to formulate these in the simplest terms, which are either immediate data of experience or verifiably derived therefrom. The scientific ' universe of discourse' does not include tran- 
scendental concepts; its aim does not include attempting to give ultimate explanations.

Religion has been described as the orienting of our life towards the True, the Beautiful, and the Good. But this does not grip; it leaves out the essential-the mystical-element. Religion in essence always implies a recognitionpractical, emotional, and intellectual — of a higher or deeper order of reality than is reached in sense-experience. It means tho recognition of an unseen universe, which throws light on the riddles of the observed world - a light which may give aid. In the scientific light of common day are seen the hosts of the Assyrians encompassing the city; the opened religious eye sees the mountains crowded with the chariots of God.

But let us quote an authority. Prof. D. S. Cairns writes (1918, p. 21) : "Religion is, fundamentally, on the human side, man's protest and appeal to the Supreme against the sorrows, indignities, and sins of this present world. It is the endeavour of man, through that appeal, to unite himself with the life of that unseen and ruling world, and so to win the power from it to dominate and transmute the life of time. That is to say, in essence, religion, on the human side, is simply the sustained endeavour to meet this great human problem of the destroying Nature and the struggling personality. All religions have this at their heart. They, one and all, start from an act of faith in an unseen world which is mightier than the world of sense and time, and which is either already friendly or may be made friendly to the worshippers." "He goes on to say that in all religions there may be recognised three great constant elements-the conception of an unseen ruling world, some idea of the supreme good which the worshipper may derive from Heaven 
for the enhancement of his life, and some way or means of uniting the worshipper with God or the gods.

It is evident, then, that the religious language is not the scientific language, and that it is impossible to intermingle the two. The religious concepts are different and apparently more metaphysical; their aim is interpretation rather than description. In short, science and religion are incommensurables.

But to call religion and science 'incommensurables' is not to fall back on the old-fashioned impossible device of having idea-tight compartments. Just as a novel scientific generalisation is not incorporated in our scientific system unless consistent with previously established conclusions, or unless the latter can be adjusted to meet the new idea harmoniously, so at a greater height, where philosophical discipline is invaluable, a religious idea, such as that of a Divine Creator, must be congruent with the rest of our world-picture, e.g., with the idea of evolution. It is the criterion of consistency that saves from superstition.

Men are led to religion along many pathways-from the perplexities of the moral life, from an appreciation of the facts of history, and from the experience of reaching the limits of practical endeavour, of emotional expression, and of intellectual inquiry. When we think of the last-named three pathways to religion, which many tread,-through baulked struggle, over-strained emotion, and baffled search after clear understanding,-we can see why the rapid development of science should, for a time of transition at least, work against religion. For science gives Man from time to time a greatly increased mastery over Nature; science, with its analytical triumphs, ever tends to diminish, in the shallowminded, the saving grace of wonder; and science is ever 
dispelling the darkness that oppresses the mind. Moreover, the scientifie mood, inherently sceptical, has been widely diffused; its activity has a growing fascination of its own; it easily comes to preoccupy the mind, and thus tends to crowd out the rsthetic, the poetic, and the religious moods. And yet we believe that religious interpretation and scientific analysis are equally natural and necessary expressions of the developing human spirit.

When we are thrilled with the wonder of the world, the heights and depths of things, the beauty of it all, we approach the door of natural religion. And when the Nature-feeling is not superficial but informed with knowledge, with no gain of the hard-won analysis unused, we may reach the threshold. And when we feel that our scientific cosmology leaves Isis still veiled, and when our attempts at philosophical interpretation give us a reasoned conviction of a meaning behind the process, we may perhaps enter in. That the entrance is not easy is shown by the unhappy prevalence of a profane world-outlook outside the ranks of disciplined thinkers and investigators, on the one hand, and religious, poetical, and artistic lovers of Nature on the other. The difficulty of the entrance is partly due to race, for North Temperate peoples with no Celtic strain never find religion easy, partly due to preoccupation either with the good things or with the thiek shadows of this life, and partly due to a misunderstanding of the results of science. It is the last hindrance to religion that conecrns us in this course of lectures.

What must be worked towards is a philosophical co-ordination of the essential results of Biology and the other sciences with the results of intellectual inquiry in other fields and by other methods, allowing at the same time for those glimpses of reality that feeling alone affords. In this task 


\section{THE UNFATHOMED UNIVERSE}

it is all-important that we get at the facts, for there are in currency many conclusions in regard to Nature which can no longer be accepted as well grounded. What we may reach can only be provisional, for the data of science are in process of rapid change; but there will be some reward if we can eliminate some spurious and obsolete coinage.

Whatever be our philosophical interpretation or religious conviction, we do well to have more than a passing acquaintance with the world without, with the process of which our life is part. The aim of this course is to state the general results of biological inquiry which must be taken account of if we are to think of Nature as a whole and in relation to the rest of our experience. The first part of the course will deal with the realm of organisms as it is-so far as its changefulness permits; the second, with its evolution, -past, present, and possible.

\section{SUMMARY.}

In primitive times man had a slowly growing recognition of an empirical order of nature, a very imperfect control of natural forces, and a theory of magic or of animism.

The empirical order bas gradually given place to a scientific order, ever broadening and deepening; and man's control of Nature has increased in proportion. One science has been added to another in elaborate specialisation, and there has also grown up a seientific system or 'world-outlook' which verges on philosophy. This worldoutlook has ceased to be geocentric or narrowly anthropocentric. The reign of law and the process of evolution have been recognised.

The direct motives of scientific inquiry are, in the main, intellectual curiosity, a self-preservative dislike of obscurities, a desire after unity and continuity in our outlook. It is a quite specific endeavour to get things under intelligent control, so that we can think of them clearly in relation to the rest of our knowledge, and so that we can act effectively on the basis they afford. The aim of science is to describe natural phenomena as precisely as possible, 

LECTURE II.

THE REALM OF ORGANISMS CONTRASTED WITH THE DOMAIN OF THE INORGANIC. 

LECTURE II.

THE REALM OF ORGANISMS CONTRASTED WITH THE DOMAIN OF THE INORGANIC.

$\S 1$. Things and Living Creatures. §2. The Characteristic Features of the Realm of Organisms. \$3. A Multitude of Individualities, yet a Systema Naturc. §4. Abundance and Insurgence of Life. §5. Struggle and Sifting. §6. A System of Interrelated Lives. §7. The Prevalence of Adaptations. §8. The Pervasiveness of Beauty. $\S 9$. The Other Side of the Picture. $\S 10$. Resemblances between the Realm of Organisms and the Domain of the Inorganic. §11. Contrasts between the Realm of Organisms and the Domain of the Inorganic. §12. The Suitability of the Inorganic to be the Basis and Environment of the Organic.

\section{§1. Things and Living Creatures.}

IN the concrete fulness of the world without, we distinguish by common consent the realm of organisms and the domain of the inorganic. Sun and stars, sky and sea, mountains and rivers, the air we breathe and the dust beneath our feet, crystals and precious stones, it seems like colour-blindness to sum this up in the negative and unattractive term 'inorganic'. But better that than use a question-begging word.

We must not dogmatically say 'inanimate' Nature, for it is making a sweeping assertion to declare that the inorganic cannot have a meta-kinetic aspect. Nor is it quite satisfactory to speak of 'the mechanical order of things', for we ourselves illustrate mechanical principles, even when we raise our arm or eyebrow in protest. Moreover, it cannot 


\section{0

be said that a mechanical summing up of even not-living occurrences is necessarily exhaustive. Nor can we speak with satisfactory precision of the 'physical order', for living creatures are also physical systems, though more; and the phrase 'purely physical' is again question-begging.

So let us call it all-from the solar system to the dew-drop - the inorganic domain. We cannot hold it rigidly apart from living organisms, for it is continually undergoing modification at their hands. Parts of it are ever entering into the bodies of organisms, and into its repository the disenchanted dust of life is ever returning. We know the inorganic system of things only in terms of mind, and our first adventure of scientific faith is to believe in its external reality; yet it looms impressively over ns-a great dumb giant, holding us, even in our defiance, in its grip and bearing us with it on its stupendous journeying through space.

\section{§ 2. The Characteristic Features of the Realm of Organisms.}

Let us begin with an impressionist survey of the realm of organisms, and afterwards contrast this with a general view of the inorganic domain. It is surely a magnificent spectacle that the obviously animate presents. What a gamut of life from the microscopic Infusorian to the giant whale, from the hyssop on the wall to the cedar of Lebanon! What abundance of life is revealed when the dredge comes up, or when the insects rise before us in a cloud as we walk through the grassland of a warm country. What variety of architecture, what abundance of individuality within the same style! All is suggestive of fertile imagination. How strong the pressure, as the waves of life surge up against their shores; how numberless the hand-and-glove fitnesses; how subtle the linkages; how constant the changefulness; 
how universal the beauty! But let us be more analytic and illustrate in due order the deeper impressions which fill the mind after the crowd of details sinks to rest, for these must form part of the materials which Biology gives over to Philosophy to build with.

\section{§3. A Multitude of Individualities, yet a Systema Natura.}

When we look at Nature with a fresh eye, in a new country, or in some novel experience such as dredging, we have a transient impression of overwhelming confusion, as if Aladdin's cave had been suddenly burst open before us. Many miss this in ordinary circumstances because familiarity breeds the contempt of inattention, and also because a very large number of living creatures are cryptozoic. For every conspicuous plant there are often a score inconspicuous, and for every readily visible animal there must be a hundred unseen. It is not of individuals that we are thinking, but of individualities, of species. There are at least 25,000 named backboned animals, ten times as many named backboneless animals, and about as many plants. There are about 100,000 Dicotyledonous Flowering Plants. Darwin speaks of finding twenty different kinds of flowering plants on a patch of turf four feet by three, and there may be as many different kinds of animals on one stone brought up from the sea-floor.

The study of marine animals has been enthusiastic and intense for many years, but those who know most about it will agree with what the poet Spenser said long ago:

"But what an endlesse worke have I in hand, To count the seas abundant progeny, Whose fruitful seede farre passeth those on land, And also those which wonne in th' azure sky; For much more eath, to tell the starres on hy, 
Albe they endlesse seem in estimation,

Than to recount the seas posterity;

So fertile be the floods in generation,

So huge their numbers, and so numberlesse their nation."

We shall come later on to the difficult problem of individuality or species; but our view of Nature as a whole must take account of the fact that species are multitudinous and that they represent discontinuous individualities, with much more constaney than the earlier Darwinians supposed. Linnæus said: "There are as many species as there were ideas in the Divine Mind ", and there is no doubt that a good species is like a clear-cut idea. At the other extreme of comparison, it is like a chemical element, but on a higher plane. As Goethe said, "The one thing Nature seems to aim at is Individuality; yet she eares nothing for individuals." If we personify 'Animate Nature', it must at least be as an artist with inexhaustible imaginative resources, with extraordinary mastery of materials.

But in the prodigal wealth of individuality, it is not a dæmonic confusion, but a rational order that we see. The species are remarkably unique and discontinuous, each with a character of its own, yet they are often like stages in individual development, and they ean often be classified in a logical series. Linnæus established his Systema Naturæ quite apart from any evolutionist coneeption, and though the fact of genetic relationship lies behind every so-called natural classification, our present point is simply that " Each of her works has an essence of its own; each of her phenomena a special characterisation; and yet their diversity is in unity". 


\section{§4. Abundance and Insurgence of Life.}

A second impression is that of wealth of numbers and of indomitable will to live. There are, indeed, organisms which multiply slowly, such as elephants, golden eagles, and century plants, but this is not the way with the majority. Most of the streams of life are ever tending to overflow their banks. Even the rarities may do so in appropriate conditions; thus a rather rare wingless Glacier-Insect was recently found on one stretch of the mer-de-glace at Chamonix in numbers almost equal to the population of Great Britain and Ireland. In the case of organisms of low individuation, which hold their own rather because they are many than because they are strong or wise, the productivity is beyond all our powers of conception. From one Infusorian there may be a million by the end of a week, and in some of the floating meadows of the sea there may be a quarter of a million units in a gallon of water.

There is a well-known British starfish, Luidia ciliaris, which produces at least two hundred millions of eggs, and yet it is not what one would call a common animal.

We are familiar with calculations of what would occur if there were no thinning of the crops--how soon the earth would be covered with a weed, or the sea filled solid with a fish, or the sky darkened with an insect, and recurrent plagues of locusts, sparrows, rabbits, and moles remind us that a possibility may easily become an actuality. After allowing a prodigious mortality of 95 per cent., it is computed that the $10,000,000$ pairs of breeding rats in Britain on New Year's Day, 1918, were represented by $40,000,000$ pairs at the end of the year, and by $12,000,000$ more pairs the following month! There is a grimness in the well-known 
remarks of Linnæus that three flies will consume the carcase of a horse as quickly as a lion can. Professor Woodruff observed the successive asexual generations of the common slipper-animalcule (Paramecium) for five years between 1907 and 1912 and found that there were 3,029 of them-over three every forty-eight hours. Careful calculation showed that they had given evidence of the capacity of producing in the five years a volume of protoplasm approximately equal to 10,000 times the volume of the earth. This power of self-increase must be taken account of in our conception of living organisms, and the resulting abundance of life must form part of our impressionist picture of Animal Nature. At the autumnal climax of productivity in lakes, there may be to the square yard 7,000 millions of a well-known Diatom, Melosira varians, so that the water is like a living soup.

We have to remember, moreover, the obvious but notable fact that we are dealing not with items like grains of sand, but with individuals, each itself and no other. Mendel put an end to the phrase " as like as two peas".

Individual organisms differ greatly in degree of complexity and of integration. Many an Infusorian has an intricate organisation and lives a by no means monotonous life, though it is only what we somewhat fallaciously call " a single cell ". Hardly any larger than some Infusorians are some of the Rotifers, sometimes with about 1,000 cells; a minnow has its millions, and a bird its millions of millions. What a contrast between the very incipient integration of a sponge, the intricate division of labour in a 'Portuguese Man of War' hesitating between colony and individual, and the compact co-ordination of the circumspect wren. As a recent student of the subject, Mr. Julian S. Huxley (1912), puts 
it, we are confronted in Nature with closed independent systems with harmonious parts and with capacity for continuance. Such are individuals. "Though the closure is never complete, the independence never absolute, the harmony never perfect, yet systems and tendency alike have real existence." The individual is Unity in Diversity-in what it is and in what it does, - a whole whose diverse parts all work together, ensuring continuance. When it transcends the limits of its substance, Mr. Huxley says, that is personality.

But in addition to the abundance of life-alike of individualities and of individuals-there is the quality of insurgence. Living creatures press up against all barriers; they fill every possible niche all the world over; they show that Nature abhors a vacuum. We find animals among the snow on Monte Rosa at a height of over 10,000 feet; we dredge them from the floor of the sea, from those great 'deeps' of over six miles where Mount Everest would be much more than engulfed. It is hard to say what difficulties living creatures may not conquer or circumvent. You may find insects in hot springs in which you cannot keep your hand immersed, or Rotifers and other small fry under fifteen feet of ice in the little lakes of Antarctica; you find a BrineShrimp and two or three other animals in the Great Salt Lake; you find a fish climbing a tree, and thoroughly terrestrial types like spiders with species living under water; there is, as Dr. Shipley has shown, a bustle of life on the dry twigs of the heather. When we consider the filling of every niche, the finding of homes in extraordinary places, the mastery of difficult conditions, the plasticity that adjusts to outof-the-way exigencies, the circumvention of space (as in migration) and the conquest of time (as in hibernation), we begin to get an impression of the insurgence of life. 
We see life persistent and intrusive - spreading everywhere, insinuating itself, adapting itself, resisting everything, defying everything, surviving everything!

The great Sequoia trees may be taken as emblems of life's tenacity. For they have been known to flourish over two thousand years. One of the oldest had 2,425 annual rings when it was killed, and must have begun to live 525 years before the Christian era. "We have," wrote Prof. W. R. Dudley, "deep in their annual rings, records which extend far beyond the beginnings of Anglo-Saxon peoples, beyond even the earlicst struggles for liberty and democracy among the Greeks-records of forest conflagrations, of the vicissitudes of the seasons, of periods of drought and periods of abundant and favouring rains." In our conception of life we must not forget these sublime instances of its power to endure.

\section{§5. Struggle and Sifting.}

By the insurgence of life we mean a certain quality of 'push' or aggressiveness often observable both in plants and animals. It is an outcome of a native self-assertiveness, and it is a factor in the struggle for existence as much as a consequence of it. More metaphorically, it is an expression of the 'will to live', or of the spirit of adventure. To the conception of the struggle for existence we shall have to give careful consideration at a later stage; meanwhile we must notice that the phrase leads us astray if it is taken literally or woodenly. It includes every form of the clash between individuals and their environing difficulties, all the novel responses that individual living creatures are always making to the pressure of limiting conditions. These responses may take the form of intensified competition, even of 
intensified cannibalism; but they have often taken the form, as Darwin emphasised, of some experiment in co-operation and socialisation, of some new departure which gives the next generation a better start in life. All theory apart, our picture of animate nature is fundamentally out of perspective unless we recognise that a large proportion of the time and energy of living creatures, whether in the fighting line or safe for the time being in organised entrenchments, is devoted to securing not self-preservation, but the welfare of the race. Nature, as Goethe said, is continually taking advantage of her children's " capacity for self-forgetfulness".

Whenever the circumstances are critical, and there is inequality or diversity in the response that living creatures make to their environing difficulties and limitations, a process of sifting begins to work, the process of discriminate elimination familiarly known as Natural Selection. This also will engage our attention later, but in the meantime let us not assume that the conventional statement of the process tells us the whole truth. Just as the struggle for existence is often more accurately described as an endeavour after well-being, so, in thinking of Nature's sifting, we go astray if we think of it as at all haphazard (that is a contradiction in terms), or as directed only to self-preservation, or as being necessarily sanguinary, or as a process in which organisms simply remain like passive branches for the pruning-shears. As a sagacious naturalist has well observed, though somewhat too paradoxically, it is not so much that Nature selects the organisms fittest to her; it is rather that each organism selects the natural conditions fittest to itself. 


\section{§6. A System of Inter-related Lives.}

The hosts of living organisms are not random creatures, they can be classified in battalions and regiments. Neither are they isolated creatures, for every thread of life is intertwined with others in a complex web. This is one of the fundamental biological concepts-the correlation of organisms in the web of life-and it is as characteristically Darwinian as the struggle for existence. No creature lives or dies to itself; there is no insulation. Long nutritive chains often bind a series of organisms together in the very fundamental relation that one kind eats the other. All things are in flux, there is a ceaseless circulation of matter; all flesh is grass and all fish is diatom; and so the stuff of the world goes round from one incarnation to another. One organism gets linked on to others, and becomes dependent on them for the continuance of its race. Flowers and insects are fitted to one another as hand to glove. Cats have to do with the plague in India as well as with the clover crop at home. The young of the fresh-water mussels are carried about for a time by minnows, and the young of the fish called the bitterling are harboured within the fresh-water mussel. Squirrels affect the cornfields and water wagtails the sheepfolds. In short, we get a glimpse of Nature as a vast system of inter-linked lives-a Systema Naturæ in a new sense -a web with a pattern (see Thomson, 1914, 1916). Without entering upon any discussion of the weaving or evolution of the web through untold ages, let us take the realm of organisms as it is, and emphasise the fact that just as there is a correlation of organs in the body, so there is a correlation of organisms in the world of life. When we learn something of the intricate give and take, supply and 
demand, action and reaction between plants and animals, between flowers and insects, between herbivores and. carnivores, and between other conflicting yet correlated interests, we begin to get a glimpse of a vast self-regulating organisation. There may be local and temporary friction and disorder; there is the clash of fierce competition in some forms of the struggle for existence; but the larger fact is the smooth working of a balanced correlated system.

In philosophical reconstruction we must surely take account of this inter-relatedness of organisms. Is it not of interest to find in Animate Nature, as in mankind, advance from comparatively isolated units towards systematisation and solidarity? The multitudinous unique threads of lifo become more and more interwoven; the warp and the woof of the web are hunger and love; we get glimpses of a changing pattern becoming ever finer. The web seems to become increasingly coherent, though man often rends the fabric ruthlessly.

Another point of importance, demanding subsequent study, is that the intricacy of the web of life becomes in itself of great significance in evolution. It is its subtlety that gives point and possibility of survival to minute variations. The very fact of complex interaction and systematisation tends to diminish fortuity and to make towards definite progression. The correlation of organisms which is a product of evolution becomes in turn a directive factor.

\section{$\S 7$. The Prevalence of Adaptations.}

The balance demonstrable on a large scale holds throughout; every higher organism is a complex bundle of adaptations. It is suited to its surroundings, to its food, to its own weight, to its way of moving, to the regularly recurrent 
exigencies of the seasons, and to recurrent risks of injury. It may be subtly adapted to its mate, in exquisite symbiosis to its offspring, to its ante-natal life, and to dying at the proper time! Wherever you tap organic Nature, Romanes said, it seems to flow with purpose. The theory of this will be discussed later on, but in the meantime without pressing the word purpose-let us emphasise the fact that almost all living creatures are definitely and detailedly fit for the particular conditions of their life. There can be no doubt that we live in a world of fitnesses, that we need to search to find misfits. When we think we have found them, we have generally made a mistake. This adaptiveness is another large fact of life, which, whatever be the scientific theory of it, must be incorporated in a concrete Philosophy of Nature. Let us take a few illustrations.

The structure of a long bone in a mammal is architecturally adapted to give the utmost firmness with the minimum expenditure of material; the pollen-basket on the hind-legs of worker-bees is adapted in detail to carrying the nutritive pollen, the golden, or otherwise coloured, germinal dust; the leaf of the Venus fly-trap or of the sundew is adapted with no little subtlety to catching insects; the parts of flowers are often adapted to attract insect-visitors and to make the most of them when they come; the colours and patterns of leaf-insects are adapted to harmonise with the foliage on which they settle; the heart of the ptarmigan is adapted to the strain of high altitudes, and the shoes which the ruffed grouse puts on in winter are adapted for treading on the lightly compacted snow; the mongoose is chemically adapted to resist snake poison; the tendrils of the mermaid's purse are non-living products of the living skate physically adapted to fasten the egg to seaweed; the flatfish 
is adapted to put on a garment of invisibility against certain backgrounds; the hedgehog is adapted to meet the winter by hibernation; the peacock is adapted to captivate the peahen; the mother mammal is delicately adapted for the prolonged ante-natal life of the offspring; and the so-called ' egg-tooth' at the end of a young bird's bill is adapted to the single operation of breaking the egg-shell-and so on throughout the whole animal kingdom, for the point of this random list is but to remind us that (with a few very interesting exccptions) every detail of structure and function may bo regarded as adaptive. As the late Professor Weismann used to say, "When you take away all the adaptations from a whale, there is not much left." To illustrate subtlety, however, let us pause for a moment over a particular case.

The illustration we select concerns the parental care in a remarkable New Guinea fish called Kurtus. Each egg has an envelope of orer a hundred twisted threads, coiled like the rubber filaments in a cored golf-ball. When the eggs are laid the filaments unwind automatically and unite in strings, which combine into a cylindrical cord. Thus the eggs are bound together, forming a twin cluster like a double bunch of onions such as we see the Breton boys carrying in the streets. But what is the bunch to be fastened to? The answer is almost incredible. At the breeding season, Prof. Max Weber tells us, a bony process on the top of the skull of the male fish grows forwards and downwards like a bent little finger, and forms eventually a ring or ' eye'. But before the hook becomes an eye the cord of the double bunch of eggs is somehow passed into the loop and attached, and the male fish goes about with his prospective family fastened to the top of his head. The female shows no trace 
of the hooked process of bone, so that we have an interesting, almost startling coincidence, of an adaptation which makes the eggs into a double bunch and an adaptation which fixes them to the male's head.

This is but a striking instance of what obtains throughout Animate Nature-Adaptation upon Adaptation. And, as we shall afterwards see, the working out of a more or less adequate Natural Selection account of how these adaptations have come to be does not lessen the wonder of the variability that supplies the raw material, or the hereditary relation which conserves each gain. The magicalness has gone; the rationality shines out more brightly than ever.

\section{§8. The Pervasiveness of Beauty.}

Another undeniable impression is that there is beauty everywhere. Apart from disease, which is almost unknown in wild Nature, apart from unfinished organisms which Nature hides away-often so carefully, apart from various domesticated animals and cultivated plants which bear too flagrantly the marks of man's artistically clumsy, though scientifically clever, fingers, all organisms are artistic harmonies, pleasing to the unprejudiced eye, evoking tho æsthetic emotion, especially when seen in their natural setting. And not only the organisms themselves, but the works of their hands are beautiful-the nest, and the web, and the honeycomb, and the coral reef, and the bower-bird's bower. Nature has given her verdict in favour of beautythe reward of survival. 


\section{§9. The Other Side of the Picture.}

It may be said, perhaps, that we have given a one-sided picture-that Animate Nature is a vast gladiatorial show reeking with blood, that every hedgerow is crowded with cruelty, that parasitism is rife, that there is much ugliness and devilry, that the exuberant abundance of life is shadowed by the obtrusive abundance of death, and that there are numerous dis-harmonies or imperfect adaptations. "Throughout the organic world," Professor Hobhouse says, "harmony is shot through with discord." It would be utterly unscientific to disregard these shadows, and we shall consider them at later stages in our argument Anticipating that discussion, we venture to say that many of the shadows are of man's making, that many are due to misunderstanding, and that those that are real do not seriously affect the general truth of our impressionist picture of Animate Nature, of which the prominent features are:-the multitude of individualities in an orderly Systema Naturæ; the abundance and insurgence of life; the ceaseless struggle and endeavour, which makes for self-preservation, selfassertion, and self-realisation, but also for the welfare of the race; the sifting and singling that works towards both these ends; the extent to which every creature is a bundle of adaptations; and the beauty that is everywhere.

$\S 10$. Resemblances between the Realm of Organisms and the Domain of the Inorganic.

With our impressionist picture of the realm of organisms clearly in view, let us now briefly compare it with what is true of the domain of the organic. We must avoid two extremes. On the one hand, there is the error of exaggerat- 
ing the differences so that an impression of utter discontinuity is created. This is undoubtedly false, for organisms have, as material systems, an inorganic aspect. On the other hand, there is the error of exaggerating the resemblances, so that we lose hold of what is distinctive in each. Let us first notice some of the resemblances.

As among plants and animals, so among lifeless things there is extraordinary heterogeneity. There are over eighty different kinds of elements; the number of different minerals is legion; the multitude of the stars is untold. But, just as there is in the realm of organisms the common denominator protoplasm (or shall we say animate protoplasm?), so there is in the inorganic domain an abstract common denominator with a few terms, such as matter in motion and ether under strain, which are not reducible to anything simpler. The living and the not-living worlds agree in showing diversity in unity, and the big generalisations of Biology such as omne vivum $e$ vivo, the hereditary relation, the persistence of the organism in spite of ceaseless change, and so on, may be compared to the great chemicophysical generalisations of the persistence of mass, of momentum, of energy.

What the physical irreducibles are is a question beyond our scope, all that we require for our argument is the agreement among physicists that there are but a few fundamental concepts. Thus Sir Oliver Lodge declared in 1913: "Matter in motion, Ether under strain, constitute the fundamental concrete things we have to do with in physics. The first pair represent kinetic energy; the second, potential energy; and all the activities of the material universe are represented by alternations from one of these forms to the other" (1913, p. 35). In terms of a few fundamental concepts, then, it 
is possible to formulate a very large part at any rate of what is observed in the inorganic domain. Whether they exhaust the reality of that domain is quite another ques tion.

In both worlds we get the impression of order and uniformity. We recognise it, for instance, in the frequent inexorableness of the hereditary relation between successive generations; we are even more familiar with it in the domain of the inorganic. There do not seem to be many big collisions in the heavens. Everything works so steadily that the return of a comet can be predicted to a night, and the occurrence of an eclipse to an hour. The weather may be changeable, but no one supposes that it is disorderly. It is not a multiverse that we live in, but a cosmos. In his famous Discourse on Molecules (1873), Clerk-Maxwell spoke of the verification of the postulate of stability in the properties of things. Unthinkably distant worlds are built up of molecules of the same kind as those which we find on the earth. A molecule of hydrogen, for instance, whether in our laboratories, or in Sirius or in Arcturus, executes its vibrations in precisely the same time. The furniture of the earth and of the hearens may be changed, but the properties of its constituents remain. "Though in the course of ages catastrophes have occurred and may yet occur in the heavens, though ancient systems may be dissolved and new systems evolved out of their ruins, the molecules out of which these systems are built-the foundation-stones of the material universe-remain unbroken and unworn. They continue this day as they were created-perfeet in number and measure and weight. . . ." For " molecules" a modern chemist would read 'atoms', and even then he would remind us of the apparent disintegration of the atom 
in radio-active substances. But in the main what ClerkMaxwell said remains true. It is evident that the fulcrum of the inorganic on which organisms rest their lever is one of reliable steadiness.

Another point of resemblance or analogy is that the eighty or so elements may well be compared to species, or better to types of organisms. We do not know very well what being an element means, and we do not know very well what being a species means, but we do know that in elements and species alike we have to do with uniqueness or specificity. One is not forgetting, of course, what has been done in the way of experimental transformism alike with organic species and chemical elements, but, taking the world as it ${ }^{\circ}$ is, the characteristic feature, whether of species or elements, is the persistence of each clear-cut entity on its own line of being.

As to the inter-relatedness in the realm of organisms, it has its analogue in any systematisation that there is in the inorganic domain. The approximation to individuality illustrated in the earth or in the solar system is associated with a certain amount of correlation between its parts. The circulation of matter in the organic realm has its counterpart in the inorganic. The persistence of matter and the conservation of energy hold true, so far as we know, in both.

As regards beauty, it varies greatly in significance, but there is no limit to its range. In its way the grain of sand is as perfect as the egg of the wren. There is often an indescribably fine finish about the inorganic natural product, as we see in agates and crystals, and there is a haunting beauty in things great and small, in the mountain and in the pebble, that makes us thoughtful as well as joyous. We venture to say, however, that in the inorganic domain com- 
binations of lines and colours that are not beautiful are not uncommon, whereas in the organic realm the non-beautiful is extremely rare, the reason being that beauty is correlated with individuality.

If we assume the external independence of what we call matter and regard it as the building-stone of the world, those of us who are not chemists and physicists must make an effort to rid ourselves of any picture of it as gross and inert. How much matter is invisible like the air! How much is transparent like the water! How tenuous is the film of the soap-bubble! How much is ever passing from phase to phase like an elusive genie! Those who are inclined to think meanly of matter should look again at its magnificence in the starry hearens and at its exquisiteness in the miniature architecture of snow-crystals. We must also bear in mind how finely it lends itself to Life's purposesthe fashioning of a feather, the sculpturing of a shell, the casting within the bud of those blue bells which ring every day by the wayside.

But when we pass from ordinary sight to scientific vision, how subtle and ethereal matter becomes! What pictures modern physics gives us of a restless activity suggestive of life!

Matter is thought of as consisting of unit particles or molecules, which move freely with great velocity in gases, and these molecules are thought of as consisting of several atoms which exist in specific and constant configurations. Until 1896 atoms were regarded as the ultimate buildingstones of the material universe, but it has since been suggested that an integration of hundreds of thousands of electrons might form an atom or form a revolving halo around an atom. The study of radium has led to the view that the 
atom is not the natural limit of the subdivision of matter, that the stream of energy poured forth by radium is due to a transmutation of the position of parts constituting the atom,- the radium slowly changing into something elsehelium, and eventually lead.

The individual molecules of matter in a gaseous state are believed to move with great velocity, incessantly colliding with one another and rebounding, making impacts on the walls of the vessel that contains them, or spreading themselves through any space to which there is free access. - . We need not try to follow what is beyond our personal scope, but to illustrate the subtlety of modern conceptions of matter-which is all that concerns us at present-let us take a few sentences from Professor Soddy's luminous Matter and Energy:-

"Every cubic centimetre of any gas, measured under standard conditions $\left(0^{\circ} \mathrm{C}\right.$. and 760 millimetres barometric pressure), contains twenty-seven million million million molecules. The weight of the single molecule of hydrogen is about three million-million-million-millionths of a gram, and its velocity at $0^{\circ} \mathrm{C}$. is rather more than a mile a second. The hydrogen molecule is, it is true, the smallest and simplest molecule of matter known, but it is a large and sluggishly moving individual compared with another known particle, the electron or atom of negative electricity" (Matter and Energy, p. 82).

When the temperature of a gas is lowered the molecules come nearer one another, till their mutual tendency to draw together restricts their wandering movements, and a liquid is formed. Inside the surface skin of the liquid the molecules move very rapidly, and collide so frequently that they follow very zigzag paths, being perpetually turned back the 
way they came. It is no dance of molecules, but a chaotic jostling. Every drop of liquid is in a state of commotion and turmoil indescribable (ibid., p. 89). Of solids relatively little is known, but in a crystalline solid where we have to deal with fixed architecture there can be no translatory motion. "But vibratory motion in constrained paths there must be among the molecules of a solid, increasing with the temperature until the molecules drag their anchors, as it were, and the substance melts" (ibid., p. 94).

Thus the concept of matter leads us to a very ethereal picture. What is to be said of energy? It is the power of doing work, and may be actual or potential, in motion or in position. But except when it changes, its existence can only be inferred. Professor Soddy writes: "The Apostle Paul had no thought of physical things in his mind when he used the words, 'The things which are seen are temporal, but the things which are not seen are eternal.' But the words can be applied with profit to illustrate, perhaps more forcibly than any other single sentence, the essential nature of energy. It is only the temporary changes in the form and relative amount of energy which are manifest. So long as energy neither changes in amount nor in position, it belongs to the unseen and eternal. No direct evidence of its existence can be obtained." Yet we are never in doubt as to its reality, for it is always conserved. And besides Matter and Energy there is the Ether which Sir Oliver Lodge describes as "the universal connecting medium which binds the universe together, and makes it a coherent whole instead of a chaotic collection of independent isolated fragments. It is the vehicle of transmission of all manner of force, from gravitation down to cohesion and chemical affinity; it is therefore the storehouse of potential energy. . . . It does not 
move in the sense of locomotion, though it is probably in a violent state of rotational or turbulent motion in its smallest parts; and to that motion its exceeding rigidity is due." Its density must be far greater than that of any form of matter, "yet matter moves through it with perfect free dom, without any friction or viscosity" (1913, p. 33).

The ether, says Sir J. J. Thomson, "is not a fantastic creation of the speculative philosopher; it is as essential to us as the air we breathe. . . The study of this allpervading substance is perbaps the most fascinating and important duty of the physicist." And Sir Oliver Lodge also speaks of the fascination of this portentous entity, material but no matter, "the great engine of continuity":- "Its curiously elusire and intangible character, combined with its universal and unifying permeance, its apparently infinite extent, its definite and perfect properties, make the ether the most fundamental ingredient in the material cosmos."

We have delayed over these elementary ideas because those who are convinced of the apartness of living creatures are apt to fail in appreciation of the inorganic domain. Even the use of the word 'inert' betrays either prejudice or ignorance, both probably unconscious.

Professor Enriques rightly objects to the false antithesis involved in opposing the spontaneity and change of everything that lives to the inertia and immutability of matter. He uses "spontaneity" here to mean " activity" or "possibility of changing through internal conditions," and rejects the idea of "an absolutely passive matter". "The view seems far more adequate," he says, "which holds that everything around us is living and active, save for a difference in degree in the intensity or in the rapidity of the changes, and in the relative importance of the internal and external 
factors for the course of the phenomena " (Enriques, 1914, p. 368). It is useful, however, to keep a term like "living" for organisms only.

\section{$\$ 11$. Contrasts between the Realm of Organisms and the} Domain of the Inorganic.

Let us turn from the resemblances to the contrasts between the realm of organisms and the domain of the inorganic.

The first great contrast is that there are no true individuals in the domain of the inorganic, though there is a great diversity of quality. A crystal approaches some of the criteria of being an individual-it has definiteness of form, coherence, a capacity for a sort of growth and repair; but a crystal is homogeneous, not made up of inter-dependent parts working together to secure continuance either of itself or of its kind. The crystal's regularity is not functional; it is perhaps the visible expression of the molecular structure. Similarly, the solar system makes some approach to being an individual, having independence and unity in diversity, but it can hardly be said that the solar system is an agent, or that its working is directed towards its own continuance.

There are few phenomena in the domain of the inorganic which can be spoken of as propagative, though one may think of the origin of a double star, or of the earth giving birth to the moon, or of the multiplication of crystals. This is in marked contrast with the abundant multiplication characteristic of organisms.

And while the volcano is insurgent enough in a sense, and the breakers seem furious in their assaults on the cliffs, we know that there is no freedom of action, that everything is without alternative.

There seems no doubt as to the general fact that the solar 
system developed from a much less differentiated, much more diffuse, condition; it is certain that our earth has passed through various stages of development, and has become increasingly differentiated in its pattern and features; and many facts point to the occasional origin of new chemical collocations in Nature; but there is nothing in the domain of the inorganic which can be compared with any precision to organic evolution and there is nothing that can be compared to the struggle for existence. We are not justified in saying that there may not have been elimination of unstable collocations which could not last and had to be scrapped, but this bears at most a superficial resemblance to the answering back to environing limitations and difficulties which is the essential feature of the organismal struggle for existence. There is neither endeavour nor selection in the inorganic domain, and till organisms emerged there was little or no power of learning in the school of time.

For plain people it was a very useful classification that Samuel Butler suggested: Living Creatures, Machines, and Things-in-General. Machines are inorganic material systems, but they must be kept quite by themselves in any discussion like this, for they are collocations put together by man with a definite intention. They are purposive constructions, and they are the only non-living things of which this can be said. A river often cuts its way very effectively, but we are romancing if we speak of its purpose. Its bed is not adapted to it, as a flower to its insect visitor. The concepts of adaptation and purposiveness do not apply in the inorganic world, where there are no alternatives.

It seems that the domain of the inorganic is contrasted with the realm of organisms by the absence of in. dividuality, reproductivity, freedom of action, endeavour, 
and purposiveness. It is a domain of mechanically necessitated sequences without alternatives and of uniformities without exceptions. In all probability this quality of uniformity has been a quite indispensable basis for the superstructure of life, affording stability for the experiments and endeavours that have doubtless been characteristic of organisms from the first.

§12. The Suitability of the Inorganic to be the Basis and Environment of the Organic.

We wish in conclusion to allude to the very interesting fact-which will demand further attention later on-that the not-living earth exhibits many remarkable fitnesses to be the home of life. Living means trafficking with the environment; to do this effectively organisms must be complex and yet coherent, plastic and yet durable, and they were able to gain these qualities because of the fundamental properties of the primary constituents of the inanimate environment. The properties of Water and Carbon dioxide, the tendency some forms of matter have to complexify, the properties of the colloid state, the character of the sea as a medium, these and other inorganic data are, as Prof. L. J. Henderson $(1913,1917)$ has shown in detail, extraordinarily well suited to be pre-conditions of organisms. We must, of course, avoid arguing in a circle, for that the earth should be 'friendly' to living creatures is not surprising, since in their physical nature they are bone of her bone and flesh of her flesh-her very children. Yet when we give full consideration to the fact that living creatures as material systems are in no wise foreign to the earth, but are in deep and subtle ways congruent and solidary with it, perhaps we shall not be inclined to brush aside hurriedly the suggestion 


\section{THE REALM OF ORGANISMS CONTRASTED}

that the domain of the inorganic is as it is for a purpose. At present we leave this as a pious anticipation.

\section{SUMMARY.}

The world without is conveniently divided into the realm of organisms and the domain of the inorganic, which stand in close inter-relation and sharp contrast. In the domain of the inorganicfrom solar system to snow crystal, from the hills and the sea to dust and dew-drops-we are impressed-by (a) the rich concrete fulness of different kinds of things and events, which, nevertheless, ean be summed up, for most purposes, in terms of a few fundamental concepts, such as matter and motion; (b) the orderly uniformity that pervades it; and (c) the restless and subtle activity that appears to obtain throughout.

A study of the realm of organisms discloses a multitude of individualities and yet an orderly systema naturæ. There is an embarrassment of different kinds-25,000 named Vertebrates, ten times as many named backboneless animals, and about as many plants, yet a rational elassification is possible.

A second impression is of the abundance and insurgence of life. Most of its streams tend to overflow their banks. Many species are represented by numberless individuals. There is also the quality of insurgence, for we see life intrusive everywhere, pressing up against limitations, circumventing or overeoming difficulties-like a strong will.

Another impression is of ceaseless struggle and endeavour on the one hand, ceaseless selection or sifting on the other. Living creatures react in manifold ways to environing limitations and difficulties, and in the clash that ensues there is often discriminate elimination.

The inter-relatedness of organisms is another fundamental fact. Animate nature is a vast system of interlinked lives, a web with a pattern. As in mankind, there is progress towards systematisation and solidarity, and the correlation of organisms which is a product of evolution becomes in turn a directive factor.

Another fundamental impression is that of fitnesses. Every higher organism is a complex bundle of adaptations. It is suited to its inanimate surroundings, to its food, it may be to other creatures, to its own weight, to its movements; it may be to a mate 
and to offspring; to regularly recurrent times and seasons and risks of injury; to its ante-natal life and to dying at the proper time!

If we are to consider Animate Nature in its totality we must not overlook the practically universal pervasiveness of beauty of form and colour.

It may be said that this impressionist picture of Animate Nature is one-sided, that it ignores the redness of tooth and claw, the cruelty, the ugliness, the parasitism, the obtrusively enormous mortality, and the mis-adaptations. Much of this objection is due to misunderstanding; the admittedly great difficulties that remain will be discussed in Lecture XVIII.

Comparing the realm of organisms with the domain of the inorganic, we must avoid the error of exaggerating the differences (so that an impression of discontinuity is created) and the error of merging the two (thus missing what is distinctive in each). In the domain of the inorganic there is little individuality (though much difference of quality), no apparent freedom of action, no endeavour, no purposiveness, no learning in the school of time. But its uniformity has been a probably indispensable fulcrum for the lever of will. It should be noted too that the old view of inert matter has given place to a dynamic conception of extraordinary subtlety. 

LECTURE III.

THE CRITERIA OF LIVINGNESS. 



\section{LECTURE III.}

\section{THE CRITERIA OF LIVINGNESS.}

§1. Living and Not-living. §2. The Essential Characteristics of Living Organisms. §3. Persistence of a Complex Specific Metabolism and of a Corresponding Specific Organisation. \$4. The Capacity of Growth, Reproduction, and Development. §5. Effective Behaviour, Registration of Experience, and Variability.

\section{§1. Living and Not-living.}

IF we are to reach a coherent view of Nature, such as could be included in a philosophy, we must arrive at some discernment of the characteristics which mark off living organisms from their not-living surroundings. In the present state of science a definition of the organism cannot be more than tentative, but it must be continually attempted.

When we pass from watching a flowing stream or the wind-swept clouds, to look at the bees visiting the flowers, or the swallows building their nest, we feel that we are facing something new-living. What we see is not, indeed, in every respect new as compared with the inorganic, for gravity acts on animals just as on drops of rain, and living creatures never disobey, so far as we know, the ordinary laws of physics and chemistry which sum up the routine of our analytic experience of the not-living. On the whole, however, especially if we look at animals rather than plants, the differences impress us more than the resemblances, we feel rightly that we are in the presence of something new. Organioms show characteristics which mark them off 
from their non-living environment. What are these characteristics? What are the criteria of living organisms? What is essential in the admitted contrast between the living and the not-living?

\section{§2. The Essential Characteristics of Living Organisms.}

In the most general way what we see is plain enough. We see organisms acting on their environment-displacing it, changing it, eating it, and so on; and again we see that the environment acts upon the organism-displacing it, changing it, stimulating it, oxidising part of it, and so on. So that living is a twofold relation between organisms and their environment-a twofold relation of action and reaction, of thrust and parry, of doing and suffering. At one moment the organism is relatively the more active, at another the environment. Living is a continual adjustment between these two relations.

When we look at the facts a little more closely we see that all living creatures-plants as well as animals-are active towards two main results, their own self-maintenance and the continuance of their race. Organisms have in their living just two main businesses-caring for themselves and caring for their offspring. But all this is living rather than life; we are only hiding the problem behind the word organism. What are the marks of a living creature?-that is the question. What is the best answer we can give for the time being? Many answers have been given, but none has found wide acceptance, which doubtless means that biologists have not yet seen the insignia of organisms in their entirety, or in proper perspective.

One of the best statements is that of Roux, who recognises five " elementary functions": 
I. Self-disassimilation.

II. Self-preservation, including assimilation, growth, movement, feeding, etc.

III. Self-multiplication.

IV. Self-development.

V. Self-regulation in the exercise of all functions, including self-differentiation, self-adjustment, self-adaptation, and in many organisms distinetly recognisable psychical functions.

It is very interesting to notice how this hard-headed founder of what he calls "developmental mechanics" speaks deliberately of self-preservation, self-increase, self-differentiation, self-regulation, and so on.

The statement we propose differs a little from this and from others, being an attempt at a logical grouping of the fundamental characteristics.

§ 3. Persistence of a Complex Specific Metabolism and of a Corresponding Specific Organisation.

The image of the organism is the burning bush of old; it is all afire, yet it is not consumed. Nec tamen consumebatur. Or it is like the sunlit top of a fountain rising in the air; its component elements are restlessly changing on their way up or on their way down, yet the form remains approximately the same. The peculiarity is not that the organism is in continual flux, for chemical change is the rule of the world; the characteristic feature is, that the changes in the organism are so regulated and balanced that the integrity of the creature is retained. The great English physiologist, Sir Michael Foster, used to say that "A living body is a vortex of chemical and molecular change"; and the image of a vortex expresses the fundamental fact of persistence in spite of ceaseless change. 
A vivid statement of this characteristic feature of life was given by Huxley in his Crayfish $(1880$, p. 84):- "The parallel between a whirlpool in a stream and a living being, which has often been drawn, is as just as it is striking. The whirlpool is permanent, but the particles of water which constitute it are incessantly changing. Those which enter it, on the one side, are whirled around and temporarily constitute a part of its individuality; and as they leave it on the other side, their places are made good by new comers.

"Those who have seen the wonderful whirlpool, three miles below the Falls of Niagara, will not have forgotten the heaped-up wave which tumbles and tosses, a very embodiment of restless energy, where the swift stream hurrying from the Falls is compelled to make a sudden turn towards Lake Ontario. Howerer changeful in the contour of its crest, this wave has been visible, approximately in the same place, and with the same general form, for centuries past. Seen from a mile off, it would appear to be a stationary hillock of water. Viewed closely, it is a typical expression of the conflicting impulses generated by a swift rush of material particles.

"Now, with all our appliances, we cannot get within a good many miles, so to speak, of the crayfish. If we could, we should see that it was nothing but the constant form of a similar turmoil of material molecules which are constantly flowing into the animal on the one side, and streaming out on the other."

Without accepting the view that the organism is exhaustively described by calling it " nothing but the constant form of a turmoil of material molecules", without forgetting that the organism-whirlpool acts on the stream, and gives rise to other whirlpools, we welcome the metaphor as vividly true 
within its limits. But the image is too general to be adequate; we must inquire into the changeful integrity of the organism more carefully. Three points are of outstanding importance: $(a)$ that the changes in the organism are very complex, having essentially to do with protein substances in a colloid state; (b) that they are specific for each kind of creature, and (c) that they are correlated in such a way that they go on, and the specific structure likewise persists. Let us take each of these points in turn.

\section{(a) Metabolism of Proteins.}

According to some physiologists the only absolute difference between living organisms and inorganic bodies is, that proteins are universally present in the former and absent in the latter. Verworn writes: "Since it is known that the nitrogenous proteids, with their allies, which in part are derived from the proteids and in part are necessary to their formation, are the sole organic compounds that are never wanting in living substance, that everywhere they constitute its chief mass and alone are sufficient for its formation, it can be said that all living organisms are characterised by the metabolism of proteids" (1899, p. 136). These protein compounds, such as white of egg or the gluten of bread, are peculiarly intricate, with a large number of atoms or atom-groups in their molecules; they diffuse very slowly and do not readily pass through membranes; they occur in a colloid state, and although some, e.g., hæmoglobin, are crystallisable, they are not known in a crystalloid state in the living organism; they are relatively stable bodies, yet they are continually breaking down and being built up again within the body, partly under the direct influence of ferments or enzymes. The constructive, synthetic, up- 
building, winding-up processes are summed up in the term anabolism; the disruptive, analytic, down-breaking, runningdown processes are summed up in the term katabolism, both sets of processes being includer in the term metabolism, for which we have, unfortunately, no English equivalent-like the German word 'Stoffwechsel', change of stuff. But when Verworn says "The life-process consists in the metabolism of proteids", he, like Huxley, is summing up too simply; it would be more correct to say that living always involves the metabolism of proteids or proteins.

(b) Specificity or Individuality of Metabolism.

A second feature is that each organism has its chemical individuality, and associated with this a specific structural collocation. There is a chemical specificity in the milk of nearly related mammals, and in the grape-juice of nearly related vines. A stain due to the blood of a rabbit can be readily distinguished from a stain due to the blood of a man-a fact that has been used with effect in some modern murder trials. Nay more, the blood of a horse can be distinguished from that of an ass. The crystals of the red blood pigment of a dog differ from those of a wolf; indeed, those of a domestic dog differ from those of the wild or feral Australian dingo. The familiar fact that there are individuals who cannot eat particular kinds of food, such as eggs, or oysters, without more or less serious symptoms is another illustration of specificity which is actually individual. It looks as if a man were individual not merely as to his finger-prints, but as to his chemical molecules. Even the sexes differ in their metabolism, as is diagrammatically shown in one or two cases where the colour of the blood is actually different. We are here in contact again with 
what we have already alluded to as one of the remarkable differences between the organic and the inorganic-Individuality. We come back to what was said of old :- "All flesh is not the same flesh: but there is one kind of flesh of men, another flesh of beasts, another of fishes, and another of birds."

Prof. Charles Richet and other physiologists have of recent years devoted much attention to the phenomenon that dosing an animal with certain poisons may bring about, if the animal survires, a peculiar physiological condition, called anaphylactic, which make the creature hyper-sensitive to subsequent doses. An extract of sea-anemone's tentacles is very poisonous to dogs, but, when the dog recovers, a very minute second dose a month afterwards may be rapidly fatal. The phenomenon of anaphylaxis is extraordinarily subtle; thus a man to whom shrimp flesh is poisonous may be unaffected by lobster. He is violently poisoned if he eats a single shrimp, and yet he is able to enjoy a whole lobster; straining at a gnat, he swallows a camel with ease. The importance of this is that it points towards the conception of the chemical individuality of the living creature. There is a specific chemical constitution which is on the whole best for the species in question, which makes for stability. Those that survive the introduction of a poison, it may be the result of digesting a particular kind of food, do not necessarily mark the surviving type, for they may be killed by the anaphylactic violence following a second dose. So much the worse for the individual, but so much the better, possibly, for the species, which cannot safely admit of any compromise with poison. Thus, speaking of man, Richet says: "Anaphylaxis appears to be an efficacious and energetic method of maintaining the chemical stability of our 
bodies by provoking an immediate and violent reactional response to the introduction of any substance which might change it."

\section{(c) Persistence in Spite of Change.}

In the ordinary chemical changes in the inorganic domain, as in the weathering of rocks, one substance changes into another. Iron becomes rust. So is it also in the living body, but there we encounter a new and characteristic feature-continual restitution or recuperation. The reactions are not self-destructive. Repair counteracts waste ceaselessly. There is a continual balancing of accounts so that debts are more or less effectively avoided. Without metaphor, the specific organisation is continuously repaired so that the specific activity continues, and if organisms-after they once got grip-had been content to remain relatively simple they need never have died-a natural death.

We regard this characteristic as fundamental,-the capacity of retaining integrity in spite of ceaseless specific change, -one may almost say through change. For the energy liberated in katabolism is used to promote compensating anabolism. The more it changes, the more it remains the same thing; the most intensely living animals have the most persistent integrity of form. In any case, an organism was not worthy of the name until it showed, for a time at least, not merely activity, but persistent activity-a power of balancing accounts. Like a clock the organism is always running down and always needing to be wound up; but unlike a clock it can wind itself up, if it gets food and rest. In green plants, as every one knows, there is usually a quite unnecessary amount of winding up-with the interesting far-off result that animals, utilising already manufactured 
food, have time for agency, and that we have time for thinking about it all.

We are familiar with the self-preservative devices and reactions of higher animals and with the self-preservativo way in which the various organs of the body work into each other's hands; and it is a remarkable fact that a specific activity in a nervous system may be restored after the destruction of the particular nerve-elements on which the activity previously depended. This vicarious functioning is all the more remarkable inasmuch as there is not in higher animals any regeneration or replacement of nerve-cells after birth. But decper than all this is the correlation of chemical processes in the individual units, so that down-breaking leads to up-building, so that up-building makes further down-breaking possible, the pluses balance the minuses, and the creature goes on. The unicellular organism spends its substance and yet has it, through its fundamental capacity for self-renewal. If the living creature is a machine, it is a self-stoking, selfrepairing machine, and it can take a rest betimes.

Several saving-clauses must be appended:-(1) The organism shows persistent functionality, but it is not known to offer any exception to the law of the conservation of energy. In living it expends energy, and suffers wear and tear; it cannot continue unless it captures more energy and is ablo to repair its structure. Fatigue and the dying of parts, such as leaves, not to speak of senescence and death itself, show that the fundamental capacity for self-maintenance is not perfect. But the broad fact is that the capacity has for a variable time a very considerable degree of perfection. The organism's chemical activities (and repairprocesses) are so correlated that it remains for a considerable time a going concern. As we shall afterwards see, some 
investigators claim for the organism a unique power of retarding the universal tendency of energy to sink into unavailable form, in other words, of evading, in some measure, the second law of thermodynamics.

(2) If a piece of organism be ground up in a mortar and the expressed juice poured into a vessel, a process of metabolism is sometimes observable similar to that which occurs in the living body. Every one knows that pepsin may be bought at the chemist's, and used to digest a shred of beef in a test-tube. It is true that neither the ferment nor the proteid can as yet be synthesised artificially, but this may be only a question of time and ingenuity. We cannot dogmatise as to the limits of mimicking in a test-tube what occurs normally in an organism, and if the reaction be mimicked, then there is nothing characteristically vital about it, any more than there is about organic substances like sugar and indigo which used to be regarded as producible in organisms only. But the point is that in the living organism the process in question is a link in a concatenated series which makes for self-repair and continuance. The essential secret of living is in the correlation which secures persistence amid change.

(3) If the whole of a living organism, say a spinach plant, were to be minced up quickly, no change of chemical composition would necessarily occur for some little time, but what exhibition would there be of the alleged fundamental characteristic of self-repair? It may be answered that the mincing has destroyed the make-up of the organism, that the living units of the body are in most cases adapted for self-repair only in particular conditions, such as an environment of other cells, in the collocation which has been abolished by the mincing. But while the power of self-repair 
cannot operate except under certain conditions, it is an extraordinary fact that some creatures can be re-made even after mincing. If a sponge be minced up and forced through a cloth filter, little drops of the débris, placed in appropriate environment, will at once proceed to build themselves up into new sponges. The characteristic metabolism is retained, re-differentiation sets in, the tiny mass begins to feed and grow, the normal organisation is restored, the sponge is once more a going concern. The restoration of the sponge from a drop of débris is as different from the re-building of a crystal from a fragment, as the highly differentiated spongo from the very homogeneous crystal, or as the intensely metabolic living sponge from the self-contained, though certainly not inert, crystal.

(4) If living implies persistent metabolism, we must admit a saving-clause to the effect that the metabolism may sink at times to a minimum. Further investigation will make things clearer, but there is difficulty at present in regard to the familiar facts that dried seeds may retain their power of germinating for as long as a man lives, or that desiccated animals and germs of animals (as in the case of some thread-worms, rotifers, bear-animalcules, and small crustaceans) may remain in a state of so-called suspended animation for, it may be, a dozen years. Small Nematode worms have been known to revive after being fourteen years dry-alive rather than living. It has not been satisfactorily proved that mummy wheat germinates, but Becquerel got scedlings from seeds which had lain for eighty-seven years in a herbarium - a hortus siccus indeed.

Becquerel took seeds of wheat, mustard, and lucerne, and perforated their air-tight seed coats; dried them in a vacuum at $40^{\circ} \mathrm{C}$. for six months; sealed them up in an almost ex- 
hausted tube for a year; submitted them to the temperature of liquid air $\left(-190^{\circ}\right)$ for three weeks, and of liquid hydrogen $\left(-250^{\circ}\right)$ for threc days; and then put them on moist cotton wool, where they germinated. We are forced by such experiments to realise that life is not an entity but a relation between organism and environment, but we must have more facts before wo deal effectively with the difficulties which the facts raise. Does the process of living suffer complete interruption, and recommence when water soaks in, and oxygen after it, as Becquerel seems to think; or does the metabolism sink to a minimum, like the combustion of a sleeping fire? Very interesting, in this connection, is Professor Waller's observation that as long as a tissue is living, or an egg capable of development, or a seed able to germinate, there is a particular electrical reaction-the 'blaze' reaction which disappears when liring has irrecoverably ceased.

(5) The criterion of an organism to which we have given prominence is that of persistence, which is obvionsly relative. Some organisms can keep agoing for a hundred years, some for only a hundred days, and some for only a hundred hours. The question arises as to the limit. Is it possible that there were primeval organisms which lived for only a hundred seconds? If so, how would these hypothetical creatures differ from the pill of potassium which flares itself out, rushing about on the surface of the basin of water on which it has been thrown? The answer must be, that it is not the length of life that counts; the criterion is whether, alongside of disruptive processes associated with protein substances, there were also correlated constructive processes, making for repair and self-maintenance. Some Infusorians divide more than once every day, some Bacteria divide more than once every hour, and these may be near the limit of 
the duration of individual life at the one extreme. The Big Trees living for two thousand years may be near the limit in the other direction.

\section{\$. The Capacity of Growth, Reproduction, and} Development.

One can readily conceive of an organiem which balanced its accounts from hour to hour, but never had much margin. Thero are such delicately-poised ephemeral organisms, which live, to use a homely expression, from hand to mouth. They are going concerns, but they are trading on a very restricted capital, and cannot survive a crisis. So we see at once that there is a commanding advantage in being able to store energy in potential form, and this is fundamentally characteristic of organisms-especially of plants. As regards the ratio between the income of energy and the work done, living organisms are far ahead of any engine, but there is also the power of accumulating energy which can be used later. Thus we are led to recognise the power of growth as one of the characteristics of organisms. A surplus of income over expenditure is the primal condition of organic growth. It has further to be noted that the growth of living creatures, as contrasted with that of crystals, is at the expense of materials different from those which compose the organism; it implies active assimilation, not passive accretion; and it is very definitely a regulated process. An organism does not grow like a snowball.

But growth leads on to multiplication. As Haeckel clearly indicated in his Generelle Morphologie (1866), reproduction is discontinuous growth. How impossible it is to draw any hard and fast line between a fragmentation which separates off overgrowths, and the more specialised modes 
of reproduction! Perhaps we are looking back to near the beginning of organic life when we see the fragmentation of a protoplasmic corpuscle which has grown too large to be a successful unity. It cannot be gainsaid that the division of a cell remains one of the mysteries of the world. Professor Bateson writes (1913, p. 39): "I know nothing which to a man well trained in scientific knowledge and method brings so vivid a realisation of our ignorance of the nature of life as the mystery of cell-division. . . . It is this power of spontaneous division which most sharply distinguishes the living from the non-living. . . . The greatest advance I can conceive in biology would be the discovery of the instability which leads to the continual division of the cell. When I look at a dividing cell I feel as an astronomer might do if he beheld the formation of a double star: that an original act of creation is taking place before me."

In most cases the cell divides into two precisely similar daughter-cells, this being associated with an exceedingly complicated division of the nucleus, which secures that each of the two daughter-cells gets a meticulously precise half of the chromatin material of the original nucleus. But the difficulty of the problem is increased by the fact that a cell may also divide into two dissimilar halves, as appears to happen in certain modes of inheritance. In exceptional cases among multicellular organisms the process of celldivision is simpler and more direct, and in some unicellular organisms it is very simple. It is probable that the complicated methods of cell-division which are now the rule are the results of a long process of evolution, and that the fundamental characteristic is simply division. But why should the protoplasmic unit divide? Spencer, Leuckart, and James pointed out independently that, as a cell of 
regular shape increases in volume, it does not proportionately increase in surface. If it be a sphere, the volume of material to be kept alive increases as the cube of the radius, while the surface, through which the keeping alive is effected, increases only as the square. Thus there tends to be a hazardous disproportion between volume and surface, which may set up instability. The disturbed balance may bo restored by the emission of processes from the surface of the cell, making it like a country with a big coast-line, as in Rhizopod Protozoa or in the amœboid cells found in most multicellular animals. But the disturbed balance is normally restored by the cell dividing into two cells. This view indicates the advantage of cell-division, but beyond the hint that a disproportion between volume and surface may induce physiological instability, perhaps a cell-solution or cytolysis, it does not tell us what brings the process about.

It is an interesting fact that if a non-nucleated fragment of cell-substance be cut off from a large Protozoon, it can move about for a time, but it eannot feed or grow, and sooner or later it dies. But a nucleated fragment does not 'die. There are other facts which point to the same conclusion-that the nucleus is a sort of dynamic centre to the cell (especially a trophic centre), and that stability depends on keeping up a certain proportion or relation between the nucleoplasm and the cytoplasm. It follows, therefore, that if growth imply an increase of cell-substance out of proportion to nuclear substance, a state of physiological instability may set in, which cell-division may counteract. In many large Protozoa there are numerous nuclei.

It has also been suggested that a period of growth is automatically followed by a process of "autokatalysis", or selffermentation, but precise data are awanting. What we wish 
to indicate, however, is that the correlation of chemical processes which makes continued self-maintenance possible, naturally leads on to growth, and that growth naturally leads on to division or reproduction. This remains true though our ignorance of the physiology of cell-division is confessed.

It is possible, however, to take another step. It is characteristic of organisms to multiply, and they multiply by division, separating off a fragment, a group of cells, or a single cell. This brings us face to face with development - the power that a part has of growing and differentiating until it has literally reproduced the whole. Development is the making visible of the latent potentialities - the intrinsic manifoldness — of the liberated fragment, or sample, or cell; and while the development of a fertilised egg-cell into an organism remains to us one of the wonders of the world, we venture to suggest that the development may be profitably thought of as a continuation of the processes which are always going on to preserve the specific organisation in good repair. Every gradation between the two may be found in the phenomena of regrowth or regeneration of lost parts. But when we associate this capacity of development with growth and multiplying we see that we may unite them all in the conception of cyclical development, which Huxley was wont to emphasise in his discussions of the characteristics of living creatures.

From a microscopic egg-cell an embryo plant derelops; the ovule becomes a seed, the seed a seedling; by insensible steps there is fashioned a large and varied fabric of root and stem, leaves and flowers. But no sooner has the edifice attained completeness than it begins to crumble. The grass withereth and the flower thereof fadeth, and soon there is nothing left but the seeds, which begin the cycle anew. It 
is, Huxley said, " a Sisyphean process, in the course of which the living and growing plant passes from the relative simplicity and latent potentiality of the seed to the full epiphany, of a highly differentiated type, thence to fall back to simplicity and potentiality again ". So is it also among animals. The microscopic egg-cell divides and re-divides, and there is built up an embryo. This may develop steadily and directly into the likeness of its kind, or it may give rise to a divergent larval phase such as we are familiar with in caterpillars and tadpoles. Through more or less critical phases of adolescence the adult stage is reached, and it is a not infrequent achievement to lengthen out this period of full epiphany and freedom. But whether the creature's life is counted in days or in months, years or centuries, there is for most an ascending and a descending curve from the vita minima of the egg-cell (which often dies in a few hours if it be not fertilised) to the vita minima of senescence or to the not less frequent terminus of violent death.

In reference to Sir Michael Foster's definition, "A living thing is a vortex of chemical and molecular change", Professor Bateson points out that the living "vortex" differs from all others in the fact that it can divide and throw off other "vortices", through which again matter continually swirls $(1913$, p. 40$)$. The parallel, he says, may be carried even further, for a simple vortex, like a smoke-ring, if projected in a suitable way, will writhe into two rings. "If each loop as it is formed could grow and then trvist again to form more loops, we should have a model representing several of the essential features of living things" (1913, p. 40). It has to be added, as we have seen, that the living vortex is the seat of complex and spccific chemical changes which are correlated in such a way that the creature lasts. 
This power of persisting on its own path-a sort of protoplasmic inertia-is very fundamental. It has received remarkable illustration in the astounding facts established in regard to the continued life of excised or explanted fragments or even cells. Pieces of skin, drops of blood, fragments of embryo may with proper precautions be kept alive for months.

Is there any unifying concept behind these extraordinary powers of growing, multiplying, developing, and growing again? The well-known physicist, Professor Joly of Dublin, made many years ago (1891) the very interesting suggestion that the living creature has a unique power of accumulating energy acceleratively. "The organism is a configuration of matter which absorbs energy acceleratively, without limit, when unconstrained" (p. 79). If we heat a piece of iron or charge a Leyden jar, the process becomes more and more difficult as we go on. "The transfer of energy into any inanimate material system is attended by effects retardative to the transfer and conducive to dissipation." But the young leaf growing in the sunlight utilises the solar energy acceleratively; the more it gets, the more it grows, and the more it can take. "The transfer of energy into any animate material system is attended by effects conducive to the transfer, and retardative of dissipation." On what this peculiar power depends Professor Joly does not tell usthat would be the secret of life; but it is very interesting to get from a physicist a clear statement of the dynamic contrast between animate and inanimate material systems. "The animate system is aggressive on the energy available to it, spends it with economy, and invests it with interest, till death finally deprives it of all." 


\section{§5. Effective Behaviour, Registration of Experience, and Variability.}

So far we have sought to arrange in a logical way certain insignia of organisms. Absolutely fundamental is the power of persistent individuality in spite of ceaseless change. There is a unifying idea of persistence or of functional inertia. This led us to consider growth, multiplication, and cyclical development. Here, perhaps, there is a unifying idea of accumulating potentialities. We have now to recognise that living creatures are characterised by effective behaviour, registration of experience, and variability. The common note in this triad of qualities may not be obvious, but is it not agency, self-expression, creativeness?

(a) Life is a kind of activity which comes to its own in effective behaviour, that is to say, in an organically determined correlated series of acts which converge towards a definite result. Behaviour is seen at many levels and in diverse modes, which will be discussed later, but its common features are correlation, concatenation, individuality, and purposiveness. Big words, indeed, for the Amœba gliding along on the mud of the duck-pond. And yet, if we take this Amœba, and lay aside the contempt which superficial familiarity breeds, we find that we are only beginning to make its acquaintance.

Professor Jennings describes a large Amœba, $a$, which had imperfectly swallowed a smaller one, $b$. The prisoner moved as if trying to escape, the swallower moved as if trying to prevent it. Finally the small one did get completely out again, whereupon the large Amœba, $a$, reversed its course, overtook $b$, engulfed it completely, and started away. The small Amœba, again imprisoned, lay still until through the movements of $a$ there happened to be but a thin layer of 
protoplasm between it and freedom. It then broke loose, escaped completely, and was not further molested. If this behaviour had been described and even drawn by a tyro, we might have distrusted it entirely, but when we have it from a master in the difficult art of observing Protozoa, we must give it careful consideration. Without saying anything just now about the Amœba's mind, must we not agree that this concatenation of following, catching, losing, chasing, re-capturing, and losing again is either behaviour or magic?

Most living creatures show more behaviour than is generally supposed, but many of them, plants especially, have little. We often complain that they do not show any interesting habits when we are watching them. This may be admitted, however, without affecting the general truth of the statement that organisms are characterised by a capacity for effective behaviour. That many men run their lives, or have to run their lives with a minimum of thinking, does not affect the general truth of the statement that men are characterised by a capacity for rational discourse.

(b) The effectiveness which characterises the behaviour of those organisms that show enough to be profitable subjects of study, appears to depend on profiting by experience in the individual lifetime, or on the entailed results of ancestral experiments (chiefly, perhaps, in the form of germinal variations), or, usually, on both. The registration of experience and experiments is one of the insignia of organisms, but we must include under the term organism the germ-cell, which is an implicit organism, a microcosm corresponding to the macrocosm which develops from it. We must include the germ-cells because, so far as we can judge at present, many if not most new departures of importance have had their origin as germinal variations. If the word 'experi- 
ment' be inadmissible, some other will serve. We refer to the permutations and combinations, the adjustments and compromises, the subtractions and additions that seem to occur in the history of the germ-cells.

As W. K. Clifford said, "It is the peculiarity of living things not merely that they change under the influence of surrounding circumstances, but that any change which takes place in them is not lost, but retained, and, as it were, built into the organism to serve as the foundation for future actions." As Bergson puts it, "Its past, in its entirety, is prolonged into its present, and abides there, actual and acting." As Jennings says, from the physiological point of view, in discussing the behaviour of the brainless starfish, "The precise way each part shall act under the influence of the stimulus must be determined by the past history of that part; by the stimuli that have acted upon it, by the reactions which it has given, by the results which these reactions have produced (as well as by the present relations of this part to other parts, and by the immediate effects of its present action). We know as solidly as we know anything in physiology that the history of an organism does modify it and its actions-in ways not yet thoroughly understood, doubtless, yet none the less real."

(c) The crowning attribute of life-and the most elusive -is variability, the organism's power of producing something distinctively new. At present we must take it as 'given'. The capacity most like it is Man's power of mental experiment, the secret of the artist, the musician, the poet, the inventor, the thinker, and the true statesman.

A discussion of this innermost secret of life must be postponed till we come to consider the factors in evolution, but two points may be noticed in the meantime. There is varia- 
tion and variation. There is a change wrought on the body by some peculiarity of nurture, environment, or habit. That is a modification, and, so far as we are aware, it is not transmissible in itself or in any representative degree. So this does not help us. There are also variations which consist in the loss of some ancestral character, such as horns or a tail, and we know that there are opportunities in the history of the germ-cells for the dropping out of hereditary items. There are also variations which consist in new arrangements of ancestral characters, as when the progeny of black and yellow rabbits are grey. Many apparently novel features are just old characters in new guise. This again is not difficult to understand in a general way. But the kind of variation before which we are dumb is the brusque origin of something distinctively novel, a new pattern, an originality. And unless one is to make the assumption that every character was given in the first organisms and that evolution is only unrolling, time counting for nothing, we are bound to assume that these momentous new departures have been of frequent occurrence all down the ages. Our suggestion meanwhile is simply an assumption that organisms are essentially creative. Even the inorganic has a tendency to complexify; a fortiori the organic. The chemist is always turning out new carbon-compounds, the organism is an unconsciously inventive ehemist. The same chemical substance can sometimes crystallise in more than one way-we know the variety of snow crystals-so, but with infinitely more subtlety, may the germ-cell experiment with its own architecture, or trade with its environment in adventurous differentiation. Just as an intact organism from the Amoba to the Elephant tries experiments, so the germ-cell, which is no ordinary cell, but an implicit organism, 
a condensed individuality, may make experiments in selfexpression, which we call variations or mutations. Such, at least, is our present view of a great mystery.

What has all this to do with Natural Theology? Little, perhaps, directly; but much indirectly. For a superficial or flimsy conception of the essential characteristics of living creatures means putting a bushel over one of the great wonders of the world. A commonplace view of Animate Nature is an impiety, and a mechanical view is a gratuitous complication of the problems of existence. Geniuses like Nietzsche of yesterday and D'Annunzio of to-day have admitted the darkening of their eyes by a mechanical view of life, accepted as scientific. We seek to show that it need not bo accepted.

But there are three concluding remarks that we wish to make:-(a) The subject is not yet a matter of exact science, and we do not say that ours is the true or the truest way of stating the criteria of organisms. It is the best answer we personally can give for the time being. Some would state, more definitely than we have done, that all organisms are psycho-physical beings. And others would reject, erroneously, we think, all such categories as individuality, behaviour, experience, experiment, and self-expression.

(b) Secondly, when we say that an organism has the capacity of retaining its integrity in spite of ceaseless metabolism, we do not explain this capacity. If we could we should know the secret of life, which remains hidden from us.

(c) Thirdly, our description of the general characteristics of living creatures remains too cold-blooded. Like every analytical and formal treatment it falls far short of giving an adequate idea of life in its concrete fulness. No one who did not know plants and animals would gather from 
our statement any idea of their sparkle and subtlety and surprises. For that requires more than science. We must use our everyday and our red-letter day experience of livingness both in ourselves and in other organisms, wherewith to enliven sympathetically all that biology can give. IVe need not be in the least afraid of engendering an exaggerated idea of the wonder of life!

\section{IN CONCLUSION.}

No one can tell us wherein a living organism essentially differs from a not-living thing. The one is alive, the other is not. Perhaps we err in speaking too much about the unread riddle of life. For this seems to imply the expectation that we shall be able some day to explain life in terms of something else-an expectation which is not likely to meet with anything but disappointment. The materialists look forward to explaining or re-describing the activity we call living in terms of matter and motion. The animists look forward to doing the same in terms of soul. But it is not at all evident why we should be so very desirous to explain life in terms of anything else, or why we should be sanguine in making the attempt. Life is an aspect of reality which found expression when there were evolved those particular collocations of matter and energy which we call organisms, just as Mind is an aspect of reality which found expression when nervous systems of considerable degree of complexity were established. We mean by Life and Mind-the capacity for certain kinds of activity and behaviour and internal experimenting with ideas, and it may well be that Life and Mind are alike irreducible, and that they are not very different from one another. But this is mere speculation. What is practically more important is to appreciate the character- 
istics of living creatures. Hence this inquiry into the criteria of livingness. The bearing of this on modern Natural Theology is that an casy-going concept of 'organism' is a dead fly that may spoil many an ointment.

\section{SUMMARY.}

If we are to reach a coherent view of Nature, such as could be included in a philosophy, we must arrive at some definition of the characteristics which mark off living organisms from their not-living surroundings. In the present state of science this definition cannot be more than tentative, but it must be continually attempted.

Living may be described as a twofold relation of action and reaction between organisms and their environment, and living creatures are always active towards two main results, self-maintenance and the continuance of their race. But the difficult question is: What are the insignia of living creatures?

The first is the power of persisting in a complex specific metabolism, and in a corresponding specific organisation. (a) The essential metabolism of life has to do with the up-building and down-breaking of protein substances in a colloid state. (b) Each living creature has its own chemical individuality and its own specific microseopic and ultra-microscopic architecture. (c) Part of the secret of life is a correlation of chemical processes so that in spite of ceaseless change the organism persists in its integrity for days or years or centuries. It is always burning away; but it is not consumed.

Secondly there are the eapacities of (a) growth, of (b) reproduction, and of (c) development-a triad of qualities. (a) Organie growth, an increase in the amount of organised livingmatter, is at the expense of materials different from those which compose / the growing substance; it implies active assimilation rather than passive accretion; it is very definitely a regulated process. (b) The power of spontaneous division-leading on, directly or indirectly, to the origin of new individualities-is one of the momentous distinctions between the living and the not-living. (c) Development is the actualisation of the intrinsic manifoldness of the liberated fragment, sample, or cell, and may be brought into line with the process of repairing the specific organisation. 
Thirdly, there is another triad of qualities-(a) effective behaviour, (b) registration of experiences and experiments, and (c) variability. The common note here is agency, self-expression, creativeness. (a) Behaviour, exhibited at many levels and in diverse modes, is an organically determined concatenated series of acts converging towards a definite result. Its common features are correlation, individuality, and purposiveness. (b) The effectiveness which characterises organic behaviour depends on the organism's power of profiting by experience in the individual lifetime, or on the entailed results of ancestral experiments (chiefly perhaps germinal variations), or, usually, on both. (c) The crowning attribute-and the most elusive-is variability, the organism's power-but, more accurately perhaps, the germ-cell's power-of giving rise to something distinctively new. 
LECTURE IV.

ORGANISM AND MECHANISM. 



\section{LECTURE IV.}

\section{ORGANISM AND MECHANISM.}

§1. Is Organism More than Mechanism? §2. Chemical and Physical Laws apply to Organisms. §3. Some Difficulties in the Application of Physical and Chemical Formula to Organisms. §4. Criticism of Mechanistic Descriptions of Everyday Functions. §5. Criticism of Mechanistic Descriptions of Animal Behaviour. §6. Difficulty of Applying Mechanistic Formula to Development. §7. Difficulty of Applying Mechanistic Formula to Organic Evolution. §8. Answers to Criticisms.

\section{§1. Is Organism More than Mechanism?}

According to Kirchhoff's famous definition (1876), the task of mechanics is "to describe completely and in the simplest manner the motions which take place in nature". When we give a mechanical description of an occurrence - the eruption of Vesuvius, the bursting of the broom-pods, or the curling of the non-living tendrils of a mermaid's purse -it is in terms of matter and motion, or in chemico-physical terms which are believed to be reducible to those of matter and motion. The mechanical account is as such entirely satisfactory when it enables us to see a process as a continuous series of necessarily concatenated mechanical operations like those which occur in the slow movement of a glacier, or like the successive explosions which mark the extension of a rapidly spreading conflagration. We shall use the slightly wider term mechanistic to include either a matter-and-motion description, which is in the strict sense mechanical, or a more dynamical description in which the 
concept of energy is emphasised, or a chemico-physical description which is ideally mechanical, that is, theoretically reducible to matter-and-motion description, though, as a matter of fact, the reduction may not have been as yet effected. A mechanistic description, in short, is in terms of the fundamental concepts of physics and chemistry; and it is the most precise and most thorough kind of description that is known.

Given three good observations of a comet, an astronomer who knows his business can prophesy with certainty when, barring accidents, it will return. He may not tell us what gravitation means, or what the comet is made of, or how it arose, or what it portends to mankind, but of the coming and going he gives a complete account, as the punctual return of the comet afterwards proves. Now the question which interests us at present is not whether the biologist, if he knew his business as well as the astronomer, could tell us at what precise date next spring the swallows will reach our shores, but rather whether the success of his prediction depends on the reduction of the swallows' behaviour to mechanistic formulation.

The question may be split into two. The first is: How far, as a matter of fact, can characteristically vital occurrences, such as the contraction of a muscle, be described in terms of the formulæ which serve for the study of tides and eclipses, the moulding of a dew-drop or the making of a star? One obvious limit is that, if the organism has mentality that counts in its agency, then the behaviour cannot be completely formulated in mechanical terms. Mind cannot be described in terms of matter, or emotion in terms of motion. As there are some biologists, such as Prof. Jacques Loeb, who hold " a tropism theory of animal conduct" which 
does not recognise mental factors as verce causce at all, and as there are organisms and vital activities which are not known to have any mental aspect, we shall leave this limit to mechanistic description for future consideration.

So the first question is whether, mentality apart, there are irreducible peculiarities in vital activities-peculiarities which cannot be adequately accounted for in terms of physico-chemical or ideally mechanical description? Or is the usually admitted incompleteness of the physico-chemical description of, let us say, a reflex action merely temporary, and likely soon to disappear?

The second question is a little different. Of the movements of the heavenly bodies Gravitational Astronomy gives mechanical descriptions which are practically exhaustive and almost perfectly useful. Now, supposing there were available a complete mechanical account of, say, the opening of a Yucca flower, would that be all that is wanted in Biology? Would light have been thrown, for instance, on the fact that only one Yucca flower opens on each plant each evening, that the flowers begin to open when the Yucca moths begin to emerge from their cocoons, that the life of the flower and the life of the moth are closely bound up together, so that the one without the other is not made perfect? The Yucca flower and the Yucca moth are organisms with a history; they have come to work into one another's hands. Are their adaptive relations only different in degree from the dynamical relations between Earth and Moon, or must we admit that the answers to distinctively biological questions do not follow from even a complete ledger (were that available) of the chemical and physical transactions? 


\section{§ 2. Chemical and Physical Laws apply to Organisms.}

The apartness of living creatures was stated by Kant in a famous passage. "It is quite certain that we cannot become sufficiently acquainted with organised creatures and their hidden potentialities by aid of purely mechanical natural principles; much less can we explain them; and this is so certain, that we may boldly assert that it is absurd for man even to conceive such an idea, or to hope that a Newton may one day arise able to make the production of a blade of grass comprehensible, according to natural laws ordained by no intention; such an insight we must absolutely deny to man" (Teleological Faculty of Judgment, $\S 74)$. We wonder how much of this he would have written had he known the bio-chemistry and bio-physics of to-day.

It is now recognised by all-vitalists included-that chemical and physical laws apply to living creatures-to what may be called their inorganic aspect. There is no confusion of 'categories' in so doing. Chemically regarded, the living creature is of a piece with its surroundings; it contains no peculiar elements. The most essential substances, which are always present, are proteins, but there is nothing rare in their composition,-just the carbon, hydrogen, oxygen, nitrogen, and so on of the surrounding world. The peculiarity of proteins is in the complexity of their molecules, which consist of a large number of atoms, and in their general occurrence in a colloid state, which has very important physical properties. It used to be thought that organic substances could be made only by the direct touch of life, but the synthetic chemist has built up samples of most of the different kinds with the exception 
of natural proteins. Even these are being approached, and their synthesis will probably be effected too.

Chemically regarded, living involves a complex of reactions in, or associated with the material which we call 'protoplasm' and some of these reactions can be reproduced apart from the organism altogether. There are oxidations and reductions, hydrations and de-hydrations, fermentings and so on, which taken separately may be mimicked in the laboratory. By freezing tissues, grinding them in a mortar, and thawing and filtering the result, a non-living material can be obtained in which some chemical reactions go on. These can be studied in isolation, and this is one of the everyday methods of bio-chemistry. Similarly, chemical laws are of indispensable assistance in enabling us to understand how the blood carries oxygen and carbon dioxide and how digestive juices change the food in the stomach.

In the same way it is certain that well-known physical processes occur in the living body. Capillarity plays some part when sap ascends in a tree, and evaporation plays some part when the leaves droop in the summer heat. Surfacetension is illustrated when an egg-cell becomes spherical, and the elasticity of connective tissue when a hen turns suddenly from scanning the sky to inspect a minute seed on the ground at her feet. We illustrate the action of levers when we walk, and the properties of lenses when an image is formed on our retina. All physiologists are agreed that, in the description of bodily functions, the formulæ of chemistry and physics carry us some way.

And just as the fundamental chemical fact, that no increase or decrease of matter ever occurs in a closed system, holds true for the living body and its environment, so it 
seems to be with the conservation of energy. An animal, such as a dog, supposed for the sake of simplicity to be at rest, takes in potential energy in the form of food, and takes in oxygen to keep the vital combustion agoing. It uses up the energy in internal activities:- the heart drives the blood round the body, the midriff rises and falls, the lungs empty and fill, and so on. Now, if we allow for the potential energy of waste-products and storage-products, we find that the heat given off is in accurate correspondence with the energy taken in. The accounts balance. The invention known as a calorimeter made it possible for Rubner to demonstrate that the heat-energy given off by an animal during a prolonged experiment was the equivalent of the food taken in, with a discrepancy of only 0.5 per cent., which is believed to be the all but inevitable discrepancy due to the conditions of experiment. There was a smaller discrepancy ( 0.1 per cent.) in Atwater's experiment of sixty-six days during which his students worked in a calorimeter. When they remained at rest, the discrepancy disappeared. It is plain, then, that the living of the animal is in general accordance with the big generalisation-that the sum total of energy in a closed system remains constant. One mode may change into another mode, but no energy ceases or is lost in the transformation.

It is certain that a chemical and physical description can be given of much that goes on in organisms, and this kind of description will certainly extend its scope. We need only refer to Professor Bayliss's Principles of Physiology as a fine illustration of the application of chemical and physical analysis to the activities of the living body, and to Professor D'Arcy Thompson's Growth and Form as its counterpart in the domain of morphology. At the same time 
it is important to notice that the working out of the chemicophysical description of vital activity is not altogether plain sailing. Let us illustrate.

§3. Some Difficulties in the Application of Physical and Chemical Formula to Organisms.

It is a general fact of experience that the rate of chemical reactions is accelerated by heat and retarded by cold. The illustrious chemist Van't Hoff formulated the law that the rate of a chemical process increases in geometric progression when the temperature is increased in algebraic progression. The velocity of the reaction may be doubled or trebled by a rise in temperature of $10^{\circ} \mathrm{C}$. or reduced by one-half or more by a fall in temperature of $10^{\circ} \mathrm{C}$. Now it has been observed that the rate of heart-beat of various animals, so widely separated as tortoise and water-flea, is reduced to about a half if the temperature be lowered $10^{\circ} \mathrm{C}$, and the same holds of some other vital processes. Therefore it has been hastily concluded that the chemical processes associated with vital activities follow Van't Hoff's law in the way they vary in rate with changes in temperature. But it looks as if the conclusion had been premature. The increase in the rate of development of the eggs of the plaice is directly proportional to the increase in the temperature within the limits of viability (Dannevig, Johansen, Krogh); it does not illustrate Van't Hoff's law. In certain fishes, in frogs, water-beetles, and sea-urchins the Danish physiologist Krogh finds that the relation between the temperature and the rate of development cannot be expressed, even approximately, by Van't Hoff's formula. According to Krogh's experiments on frogs and goldfishes and some other animals, the influence of temperature on the 'standard' metabolism, 
of which the absorption of oxygen is taken as an index, is regular and constant, and cannot be expressed either by Arrhenius's formula or by the rule of Van't Hoff. Ege and Krogh have shown that Van't Hoff's rule does not apply to the relation between temperature and the respiratory exchange in goldfishes. Indeed, there are many cases where Van't Hoff's rule does not seem to apply. It is said to hcld good for such a subtle thing as the rate of cell-division in the growing point of a root, but this is not to be taken as indicating a simple chemical process. There appears to be a repertory of intricate processes, the peculiarities of which are mutually neutralised.

There are also some difficulties in regard to the transformations of energy in living creatures that make one hesitate to assert dogmatically that conclusions based on a study of the inorganic must hold true for organisms. It is possible, for instance, that living cells may act selectively in relation to the molecules that bombard them, and that the organism may be able in some measure to evade the second law of thermodynamics.

The best steam-engine is only able to change about 12 per cent. of its income of potential energy into work; the animal can change about 25 per cent., and is therefore from this point of view quite remarkably efficient. Moreover, as Professor Soddy points out, the organism has a capacity for dealing with kinds of chemical substances which cannot be converted by inanimate agencies into useful forms of energy without terrible waste. "The chemical energy of food suffers direct transformation into work without first being converted into heat."

In any case it is well to remember that while there is a general, and for certain purposes very useful, applicability 
of chemical and physical laws to the activities of organisms, there are also in organisms novel circumstances which seem to alter cases.

In this connection, the Italian physicist and mathematician Enriques writes (1914, p. 376) : "Only a few general physical relations, persisting through all varieties of conditions, are found to be verified without change in the realm of biology, as, for example, the conservation of matter and of energy. But among the less extended laws that refer to diffusion or osmosis or electric conductivity, etc., we meet at every step with exceptions and apparent contradictions." He refers, for instance, to the fish known as the Torpedo, as "a living Leyden jar", and says: "While the functioning of an electrical machine is so easily hindered by the moisture of the insulator, here we see a charge which is not lost in the watery fluid with which the tissues of the animal are saturated." The living cells of the bladder hinder the diffusion of water:- "We can only say that a moist tissue prevents the passage of water by virtue of being alive, for it loses this property as soon as death has taken place." Enriques also refers to the work of Galeotti, who has shown that protoplasm hinders the diffusion of certain substances, and in certain cases offers an especial resistance to the ions moved by electro-motor force. It may be said that these difficulties are due to the particularly complex conditions. But in the meantime it is not unscientific to state that the 'analytical explanation' is not as yet forthcoming. What is gained by advancing to a 'synthetic explanation', which starts with the fact of life, is another question to be considered later on.

So far, then, our conclusions are, (1) that many chemical and physical processes go on in the living body which are 
quito in line with those that occur in conditions apart from living creatures altogether; but (2) that at present, without going far, we are met by certain difficulties which suggest that we should be cautious before concluding that the physico-chemical re-descriptions of vital events are adequate or on the way towards adequacy. It is certain that some bodily occurrences admit of mechanistic description and that this is very useful, both practically and theoretically. Thus the production of animal heat, which was a riddle to the old physiologists, has in great measure been accounted for just as one might account for the heat in a basin of water after electric discharges have been passed through. The clearing up of this problem may be practically useful to us on a cold day or to our physician if we are fevered. It has also been theoretically useful in the science of physiology, for instance because it brought into prominence the more intricate problem of the regulation of the body temperature, which does not seem to admit at present of mechanistic solution. This example seems to us to be typical. Along many lines we advance so far with mechanistic formulation, and then we are suddenly pulled up. Let us, then, methodically test the mechanistic descriptions of occurrences in the realm of organisms, keeping in view both the degree of completeness in the descriptions and their relevancy in biological study. It will conduce to clearness if we omit in the meantime all reference to conscious control. Let us consider (1) the everyday functions of the body, (2) animal behaviour, (3) development, and (4), very briefly, evolution. 


\section{§4. Criticism of Mechanistic Descriptions of Everyday} Functions.

There has not yet been given any physico-chemical description of any total vital operation. Soon after the establishment of the doctrine of the conservation of energy, about the middle of the nineteenth century, there was a remarkable mechanistic boom. The impression became prevalent that the citadel of life was about to be taken by storm. Nerves were like wires along which electricity flowed; the kidney was a group of filters; respiration was a matter of the diffusion of gases; the passage of digested food from the alimentary canal to the blood-vessels was a process of osmosis; and so on.

The inevitable reaction followed; it was found that things were not so simple as they seemed. The physico-chemical descriptions leave out a good deal-big residual facts which seem to many to be the crucial facts. Dr. J. S. Haldane writes: "The application to physiology of new physical and chemical methods and discoveries, and the work of generations of highly-trained investigators, have resulted in a vast increase of physiological knowledge, but have shown with ever-increasing clearness that physico-chemical explanations of elementary physiological processes are as remote as at any time in the past, and that they seem to physiologists of the present time far more remote than they appeared at the middle of last century" (1913, p. 47).

In his contribution to Life and Finite Individuality (1918), Dr. J. S. Haldane says (p. 13): “I need only refer to such activities as the oxidative processes in living tissues, the processes of secretion and absorption, or reflex action. There is a prevalent idea that the progress of chemistry, 
and particularly of physical chemistry, has furnished explanations of these processes. This is most certainly not the case. What physical chemistry has helped us to do is to obtain measures of the processes in the living body; but the results of measurements have been to show with everincreasing clearness that the processes in the living body do not correspond with our conceptions of those in nonliving structures, and that we are not remotely in sight of mechanical explanations of the former.

"As an example, I need only take the case of the exquisitely thin and delicate living membrance which separates the blood in the lung capillaries from the air in the alveoli or air-cells of the lungs. A short time ago it was assumed that this membrane plays only a passive part which we regard a non-living membrane as playing, and allows oxygen to diffuse through it just as a non-living membrane would. On applying accurate methods of measurement we found that, whenever there is need for an extra supply of oxygen, as, for instance, during muscular exertion, the membrane assumes an active rôle and pushes oxygen inwards, without regard to the mechanical laws of diffusion. In this respect the alveolar epithelium acts just like the epithelium of the swim-bladder, or that of the kidney or any other gland, or the alimentary canal. The progress of physical chemistry is enabling us to distinguish sharply between physiological activity and the processes occurring in non-living structures; and the establishment of the distinction is sweeping away the easy-going mechanistic explanations which became current during the latter half of last century." "On the whole, there is no evidence of real progress towards a mechanistic explanation of life."

The inadequacy of the mechanical description is apparent 
when we consider any function in its totality. There is a correlated sequence of events, and it is the correlation that is characteristic. One group of cells has not only to do its own work, but has to keep in exact co-ordination with the working of other groups, sometimes at a distance. It goes without saying that we know a good deal about this internal regulation-we do not expect action without means-but we cannot give a complete chemico-physical account of it. It is sometimes achieved by the nervous system, sometimes by the blood, sometimes by internal secretions. Dr. J. S. Haldane points out that " a minute and scarcely measurable increase in the hydrogen ion concentration of the blood excites the respiratory centre of a normal warm-blooded animal to intense activity. Similar minute alterations in the concentration of water, or sugar, or sodium chloride, or hydrogen ions, have a corresponding influence on the secretory action of the kidney." It might be thought that a multiplication of items of facts of this sort would eventually give us precisely what we want-a coherent description of integration. But that is not in view as yet, for we have always to unite the chemico-physical facts by vital links, by postulating primary properties of the organism, referred to in Lecture III., which remain unreduced. Unless we do this we cannot explain how the numerous activities work in a variable way into one another's hands, how they are coordinated in a harmonious result, how they are adjusted in a regulatory fashion to the changeful environmental conditions.

The temperature of a furnace depends upon the amount of thorough combustion that ean be made to take place within a given time, and on the arrangements to prevent waste, and so on. It can be kept from exceeding a certain limit, if 
the stoker cease to stoke or if the draught of air be lessened, or in other ways. Similarly, the temperature of the body in a 'warm-blooded' animal is automatically regulated to a nicety so that, if it exceed the normal even by a very little, we know that something is seriously wrong. But there are great differences between the organism and the furnace. Thus in the organism "the oxidation does not, like ordinary chemical oxidation, increase or diminish in proportion to the varying supply of oxygen brought to the seat of oxidation, but is controlled by living cells".

We can picture a complicated series of mechanical operations with here and there an intelligent workman who is essential because what is required is like very intricate shunting - a regulation, an adjustment, a co-ordination. So is it with the organism. We can give a chemico-physical account of isolated processes, but we cannot give a connected description of the whole without postulating the intervention of living cells. Not hypothetical agents, like ClerkMaxwell's "sorting demons," but observable living cells like Amœbæ.

Let us take another illustration. When we strike a match we can give a complete chemico-physical account of the later phases of the process, apart, that is, from our own intention and movement. When we draw back our finger from a hot iron, are we illustrating more than a very complicated form of the match's response to the friction? According to Dr. J. S. Haldane, we are. "In identifying stimulus and response with physical or chemical cause and effect, the mechanistic theory makes a gigantic leap in the dark."

When the sun's rays passing through a knot in a roof-light set fire to a heap of cotton-waste and the flames spread till they reach a barrel of gunpowder, which explodes, and other 
things happen, there is a chain of events which may be long or short, intricate or simple, but which is quite clearly stateable in chemico-physical, i.e., theoretically mechanical, language. But it is otherwise when a living structure responds to a stimulus. "There is in reality 110 experimental evidence whatsoever that the process can be understood as one of physical and chemical causation. . . . When we attempt to trace a connection we are lost in an indefinite maze of complex conditions, out of which the response emerges" (Haldane, 1913, p. 34). A very familiar fact is that the same stimulus applied to two apparently similar animals or to the same animal at different times evokes different answers. We can indeed give reasons for this, but the reasons are not mechanical reasons.

Why is it that we cannot adequately describe the life of the organism in terms of chemistry and physics? Let us take an answer from the philosophical physiologist, already quoted, Dr. J. S. Haldanc, in his contribution to Life and Finite Individuality (1918). Because the organism "forms itself and keeps itself in working order and activity" (p. 14), and "the idea of a mechanism which is constantly maintaining or reproducing its own structure is self-contradictory" (p. 16). "Empirical observations with regard to the behaviour of living organisms point clearly to the conclusion that in each detail of organic structure, composition, environment, and activity there is a manifestation or expression of the life of the organism regarded as a whole which tends to persist. It is this manifestation which distinguishes biological phenomena; and, through all the temporary variations of structure, activity, composition, and environment, it can be traced more and more clearly with every year of advance in biological investigation. We can 
trace it through the ordinary metabolic phenomena in living organisms, as well as through the phenomena of senescence, death, and reproduction" (p. 21).

The everyday life of any common animal is an extraordinarily complex affair. "For what is a creature but a great and well-disciplined army with battalions which we call organs, and brigades which we call systems? It advances insurgently from day to day, always into new territory of time and space-often inhospitable or actively unfriendly; it holds itself together, it forages, it makes good its expenditure of explosives, it even recruits itself, it pitches a camp and strikes it again, it goes into entrenchments and winter-quarters, it retreats and lies low, it recovers itself, it has a forced march, it conquers" (Thomson, Wonder of Life, 1914 , p. 627). What the biologist wishes is not merely a complete ledger of all the osmotic and capillary processes in the body, all the oxidations and reductions, all the solutions and fermentations,-though that will be a great achievement-he wishes a description of the organism's daily march which will not ignore the correlated organismal tactics or the strategy which, in some cases at least, lies behind these.

§5. Criticism of Mechanistic Descriptions of Animal Behaviour.

Let us pass from the everyday functions of the body to a connected series of external activities-to animal behaviour, a subject to which we shall return in the sixth lecture. We know that a young British-born swallow which leaves us for the south towards the end of summer may return the following spring to the parish, even to the farmsteading, of its birth,-moved, who shall say by what deep 
compelling constitutional homesickness. Professor Yung of Geneva took twenty bees from a hive near the lake, put them into a box, and carried them six kilometres into the country, where he set them free. Seventeen returned to the hive, some of them in an hour.

The fresh-water mussel carries her young ones in her outer gill plate, and keeps them there, even long after they are ready to emerge, until a stickleback or a minnow comes into the immediate vicinity. When the fish comes near, the mother-mussel, whom it is no libel to eall 'acephalous', liberates a crowd of the pinhead-like larvæ, which swim out into the water, snapping their tiny toothed valves, and secreting viscid attaching threads. They have the beginnings of a nervous system; they are sensitised to some stimulus from the fish; they fasten on to it and begin another chapter of their life. Even in the laboratory, when they have been removed from the mother, they become extraordinarily excited if a morsel of minnow be dropped into the dish in which they are. They respond definitely to the only stimulus which will enable them to continue their life. In some North American fresh-water mussels only one particular kind of fish will serve the purpose of temporary host.

In the remarkable life-history of the liver-fluke of the sheep, microscopic ciliated larvæ emerge from egg-cases which have fallen into water. These larvæ have no organs in the strict sense, no hint of a nervous system, and only a few cells altogether. They have energy enough to go on swimming for about a day in the water-pool. They may come in contact with many things, sticks and straws, roots of aquatic plants and various aquatic animals, but there is (in Britain) only one touch to which they respond-that of the small fresh-water snail, Limnoea truncatula, the only 
host that will enable them to continue their life-history. When they touch the molluse they work their way into it and cxhibit a remarkable succession of multiplications and metamorphoses. The point is that a minute, brainless creature responds at once to the one stimulus which will enable it to continue its life.

These instances have been taken from different levels: the swallow is very intelligent and yet instinctive, the bee is very instinctive and yet intelligent, the larval mussel has just the beginnings of a nerrous system, the larval fluke has none. Our point is that we can find objectively analogous kinds of behaviour at all levels of nervous organisation, and that we have to do with a general capacity of living creatures-the capacity of enregistering past experiences and experiments, either individual or racial, so that present behaviour is influenced by them in very specific ways. There are several characteristic features in behaviour which appear to be beyond all mechanical description. The behaviour is made up of a succession of acts which are correlated in a particular sequence. At any one moment there are chemical and physical processes going on, about which we know or may know a good deal, but it is the bond of union that eludes the chemist and physicist. To take items in the process and reduce them (as far as we can) to physical and chemical common denominators is interesting in its way, and for certain purposes useful, but it does not make any clearer the interlinking, the co-ordination, of all the items in a piece of behaviour. When we consider the larval liver-fluke arrested by contact with the fresh-water snailwith a particular species of water-snail, or the larval mussel arrested by the proximity of a minnow, or a stickleback, or, it may be, by one and only one particular species of fish, 
we are face to face with a common and characteristic feature in animal behaviour, that the creature is historically tuned to be a receptor of a unique but absolutely indispensable stimulus which may not occur more than once in the life-history. We may find pcrhaps some analogies to this in the inorganic world-from our point of view it would be strange if there were not-but it is supra-mechanical. By which we mean that it requires other than mechanical concepts for its formulation-especially the concept of the organism as a historic being.

Sometimes, it must be confessed, even the postulate of historic enregistering does not help us very much as yet, witness the well-known riddle of the homing of birds. Prof. J. B. Watson and Dr. K. S. Lashley took four nesting terns (two 'noddies' and two 'sooties') from Bird Key in the Tortugas to Havana, 108 miles off, and liberated them in the harbour there. They were back at Bird Key next day, having probably spent most of the time recuperating around the shores of Cuba. Of five birds liberated off Cape Hatteras, in waters which these terns never visit, for Bird Key is the northern limit of their migratory range, at least three returned to their nests in a few days, having accomplished a journey of 850 miles as the crow flies, and of much more if the alongshore route was followed. Four noddies and four sooties were taken in a hooded cage on a Galveston steamer and liberated at a point in the middle of the Gulf of Mexico, 461 statute miles from home, and out of sight of everything. On release, all birds, with one exception, started eastwards. That one headed westwards and continued for about 200 yards, then turned suddenly towards the east. The birds had a strong head wind against them throughout the first day, but two of them returned to their nests in safety 
across the waste of seas. This seems to us so different from the return of the boomerang to the thrower's hand that we venture to call it different in kind.

When we are dealing with higher animals, presumably with conscious processes analogous to our own, the contrast with a mechanism stands out even more clearly. An engine overcomes hindrances, force against force, but it has no resource, no alternatives, no tactics. But an organism with a mind at work, a conscious organism, is different in its relation to hindrances. As Dr. J. S. Haldane says, "It is aware of, and avoids, neutralises, or even takes advantage of them. It adapts its behaviour in such a manner as to maintain itself in the presence of what is outside the mere organic unity of its life. But in so doing the organism shows itself to be more than a mere organism; it includes within the unity of its life what seemed to be independent" (Life and Finite Individuality, p. 23).

§6. Difficulty of Applying Mechanistic Formula to Development.

Our third test of mechanistic interpretation is with regard to development. When we watch a transparent marine animal, such as one of the Salps, we can see the movements of internal parts-the beating of the heart, for instanceand though what we see is not like anything in inorganic nature, we are reminded of a smoothly-working machine like a chronometer. On the other hand, when we have the good fortune to observe a development actually going on in perfect translucency, for instance in the egg of the moth Botys hyalinalis, our unprejudiced impression must surely be, that this is very far away from anything mechanical, that it is in fact very unlike anything else in the world. 
When we take the most familiar case of all, the development of the chick in the course of twenty-one days from a minute drop of living matter lying on the top of the yolk-the gradual emergence of the obviously complex from the apparently simple-we feel how true it is still, what Harvey wrote three centuries ago:- "Neither the schools of physicians nor Aristotle's discerning brain have disclosed the manner how the cock and its seed doth mint and coin the chicken out of the egg." It is not surprising that the facts of generation and development have often led naturalists to the conclusion that the categories of mechanism fall short in the domain of the organic. What particular facts of development seem to require more than mechanical description? There is the condensation of the inheritance into the microscopically minute germ-cell-an extraordinary telescoping of individuality, of which we can form no image. It is quite true that there is within egg-cells a demonstrable complexity of organisation far greater than used to be supposed, that the nucleus is a little world in itself, that there is a growing knowledge of extremely minute, yet often distinctive, organ-forming plastosomes in the cytoplasm of the egg, that the artificial removal of part of the egg-cell is sometimes, as in Ascidians, followed by the non-development of a particular structure in the embryo, and so on. More and more we are coming to see in the germ-cell an implicit individuality with complex and specific organisation. But no sooner have we got this idea clearly focused in the mind than we are confronted with such facts as those of merogony, that a fragment of an egg-cell is able to develop into a normal embryo. It may be an argumentum ad ignorantiam, but if it be held, as the mechanists hold, that the egg-cell is completely describable as a chemico-physical mechanism of 
great complexity, it is not unfair to recall some of the difficulties,-that the supposed mechanism has to form in fertilisation a working unity with another mechanism as complex as itself; that it has thereafter to divide over and over again; that a part is sometimes as good as a whole; and so on. It is sometimes easy to get twins from one egg by shaking the first two cleavage-cells apart, and even at the four-cell stage of the lancelet's development the same method may result in quadruplets. It almost seems as if we here reached a Euclidean reductio ad absurdum of a mechanistic interpretation.

The central problem of development is differentiation, and the biological study of this is not more than incipient. We cannot even elucidate the fact that the two cells into which a germ-cell divides are sometimes exactly alike and sometimes distinctly different. Out of apparent simplicity there gradually emerges obvious complexity. As Roux puts it, there is a self-manifestation of intrinsic manifoldness. What was a clear drop a few hours ago is now a manifest organism with nerve and sense-organ, food-canal and muscle. It is the most wonderful thing in the world. Sometimes the whole scene has changed when we return to observation after the interruption of an hour's lecture. Be it understood that no theory explains it, but while the biological interpretation may try with some success to bring development into line with, say, the organism's characteristic selfrepairing activity, the mechanistic interpretation has not yet begun its task. It is a mere impious opinion that development will one day be described in terms of mechanics.

Another prominent fact in development is its regulatedness or correlation. Driesch and others have directed attention to the power the embryo often shows of righting it- 
self after the building materials of its edifice have been artificially disarranged, of re-adjusting itself after the proportions have been artificially disturbed. A fertilised egg-cell frequently divides into a ball of cells like a microscopic mulberry fruit; the constituents of this ball may be disarranged and the ball pressed out of shape between two glass plates; yet if the interference be not too prolonged, the developing embryo may right itself and develop normally. Can we think of a machine which is practically unaffected if we cut off half of it, or which, being scrapped, patiently re-arranges its parts and begins over again!

If the developing organism is in its behaviour 'conational '-that is to say, on the way to being 'purposeful 'the difference between it and a developing sidereal system is great. But what grain of evidence is there of this 'conational' element? Not perhaps very much when we confine our attention to normal embryonic stages, where one phase appears to be the natural and necessary outcome of its antecedent. But we get another impression when we consider some of Driesch's cases of self-regulation and of re-adjustment after profound dislocation.

Whatever we make of it, one of the marvels of development is the manner in which separate parts are often correlated, as it were conspiring together towards some future result. In the making of the Vertebrate eye, an outgrowth from the brain forms the retinal cup, an independent ingrowth from the skin forms the lens, some mesoderm 'cells migrate into the interior to form the vitreous humour, others combine to form the protective envelopes, and so on. Strange anticipations of coming events are well known to embryologists.

In a trivial detail, such as the making of the silk-like 
threads composing the skeleton of the common bath sponge, large numbers of secretory cells called 'spongoblasts' group themselves in double file every here and there throughout the middle stratum of the sponge, as if some unseen captain marshalled them. Up the middle of the double file the spongin is secreted, made at the expense of the living matter of the spongoblasts, and the many individual contributions coalesce into a spongin-fibre.

In his Science and Philosophy of the Organism (1908), Driesch has with unexampled thoroughness and subtlety tested the possibilities of mechanistic description with particular reference to the facts of development. He reaches a conclusion of the first importance:- "No kind of causality based upon the constellations of single physical and chemical acts can account for organic individual development; this development is not to be explained by any hypothesis about configuration of physical and chemical agents. . . L Life, at least morphogenesis, is not a specialised arrangement of inorganic events; biology, therefore, is not applied physics and chemistry; life is something apart, and biology is an independent science." But what, it may be said, of the science of 'developmental mechanics' and of the lengthening row of volumes entitled Archiv für Entwicklungsmechanik? The first answer is, that, after all, the developing embryo is a material system, and must exhibit chemical and physical means. Development shows a continuous action and reaction between an implicit organisation and the environing conditions, and 'developmental mechanics' so-called is in great part concerned with discovering the correlation between steps in development and their appropriate external stimulation and nurture. These correlations are of great interest, but as our knowledge of them 
increases we do not get appreciably nearer a mechanical description of development. We do, however, recognise more and more that physical and chemical processes are in evidence.

The second answer is that the word mechanical is sometimes applied illegitimately to a systematic or connected account which displays a series of events in causal coherence without the intervention of mentality. Given certain properties of organisms in general, of nerve-cells and musclefibres in particular, we may give a more or less connected and complete account of a reflex action without dragging in any psychical agency. But this should not be called a mechanical description. It is simply, what it pretends to be, a physiological or biological description, and it implies various non-mechanical concepts. Similarly, given the organism's power of registration and of persistently reproducing its specific organisation, given the cell's mysterious power of dividing - of dividing now into similar, and again into dissimilar halves, given the capacity of utilising nurtural stimuli to educe the inherent manifoldness of the germ, and so forth, we can make a show of discovering the connectedness and inevitableness of the successive stages in development. But we cannot without abuse of terms speak of this as a mechanical description.

§7. Difficulty of Applying Mechanistic Formulae to Organic Evolution.

As a fourth test of the adequacy of mechanistic description in the realm of organisms, we may refer very briefly to evolution, which will engage our attention in detail by and by. Such phrases as 'cosmic evolution' and 'inorganic evolution' are apt to suggest the mistaken idea that organic 
evolution is simply a continuation of a historical inorganic process of increasing differentiation and heterogeneity. It may be continuous with it, but it is not a continuation of it, any more than the evolution of human societary forms is a continuation of the evolution of mammals. The issues changed when organisms began, and again when man began.

Moreover, what is called, for instance, the evolution of the solar system should rather be called the development of the solar system, since it is the differentiation of one mass into explicit manifoldness. The originative nebula or whirling mass of planetesimals is comparable to a great world-egg, to borrow Hume's phrase, and we may think of it as developing into several embryos, as eggs sometimes do. But, so far as we know, there was no struggle between the various planets, or between them and their environmental limitations. There was no sifting process which eliminated some and left others surviving. Whether we speak of the history, or differentiation, or development, or evolution of the solar system, we must recognise that it was a very different process from organic evolution. In the former there were no alternatives, no trial-and-error methods: There was nothing comparable to the staking of individual lives and losing them which is characteristic of that sublime adventure which we call organic evolution. The theory of organic evolution starts with the assumption of variability, which transcends mechanical interpretation and is perhaps least obscure at present when we think of it most anthropomorphically as experimenting in self-expression. Moreover, the organism is in some measure a genuine agent even in the process of natural selection. It is often anything but a passive pawn. It does not simply submit to the apparently inevitable. It often evades its fate by a change of habit 
or of environment; it compromises, it experiments, it is full of device and endeavour. The evolving organism is a historical psycho-physical being, an agency trading with time; and the humblest creatures are in their mutations creative. Such mechanical description as is possible leaves the essential features undescribed.

IN CONCLUSION.

The result of our consideration is that while mechanical description has its place and utility in the organic domain, it is inadequate to cover the characteristic facts of everyday functioning, of animal behaviour, of individual development, and of racial evolution. For all these demand other than mechanical concepts.

Our study has led us away from the view that there is only one science of nature, consisting of precise chemicophysical descriptions which have been, or are in process of being, summed up in mechanical or mathematical terms. As it seems to us, there is greater utility and accuracy in frankly recognising successive orders of facts, each with its dominant categories. There is the domain of the inorganic, the physico-chemical order, where mechanism perhaps has it all its own way. There is the realm of organisms, the biological order, where mechanism is checkmated by organism. There is the kingdom of man, the social order, where mechanism is transcended and personality reigns. Another grouping would be inorganic, animate, and psychical, but we wish to emphasise the apartness of man which has been obscured by the Darwinian theory-true as that is.

These orders, which we separate that we may conquer them scientifically, do as a matter of fact overlap. The inorganic overlaps the organic, for organisms are material 
systems, and their living implies a concatenation of chemicophysical processes. But organisms require a science for themselves. The organic overlaps the human, for Man is affiliated to mammals, and his personality is tethered to protoplasm. But Man requires a science for himself. Or, if one prefers it, the organic overlaps the psychical, since the mind has a body, so to speak, and the spirit works in part through the flesh. And, looking in the other direction, who can be quite sure that the domain of the inorganic is as thoroughly exhausted by mechanical formulation as is usually supposed?

The important point is that the sciences are differentiated not merely by their subject-matter, but by their characteristic questions and methods and concepts. In this sense we claim autonomy for biology.

In so doing we are not in the least weakening the hope and endeavour that biology may approximate more closely to the position of an 'exact science'. Our sole proviso is that this is not to be attained by the naïve device of leaving life out. The honourable rank of exactness is not to be allowed to remain the prerogative of sciences which deal with processes that can be described "by aid of elementary corpuscles having ideal motions". It may be attained by all sciences that have resolutely begun to 'measure', including in 'measurement' every form of precise registration. Thus not a little of modern psychology is very exact, although a description of its subject-matter in terms of ideal motions is certainly not its end! Biology is inexact compared with gravitational astronomy, partly because there have been more first-class minds among the astronomers than among the biologists, partly because in biology we deal with phenomena which are more difficult to measure than those with 
which astronomy deals, but mainly because biology has to deal with individualities which are variable and spontaneous, always to some extent unpredictable. It must be granted, however, that there has been a strong modern movement towards exactness even in the most difficult departments of biology. There has been for a long time much exact science in comparative anatomy and comparative physiology, but the recent labours of the biometricians on the one hand, and of the experimenters in genetics on the other, have already done much to bring the study of evolution problems nearer the ideal of exact science. In fact, as has been sagaciously pointed out, biology has already become a science to a degree that Kant deemed impossible, and this achievement helps to keep the biologist from admitting the validity of Kant's view that there is only one science of Nature.

\section{§ 8. Answers to Criticisms.}

Our argument may perhaps be strengthened by meeting some criticisms brought against what may be called the biological position.

(a) It has been suggested that those who think that vital phenomena require special biological categories are underrating what physico-chemical material systems can do. "Many a machine is constructed to oil itself the more copiously when it works the faster, and the printing-press, as we urge it to put out more newspapers on the one side, pulls in more blank paper on the other " (D'Arcy W. Thompson, Life and Finite Individuality, p. 37). Now there is undoubted utility in comparing a living creature with a machine, especially a machine with automatic regulatory arrangements. Both are systems effecting the transformation of matter and energy; both illustrate the co-operation 
of many parts to an effective result. But the living creature is always working, even in dying, towards its own preservation; it can adjust its activity to varying needs and circumstances; it can rest and begin again; in normal conditions it can give rise to another organism with activities like its own. The explicit organism develops in appropriatc conditions from the implicit organism or germ-cell; if disturbed it can re-arrange itself; if it loses a part it can replace it; if it is broken into fragments it can sometimes reconstruct its living edifice.

(b) Those who claim autonomy for biology are sometimes rebuked by a reference to the music of the spheres. We are told that " in Nature herself, if we look at her larger handiwork, self-regulation and self-maintenance become paramount attributes and characteristics of her machines. The solar system, qua mechanism, is the perfect specimen, the very type and norm, of a self-maintaining, self-regulating mechanism; and so also, grade after grade, are its dependent mechanisms, such as the world-wide currents of the atmosphere and of the sea" (D'Arcy W. Thompson, Life and Finite Individuality, p. 37).

The order and balance of Nature's larger handiwork must indeed be recognised and admired. The same laws that are used in formulating cosmic architecture and regularity may be usefully employed, as we have admitted, in the realms of organisms. But our point is that the animalcule is in a way greater than all the stars, as stars, for it is an agent, it has alternatives, it shows experimental indeterminism, it commands its course. And when this began it was something new in the world.

(c) But where, precisely, it is asked, does the mechanistic description fail? The answer is twofold, that as yet 
it fails all along the line in thoroughness of description, and that it does not give us the kind of answer that as biologists we want. No student of science could have anything but delight in learning that the contraction of a muscle, or a reflex action, or the movements of an Amœba had been satisfactorily described in terms of chemistry and physics. But it has not been done as yet in the case of any single vital activity. Diffusion plays its part in the interchange of gases in the lungs, but the lining epithelium of the air-sacs behaves, Dr. J. S. Haldane tells us, in a way which modifies diffusion processes, and that elusire modification keeps us alive. In the second place, the mechanistic description, even if it attained to the completeness of a ledger of all the chemical and physical processes in a piece of behaviour, would not thereby give us a natural history description of the behaviour. We need historical or genetic concepts. So we do not propose to sum up the ways of a starfish as those of a physico-chemical machine.

(d) The distinctively biological position admits that physical and chemical formulæ, concepts, or 'categories' are applicable to organisms, but argues that they are inadequate, notably, for instance, because life is always in a sense history. But has not the line of physiological progress been mechanistic? The answer is that it is part of the method of science to ' abstract', and that it has been of great service to corner off and analyse physical and chemical operations which occur in organisms. But the success that has attended the study of the chemistry of the blood or the study of the optics of the eye, does not prove that the physico-chemical description of a living creature is or can be adequate.

(e) A thoroughly sound criticism is, that the concepts of physics and chemistry are not stationary but in process of 
development, so that any argument we use to-day about the 'irreducibility' of vital phenomena refers only to modern chemistry and physics (unluckily, to be frank, to what we happen to understand of that chemistry and physics). The only answer to this criticism is that at any given time we must use the science we have got. No judgment in regard to irreducibility can be prophetic, unless we feel confident that we are dealing with generic differences, such as those between a conscious organism and a crystal.

(f) Finally, some would ask whether it matters much after all whether a chemico-physical formulation of a living organism is possible or not. Is there any depreciation of the "lily-muffled hum of a summer bee" if it be "coupled with the spinning stars"? The answer is twofold:-(1) that science is all for veracity, and that the matter-and-motion summing up of an organism seems to many to be at present a false simplicity; and (2) that the treatment of a living creature, say horse or dog, as exhaustible in chemical and physical terms does not seem the way to get the most or best out of them. A physician's success in treating his patient from the purely chemical aspect is often remarkable, but it may be eventually necessary to recognise other aspects!

We agree, however, that what really matters is, that our view of the living creature be thoroughly well-informed. Whether our theoretical interpretation of it be, that it is like a very subtle engine or an intricate solar system, or that it is a system in which a new aspect of reality has manifested itself so that special biological categories are required, the most important thing is that we appreciate the facts of the case. When the methods of theoretical discussion have been exhausted, and it is doubtful whether they have ever made any biologist change his mind from a position to which 
personal experience had led him, the practical conclusion is that we must keep as close as we can to the observable realities, for it is in touch with these that we are most likely to get fresh light.

\section{SUMMARY.}

Chemically considered, the organism is of a piece with its surroundings (though very much more complex than any mere thing); it may be usefully studied by chemical methods; it exhibits many chemical processes which can be studied in isolation. Similarly, many well-known physical processes occur in the living body, and there is in its activity no known contradiction of the law of the conservation of energy. A chemical and physical (i.e., theoretically mechanical) description can be given of much that goes on in the living body, and this kind of description will certainly extend its scope. At the same time, there are difficulties in this chemicophysical description; some vital processes do not illustrate Van't Hoff's rule and it sometimes seems as if the organism were able to effect some evasion of the second law of thermodynamics.

But while chemical and physical (ideally mechanical) description has its place and usefulness in the organic realm, it is inadequate to answer the distinctively biological questions. It does not cover the characteristic facts of life.

If we consider the everyday functions of the body, we find that there has not been given any chemico-physical description of any total vital operation, such as the contraction of a muscle. We cannot satisfactorily describe in mechanical terms either the concatenation of events in a function or the correlation of one set of events with another set. This is still more marked when wo consider animal behaviour, with its co-ordination of acts in an effective series.

As to individual development, we cannot give a mechanical description of the condensation of the inheritance into a germ-cell, or of the differentiation of the embryo, or of the regulation-phenomena observed when an embryo rights itself after the building materials of its living edifice have been seriously disarranged, or of the way in which many developing parts seem to conspire towards one result. Similarly, as regards organic evolution, we cannot offer a mechanical 
theory of variability, and the process of selection is more than mechanical sifting. The evolving organism is a historical psychophysical being, an agency trading with time; and the humblest creatures are in their mutations creative.

The conclusion is thus arrived at, that mechanical formulæ do not suffice for answering biological questions. 
LECTURE V.

THE UNIQUENESS OF LIFE. 



\section{LECTURE $\nabla$.}

\section{THE UNIQUENESS OF LIFE.}

§1. The Inadequacy of a Mechanistic Description of Organisms Is a Negative Conclusion. §2. The Problem: Vitalism or Mechanusm, or Neither \$3. Are Organisms Unique in Virtue of their Complexity? §4. Have Organisms a Monopoly of Some Peculiar Energy or Energies? §5. Is there a Non-perceptual Vital Agency resident in Organisms and Operative in distinctively Vital Activities? §6. Descriptive or Methodological Vitalism: the 'Biological' View. §7. Speculative. §8. Retrospect. \$9. Why Cannot the Controversy between Mechanistic and Vitalistic Theory be Ended?

\section{\$1. The Inadequacy of a Mechanistic Description of Organisms Is a Negative Conclusion.}

WE have considered the chief characteristics of living creatures-such as persistence in spite of change, cyclical development, and effective agency. We considered the organism under the category of a material system-to see how that fitted, and we reached the conclusion that, while this is a legitimate and useful way of looking at a living creature, the formulæ of physics and chemistry are inadequate for the re-description of the everyday bodily functions, or of behaviour, or of development, or of evolution. We did not reach any conclusion as to the depth of difference between organisms and not-living things; our result was a negative one, that the chemico-physical formulæ do not suffice for answering the distinctively biological questions.

It is an unfortunate tendency of the human mind to regard evidence against one theory as evidence in favour of 
another. This holds only when we are dealing with two logical opposites, one of which must be true. Many times over in the history of thought there has been a rebound from mechanistic interpretation discovered to be inadequate, and the rebound has almost always landed the inquirer in a doctrine of positive vitalism, in the assumption that there is some non-perceptual agency at work in a living body which is not present in the inorganic domain, and without which the results would be otherwise. We shall not jump to this conclusion, but we must consider it carefully. In its clearest form it asserts the actuality of a 'vital principle', or 'vital impulse', or 'entelechy', of a non-perceptual character, occasionally operating in living creatures and operating directively. Is this a tenable theory?

\section{§2. The Problem: Vitalism or Mechanism, or Neither?}

Before we discuss the theories of vitalism, it may be useful to refer to three preliminary considerations.

(a) It is maintained by some that mechanistic formulation (i.e., description in terms of matter and motion) is not exhaustive even within the domain of the not-living. It seems to be adequate for certain purposes, e.g., when the navigator deals with the tides, but is it certain that it is an ideal formulation for things in general? Does it take account of everything, e.g., of the probability that the living evolved from the not-living? But the adequacy of mechanical categories in the domain of the inorganic is a question for expert physicists; it is not the biologist's business. Our question is whether the formulæ which work adequately, if not exhaustively, in describing the not-living world, are beginning to answer the distinctively biological problems. If not, what alternatives are there? 
(b) Secondly, there is a sense in which all biologists may be called vitalists, inasmuch as no one can pretend that the mechanical re-description of vital phenomena has as yet gone very far. Professor Bateson writes: "If those who proclaim a vitalistic faith intend thereby to affirm that in the processes by which growth and division are effected in the body, a part is played by an orderly force which we cannot now translate into terms of any known mechanics, what observant man is not a vitalist?" (1913, p. 80).

We must distinguish between a negative and a positive vitalism. When we assert that no vital activity in its observed totality has ever been completely described in mechanical terms, as one might describe the movement of a glacier or the spread of a conflagration, we are making a scientific statement which we believe to be accurate at the present time (1919). That it will hold true a hundred or a thousand years hence does not follow from the evidence submitted, for we do not know what changes are still to be made in the concepts of chemistry and physics, or what discoveries will reward inquiry into, for instance, the physiology of correlation. It may be that a mechanistic formulation of the essential activities of organisms is quite impossible, but that could not be legitimately inferred from the arguments we used. These went to show that the description of vital occurrences in terms of present-day chemistry and physics does not adequately express the connection of the sequences, still less their correlation. We can speak only about the chemistry and physics that we know. Sufficient unto the day is the mechanism thereof. The formulæ of chemistry and physics prove inadequate, and in part irrelevant. If we go on to say that they are inadequate because the organism has a monopoly of a peculiar kind of energy, or 
because it has an entelechy, we are embarking on a new adventure-that of a positive vitalistic theory.

(c) It is held by some that it is the presence of consciousness or some expression of mentality, that makes all the difference, and here again there is probably a great truth - to which we point in using the term Animate Nature. But the suggestion as it stands cannot be pressed in the meantime, for the obvious reason that there are many living creatures about whose mind or consciousness we cannot make any secure statement, where even the argument from analogy fails us. So it must be clearly understood that the problem of vitalism is different from that of animism. The problem of vitalism would remain even if the world held only plants and no animals besides ourselves-Jack and his beanstalk, in fact. Now whatever we may believe, we do not know anything about the mind of the beanstalk. Yet we may, and do maintain that mechanistic formulæ do not suffice to answer our biological questions concerning the beanstalk.

Among those who bold that plants and animals stand apart from things in general, we may distinguish three grades. (I) The first view is that the configurations that occur in organisms are so different from those in the inorganic domain that the activities of organisms cannot be predicted from any formulation of what occurs in inorganic systems. This is the very thin edge of vitalism. (II) The second view is that there operates in living creatures a new kind of physical energy which does not operate elsewhere. This is a lineal descendant of the mediæval form of vitalism-the doctrine of a vital force. (III) There is the theory of a nonperceptual vital agency or entelechy which operates directively in organisms. This is the clearest and the most thoroughgoing form of vitalism. 
If the term vitalism be restricted to (III), as many would restrict it, and if a mechanistic theory mean that the categories of physics and chemistry suffice for the adequate description of the life of organisms (leaving mental processes out of account), then we suggest that the proper answer to the question "Mechanism or Vitalism?" is "Neither". We regard the question as one of the many false dichotomies with which Man in his search after clearness has been led astray. The biologist is not bound to accept either a Vital Force Theory, or a Machine Theory; he may demand a biological theory in terms of concepts neither transcendental nor mechanical.

\section{§ 3. Are Organisms Unique in Virtue of their Complexity?}

The first position, recognising, as every one must, a notable difference between an organism and a not-living thing, finds the difference in the much greater material complexity. The configurations of elementary particles are so much more intricate in organisms that the activities of organisms cannot be predicted from our formulation of what occurs in inorganic systems. This idea applies in other fields: If we have never seen more than two or three people together, we are not likely to be able to predict how a great crowd will behave. The mechanist passing to the study of living creatures is like the student of inorganic chemistry who is suddenly confronted by the carbon compounds; he is assured that he is still at the same science, but he finds this difficult to believe, the data are so different. This is a vitalistic view in so far as it recognises the apartness of living creatures from things in general, but it does not admit that the problem of the Amœba on the hunt is more than a very difficult problem in dynamics. It does not admit that new concepts 
are required for the description of the activities of living creatures. The biologist may be allowed a laboratory to himself as a matter of convenience and courtesy, just as there is a laboratory for Electrodynamics quite apart from another for Hydrodynamics. But the idea of biology being an autonomous science must be nipped in the bud.

It is interesting to notice that many physicists, who are familiar with the capabilities of mechanical formulation, have been very cautious in their statements regarding the extension of this to vital phenomena. Gauss, Cauchy, and Kelvin may be mentioned as investigators of the first rank in mathematics and physics who regarded life as belonging to an entirely different field. Hertz again was very careful: "We can neither maintain that the internal phenomena of animated beings obey the same laws (as in inanimate nature) nor that they follow other laws. . . . Our principle, sufficient perhaps to describe the motion of lifeless matter, appears at least prima facie to be too simple and limited to describe the manifoldness of even the lowest vital phenomena."

Lord Kelvin's view was more dogmatic, and assertive rather than reasoned. Yet it is important, for surely he, of all men, must have known how far his physics would carry him. "The only contribution of dynamics to theoretical biology is absolute negation of automatic commencement or automatic maintenance of life. . . The opening of a bud, the growth of a leaf, the astonishing development of beauty in a flower, involve physical operations which completed chemical science would leave as far beyond our comprehension as the differences between lead and iron, between water and carbonic acid, between gravitation and magnetism, are at present. A tree contains more mystery 
of creative power than the sun, from which all its mechanical energy is borrowed. An earth without life, a sun, and countless stars contain less wonder than that grain of mignonette."

With the first grade of vitalism-that the problem of the homing of the bird is only a very complicated form of the problem of the return of the boomerang-we cannot be satisfied. And a sufficient reason for dissatisfaction-though not the only one-is to be found in the fact that it has not yet been found possible to give a mechanistic answer to any biological question. We know a great deal about the structure of muscle, the chemical, thermal, and electrical changes that go on in muscle, but we cannot give a chemicophysical account of the contraction of a muscle. If 'explanation by analysis' had begun to be successful, we might hesitate before resorting to 'explanation by synthesis', as we do, for instance, when we say that the bird comes home because it is a creature in whose present the enregistered past counts.

\section{§4. Have Organisms a Monopoly of Some Peculiar Energy or Energies?}

According to the second grade of vitalism, there is a peculiar kind of energy operative in living creatures and nowhere else. Organisms have a monopoly of some power in the same (perceptual) series, as, say, electricity. This is a continuation of one form of the old hypothesis of 'Vital Force', and it has not found many supporters in recent years. But it is an honest theory, and may be illustrated by a reference to the work of a thoughtful biologist, Prof. M. Hartog of Cork. Every one admits that one of the commonest phenomena of life is also one of the most stag- 
gering, namely, cell-division. After extraordinarily intricate and uniform internal movements of particles a cell divides with meticulous accuracy into two precisely similar halves, sometimes, strange to say, into two quite dissimilar halves. As we have already remarked, it is one of the wonders of the world. Like not a few others, Professor Hartog has been studying the dividing cell for many years, and he believes that he has discovered a new force operative in the process. $\mathrm{He}$ is quite clear that well-known physical forces are at play in the dividing cell, such as mechanical tensions, surface tensions, and osmutic actions; he is also clear that agencies are at work which occur elsewhere in living organisms, but whose physical interpretation is uncertain, such as protoplasmic streaming; yet when he has made allowance for all these he finds evidence of the working of a new force which he calls "mitokinetism". He does not know the proximate cause of this force or its relation to other forces, he knows it by its works, and he cannot identify it with any other force, electrostatic for instance. Nor does be base his own vitalistic belief on his "mitokinetism". We have here the basis of a theory that organisms have a monopoly of some peculiar energy or energies, and are therefore apart both from machines and from not-living things in general.

A clear statement of this position was given by the late Prof. Richard Assheton, who suggested that instead of being satisfied with the more or less mystical Entelechy we should look out for some form of energy peculiar to living matter. In 1894, Roux observed that if the cleavage-cells of the ovum of the frog (Rana fusca) towards the end of segmentation be isolated and floated in a suitable medium, they show mutual attraction. The sides of one cell become drawn out towards a neighbouring cell; the cells move towards one 
another and touch; they actually become pressed and flattened up against one another. This interesting attraction was called by Roux cytotropism or cytotaxis, and it has been observed in other cases. Assheton was particularly concerned with the development of the lancelet or Amphioxus, where the ovum divides into a hollow ball of cells, which again is indimpled or invaginated to form a two-layered sac of cells, the gastrula. Assheton sought to show that, if there were an attractive force between cell and cell, acting from centres represented by the nuclei of the cells, the hollow ball of cells would at a certain stage become invaginated. The explanation of how gastrulation might come about was put forward as indirect evidence in favour of the existence of some force acting from a centre like gravitation or magnetism or statical electricity, but probably of a different nature and with different laws, and an attribute of living matter alone. Assheton meant definitely a kind of physical energy "which could be investigated by the ordinary methods of mensuration and computation available to the mathematician".

Herbst made the remarkable observation that if the ova of the sea-urchin be allowed to develop in sea water deprived of its calcium salts, the blastomeres separate from one another, instead of adhering. What looks like repulsion between two centres is seen in the normal process of celldivision, where the incipient daughter-nuclei, while still parts of the parent cell, seem to repel one another, and yet immediately after separation appear to attract one another strongly. Assheton suggested that the hypothetical form of energy exhibits an unceasing recurrence of a bipolar state out of a unipolar state. "The attraction and repulsion observed between cell and cell are certain of the manifestations of this supposed form of energy-but probably not by any means 
all; just as attraction and repulsion are manifestations of electrical energy under certain conditions, but are not by any means the only manifestations." Dr. Assheton went on to suggest that in nerve impulses we may experience " manifestations in another way of the same form of energy which under other conditions produces the attractions and repulsions and the figures of strain in the dividing cells, and the actual cell division". "Driesch's Entelechy," he concludes, " although not supplying the essential qualities of a driving force, may perhaps be a complex system of a simpler vitalistic force with other forces which has within certain limits a balancing or compensatory influence upon the course of development like that which a gyroscope has in compensating (within certain limits) for disturbances to the course of a monorail vehicle" (p. 76).

The disadvantages of this position are the following: first, it is difficult to prove the independence of the alleged new force or energy; sccond, to attach much theoretical importance to it reminds us warningly of the old mistake of making much of organic compounds, which it was alleged, could not be formed without the aid of the 'vital force' resident in organism; third, the inadequacy of the physicochemical formulæ to describe animal behaviour or the like, does not appear to be of a kind which would be affected by the discovery of a new form of physical energy either within or without the organism. Yet the theory that there may be a special kind of power or energy operative in living creatures is on the lines of sound science, and must be impartially tested by biologists. There seems nothing very unlikely in the idea that living matter may be able to effect an organisation of movement in some way which we do not understand. The theory has nothing to do with Ostwald's sug- 
gestion that the chemical energy of protoplasm may be transformed into the mental energy of thinking, which seems to us a contradiction in terms.

It is stated that the movements of molecules in the domain of the inorganic obey the law of probability; it is interesting to ask whether that is true of the molecules within organisms (see Soddy, Matter and Energy, p. 101). But we cannot suggest a test ease! Is it conceivable that, just as lowering the temperature of a gas makes it into a liquid whose molecules below the surface have movements quite different from what they had in the gas state, so complicated molecules in a colloid state have movements which obey some other law than that of probability, and is it conceivable that the reality of which the molecular movements are one expression then begins to show another aspect, perhaps, as some would say, a metakinetic aspect?

$\S 5$. Is there a Non-perceptual Vital Agency resident in Organisms and operative in Distinctively Vital Activities?

The third view is thoroughgoing vitalism, best represented by Driesch, whose ingenuity and consistency command our admiration. Its postulate is a non-perceptual vital agency, which does not occur in not-living things but is confined to organisms, where it operates in certain cases, directing the chemico-physical processes so that their results are different from what they would have been apart from its intervention. Three points should be carefully noted:-(1) that the postulated vital agency or entelechy is not the outcome of more complex physical conditions, "not a new elemental consequence of some constellation"; (2) that it only intervenes at certain steps, introducing an occasional indeterminism; and (3) that it is supposed to be a genuine agent, count- 
ing for something, "at work" as Driesch says. On this view, obviously, there is a deep-lying distinction between the flight of a bird and the movement of a comet, and Biology is by hypothesis autonomous. A general statement of this third position, apart from Driesch's particular formulation, has been given by Ritter (1911, p. 437). After stating that materialism is the belief that all vital phenomena can be completely explained in terms of the material elements that go to make up the organism, he defines vitalism as "the belief that organic phenomena cannot be fully explained by referring them to the material elements of which organisms are composed, but that something not really belonging to the natural order, either explicit or implicit, is present in living things. The essence of the conception, whatever be its variety or form of statement, is that something absolutely new and novel came into the world when living beings came and that this came as a special force, or principle, or factor-anything you have in mind to call it, so long as it is not material. A further essential to the conception is that this new thing is elemental, protean, once-for-all. It is not exactly the life itself of the organism. It is rather the informing, underpinning, ultimate motor, of life."

The general nature of the argument that Driesch uses to support his conception of Entelechy may be briefly indicated. He takes in particular the facts of morphogenesisthe development of the embryo or the regeneration of a lost part. If what takes place is determined solely by physical factors there must be something in the nature of a very - complex machine in the egg or at the cut end of the hydroid branch from which a new polyp grows. He allows the imagination to erect this machine with all conceivable intricacy and device, and then proceeds remorselessly to 
bring forward fact after fact which contradicts the possibility of such a machine accounting for the result observed. Thus by an argument by exclusion he seeks to prove that the development must be determined by a non-spatial, nonperceptual agent or Entelechy.

(a) One of the objections to thoroughgoing vitalism is that it implies a definite breach in the fundamental law of the conservation of energy. If a non-perceptual agency occasionally directs the chemico-physical operations of the body, there must be some exertion of power which does not figure in the chemical and physical accounts. The calorimeter experiments seem to show that for a man in a closed system the expenditure is equal to the income over a term of days. There is no gap for the intervention of a physical agency; no, not for a moment. This is a serious objection, yet apt to pierce the hand of those who rely on it. For it is a rash procedure to use a physical generalisation as a dogma in the realm of organisms. It is begging the question. Boyle's Law did duty for a couple of centuries before physicists discovered that it is accurate only between certain limits. The Law of Gravitation does not hold below certain sizes and distances. Perhaps the Law of the Conservation of Energy does not quite hold for living creatures. The calorimeter experiments are not so absolutely exact that it can be asserted that the balance at the end of the day is precisely what it should have been if the organism were a mechanism and nothing more, and that therefore an Entelechy does not exist. One remembers that a very minute expenditure of energy may effect a great deal, just as cutting a tape or pressing a button launches a vessel. Driesch's Entelechy is supposed to act by inhibiting for a time the transformation of one kind of energy into another. 
In a case of this sort it is the opinion of expert physicists that is most valued, and in discussing the analogous case of the operation of our will, the late Prof. J. H. Poynting, an authority of eminence, suggested that a merely deflecting force does no work though it changes configuration. The will may introduce a constraint which guides molecules to glide past one another instead of clashing-a slight change of spin which may be compensated for by a slight opposite spin put on the rest of the body. "The will may act as a guiding power changing the direction of the atoms and molecules in the brain, and we can imagine such a guiding power without having to modify our ideas of the constancy of matter or the constancy of motion or even the constancy of energy" (Poynting, 1903, p. 745).

(b) A recurrent argument in Driesch's exposition of his doctrine of vitalism is that no machine-like agency can possibly account for the facts of development, inheritance, and behaviour. A machine is defined as " a given specific combination of specific chemical and physical agents", and Driesch seeks to reduce to absurdity the theory that any machine could do what is required. His argument is very convincing, but of course we can argue only about machines that we know, and imaginative combinations or improvements of these, so it seems open to the critic to reply that no one knows all possible machines, and to urge that proving the untenability of a machine-theory does not prove the necessity of postulating an Entelechy.

Concerning the ingenious machines-almost supermachines-invented by man, it may not be needless to remind ourselves that their introduction into the argument is apt to be fallacious. For they, like the wonderful achievements of the synthetic chemists, are the fruits of intelligence, 
not fair samples of the inorganic world. An ingenious machine, like a type-writing or a calculating machine, is an elaborated tool, an extended hand, and has inside of it, so to speak, a human thought. It is because of these qualities that it is a little like an organism. Practically, however, most of those who have an intimate acquaintance with living creatures will agree with Driesch in the negative part of his position that their behaviour is not very like the working of machines. For certain purposes it is not amiss to think of the organism as an engine, but it is a self-stoking, self-repairing, self-preservative, self-adjusting, self-increasing, self-reproducing engine!

(c) Dr. J. S. Haldane states another objection. "In order to 'guide' effectually the excessively complex physical and chemical phenomena occurring in living material, and at many different parts of a complex organism, the vital principle would apparently require to possess a superhuman knowledge of these processes. Yet the vital principle is assumed to act unconsciously. The very nature of the vitalistic assumption is thus totally unintelligible." Because wo do not understand vital phenomena in terms of mechanism, we postulate an Entelechy, only to discover that we have no idea how the Entelechy can know what to do. We believe that a dog's appreciation of the meaning of certain circumstances is real and an effective factor in its ensuing behaviour, and there are various ways of thinking of the dog's intelligent behaviour so that it does not appear magical or miraculous, but we find it difficult to think of the Entelechy's appreciation of an intricate chemical situation within the body. Even if we suppose a hierarchy of psychoids with division of labour, acting like the various men about a railway station, some of whom put people into the proper trains, 
while others put them into the proper compartments, others shut the doors and give the signals, and others work the points, the correlation of the whole by the chief Entelechy is just the problem we started with.

To many it appears that to assume the existence of an Entelechy does not help in the least. "It seems to be merely a way of collecting all the difficulties together and giving the bundle a name." Professor Jennings asks persistently how the Entelechy gets its power of co-ordinating and harmonising. "To accept the Entelechy unanalysed and unexplained is merely to give up the problem as insoluble." And if we try to work out a comparative development of Entelechies,- " then surely we are merely transferring our problem from the complex that we actually find in time and space to a sort of manufactured copy of this problem, presenting the same difficulties, with the additional one that it is impalpable and cannot be directly dealt with at all. The Entelechy simply adds to our difficulties."

We confess to some sympathy with those who ask why there should be all this straining and striving to remove organisms from the domain which includes the stars and precious stones, Northern Lights and dew-drops. For the world that we parcel out is probably one after all, and in any case there is no stigma in being mechanical. With this sympathy we would quote from a colleague:- "I am neither afraid nor ashamed to uphold (to the great length that I have gone) a mechanical theory of the organism and its activities, or rather of its reactions with the outer world. I do not admit that in doing so we degrade our conceptions, or belittle our notions, of the organism. The mechanical concept is no base one at all. The earth itself and the sea, the earth with her slowly changing face, and the sea multi- 
tudinous with all its tides and currents and great and little waves, constitute a mechanism; the heavens themselves, the sun and moon and all the little stars, are a glorious mechanism. The whole material aspect of the universe is a mechanism; we know not how it has its being, but we know that it lives and moves obedient to everlasting laws; and the same Benedicite Dominum is addressed to the Showers and Dew and to the Winds of God as to all that move in the waters and all that move in the air, and to all the Beasts and Cattle, and unto the Children of Men" (D'Arcy Thompson, Life and Finite Individuality, p. 52).

This is admirably said, yet we do not think that the category of 'mechanism' exhausts the reality of the earth and the heavens, still less that of the flower in the crannied wall. It is mainly a matter of method: Are mechanical categories sufficient in biology or must we have biological categories as well? For practical purposes, moreover, the theory of organism transcending mechanism is to be recom. mended. It has pragmatic sanction.

\section{§6. Descriptive or Methodological Vitalism: the}

\section{'Biological' View.}

Looking backwards, we cannot accept the view that the study of animal behaviour is just the study of very intricate and at present insoluble problems in chemistry and physics; we cannot accept the view that organisms exhibit a new kind of physical energy or several of them; and we cannot accept the thoroughgoing vitalistic theory of an Entelechy. What, then, is our position?

We wish primarily and scientifically to stand for what may be called 'descriptive' or 'methodological' vitalism. Unable to attain any discernment of the essence of the differ- 
ence between organisms and things in general, we hold to what we believe to be a fact, that mechanical formulæ do not begin to answer the distinctively biological questions. We do not doubt the value of bio-chemistry and bio-physics, but when these are added up the summation is not biology. We need new concepts-such as that of the organism as a historic being which has traded with time, and has enregistered within itself past experiences and experiments, and which has ever its conative bow bent towards the future. We need these new concepts because there are new facts to describe, which we cannot analyse away into so-called simpler processes. In the present state of knowledge we cannot tell in what the newness essentially consists. This appears to us to be a quite legitimate stopping-place, without going on (except speculatively) to any positive vitalistic theory which must be, from the nature of the case, metaphysical.

The best statement that we know of methodological vitalism is that given by Mr. E. S. Russell, and we take one of . his illustrations-the migration of the European eel to its spawning ground in the deep, warm, and salt waters on the verge of the abyssal Atlantic. Chemical and physical methods can tell us much-how the eel gets energy for its long journey, and a score of other things; they might conceivably give us an account of every transformation of energy within the eel from the time it left the pond to the time of its death in the dark abysses, but they do not illumine the biological fact of the eel's migration. As Mr. Russell says, "The migration is, so to speak, a fact of a higher order than any physical or chemical fact, although it is made up of an indefinitely large number of physical and chemical facts. To explain the fact one must accept it as a whole, not seek 
to conquer by dividing it, for if one analyses it into its components one inevitably misses the bond of union. . . . The explanation of a biological fact cannot be obtained by decomposing it, any more than the properties of a chemical compound can be deduced from the properties of its constituent elements. . . A biological fact is something more than a mere arbitrary assemblage of component physical and chemical facts, and the component facts may be explained without touching at all the problem of their composition. In the case of the eel it is possible to decompose the act of migration into a large number of acts of a different order, into the chemical reactions occurring in muscular movement, in nervous conduction, in the stimulation of peripheral sense organs, but by doing so one cannot but lose sight of the interconnection of these single acts, the interconnection which really binds together all these acts into the single act of migration. - . To decompose the act of migration into an infinity of physico-chemical processes is to take an infinity of little partial views of the act, but what one needs for an explanation of the fact is a comprehensive view which will unite all the relevant features of it into one picture. To the chemist confronted with the problem there is no fact of migration at all, there is only an intricate enravelment of chemical reactions; to the biologist the fact of migration to a particular region for a particular purpose is cardinal, and the chemical processes involved in the action are negligible."

But, it may be said, if the mechanistic description leaves the eel's migration obscure, does any other description fare better? The answer is that we must look at the migration in the light of what we know of organisms in general. It is certain, for instance, that what a living creature does 
is in part determined by the past-its own experience and the history of its race. In the organism, as Bergson says, the past is prolonged into the present. "Living things therefore require an historical explanation. Non-living things, on the contrary, have no history in the biological sense of the word, and no inorganic thing carries its past about with it" (Russell, 1911, p. 338). We have to pass, therefore, to a new level of explanation, and whenever we mention that the eel is one of a deep-sea race which has adventurously taken to colonising the fresh waters-just as the salmon is one of a fresh-water race which has taken to exploiting the resources of the sea,-and notice further that many animals return to their birth-place to breed, and that some go back to their birth-place to die, a biological light begins to be shed on the eel's strange story. And we have but begun. Of course if the objector is prepared to maintain that the enregistering of experience by organisms is nothing more than a special case of the peculiar way in which colloids are influenced by their history, we can only say that this theory must get more facts to back it before we can take it very seriously.

No one wishes to slacken investigation into the physiology of migration-a most fascinating and suggestive inquiry. It is known that when eels become mature there is an alteration in the metabolism, and that the altered metabolism affects the carbon dioxide content of the blood, that this increases irritability, and that this increases range and vigour of movements, and, moreover, that changes in the metabolism of the animal affect its reactions to chemicals in the water, to gravity, and to currents. Much knowledge of this kind is accumulating, but it seems to many that it does not grip the problem unless it be taken along with the concept of the 
organismal enregistration of past experiences, individual and racial. We must bear in mind that organismal reactions are often very precise-the North Sea will not suit the eel, it must move on; that they are often extraordinarily insistent, as we may infer from Maitland's experiments on Smolts which were always jumping out of the pond at the time when they should naturally have been leaving fresh water; that the internal adjustments are so delicate that they begin to operate long before the situation is at all critical; and that, after all, what we see is an active searching out of regions or conditions of optimum stimulation.

\section{§7. Speculative.}

Such, then, is the position which may be called descriptive or methodological vitalism. If we are pressed to go beyond Science in the endeavour to form some connected reconstruction, we should say that those constellations of 'matter' and 'energy' which we call organisms afford opportunity for the expression of aspects of reality which are undetectable in the inorganic doman. 'Matter' and 'energy' are scientific concepts defined for the description of the socalled physical universe; they are defined by certain methods-the intellectual instruments of physics and chemistry; they are admittedly reached by processes of abstraction. In dealing with the outer world apart from life, these formulx work well, but we find no warrant for asserting that they exhaust the reality of Nature. They correspond to reality, for we risk our lives on this correspondence, but it does not follow that they are exhaustive. Reality is richer than they. For just as a physician may on occasions treat his patient successfully without recognising him as a rational being at all, yet will on other occasions fail grievously through not 
doing so, so it is possible that an aspect of reality which may be safely neglected, being latent or hidden, in one constellation of matter and energy, may be patent and dominant in another. Instead of supposing the intervention of vital impetus or Entelechies as bolts from the blue which enter organisms, may we not conclude that the qualities which render the postulation of vital impetus and Entelechy necessary to some minds have been in kind present throughout. We say "in kind", since most naturalists agree in believing that we share in a movement which is not the unwinding of something originally given, but an evolution in which time counts.

Our argument for the autonomy of biology may be expressed in general form by saying that it recognises the correlation rather than the unity of the science of Nature. We find it technically stated by Prof. Arthur O. Lovejoy:"Scientific unification takes place in so far as diverse classes of phenomena come to be recognised as deducible from a single, relatively simple generalisation concerning the correlation of certain variables-provided that in each particular case the actual natures or values of the variables be known. And unification fails of attainment in so far as two or more kinds of phenomena appear (in the light of existing knowledge) as undeducible from any single, already verified law, even were the actual values of the variables referred to by any such law precisely ascertained for the phenomena in question. When two or more comparatively specific laws are, in the latter sense, incapable of being deduced from any common, more general, law-in other words, are not thus far unified-we may speak of the laws as being discontinuous with one another" (1912, p. 17). $\mathrm{He}$ goes on to say that while discontinuity emerges if the 
behaviour of an animal is shown to be not deducible from the laws of thermodynamics, though in conformity with them, a greater discontinuity will appear if it should be shown that in some cases (distinctively vital processes) the motion of particles in an organism, say an Amœba, neither follows from nor conforms to the motion of particles in an inorganic system, such as, let us say, a whirlpool.

It may be justly said that if Biology requires categories of its own, it should be able to give some indication of what they are. They may not be clear as yet, the science is so young, but they should be emerging. And surely some of them are beginning to be discerned. First, there is the fact of organic retention, the capacity of enregistering experience, garnering the past, capitalising gains. We see this in the results of training and habituation, in the establishment of organic rhythms or periodicities, in the organisation of steps which have proved adaptive, in the organic inertia which the hereditary relation reveals. Second, there is the selfmaintaining, self-preserving, and purposiveness of the organism Life has been defined as "effective response", but it is more; it is effective prospectively as well as immediately, it is effective not only in external action, but in self-preservation. We see in the developing organism a remarkable 'conativeness', especially when what is artificially disarranged is put to rights again. We see in the simplest behaviour, where the meaning of things counts, an element of pre-awareness that is essentially teleological. Third, there is the fact of variability, the capacity and habit of giving origin to the new. 


\section{§. Retrospect.}

How does the 'biological' position differ from the theories already illustrated? The first theory was that the activity of living creatures stands apart from that of not-living things only in being very much more complex. The 'biological' view recognises that many describable chemical and physical processes occur in the living body; and admits that many more such processes-and much more complicated oneswill be eventually sifted out,-but insists that even if the ledger of all the chemical and physical transactions were complete, it would not furnish an account of the creature's life from day to day, nor of its behaviour, nor of its individual development, nor of its racial evolution; and why not? Because the concepts of chemistry and physics fail to grip. This is what one of the acutest and best-informed of modern methodologists, Professor Enriques, means by saying: "The mechanical hypothesis does not appear to be incompatible with the phenomena of life, but it is unimportant for the study of these phenomena" (1914, p. 385). And again he speaks of "the irrelevancy of the mechanical explanation in biology" (1914, p. 384). And why do the chemico-physical formulæ fail to grip the essential features of the activity we call living? Not because the processes involved are too difficult or too complex-but because they demand a different order of scientific explanation.

The second theory was that living creatures have exclusive possession of a peculiar form of energy in a line with the other forms of energy, like heat and electricity, and not in any way mystical, but amenable to experimental. and mathematical treatment. The 'biological' position differs from this in refraining (in the meantime) from any 
hypothesis as to the nature of the difference between stone and tree, between boomerang and homing bird, in being content with holding to the fact that new aspects of reality have somehow risen to the surface and demand other than mechanical formulation. Learning, choosing, struggling, and the like appear to transcend mechanism.

The third theory asserts that something not really belonging to the natural order, something not material, is present in living creatures, informing them, underpinning them, inspiring them. The 'biological' view differs from this in keeping to the idea of continuity, in supposing that aspects of reality which in azoic days were only implicit became explicit in the first living creatures, and have become more and more patent as evolution has gone on.

We are here in the difficult position of agreeing on the one hand with the positive vitalists in their emphasis on the uniqueness of organisms as compared with not-living things, and yet of disagreeing with them (or many of them) in their emphasis on discontinuity. It is plain from our argument that our understanding of the facts of the case leads us to a high appreciation of the apartness of organisms and to a conviction that living transcends all mechanical description, but we are not compelled by this to a rejection of the central idea of Evolution, which is continuity.

To ignore distinctions yields false simplicity; to exaggerate them yields false complexity. There is very little individuality in the inorganic domain, but it must be remembered that gold and iron, phosphorus and sulphur, oxygen and nitrogen remain quite distinct things with properties and ways of their own, specific like organisms, "each something of a law unto itself". There are, indeed, logical 
relationships between the elements as members of a system, and the radio-active elements are known to be transmuting themselves, but these facts also bear out our point that there is more analogy between the inorganic and the organic than at first appears. And just as the breeder and cultivator help to make new animals and plants, so the synthetic chemist makes camphor and sugar, rubber and alizarin, and the physicist as engineer makes the cleverest machines which borrow some of his own individuality. The breeder works mainly by analysis, the chemist by synthesis, but both are creative. We agree with those thinkers, like Lloyd Morgan, who have tried to link on the synthetic tendency which they detect in the formation of crystals and the building up of carbon compounds to the synthetic tendency which they see in organic development. Lloyd Morgan refers to the teaching of Nernst that, while a large number of physical properties are clearly additive, there are other properties which are non-additive, and should be called constitutive. "The kind of influence of the atom in a compound is primarily dependent upon the mode of its union, that is, upon the constitution and configuration of the compound" (Nernst, Theoretical Chemistry. Translated by Lehfeldt. Quoted in The New Realism, New York, 1912, p. 238).

Instead, then, of seeking to interpolate a new agencynon-material and not perceptual-we express the fact that living is not explicable in terms of matter and motion by saying that all organisms-known to our senses as collocations of protoplasm-reveal new aspects of reality, transcending mechanical formulation. That these new aspects of reality are analogous to those which are exhibited by the higher organisms-namely, intelligence and personalitymay by and by appear, for our central idea is that the 
organism is a psycho-physical individuality. That they probably have their infra-conscious and implicit analogues in the domain of the inorganic is our metaphysical hypothesis, which is but little different from the Aristotelian dictum that there is nothing in the end which was not also in kind in the beginning;--but little different from the doctrine that in the beginning was Mind.

\section{§9. Why Cannot the Controversy between Mechanistic and Vitalistic Theory be Ended?}

The persistence of the controversy between mechanism and vitalism has often been the subject of remark. Aristotle was a vitalist and his biology was in conscious opposition to the dogmatic mechanism of the school of Democritus. Yet we are facing the same antithesis to-day. Whence this terrible longevity?

Part of the answer is probably to be found in the intrinsic difficulty of the problem of vital activity, which seems to be midway between mechanical uniformity and our own conscious purposing. The secret of life is baffling, receding as we approach. Perhaps when it seems almost within the physiologist's reach, it is farthest away. Perhaps, as Bergson says, our intelligence is not suited for this quest, and we get nearest life in sympathy.

But apart from the unanswered question: What is the essential difference between the Amoba and the crystal, between the bird and the boomerang, is there not something strange in the historical oscillations of opinion between mechanistic and vitalistic interpretation of the living organism? Now it is a machine and again it is a spirit, now an automaton and again a free agent, now an engine and again an entelechy: Why does the pepdulum of reflec. 
tion swing so? It is partly because new knowledge always rewards the prosecution of chemico-physical analysis, and the investigators, flushed with success, insist on premature generalisation. It is partly because vitalism is apt to become vague and mystical, provoking a positivist recoil which is, within its limits, quite wholesome.

According to Prof. W. E. Ritter, vitalism is the lineal descendant of early animism, sharing with it the assumption of non-material, essentially extra-corporeal forces or principles to explain observed phenomena. Similarly, materialism is the lineal descendant of early magic, sharing with it the assumption of crediting observed bodies with qualities which are not verifiable. "Both attempt to explain everything in terms of 'something else', and this in essence amounts to a denial of the reality of the organic beings which we actually see and deal with" (Ritter, 1911, p. 441).

\section{SUMMARY.}

It is plain that at present chemical and physical formulations do not suffice to answer biological questions, do not adequately cover what is distinctive in the functions, behaviour, development, and evolution of living creatures. But this does not in itself prove the validity of any of the various forms of positive vitalism. These must be considered on their merits.

(a) Some have maintained that mechanistic formulation is not exhaustive even within the domain of the inorganic. If so it will be $a$ fortiori inadequate in the realm of organisms. (b) Others, while admitting that we cannot now translate vital processes into terms of any known chemistry and physies, suggest that we may be able to do so eventually. The concepts of chemistry and physics may have to be modified. But we can only discuss the sciences as we know them now. (c) Others, again, maintain that it is mind that makes all the difference. But the problem "Vitalism or Mechanism?" is the same for plants as for animals, and we do not know anything about the mind of plants.

It may be said that there are three grades of vitalism. (1) The 
first finds the differentia of organisins in the greater complexity of their configurations or collocations of elementary particles. Living creatures are apart, hut they do not require new concepts (an autonomous science) for their description. They only require separate laboratories for their study. (2) The second vitalistic theoery holds that organisms have a monopoly of some peculiar physical energy or energies in a line with, say, electricity. (3) The third theory-the only thoroughgoing vitalism-postulates a nonperceptual vital agency, associated with organisms, operating actively in certain cases, directing the chemico-physical processes, so that their results are different from what they would have been apart from intervention. The finest expression of this view is Driesch's doctrine of Entelechy, the advantages and difficulties of which must be carefully considered.

Perhaps it is safer to be content with a descriptive or methodological vitalism - that is, with maintaining that in describing organisms we require ultra-mechanical concepts. But if the word vitalism is taken to imply dualism and intervention, we may call our position simply biological or organismal. The central idea is that of the organism as a psycho-physical individuality which has enregistered within itself the gains of experience and experiment, and has ever its conative bow bent towards the future. Instead of trying to interpolate a new agency, may we not simply recognise that organisms reveal certain aspects of reality which are not apparent in the domain of the inorganic? 



\section{LECTURE VI.}

\section{ANIMAL BEHAVIOUR.}

§1. What Is Behaviour? §2. Diverse Views as to Animal Behaviour. §3. Activities of Unicellular Organisms. §4. Special C'ase of Shell-building among Arenaceous Foraminifera. §5. Reflex Actions. §6. Tropisms. §7. Non-intelligent Experimentation. §8. Instinctive Behaviour. §9. Theories of Instinct. §10. Evidence of Intelligent Behaviour. §11. Secondary Simplifications of Behaviour. §12. Rational Conduct. §13. General Impressions of Animal Behaviour.

Is our preceding studies we reached the conclusion that a matter-and-motion description of living creatures is far from being adequate, that it does not grip the kernel. While organisms are collocations of matter and energy, there has welled up within them a new aspect of reality which demands other than mechanical, chemical, and physical concepts. Wherein the newness precisely consists we have not discovered; but we recognise the livitig creature as a historic being which has enregistered the experiences and experiments of the past, which trades to good purpose with time, which has its conative bow often bent. In the hope of a further appreciation of the significance of life we turn now to a more systematic consideration of animal behaviour.

\section{§1. What Is Behaviour?}

The movements of the planets in their courses afford an object-lesson of orderliness on a grand scale, and yet the least in the realm of organisms is greater than they-in being an agent. The movements of a rolling stone are completely 
determined by its momentum and the circumstances, but there is a spice of unpredictability in the ways of most living creatures. The unexpected often happens. There are indeed uniformities of sequence in the reactions of organisms, otherwise no science of behaviour were possible, but there is an undeniable appearance of free agency. It is interesting to watch under the microscope the Brownian movement seen when minute granules of sepia or the like are jostled hither and thither, probably by the invisible ions which abut against them, but the scene changes in character when we put in a vigorous unicellular organism. It does not 'take charge' like a gun torn from its attachment on board ship; it commands its course. Only in the realm of organisms is there true behaviour-in which the creature is an agent and exhibits a correlated or concatenated series of acts, effective towards some definite result, favourable to the continuance and harmony of vital processes.

There are two master-activities in the animal organismfor the sake of which life is worth living-movement and feeling, contractility and irritability, the functions in most cases of the muscular and nervous systems respectively. These master-activities are kept agoing, the relevant structures are kept in working order, by the other everyday functions of nutrition, circulation, respiration, excretion, and so on; never forgetting, in connection with Vertebrates at least, the fundamental trigger-pulling and regulative function of the organs of internal secretion. These everyday functions are the pre-conditions of behaviour; and growth and maturity may also condition behaviour. But behaviour itself is much more, it means that the organism is an agent and that it exhibits a correlated or concatenated series of actions. 
§2. Diverse Views as to Animal Behaviour.

The difficulty of rightly interpreting the observed behaviour of animals is confessedly great. It is not casy for us to get mentally near them. In many cases the structure of their body in general and of their nervous system in particular is very different from ours; their sense-organs are often on another plan, and there are some whose functions we do not yet know; such words as a few of the higher animals have, we can only vaguely understand. How are we to get into mental contact with ants and bees? $\Lambda$ nd even for more accessible animals, like horse and dog, there is a great difficulty involved in the simple fact that all our psychological terms are saturated with human meaning.

Some investigators have found a short and easy way out of difficulties by dogmatically declaring that there is no more mind among animals than there is among plants, and that the sensible course is to keep to physiological description. If that suffices for giving an account of the bryony climbing up the hedge with its exquisitely tactile and adaptively motile tendrils, will it not serve for the sea-urchin climbing up the rock, the squirrel climbing up the tree? This is the extreme of over-simplicity. It was indeed a wise saying of Spinoza:- "No one has yet learned from experience what the body regarded purely as a body is able to do in accordance with its own natural laws, or what it cannot do", but it seems to most naturalists to make the behaviour of higher animals magical if we do not credit them with an awareness and pre-awareness of meaning.

There are others who think that we get nearer the truth the more anthropomorphic we are, who believe that the behaviour of all animals shows evidence of mind. That is 
to say, the description that we give of an animal's behaviour, or of critical corners in it at least, is bound to be inadequate unless we use psychical terms. This is the other extreme. It was expressed by Hume when he said: "No truth appears to be more evident than that beasts are endowed with thought and reason as well as men." That may be tenable generosity for horse and dog, but it cannot hold good for starfish and earthworm.

How are we to avoid the stern over-parsimony of Descartes on the one hand, and the delicious over-generosity of Montaigne on the other? We must not give a false simplicity to the facts by reducing the animal to the level of an automatic machine, but we must not read the man into the beast without critical hesitation. The hive-bees that make the honeycomb so symmetrically are not automatic machines, but neither are they little geometricians.

To keep to the via media of good sense must always be difficult, for the assumption of mind in an animal or of a psychological aspect in the behaviour of an animal cannot be demonstrated. There is no litmus paper for mentality. "Every statement," says Bethe, "that another being possesses psychic qualities is a conclusion from analogy, not a certainty; it is a matter of faith." Our assumption of mind in our fellow-men rests on the same sort of basis (though with inter-subjective corroborations); it is a necessary hypothesis and one that works. Is not a similar hypothesis indispensable in regard to animals if we are to understand them and make the most of them? But animal behaviour has such a long gamut that each case must be judged on its own merits. We ask in each case whether we can make sense of what we see without assuming mental factors, whether we can adequately describe what we see without 
using psychological terms. We inquire into the creature's power of profiting by experience, as to its pursuance of trialand-error methods. The growth of experimental psychology has furnished many a welcome check to interpretations, showing some to be too simple and others to be too generous. Some weight will also be attached to the degree in which the nervous system of the animal in question resembles ours, or that of some types previously judged to be capable of, let us say, making an inference.

The sound practical rule is to try to re-describe the observed behaviour in as simple terms as possible without leaving out any essential feature. As Prof. Lloyd Morgan has put it, "In no case may we interpret an action as the outcome of the exercise of a higher psychical faculty, if it can be interpreted as the outcome of the exercise of one which stands lower in the psychological scale" (1894, p. 53). The simplest description is not necessarily the true one, as we know in human affairs; but the scientific method is to hold to it till facts force us to give it up.

\section{§3. Activities of Unicellular Organisms.}

Many unicellular organisms show restless movements which may be ranked at the foot of the inclined plane of behaviour. As long as certain combustible materials within the organism hold out, and as long as certain external stimuli continue to act, the creatures continue moving; and we see them responding to various calls which summon them now to one side and now to the other. This is like the unworked ore of behaviour, and not much beyond the level of everyday internal activities. We may speak of it as general organismal activity among unicellulars.

But even among the simplest creatures we notice three 
facts:-(1) The movements of one animalcule are often quite different from those of another, even in the same medium: so soon is the note of individuality struck. (2) The restless roving is not at random, and when food is scarce it is intensified, passing insensibly into ' hunting'.

(3) Many of the simplest animals exhibit quite definite reactions to stimuli. They respond by particular movements to changes in temperature, in illumination, and in the chemical composition of the medium. As there is no nervous system, but simply a specific inborn protoplasmic organisation, we may use the phrase unicelluiar organic reaction for what is in a far-off way comparable to the reflex action of a higher animal.

The adherents of the mechanistic school point out that the Amœba is a reservoir of energy which is tapped by various stimuli-such as the freshness of the water, the chemical composition, the temperature, and the illumination. Its locomotion represents the natural outflow of the stored energy, and the direction of its journeying depends on the continually varying stimuli with which it meets. But when we really study the Amœba, as Professor Jennings (1906) has done, the possibility of any simple description of its doings disappears. Its general condition has much to do with its reactions; the direction of movement is not wholly determined by the position of the stimulus or the part of the body on which it acts; the moving Amœba shows in its transient differentiation a trafficking with time; what it has done is an important factor in determining what it will do; the types of reaction are not stereotyped; it is not possible to predict the movements from a knowledge of the direct results of the external influence. So the life of the Amœba is not such a simple affair as some would make out. We require a kind of description different from that which 
suffices for the potassium pill rushing about on the surface of the water.

The Amoba encounters a hurtful stimulating influence affecting part of the cell; it withdraws the stimulated part, and that is related to the localisation of the influence. But it proceeds to send forth a finger-like process of its living matter in a new direction, and the issue of this is determined by internal conditions. "If the new direction of morement leads to further stimulation, a new trial is made. Such trials are repeated till either there is no further stimulation, or if it is not possible to escape completely, until the stimulation falls on the posterior end, and the animal is retracted directly from the source of stimulation" (Jennings, 1906, p. 22). The importance of this is great. A direction is taken because it relieres the Amcba from hurtful stimulation. There is, Jennings says, "selection from among the conditions produced by raried morements". "Thus the behariour of Amoba is directly adaptire; it tends to preserve the life of the animal and to aid it in earrying on its normal actirities" (p. 23).

"The writer is thoroughly convinced, after long study of the behariour of this organism, that if Amcba were a large animal, so as to come within the everyday experience of human beings, its behariour would at once eall forth the attribution to it of states of pleasure and pain, of hunger, desire, and the like, on precisely the same basis as we attribute these things to the $\operatorname{dog}$. This natural recognition is exactly what Münsterberg (Grundzüge der Psychologie, Bd. I., 1900) has emphasised as the test of a subject. In conducting objectire inrestigations we train ourselres to suppress this impression, but thorough investigation tends to restore it stronger than at first" (p. 336). 
Miss Washburn (1909, p. 41) has inquired into the nature of the Amœba's mind, if haply it has one. There cannot be more than three or four qualitatively different elements in its experience; there is no evidence of memory images; it probably has not more than flashes of consciousness. The problem of the Amœba's mind can wait, but it seems to us clear that when we allow as much as possible to physical properties (such as we see in the improvement of a violin in the hands of a master), to the response of chemical bodirs to certain stimuli and no others (such as we see in photography), to the purely physiological registration of experience (such as we know in the improvement of well-exercised muscles), there is a new aspect of reality appearing in the behaviour of even an Amœba.

The slipper-animalcule, Paramecium, abundant in water with decaying marsh plants in it, is a minute, cigar-shaped, ciliated Infusorian, just visible to the naked eye as an elongated whitish particle. Its rudimentary but very effective behaviour has been much studied, especially by Prof. $\mathrm{H}$. S. Jennings. One of the commonest episodes is that in its swimming the Paramecium meets with something injurious in the water, and exhibits what is called the "avoiding reaction". It reverses the action of its cilia and swims away from the stimulus; at a certain distance it moves so as to swing its anterior end in a circle, testing the water in different directions; when the sample from a certain direction no longer contains the obnoxious influence, the Paramecium goes ahead again in that direction, and may have a free course till the next stimulus is experienced. When the original stimulus is due to some mechanical obstacle, Paramecium can get no hint from testing the water; it " tries going ahead in various directions, till it finds one in which 
there is no further obstacle to progress. In this direction it continues. Through systematically testing the surroundings, by swinging the anterior end in a circle, and through performing the entire reaction repeatedly, the infusorian is bound in time to find any existing egress from the difficulties even though it be but a narrow and tortuous passageway" (Jennings, 1906, p. 49).

The behaviour of Paramecium is very instructive in its combination of effectiveness and simplicity. It drives itself forward in a narrow spiral, revolving on its long axis and swerving a little towards the aboral side-such is its action system; and most of its behaviour consists of slight variations on this simple tune. "It constantly feels its way about, trying in a systematic way all sorts of conditions, and retiring from those that are harmful. Its behaviour is in principle much like that of a blind and deaf person, or one that feels his way about in the dark. It is a continual process of proving all things and holding to that which is good" (Jennings, 1906, p. 106).

"The behaviour and reactions of Paramecium consist on the whole in performing movements which subject the organism to varied conditions (using this word in the widest sense), with rejection of certain of these conditions, and retention of others. It may be characterized briefly as a selection from among the varied conditions brought about by varied movements" (Jennings, 1906, p. 108). On the whole the animalcule rejects or avoids what is injurious and accepts or seeks what is beneficial, just as higher animals and men do. The behaviour is adaptive and purposive. Indeed Jennings goes the length of saying: "In no other group of organisms does the method of trial and error so completely dominate behaviour, perhaps, as in the Infusoria." 
A fact of great interest has been established by Professor Jennings, that the behaviour of unicellular organisms is modifiable by experience. He has experimented, for instance, with a trumpet-shaped ciliated Infusorian called Stentor which abounds in marshy pools, attaching itself by the narrow end to a water-weed, and surrounding the lower half of its body with a mucus-like sheath, the so-called tube. A cloud of carmine particles is introduced into the watercurrents passing to the ciliated mouth of the Stentor. It bends to the aboral side, twisting on its stalk two or three times as it bends, and thus often avoids the cloud of particles. That is answer one. But if the particles continue to come, the ciliary movement is suddenly reversed and the water is driven away from the mouth. This may be repeated two or three times, and is answer two. If the Stentor does not get rid of the obnoxious stimulation in either of these two ways, it contracts into its tube and suspends activity, this being answer three. After half a minute or so it re-expands, and if the carmine particles still reach it, it contracts again. It will do this many times, and after each contraction it stays a little longer in its tube than it did before. Finally, if no improvement in circumstances rewards its trials, it breaks its attachment and swims forwards or backwards away from its tube. And this is answer four. "The stimulus and other external conditions remaining the same, the organism responds by a series of reactions becoming of more and more pronounced character, until by one of them it rids itself of the stimulation" (p. 176). "The same individual does not always behave in the same way under the same external conditions, but the behaviour depends upon the physiological condition of the animal. The reaction to any given stimulus is modified by the past experience of the ani- 
mal, and the modifications are regulatory, not haphazard, in character. The phenomena are thus similar to those shown in the 'learning' of higher organisms, save that the modifications depend upon less complex relations and last a shorter time" (p. 179). Our view of living creatures must make room for the new fact that behaviour reaches this level among the unicellulars.

Among unicellulars, then, we see the beginning of exploring and testing, the beginning of actual 'hunting', and this is on the main line of advance. WVe see, also, the enregistration of particular reactions to stimuli, an organisation of behaviour that is economical and in its rapidity of response often life-saving. But we sec, also, a selection of reactions, a trying of one after the other till haply one meets the needs of the case, and this 'trial-and-error' method is likewise on the main line of advance.

\section{\$4. Special Case of Shell-building among Arenaceous} Foraminifera.

In the shell-building of some of the so-called arenaceous Foraminifera Mr. E. A. Heron-Allen ard Mr. A. Earland have described (1915) what looks like constructive skill in the use of materials. $\Lambda$ s every one knows, many unicellular animals secrete shells of exquisite beauty, the 'organic crystallisation' of which is as much of an unsolved problem as the adaptive internal architecture of bones, but in the case of the arenaceous Foraminifera the building materials are found ready-made in the environment and are utilised very effectively to form a casing. The points of special interest are two,-(1) that a particular kind of material, such as sponge-spicules, is selected from the surrounding débris, from 
amid a multitude of apparent alternatives, and (2) that it is utilised in a fashion which is interpretable as peculiarly adaptive. The first point may be illustrated by the case of Technitella thompsoni, which covers itself with minute perforated Echinoderm platelets; the second point by the case of Marsipella spiralis, which arranges its encasement of sponge-spicules in a spiral, doubtless of considerable architectural value.

\section{§ 5. Reflex Actions.}

Among simple multicellular animals we find, as among the unicellulars, abundant illustrations of exploring, testing, and hunting. Perhaps we may recognise more staying power, persistence, and momentum, advantages naturally accruing from the acquisition of a body.

But the establishment of a nervous system opened the way to the organisation of reflex actions, which are the outcome of hereditarily prearranged linkages of nerve-cells and muscle-cells. These play an important rôle in behaviour. The sea-anemone's tentacles close upon their victim; the nestling's mouth opens at the touch of the food in its mother's beak; the earthworm withdraws into its burrow when it feels the tremor of a thrush's footstep; we cough in spite of ourselves when the crumb of bread is going the wrong way, and so on. These reflex actions are uniform reactions to a particular kind of external or internal stimulus; they are exhibited by all animals of the same kind in approximately the same way, though some individuals are quicker than others; they are independent of individual experience and do not require control on the part of the central nervous system; they depend on inborn structural linkages of particular sensory and particular motor nerve-units or neurons. 
In typical and simple cases, a reflex action involves (1) the receptor of a stimulus - the sensory or perceptory nerve-cell from which impulses pass in to the central nervous system; (2) a ' motor' nerve-cell which connects the central nervous system with a muscle or a gland; and (3) between these two a 'communicating', or internuncial, or 'associative' nerve-cell connecting them within the nervous system. The receptor neurone has its cell-body outside of the nerve-centre; the motor neurone, with its ccll-body within the nerve-centre, sends a nerve-fibre to some peripheral effector organ; the associative neurone connects the two others. Thus is formed a 'reflex are', the functional unit of the nervous system. In most cases the arrangements are more complex and several 'reflex ares' become interlinked. But the point is that reflex actions do not require individual correlation; that is pre-established. Yet it is important not to think of reflexes too simply.

Combination of Reflexes in Unified Behaviour. The perfection of reflexes is well illustrated in the behaviour of a sea-urchin, which has no nerve-ganglia. Its test is covered with mobile spines and snapping blades (pedicellariæ) which react in definite ways to definite stimuli and have an astonishing independence. For a single spine or pedicellaria on an isolated fragment of shell reacts very much as usual. In the uninjured creature the spines and other structures are all connected by a nervous network on the surface of the shell, and they act harmoniously, working into one another's hands, securing effective defence and locomotion. According to von Uexküll the sea-urchin is a "republic of reflexes". "The separate reflex ares are so constituted and so put together that the simultaneous but independent course of the reflexes in response to an outer stimulus produces a definite 
general action, just as in animals in which a common centre produces the action." As von Uexküll puts it, when a dog runs, the animal moves its legs; when a sea-urchin crawls, the legs (spines) move the animal.

The astounding fact is the unification of behaviour that may occur in such a "republic of reflexes". When a seaurchin is placed upside down, a continuation of all the usual reactions would cause it to move on in an inverted position. But as von Uexküll has shown, the unusual physiological state induces a thoroughgoing change in the behaviour of the spines, they depart altogether from routine, and work adaptively to the needs of the organism as a whole, the animal being turned right again. This warns us not to think of reflexes woodenly; and if we need another warning we may get it in the extraordinarily subtle reflex by which a flatfish adjusts its coloration to that of the immediate environment of shingle.

Reflex Responses are Affected by the Physiological Condition of the Organism. In stinging animals, such as seaanemones and medusæ, there are numerous reflex actions of an adaptive kind, concerned, for instance, with feeding. But it has been shown by Professor Jennings and others that the reaction is not simply a question of predetermined structure and an external stimulus. The answer depends on the relation of external conditions to internal processes. "We cannot predict how an animal will react to a given condition unless we know the state of its internal physiological processes" (Jennings, 1906, p. 231). Thus, to take a simple case, a sea-anemone cheated several times with false food ceases to exhibit the normal reflex. Many a sea-anemone, e.g., the large Stoichactis helianthus, will remove food from the oral disc if it is not hungry. A specimen of Metridium 
or Aiptasia will refuse to take bits of filter paper, though it will still take meat. "After it has thus refused paper, two or three pieces of meat are given in succession, and taken readily. Now the bit of paper is placed again on the disc, and it too is swallowed. Clearly, the uninterrupted taking of a number of pieces of meat changes the physiological condition in some way, preparing the animal for the taking of any object with which it comes in contact. One cannot fail to note the parallelism with what occurs in higher animals under similar conditions" (Jennings, 1906, p. 226). Wo see, then, that in relatively simple creatures, such as sea-anemones and starfishes, which have no nerve-ganglia, past stimuli and past reactions are important factors in determining present behaviour. Thus an elongated seaanemone, Aiptasia annulata, which lives in crevices beneath and between stones, will bend into a new position if it is touched too often, and if it be molested still further will release its foothold and move to a new region (p. 206). In its natural surroundings it often has to cramp its body into quaint zigzag shapes, and a point of some interest is that this may become habitual and may persist for some time after the creature is removed to an unimpeded habitat. This illustrates what is meant by registration.

In his valuable study of the behaviour of the earthworm, Prof. H. S. Jennings shows that the response to a stimulus depends on external factors (such as the intensity and localisation of the stimulus), and on internal factors (such as the state of the animal at the time, its tendency to move in a certain way, e.g., head foremost, and the direction in which it was crawling at the time). But what is particularly interesting is the definite evidence that the behaviour 
at a given time depends on past experiences-on former external conditions and on former actions.

Succession of Tentative Reflexes. Because of the abundance of reflexes in the simpler animals the impression has gained ground that behaviour in these lower reaches of life is very stereotyped. But this impression requires critical consideration. When a particular reflex action solves a particular problem at a stroke, there is no more to be done. But the problem is often more difficult, and what the creature does is to exhibit varied movements and to select certain resulting conditions. Even in such predominantly reflex creatures as sea-urchins, the tube-feet, spines, and pedicellariæ may in difficult situations continue in varied tentative movements, as if trying all expedients, and long after the original stimulation has ceased. The 'righting' reaction of an 'inverted' starfish is singularly varied and flexible. Professor Preyer repeatedly slipped a short india-rubber tube over one of the arms of a brittle star, and observed five different ways in which it was removed, including, it must. be confessed, as one desperate method, the surrender of the arm itself. As the observer remarked, "If one method does not help, another is used."

Professor Preyer's experiments on pegging down starfishes (of course without injuring them) revealed extraordinary flexibility of behaviour and also a shortening of the time required for escape. The number of useless movements, "superfluous twistings, feelings about, and forward and backward motions", becomes less the oftener the individual has been placed in such a situation. If this is true (Prof. Jennings notes), we have in so low an animal as the starfish regulation through the selection of conditions produced by varied morements passing into a more directly regulatory action; in other 
words, what is commonly called in higher animals intelligence" (Jennings, 1906, p. 241). In many cases we have to do with ' chain reflexes', one phase leading on to another, but the fact is that " in most cases the succeeding phase is not invariably and irrevocably called up by the preceding one" (Jennings, p. 251), the present action depending upon the entire physiological state of the organism, which, again, is determined by various factors.

One of the clearest results of the modern study of the behaviour of the lower animals is that the kind of action depends greatly on the physiological state as a whole, which, again, depends in part on history and experience. That experience can be enregistered in organisms with the simplest of nervous systems or with none is certain. Two individual Planarias (small ciliated fresh-water worms) often react in opposite ways to the same stimulus. What they do varies with their appetite, their freshness or fatigue, their recent stimulation and degree of excitement, and their history. After long study of Planaria, Professor Pearl concludes that " it is almost an absolute necessity that a person should become familiar, or perhaps better, intimate, with an organism, so that he knows it in something the same way that he knows a person, before he can hope to get even an approximation of the truth regarding its behaviour" (quoted by Jennings, 1906, p. 254).

If a reflex be an invariable reaction to a given stimulus, then there is much more than that in the behaviour of lower animals. For different answers to the same stimulus may be given by the same kind of creature or by the same creature at different times. The answer depends on the organismal condition as a whole. Moreover, the fact that stands out most clearly in the behaviour of the lower organisms is this:- 
"Each stimulus causes as a rule not merely a single definite action that may be called a reflex, but a series of 'trial' movements, of the most diverse character, and including at times practically all the movements of which the animal is capable" (Jennings, 1906, p. 280).

\section{§6. Tropisms.}

From chains of reflexes, suffused with awareness, it is not difficult to pass to the level of instinctive behaviour, but before we pass to that level we have to recognise the important rôle played by tropisms (see Loeb, 1918). Tropisms are obligatory or forced movements of the creature as a whole, which more or less automatically secure physiological equilibrium in relation to outside stimuli, such as light or heat, gravity or electricity, diffusing chemicals or water-currents. When a moth, constitutionally adapted to nocturnal activity, comes in its flight within the sphere of influence of a candle, and has one eye much more illumined than the other, owing to the direction in which it happens to be flying, more intense chemical processes are set up in the illumined eye. On that side there is therefore a relative increase in the mass of certain chemical products. But messages, impulses, stimulations, or waves of chemical reaction are always passing from the brain of the flying moth to the contracting muscles, and if the physiological symmetry of the brain has been disturbed by the unequal illumination of the eyes, the muscles on the more illumined side are thrown into a state of stronger tension or tonus, with the result that they will respond more forcibly to stimulation from the brain, and will therefore turn the head and body of the moth directly towards the candle near which it is flying. "As soon as the plane of symmetry goes through the source of light, both eyes receive 
again equal illumination, the tension (or tonus) of symmetrical muscles becomes equal again, and the impulses for locomotion will now produce equal activity in the symmetrical muscles. As a consequence, the animal will move in a straight line to the source of light until some other asymmetrical disturbance once more changes the direction of motion" (Loeb, 1918, p. 14). Such, in outline, is Prof. Jacques Loeb's ingenious and convincing theory of the tropism or 'forced movement' which brings the moth into the candle.

Tropistic actions are obligatory in the sense that every creature of the same kind and in the same physiological state will in similar circumstances behave in the same way; there is no alternative. But it is a very notable fact, to be carefully thought over, that a tropism may be changed, reversed, or annulled by changes in the physiological condition of the body or by changes in the surrounding medium. The common Amphipod Crustacean Gammarus of freshwater pools always moves away from light-that is its tropism, but add the least trace of acid to the water, and it moves towards the light-as if a drop of philtre changed the creature's whole nature!

The tropistic movements often appear as if they had a very definite external aim-such as the candle-but that is illusory. The orientation is physiologically coerced. There is no desire of the moth for the star. It should be noted that their general adaptiveness is not contradicted by cases like the moth flying into the candle, for organisms are not and could not be adapted to the altogether exceptional and unnatural. In some cases one tropism way thwart another, and it may be that a tropistic movement is sometimes interrupted by some strong internal stimulus such as a desire. 
One of the criteria of organisms is the power of retention or registration which eventually finds remarkable expression in human memory, and the general view we wish to suggest, as a clue to the maze of animal behaviour, is that there has been at level after level a process of automatisation or organisation, which makes for economy of time and energy, and also, if it does not go too far, leaves the organism free for experiment and initiative. So in established reactions, in reflex actions, and in tropisms we see enregistrations which are, in a way, off the main line of advance.

Besides established reactions, reflex actions, and tropisms there are rhythmic activities adjusted to external periodicities, such as change of position in shore animals when the tide goes out or comes in. That these may be more than tropisms is shown by cases where the rhythm is so engrained in the creature's constitution that it persists for a time in periodic expression even when the extermal stimulus has ceased. The interesting green worms called Convolutas, well-known on some flat beaches, such as that of Roscoff, come up to the surface of the sand when the tide goes out, and retreat again when the tide comes in. Bohn has found that they will continue doing this for a couple of weeks in an aquarium away from the sea. Similarly, some hermitcrabs which make for the light at high tide and away from the light at low tide have been observed doing this for some time at the proper hours in a tideless aquarium.

It is a question for expert discussion and further experiment how far the conception of tropisms will carry us as an interpretation of the ways of the lower animals. Loeb believes it will cover most cases; Jennings thinks its scope is narrowly limited. Just as tropisms differ from ordinary reflexes in being usually adjustments of the animal as a 
whole, so behaviour differs from tropisms in being an effective concatenation or correlation of successive adjustments. In a tropism there is really but one adjustment, which is repeated over and over again. In behaviour there is trial after trial of different reactions, and a selection of the best available result.

\section{§ 7. Non-intelligent Experimentation.}

Preoccupation with reflexes and tropisms is apt to lead to an ignoring of the 'trial movements' which are common among the lower animals. "Unprejudiced observation of most Invertebrates will show that they perform many movements which have no fixed relation to sources of external stimuli, but which do serve to test the surroundings and thus to guide the animal " (Jennings, p. 247). Prof. S. J. Holmes writes to the same effect and gives many illustrations:- "The lives of most insects, crustaceans, worms, and hosts of lower Invertebrate forms, including even the Protozoa, show an amount of busy exploration that in many cases far exceeds that made by any higher animal. Throughout the animal kingdom there is obedience to the Pauline injunction, "Prove all things, hold fast that which is good" " (quoted by Jennings, p. 250).

Among simple multicellular animals there is, one must admit, not a little of that restless locomotion which we see in Infusorians and the like, which we have called general organismal activity. But at any moment this may give place to more definite behaviour. The creature commands its course and is neither blown hither and thither by every tropistic gust nor bound by reflex routine. It makes sensorimotor experiments which work towards an end, such as the systematic exploration of a corner in search of food. It 
shows control and selection. It may profit by experience, even though it has no brain.

The sea-anemone Antholoba reticulata, described by Bürger, usually lives on the back of a crab. If it be removed it fixes itself to the stony floor of the sea and spreads its tentacles, biding its time. After four or five days it frees itself and turns upside down. Now if the upturned base of the sea-anemone be touched by a crab's leg, it lays hold, folding itself about the limb. "It now, in the course of several hours, climbs up the crab's leg to its back, where it establishes itself. The sea-anemone thus by its own activity attains the extraordinary situation where it is usually found. The whole train of action is like that shown in the complicated and adaptive instincts of higher animals" (Jennings, p. 197).

As the type-case of what we propose to call simply organismal behaviour (or perhaps sensori-motor behaviour), we take the attack which the brainless, ganglionless starfish makes on the brainless, ganglionless sea-urchin (see Prouho, 1890). The starfish lays an arm upon the spinose surface of the sea-urchin and grips with its suctorial tube-feet. The seaurchin responds by biting with its numerous snapping organs or pedicellariæ which close on the tube-feet. The starfish then draws away an arm, wrenching off the pedicellariæ. It repeats the process with the same or another arm until the sea-urchin is cleared of its weapons. The starfish then protrudes a portion of its highly elastic stomach over its victim, and the business is over. Now some of the items in the procedure are probably purely reflex, such as the attachment of the tube-feet, but the point is that the starfish exhibits a chain of actions, certainly not in the line of least resistance, which are mutually adjusted or correlated in such a way 
that they bring about an end. How the conative bow of the starfish was bent towards that end and kept towards that end, who shall tell us, but that we have here to do with behaviour seems undeniable. It appears to us to be an important fact that ganglionless animals show a trial-anderror method, a selection of the responses that put things right, and for a short time, at least, a profiting by experience. We cannot call this intelligent behaviour, but it is objectively the counterpart of intelligent behaviour.

This stage in the evolution of behaviour may be said to mark one of the great events in the history of life. As the organism became more differentiated it was open to a larger number of stimuli; as it gained a foothold in particular situations "the door to choice was unlocked"; as experience began to be garnered it became possible for an internal impulse to control the natural reaction to a stimulus. This was the dawn of freedom.

\section{§ 8. Instinctive Behaviour.}

When a spider makes a web or the bees a honeycomb, when a digger-wasp paralyses insects and stores them in its burrow as provender for its offspring, when a male stickleback builds a nest, when a young moorhen swims deftly the first time it touches the water, we have to deal with instinctive behaviour. It reaches its climax and its purest expression in Arthropods, such as ants, bees, and wasps; in birds and mammals it is more likely to occur in co-operation with intelligence.

There seems indeed to be a sharp contrast between what Sir Ray Lankester calls the big brain type, which reaches its finest development in birds and mammals, and the little brain type, the climax of which is in ants, bees, and wasps. The 
big brain type is relatively poor in ingrained capacities of instinctive behaviour but is eminently educable: the chick reared in an incubator in the laboratory does not recognise what water is, even when it is thirsty and standing in it; it does not know what its unseen mother's cluck means; and it will stuff its crop once or twice with worms of red worsted. But it learns to find its way about with prodigious rapidity. The little brain type is rich in ingrained capacities of instinctive behaviour, but is relatively non-educable. If a belljar be placed over the nest of a ground-wasp, from the door of which the inmates are wont to fly away, they are psychically unable to force a path out amid the herbage pressed down by the edge of the glass. Even when those outside force a way in, they cannot come out again, or give their fellows a hint how to escape.

It must not be supposed, however, that the little brain type is unable to profit by experience. We know in fact that they build up complex chains of associations. It is instructive to recall Professor Yung's experiments with hive-bees. Of 20 taken in a box into the country 6 kilometres from Geneva, 17 returned; of those 17 taken next day out on to the lake, none returned. This is to be contrasted with the successful return of the terns which were taken from Bird Key in the Tortugas to Cape Hatteras, 850 miles into seas never before visited; yet some returned in safety to their nests.

Those who incline to use in reference to ants and bees, crabs and spiders, the terms we need in describing our own activities, should remember the great differences in the plan of the nervous system in the respective ranks of Arthropods and Vertebrates. In the former there is much less centralisation; the cerebral ganglia are connected with a ventral chain 
of ganglia which are able to control many actions by themselves. We must remember that a wasp or a bee may go on feeding after its tail has been cut off, as Baron Munchausen's horse went on drinking after most of its body had been shot away. Even a decapitated insect can do a good deal, like St. Denis who walked round the town with his head in his hands. But whatever may have bcen the saint's reflections, we may be sure the insect has none.

Before going further let us take a thoroughly typical instance of instinctive behaviour, and there is no better than that of the Yucca Moth (Pronuba yuccasella), which has been often cited. When the large yellow bells of the Yucca open, each for a single night, the silvery moth, just emerged from her chrysalis, sets forth to visit them. From the anthers of one she collects pollen, which she kneads into a ball, and holds beneath her head. She flies to another flower, pierces the pistil with her ovipositor, lays her eggs among the ovules, and then places the fertilising pollenpellet in the funnel-shaped opening of the stigma. Without the pollen thus brought by the moth the ovules would not develop. The larvæ of the moth eat a share of the developing ovules, but not more than about half are required. So that both plant and insect are served. In referring to this extraordinary case Prof. Lloyd Morgan writes: "These marvellously adaptive instinctive activities of the $\mathrm{Yucca}$ moth are performed but once in her life, and that without instruction, with no opportunities of learning by imitation, and, apparently, without prevision of what will be the outcome of her behaviour; for she has no experience of the subsequent fate of the eggs she lays, and cannot be credited with any knowledge of the effect of the pollen upon the ovules. The activities also illustrate what is by no means 
infrequent in the more complex instincts, namely, the serial nature of the adaptation. There is a sequence of activities, and the whole sequence is adaptive in its nature."

What are the general characteristics of instinctive behaviour as exhibited by animals like ants, bees, and wasps, of the little brain type?

(1) Instinctive behaviour in its typical form is always specific or particulate. The garden-spider's web is not like the hedge-spider's web; the nest of one wild-bee is not like another's; each wasp has its own victims which it deals with in its own way; the female butterfly lays eggs on specific food-plants which are appreciated not by her but by the future caterpillars; and so on. Another aspect of the particulateness is a certain wooden lack of plasticity.

(2) The routine of instinctive behaviour has often a considerable degree of perfection the very first time, and while it may be improved by practice, it certainly does not require learning or experimenting. In other words, the instinctive behaviour depends upon a hereditary predisposition of the nervous system. Professor Driesch has defined instinctive behaviour as "a complicated reaction that is perfect the very first time", but this inclines to be too hard and fast, for there is a certain amount of individual development in some instincts. None the less Paley expressed one of the characteristics of instinct when he spoke of it as " a propensity prior to experience and independent of instruction". Instinctive behaviour ' just comes' when the organism is exposed to the appropriate stimulation.

(3) The capacity for a particular piece of instinctive behaviour is shared with approximate equality by all like members of the species. All the female spiders of a given species make an equally fine web; all the males an equally inferior 
one. The capacity is often very markedly sex-linked, the one sex doing with perfect finish what the other does not do at all; thus the drones of the bee-hive take no part in combmaking. One must not, of course, suppose that instinctive capacities are not variable; the point is rather that instinctive equipment is much more uniform than intellectual endowment. It may be admitted that part of the individuality of intelligence is due to the fact that intelligence is as much made as born, which brings us back to the contrast that instinctive capacity is much more inborn than made.

(4) Instinctive behaviour is always adaptive to the normal conditions of the animal's life, though it may prove ineffective or misleading in face of peculiar exigencies. It has to do with particular events and circumstances, particular stimuli and configurations, which frequently recur, or, if not, are of vital moment (as in the escape from the imprisoning egg-shell); and a slight change in the conditions is likely to result in extraordinary nonplussing.

A study of these limitations tends to, impress us with the difference between purely instinctive behaviour, and that experimental, inferential, or reflective kind of behaviour which we call intelligent. Let us illustrate.

The veteran French naturalist Fabre, who died in $\mathbf{1 9 1 5}$ at the age of ninety-two, relates that he induced a long file of procession caterpillars to move round the circular parapet of a fountain, and by making the head of the leader touch the tail of the last member formed a living circle which continued for days circumambulating futilely. "They knew nothing about anything." The grub of the mason-bee is hatched in a mortar-cradle with a lid through which it has to cut its way. This it does without difficulty. If the lid be artificially thickened by gluing on a piece of stout 
paper, this makes no difference to the success of the boring. But if a little empty paper box be placed over the lid the grub emerges into this, and having completed the boring part of its inborn routine cannot recommence it, and dies in its paper prison. Limitations of this sort are quite characteristic of purely instinctive behaviour and seem to remove it far from intelligence.

But the rigidity of instinctive routine must not be exaggerated. Professor and Mrs. Peckham have made a careful study of the instincts of wasps, both solitary and social. Several of the solitary forms go through the same general routine, but with interesting generic, specific, and even individual differences. When the female-Ammophila, for instance-is ready to lay eggs, she makes a hole in the ground, closes it up, searches for some kind of prey (such as a caterpillar), stings it several times and pinches it, drags it to the nest, lays it down, opens the nest, drags in the paralysed victim, deposits an egg beside it, and then covers up the bole. On the whole it works like clockwork, but there may be variations and mistakes at every step! Moreorer, in the wasp's routine there is probably help from intelligencein choosing a good site, in adapting the shape of burrow to the soil, in remembering the locality, in biting at the prey to suit the size of hole, and so on.

The general characteristics of instinctive behaviour have been admirably summed up by Prof. Lloyd Morgan. "Instinctive behaviour is that which is, on its first occurrence, independent of prior experience; which tends to the wellbeing of the individual and the preservation of the race; which is similarly performed by all the members of the same more or less restricted group of animals and which may be subject to subsequent modification under the guidance of 
experience. Such behaviour is, I conceive, a more or less complex organic or biological response to a more or less complex group of stimuli of external and internal origin, and it is, as such, wholly dependent on how the organism, and especially the nervous system and brain centres, have been built through heredity under that mode of racial preparation which we call biological evolution" (Instinct and Experience, 1912, p. 5).

It is confusing to use the term instinctive so loosely that it becomes almost equivalent to hereditary or inborn, as in phrases like instinctive pugnacity or instinctive gregariousness, for the usefulness of the term is in reference to specific behaviour. Yet it may be legitimate and useful to distinguish between general instinctive tendencies and specialised instinctive behaviour. A general instinctive tendency is the expression of an inborn impulsion which has not much particular content, such as is shown by mammals who are about to become mothers for the first time, or by an isolated henbird who fumbles at nest-making, or in the so-called 'sexinstinct'. Thus we ourselves have many instinctive tendencies, but few instincts. These general instinctive tendencies are to be distinguished from fundamental appetites such as hunger, and also from general tropisms, illustrated, for instance, when young birds gather under a tea-cosy as under a mother-where we have evidently to do with similar responses to similar stimuli.

\section{§ 9. Theories of Instinct.}

It is too soon to come to any hard-and-fast conclusion in regard to the nature of instinctive behaviour. We have not yet got the facts fully before us, and there is much need of more experimental study. It is almost certain that 
there are different grades of instinctive behaviour. There are three main theories at present in the field. (A) Some investigators rank instinctive behaviour as closely comparable to chains of reflex actions, and as due to non-cognitive hereditary predispositions to follow a certain routine when a number of stimuli present themselves. (B) Others regard instinctive behaviour as quite inseparable from intelligent behaviour. (C) According to a third view, instinct and intelligence are two radically different though often co-operative kinds of knowing, which have evolved along divergent lines.

(A) Some investigators rank instinctive behaviour as near compound reflex actions, as the outcome of non-cognitive hereditary impulsichs or predispositions to enter upon a certain routine when a certain trigger is pulled, and to follow on in a perfectly definite manner, the result of one triggerpulling leading to another trigger, and so on. This may be called the reflex theory of instinctive behaviour, and it is often held by mechanists in the strict sense. It may, however, be held by biologists who admit that vital processes cannot be adequately re-described in terms of chemistry and physics, who are, however, unwilling to admit in instinctive behaviour any reality beyond the physiological processes of the animal's nervous system. We shall call it, therefore, the reflex theory, rather than the mechanistic theory of instinctive behaviour.

Instinctive behaviour agrees with reflex acts in not requiring to be learned, in being dependent on hereditary nervous predispositions, and in being exhibited approximately in the same way by all similar individuals of the species.

It differs from reflex acts in being the activity of the 
organism as a whole and in requiring (with few exceptions) an intact nervous system. It differs also in sometimes having some measure of plasticity or of variability, which is quite unknown in reflex actions. It differs also inasmuch as it does not always consist of acts soon over and done with and attaining a result useful in itself; it is often a unified many-linked concatenation of acts, working towards a distant result. In many of the chains of instinctive behaviour connected with parenthood, the end is very remote, sometimes never experienced; and making a dark burrow in a bank can hardly be its oxn reward. To describe instinctive behaviour as nothing more than a series of intricately dovetailed reflex actions suggests a false simplicityslurring over the characteristic unification or concatenation. Considered physiologically, instinctive behaviour is based on neuro-muscular prearrangements, but to many naturalists it seems impossible to do descriptive justice to what takes place without supposing that the behaviour is suffused with awareness and sustained by endeavour.

According to Prof. W. MeDougall, the higher or more complex instinctive activities are much more than compound reflexes. They are induced not by simple sense-impressions as reflexes are, but by complex groups of sense-stimuli, such as some scene. Thus insects visiting flowers show "a total complex reaction to a total complex sense-impression". There is meaning or significance in it; and a sustaining conation or endeavour.

Prof. Lloyd Morgan holds an interesting view which seems more applicable to the 'big brain' than to the 'little brain' type. Instinctive behaviour he regards as physiologically akin to reflex action; it consists of concatenated reactions of the whole organism. The capacity for this in birds 
and mammals probably has its seat in parts of the brain below the cerebral cortex. But the lower centres stimulate the higher centres and intelligence qualifies the instinctive behaviour.

On Prof. Lloyd Morgan's view, intelligent guidance is the function of the cerebral cortex with its distinguishing property of consciousness; the co-ordination involved in instinctive behaviour, and in the distribution of physiological impulses to the viscera and vascular system is the primary function of the lower brain-centres; in instinctive behaviour as such, consciousness correlated with processes in the cerebral cortex is, so to speak, a mere spectator of organic and biological occurrences at present beyond its control; but, as spectator, it receives information of these occurrences through the nerve-channels of connection between the lower and the higher parts of the brain. Thus instinct and intelligence are different organs, but they co-operate, and as intelligence is kept more or less informed of the steps of instinctive behaviour it is sometimes on the spot to help the animal out if some critical situation arise which the routine-behaviour cannot meet.

Some who think that it is feasible to interpret instinctive behaviour biologically as a concatenation of reflexes are at the same time willing to admit that there may be a psychical accompaniment which does not rise to the cognitive level. Thus Minkiewicz, who has made very important experiments on animal behaviour, regards instinctive performance as implying " a certain low form of unconscious, but none the less purposive psychical activity".

(B) Others regard instinctive behaviour as inseparable from intelligent behaviour. Thus Professor Stout regards instinctive behaviour as being biologically a concatenated series 
of reflex-like actions, dependent on hereditary neuro-muscular prearrangements. Subjectively, however, it shows " conative impulse, unity and continuity of attention, perseverance with adaptive variation of behaviour corresponding to felt success or failure, and, in many cases, the evidence of having learned by experience". "The congenital prearrangements of the neuro-muscular mechanism for special modes of behaviour do not of themselves suffice to explain the animal's conduct. Their biological utility depends from the outset on their operation being sustained, controlled, and guided by intelligent interest in the pursuit of ends." It seems to us that this view fits the blended instincts of birds much better than the pure instincts of bees.

According to Prof. C. S. Myers there is but one psychological function-instinct-intelligence. "In what is ordinarily called instinctive behaviour the innate mechanism is relatively fixed and given; in what is ordinarily called intelligent behaviour the mechanism is relatively plastic and acquired. But I maintain that such differences are only relative and that no mental state (or process) can be spoken of as solely instinctive or as solely intelligent."

(C) A third view, particularly associated with Professor Bergson, regards instinctive behaviour and intelligent behaviour as two quite different kinds of efficiency, implying different kinds of knowing.

If we define intelligent behaviour as that which involves objectively some trial-and-error experimenting and profiting thereby, and subjectively some perceptual inference, we may say that instinctive behaviour differs in being non-experimental (though it may improve as the result of experience) and non-inferential (though not necessarily destitute of awareness). It is the impression of many observers that 
instinctive behaviour differs from intelligent behaviour in the rigidity of the routine and in the absence of awareness of the end to be attained. In intelligent behaviour, as we know it in ourselves, there is an awareness of ends as ends, and there is a power of adapting old means to new ends. But it is only by an argument from analogy that we can speak about absence or presence of awareness, and even in intelligent behaviour the degree of awareness varies greatly in intensity.

According to Professor Bergson, instinct and intelligence differ in kind and have evolved on divergent paths. The ways of ants and bees cannot be described as intelligent. As Prof. H. Wildon Carr puts it, "the fundamental difference lies in the mode of apprehension of reality, and the kind of knowledge that serves the activity of each". "We can never know what this instinctive knowledge is." But we may approach it sympathetically in our power of intuition - " a direct vision of reality that is not clothed, so to speak, with the categories of the understanding". "This reality is the living activity itself apprehended as a real duration."

One of the fundamental sentences in L'Évolution Créatrice is this: "The cardinal error which, from Aristotle onwards, has vitiated most of the philosophies of nature is to see in vegetative, instinctive, and rational life three successive degrees of the evolution of one and the same tendency, whereas they are three divergent directions of an activity that has split up as it evolved. The difference between them is not a difference of intensity, nor, more generally, of degree, but of kind." To this, M. Bergson has, indeed, immediately to add that intelligence and instinct are rarely to be caught pure, for instinct is often accompanied by gleams of intelligence (seen, for instance, when hive-bees nest in the open 
air), and there is no intelligence in which some traces of instinct are not to be discovered.

Intelligence uses unorganised instruments-tools; instinct uses inborn organised instruments. The innate knowledge in instinct is of things, of particular pieces of matter; the innate knowledge in intelligence is of relations, of forms. Instinct implies intimate and full awareness of a particular configuration of things; intelligence makes frames applicable to many things. If instinct has signs or words, they are adherent, "invariably attached to a certain object or a certain operation". Intelligence has mobile signs, which can pass from things to ideas, and this language has been a great liberator. In short, instinct and intelligence are quite different expressions of life. As to the much-debated question whether instinct is conscious or not, Professor Bergson holds that there may be lively consciousness in some cases, and that it may be nullified in others. Consciousness is the light that plays around the zone of possible actions, in the interval between representation and action; it is associated with hesitation and choice. Therefore since there is much choice in intelligent behaviour and little in instinctive behaviour, the latter tends to be less conscious than the former.

The position that instinctive behaviour is on a different evolutionary tack from intelligent behaviour may be defended apart from Professor Bergson's particular view of the difference. When we observe a spider executing an extraordinarily complex and sharply punctuated series of movements which result in a web and doing this effectively the very first time, we seem to be in a world different from that of intelligence. And again when we observe insects continuing to go through a laborious routine which has lost all its point, and from bondage to which the least modicum of intelligence would 
deliver them, we seem to be in a world very different from that of intelligence.

While the frequent limitations of instinctive behaviour seem to us to point to a differentia between it and intelligent behaviour, we find further evidence in considering its achievements in preparing for the unforeseen and remote-for offspring which will never be seen, for the evasion of a winter which will never be experienced. There is an adjustment of means to ends which certainly does not rest on a basis of individual experience. It is possible to say that this organisation for the attainment of remote and unknown ends is the inherited result of an originally intelligent prevision, but there are great difficulties in face of this theory. There is certainly inherited organisation, but there is no evidence that the instinctive behaviour ever passed through an intelligent phase. In simple cases, we can imagine a sort of intelligent argument from analogy: thus the woodpecker-like bird, Colaptes mexicanus, feeds on insects while it can, but stores acorns against the day when no insects will be available. But no analogy can suggest making elaborate provision for offspring that are never seen.

If we rule out the theory that instinctive behaviour has no psychical side, for that is an outrageously false simplicity, we may say that there is a considerable amount of common ground between the various theories. There are plainly two aspects of instinctive behaviour-objective and subjective. There is the hereditary organisation of the nervous system which has been so prepared or evolved that the specific behaviour comes automatically when the organism is appropriately stimulated. But there is also the associated instinctive experience, some degrees of awareness of the situation, some memory of analogous past experiences, some more or less dim 
consciousness of an end. Along with this cognitive factor there is a conative one, a predetermined bending of the constitutional bow in a particular direction. And there may also be, in some cases, an evocation of associated emotions.

According to Professor MeDougall, instinct is a functional unit which is transmitted as such from generation to generation, but it implies the existence in the creature's innate constitution of three things- "first, a specialised perceptual disposition; secondly, a specific conative tendency that is excited when this perceptual disposition is played upon by the appropriate sense-impression; and thirdly, some co-ordinated system of motor channels through which the conative tendency works towards its satisfaction".

Less technically we may say that there is (1) some degree of awareness of what is being done, (2) a feeling of activity and a bent bow, and (3) the constitutionally ingrained linkages which make a chain of reflex-like acts possible.

\section{§10. Evidence of Intelligent Behaviour.}

Especially among birds and mammals we find behaviour which cannot be adequately described without using psychological terms. It implies, objectively, some 'trial-and-error' experiments and profiting thereby, some 'learning' that is more than woodenly associative, something more than the dog's secretion of salivary juice when the dinner whistle is blown. We infer that it implies, subjectively, some perceptual inference, some working with ideas, some appreciation of the relations of things. It is reflective and experimental as contrasted with reflex and instinctive.

The Greek eagle lets the tortoise fall on the rocks so that it is broken, just as the rook does with the fresh-water mussel. The collie anticipates a possible straying of the flock 
and guards against its occurrence. Beavers cut a canal right through an island in a big river-a task not practically justified till it is completed. It is strictly impossible to prove that these animals really put two and two together as we do in perceptual inference, but no less generous interpretation seems adequate.

When Dr. G. T. Romanes's chimpanzee was asked for a number of straws up to five, it used to pick up the required number and present them with the ends exposed between finger and thumb. When it was right it got its reward. Sometimes, however, if asked for four straws, it would gather three to save time and double one of them so that four ends showed. When a reward was refused on such occasions, it would straighten out the doubled straw, pick up another one, and present the required number. In a case of this sort we are inclined to admit intelligence, for it was rather subtle and novel, and we know that the chimpanzee has a highly developed brain.

But pass to one of Miss Drzewina's experiments with hermit-crabs. She removed them from their borrowed shells and gave them similar shells which had been plastered up. The hermit-crabs spent a long time trying to get into these closed shells. Eventually, however, they gave it up as hopeless, as of course it was. When some shells of the same sort, but empty, were put into the aquarium the hermitcrabs would not look at them. The established association was too strong. Yet when some other shells of a different shape were introduced, the hermit-crabs tried them at once. The question is whether this also was intelligent behaviour, or whether it illustrated what we do not understand, a profiting by experience on a lower than an intellectual level, such as must form the basis of the very effective agency of the 
brainless, ganglionless starfish already referred to. And our inclination to be parsimonious in our interpretation is of course strengthened by the fact that the hermit-crab belongs to the 'little brain' type of organisation on quite a different line of evolution from Vertebrates. Many spiders are readily deceived if a vibrating tuning fork is brought near their web. They rush out to deal with the situation-responding to the familiar tremor stimulus. They may be cheated over and over again. In one case, however, after a tantalising deception extending over fifteen days, the spider ceased to give any attention to the tuning fork. The question is whether we must in such a case postulate memory and perceptual inference, or whether some purely physiological interpretation is adequate. Thus the 'getting used to' a stimulus may be in some cases due to fatigue, in the wide sense, including dulled sensation. Our inclination to a parsimonious interpretation in such a case as this is strengthened by the fact that even brainless and ganglionless animals illustrate a modification of activity by individual experience. Repeated stimulation alters 'the physiological condition' of an animal so that it gives an intensified reaction to a moderate stimulus, as in the case of an earthworm that has been teased a little. Contrariwise, repeated stimulation that leads to nothing may result in the suppression of a reaction, as in sea-urchins that soon stop answering back to fruitless changes in light and shade, or in sea-anemones that cease to respond to the touch of false food. Even the carnivorous plant, Venus's Fly Trap, refuses to be duped many times in succession.

One of the marks of intelligence is profiting by experience -learning. At a lower level there is temporary modification of behaviour, and this passes, insensibly we think, into last- 
ing modification. A crab or a crayfish learns in a week or two to distinguish infallibly between the right way and the wrong way to food and freedom. How far down this capacity extends we do not know; perhaps it requires a nervous system of considerable complexity. If we obey the law of parsimony, we are led to the conclusion that the creature under sufficient stimulus of reward and "of shortening a period of unpleasantness and unrest", forms a habit without 'knowing how', though probably with high-strung attention and delicate quivering sensitiveness, and precise registration of sequences of movements; and that after the trick has been learned it trusts itself, as a piano-player does who learns in quite a different way. Miss Washburn notes that "an animal that has gone astray on the path will often find the way back to the starting-point, and from there traverse the whole road rapidly and unerringly, apparently in the same way that a piano-player who has a piece "at his fingers" ends", but has stumbled in a passage, can go through with entire success if he starts over again. As piano-players know, in such a case it is much better not to attend to stimuli at all, but to think of something else; the movements will take care of themselves better if consciousness intervenes as little as possible" (1909, p. 231).

Many experiments have been made with rats, dogs, cats, chicks, and other creatures, which learn in the course of time to find their way out of labyrinths and puzzle-boxes. After some practice they are left in peace for a few days and then replaced in the previous situation. It is observed that they make fewer useless movements, that they sometimes make none. The question is whether ideas are at work, whether the creatures think. Have they remembered images of their successful movements, or do they obey the prompt- 
ings of an organismal registration in which ideas have not been involved?

In her admirable book on The Animal Mind, Miss Washburn points out that images of a Hampton Court maze are difficult, and that the slow learning and the nature of the mistakes do not suggest working with ideas. Similarly, in regard to puzzle-boxes, she says that the slow learning, by gradual elimination of useless movements, suggests the absence of any guiding idea of the action, and Professor Thorndike, who initiated these experiments, corroborates this view by pointing to the entire lack of inferential or reflective imitation. That is to say, the successful behaviour of companions does not seem to be suggestive. But other observers, such as Professor Hobhouse, have come to the opposite conclusion, and in any case, as has been well said, "We cannot conclude that an animal is incapable of ideas because it does not have them suggested to it under circumstances that would suggest them to our minds."

\section{§11. Secondary Simplifications of Behaviour.}

The difficulty of understanding animal behaviour is increased by the occurrence of secondary simplification. We are familiar with this in the individual habituation of exercises which originally required attentive selection and detailed control. What required conscious regulation from step to step becomes ' automatic', requiring very little attention, and the objective side of this is believed to be the establishment of nerve-paths of least resistance, of linkages such that one phase of the behaviour automatically evokes the next. One of the features is the dropping out of what is called implicit behaviour, a common name for the movements, too slight for detection, which seem at first to inter- 
vene, e.g., in type-writing and piano-playing, between the external stimulus and the overt reactions when more than a single reflex is involved.

There is not at present any convincing evidence that the direct results of habituation can be as such entailed on the offspring, and there are few available facts in support of the theory once widely held that instinctive predispositions to go through a certain routine are the hereditary results of the habituation of what was originally intelligent. That the instinctive capacities are inborn is certain, but it does not follow that they have been due to 'lapsed intelligence'. At the same time, it is a fact of observation that the individual performance of a piece of instinctive routine may bring with it an increased perfection.

It is very interesting to find that particular reactions periodically repeated may take such a grip of the individual constitution that they are exhibited even in the absence of the liberating external stimulus. It is probable that this implies, in part at. least, that long continuance of external periodicities has established internal rhythms in some important part of the metabolism of the individual creature.

In the simplest forms of behaviour, which imply little more than a co-ordination of a series of reflexes towards a desired result, there must also be organic registration. This is shown by the simple experiment of putting a starfish on its back, for it learns to right itself more and more quickly as time goes on. Although its effective behaviour is not instinctive, for it has to be learned, nor intelligent, since there are no nerve-ganglia, it improves with practice.

We shall return to the subject when we come to discuss the evolution of behaviour, but in the meantime we notice the suggestion that it is, metaphorically speaking, part of the 
tactics of Animate Nature to economise mental activity for higher issues by a structural organisation or registration (badly called mechanisation) of capacities for effective agency. Thus instinctive capacity being a substitute for instruction may make emancipated experiment practicable, as birds well illustrate.

\section{§12. Rational Conduct.}

In the case of man, and probably in his case only, there is sometimes evidence of rational conduct as contrasted with intelligent behaviour. We cannot describe such conduct without using general terms; we know personally that, like original thinking, it involves experimenting with abstract ideas; it implies conceptual as distinguished from perceptual inference; it is controlled in reference to an ideal or purpose. Wo wonder whether even at this level there may not be a continuance of the organisation-process, for mathematicians of distinction and other original thinkers assure us of the reality of unconseious cerebration, and the absolute trustworthiness of the immediate ethical judgment of fine characters may be another illustration in a different field. There is an assured immediacy of reaction in many cases that makes the ordinary person marvel, and leaves the moral genius free to tackle more difficult problems.

\section{§13. General Impressions of Animal Behaviour.}

What we see is like a great staircase, exhibiting wonderful perfection at different levels, such as those of tropisms, instincts, and intelligence. We may distinguish a main line of experimenting, 'trial and error', and initiative from the side lines in which organisation or automatisation of behaviour predominates over immediately controlled direction. 
But while there is a hierarchy of activities, the diverse modes often overlap. Just as the surface relief of a countryside may show in one feature the outcrop of various strata of very different geological age, so in an animal's behaviour there is often a mingling of different kinds of activities unified in a way that baffles analysis. Instinct concatenates reflexes, and intelligence catches up tropisms. Instinctive capacities may form a basis for an advance in intelligence; and intelligently controlled behaviour may sink into habit. We have to distinguish in general $(a)$ the ingrained or entailed hereditary capacities of responding effectively to certain stimuli, circumstances, and situations; $(b)$ the individual tentatives, selections, adjustments, and 'learning' which seem to many to imply some degree of awareness or pre-awareness and some conative element; and $(c)$ the individual retention and registration of experience which facilitates for the individual the rapid repetition of effective reactions.

Our survey suggests some general impressions:-(1) The first is a deepening of rational wonder before the extraordinary variety of ways in which living creatures express themselves, assert themselves, enjoy themselves, and bend the Titan of the inorganic to their indomitable endeavour. An unsophisticated but shrewd observer of Nature once said that he could not understand a man intelligently watching an anthill and remaining irreligious.

(2) The second is an impression of the pervasiveness of a kind of behaviour which, considered objectively, is closely analogous to what we know in our case to be associated with intelligent control. The inference, which does not admit of direct verification, is that consciousness in some form is pervasive. We cannot well describe the behaviour of even 
brainless animals without using words like selecting, trying, learning, and profiting by experience. We cannot demonstrate the existence of consciousness in the lower animals, but, as Professor Jennings observes, "objective investigation is as favourable to the view of the general distribution of consciousness throughout animals as it could well be" (1906, p. 337). "So far as objective evidence goes there is no difference in kind, but a complete continuity between the behaviour of lower and of higher organisms" (1906, p. 335). We start at one end with our own doings, in some of which intelligence counts, we pass gradually, though never perhaps by rigid demonstration, through the behaviour of our fellows, our horses and dogs, birds and fishes, spiders and hermit-crabs, ganglionless starfishes and sea-anemones, to the extraordinarily puzzling condensed individualities of Infusorians and Amœbæ. Nor will it be easy to shut out carnivorous plants and others that stir themselves in what seems to us a sleep-life, whose dreams are flowers. At all levels of organisation we find behaviour which, objectively considered, is like our intelligent behaviour. We know that in many cases the creatures are not so clever as they look, and we do not know of any way of proving that mentality pervades it all. But it is impossible to think of intelligently controlled behaviour evolving from behaviour in which mentality was wholly absent, and it seems clearest to think of all organisms as psycho-physical individualities.

(3) Third we get a vivid impression that the realm of organisms stands out in strong relief against the inorganic background. The not-living world is a domain of mechanical necessitation, without initiatives; a domain of uniformities, without alternatives; a domain of absolute determination, without spontaneity; a domain where there is no individu- 
ality, and therefore no behaviour. It is an interesting point that the rare occasions on which one applies the term behaviour to a not-living thing are when one is dealing with something like a ship to which man has given a quasi-individuality.

(4) Perhaps the most important question before us is whether the behaviour of organisms has any real spontaneity, precluding or limiting the possibility of prediction, or whether the suggestion of spontaneity is fictitious and due to the complexity of the conditions. It was once true to say that the wind bloweth where it listeth, but now the meteorologist tells us whence it comes and whither it goes. Are we, in our ignorance or obscurantism, postulating for the living creature a spontaneity and unpredictability such as our forefathers believed to be exhibited by the wind? This is the problem of biological determinism, analogous to the problem of psychological determinism and free will. We venture to say just a little on this difficult problem.

As we ascend the scale of being there is a growing amount of experimental indeterminism. An organism is free as compared with a not-living system. When we begin experimenting with a starfish, we cannot tell what it will do in the various situations in which we place it, but after we have experimented for a long time we can tell what the starfish we have worked with will do under certain circumstances, provided always that we know its 'physiological condition'. For a hungry animal does not behave as a full-fed one does. But when we are rash enough to make a prediction in regard to the behaviour of a fresh starfish, of the same kind and weight and size, we are very likely to be very far wrong. Why is this? It is otherwise in the inorganic world, where we can safely argue from one thing to another thing of the 
same kind. The difference is not one of complexity, but of kind. The starfish is not mechanically necessitated to act as it does; it often checkmates mechanism. Even when we say that it is coerced by its own brainless constitution we must remember that it was itself in some degree an agent in establishing that constitution.

Similarly, an animal with a big brain, i.e., a welldeveloped capacity for intelligent behaviour, is free compared with a starfish. By careful study we may reduce the experimental indeterminism and predict with some success what our dog will do in a particular situation. But we are likely to make a bigger mistake than we made with our starfishes if we argue from our dog to our neighbour's. For why, the individuality of the dog is so much greater than that of the starfish. The details of its behaviour are determined much less by its general constitution and much more by the character which it has itself been an agent in building up. Thus we see in the realm of organisms a ladder of emancipation-the evolution of free-will.

The impression which we get from the study of even starfishes seems to us to hold for the whole realm of Animate Nature and for ourselves in it. We find neither systems of absolute determinism nor 'miscellanies of miracles', but systems in which determinism and freedom are both illustrated, sometimes more of the one and sometimes more of the other. The enregistrations within an organism limit its actions within certain trammels; the reflexes, the tropisms, the instincts, the hereditary appetites are all determinist in effect; but our conception of the typical organism is not complete unless we recognise its possibilities of initiative and experiment, of trial and error, of choice and control. Perhaps we may profitably continue into the realms of ethics 
and religion this compromise between determinist and freewill interpretations which biology suggests.

\section{SUMMARY.}

Only in the realm of organisms is there true behaviour-in which the creature is an agent and exhibits a correlated or coneatenated series of acts, effective towards some definite result favourable to the harmony of vital processes and the continuance of the race.

Among unicellular or non-cellular organisms there is often a restless locomotor activity, hardly on the level of behaviour, which is sustained by the everyday internal functions and is not very clearly separable from them. There are also definite organic reactions to all sorts of stimuli except sound waves, corresponding in a far-off way to reflex actions in higher animals. In difficult situations there may be a trial-and-error procedure, a selection of the fittest answer and a short-lived modification of behaviour in relation to experience. As Professor Jennings especially bas shown, there is among the simplest animals the counterpart of intelligent behaviour.

Of great interest is the shell-building of some of the arenaceous Foraminifera, where particular materials, such as sponge-spicules, are selected from amid an embarrassment of alteruatives, and where the selected material is utilised in a particularly effective way.

Reflex actions are usually movements of parts, uniform reactions to a particular kind of external or internal stimulus, exhibited approximately to the same extent by all animals of the same kind, and depending on inborn structural linkages of nerve-cells and muscle-cells. But reflexes, though not alterable by experience, are sometimes controlled by what looks like some appreciation of eireumstances. 'Chain-reflexes' are often broken.

Another simple form of animal activity is seen in tropismsmore or less obligatory movements, like the moth's to the candle, which automatically tend to secure physiological equilibrium in reference to particular stimuli. But the tropistic coercion is sometimes successfully thwarted by individual experiment on the part of the organism.

One of the most important results of recent studies is the proof that many brainless and even ganglionless animals, such as starfishes and sea-urchins, exhibit a counterpart of the intelligent be- 
haviour of higher animals. They show a 'trial-and-error' method, a selection of regulatory responses, and, for a short time at least, a profiting by experience. There is experimenting below the level of perceptual inference.

Among the more complex animals there seem to be two distinct modes of effective behaviour, namely, instinctive and intelligent behaviour. The former finds its finest expression in the 'little brain' types, such as ants, bees, and wasps; the latter in the 'big brain' types, such as birds and mammals. Each mode has its excellencies and its limitations.

Instinctive behaviour agrees with reflex action in being dependent on a hereditary nervous predisposition characteristic of the species, but it is a concatenated series of correlated acts of the whole creature. There is a hereditary awareness of the practical significance of certain things and configurations, and a hereditary impulsion to a precise routine. The capacity may be improved by experience, but it is to some degree independent of individual learning. It is not experimental, inferential, or reflective like intelligent behaviour, and has very striking limitations. It is often linked with intelligence, especially in the 'big brain' types, such as birds.

As regards the nature of instinct, there are three main theories at present in the field, between which it is too soon to decide dogmatically. (A) Some investigators rank instinctive behaviour near reflex actions, as due to non-cognitive hereditary predispositions to follow out a certain routine when a number of triggers are pulled. (B) Others regard instinctive behaviour as quite inseparable from intelligent behaviour. (C) According to others, instinct and intelligence are two radically different, though often co-operative, kinds of knowing, which have evolved along divergent lines.

Among birds and mammals, in particular, there is evidence of intelligent behaviour. It implies, objectively, some 'trial-anderror' experiments and profiting thereby. It implies, subjectively, some perceptual inference. It is reflective as contrasted with instinctive.

As is well known, a secondary simplicity often comes about in the individual lifetime, when what originally required attentive selection and detailed control becomes habitual. But it is not known to what extent, if any, the results of habituation can be entailed on the offspring. It seems at present improbable that instincts can arise in this way. Yet, as will be seen later on, it seems to be part of the tactics of Animate Nature to economise mental activity 
for higher issues by a structural organisation (badly called mechanisation) of capacities for effective behaviour.

In the ease of man there is evidence of rational conduct on a higher level than intelligent behaviour. It implies conceptual as distinguished from perceptual inference, and is controlled in reference to general ideas, 'values,' or conscious purpose.

Four general impressions stand out:-(1) The extraordinary variety of ways in which living ereatures express themselves, assert themselves, and bend the Titan of the inorganic to their endeavour. (2) The pervasiveness of mentality at all levels of organisation. (3) The growing scope of spontaneity and individuality as we ascend the series. (4) A gradual emancipation of the organism from environmental coercion. 
LECTURE VII.

THE PROBLEM OF BODY AND MIND. 



\section{LECTURE VII.}

\section{THE PROBLEM OF BODY AND MIND.}

§1. The Approach to the Problem. §2. What Must Be Recognised from the Biological Side. §3. What Must Be Recognised from the Humanist Side. §4. Various Theories of the Relation of 'Mind' and 'Body'. §5. Monistic Speculation along the Line of the Double-Aspect or Correlation Theory.

\section{§1. The Approach to the Problem.}

IT is with a heightened senso of responsibility that we turn to the ancient problem of the relation of body and mind. But it is a question in regard to which the biologist has something to say, and it cannot be evaded in a study of Animate Nature nor in prolegomena to a philosophy of Animate Nature. By the latter we mean a consistent thinking together of what we know and feel about Animate Nature along with what we know and feel about other orders of facts.

As the view to which a biologist is most naturally led may seem, at first sight, disappointing, and may even be misunderstood as a capitulation of the citadel of personality, we would plead that after we get past what seems to most thinkers the quite untenable position of crude materialism, with its Gothamite metaphysic, and what seems to most scientific workers the quite untenable position of subjective idealism, and the theory of epiphenomenalism, which is materialism in modern garb, the conclusion we come to does not imply any practical depreciation of the reality of the bodily system and activity on the one hand, or of spiritual 
values and the thought-life on the other. If we avoid the three fatal errors of false simplicity just mentioned, it is not perhaps of great moment what theory-monist or dualist, parallelist or animist-we are led to adopt. We must choose the interpretation which is most consistent with the rest of our thinking and experience.

What is familiar ground to the expert philosopher is full of pitfalls alike to the biologist and to the man in the street, and we probably do well to remind ourselves that the way we put the question of the relation between mind and body may be misleading. It is often asked: Is the body the real thing and the mind a derivative illusion? Or is the mind alone real and the body in some way dependent? These questions are badly put, for both bodily activity and the thought-life are real. A conviction of the actuality of the body as an agent to be reckoned with need not imply that the mind is in any way illusory. Nor need a conviction of the reality of the mind, readily reached by any one who has ever made up his mind, imply that the body is not substantial and effective. The practical truth is, that what we call the mind counts, and that what we call the body counts; or perhaps that what counts is body-mind or mind-body. So far there is general agreement. But are there two distinct and disparate real activities - a player and an instrument, so to speak, or is there one order including both bodily and mental processes, metabolism and awareness of meaning? Is there interaction of two orders of being, or correlation within one order? (See Lloyd Morgan, 1915, p. 6.)

We know ourselves by our senses as organisms; we know ourselves also as thinking, feeling, purposing, endeavouring beings. For immediate experience there is unity. For scientific purposes, however, it seems almost necessary to 


\section{THE PROBLEM OF BODY AND MIND}

separate off the two aspects, or processes, or systems, and the problem arises how we are to think of them in relation to one another. But the fact is that 'body' and 'mind' are alike abstractions. Prof. A. E. Taylor has said: "The severance of the original unity of experience into a physical and a psychical aspect is entirely a product of our own abstraction-making intellect. 'Body' and 'Soul' are not given actualities of experience, but artificial mental constructions of our own" (1903, p. 314).

Yet here again, while many of us are impressed in our experience with the inter-dependence rather than independence of these "two aspects" - bodily and mental—we must admit that we do not find it an easy task to explain what we mean by the phrase "two aspects" in this particular connection. The words do not seem to grip.

In stating the problem Prof. Lloyd Morgan takes the case of the processes involved in seeing a candle. The rays of light affect the receptors of the retina, a physical relatedness $(a)$, but as the stimulus passes by optic neurones to the visual centre in the occipital lobe of the cerebrum, there is a superadded physiological factor $(b)$, so that the entire process may be called $a b$. But if we definitely take note of the candle and adjust ourselves deliberately to it there seems to be a third kind of relatedness, a psychical process, so that the whole process may be called $a b c$. We have thus (1) the receptors in physical relation to the physical object; (2) the visual centre in physiological and physical relation to the receptors and through them to the object; and (3) something in psychical relation in some way to the visual centre, and through it to the receptors, and ultimately and essentially to the candle as representing the external world. This something we call the mind.

(1915, p. 4) . . 
"The mind is somehow a mid-term receiving messages from the object in the external world and issuing messages to the organs concerned in behaving appropriately to that object. Whenever the mind is thus effective in guidance we have what we called $a b c$-process. The distinguishing feature in such guidance is a context of meaning within a sphere of interest." Using the term mind in this sense, we have to consider its relation to the processes that go on in the cortex of the brain, and, anticipating our subsequent discussion, we may say that there are two main views. "According to the first there are two radically distinct and wholly disparate orders of being-the mental order and the physical order," which interact. "According to the second there is only one order within which there are distinguishable types of relatedness and of process, e.g., physical, physiological, and psychical. Any given term may be coincidentally related to other terms in these severally distinguishable ways. This is the $a b c$-interpretation already suggested." On the second view the $c$ process is always correlated with $a b$ processes; on the first view the $c$ process is independent of any physiological correlate.

\section{§2. What Must Be Recognised from the Biological Side.}

It is possible, as we have seen, to apply to a living body many of the methods of chemistry and physics, and to give chemical and physical descriptions of isolated observèd processes. The more that is done, the more will the distinctively vital stand out in relief. If it can be shown that the balsam's jerking out of its seeds admits of complete mechanical description in terms of tensions, elasticity, and the like the more obvious will be the distinctively vital factor in the sundew's fly-catching successes. But no adequate chem- 
ico-physical deseription has yet been given of any distinetively vital process. A new aspect of reality wells up within organisms, which are material systems none the less, and we require new concepts for its deseription. Even in their simplest forms organisms are integrated systems, eapable of unified regulatory action and of registering experiences.

But just as the mechanieal description has its limitations, so is it with the biological. In our study of Animal Behaviour we have seen evidence of the gradual disclosure of another aspect of reality which transeends the biological. Mentality wells up from the spring. It appears at first in traces only, so that we are not quite sure whether it is there or not, just as it is not very easy to be sure whether a calcareous Alga, or a dormant chrysalis, or a hibernating snail is living or not. But by and by there is a copious flow, and we have no hesitation in saying that the rook or the parrot, the dog or the elephant, has a mind of its own. The student of science is organically more interested in establishing the fact that the study of living things requires concepts which are not needed in the study of the heavenly bodies, than in a discussion of what, in principle, is meant by Life. Similarly he is more interested in establishing the fact that the study of animal behaviour-and not in its higher reaches only-requires concepts which are not needed in the study of the everyday functions of the body, than in a discussion of what we mean by Mind. But we cannot be satisfied without at least facing the old problem of the relation between body and mind. It is in reality a metaphysical question, but the metaphysical interpretation must be consistent with what we know of the facts, and we shall begin by stating what must be recognised from the biological side. 
Our theory of the relation of mind and body (if it be a relation) must be consistent with what we know of individual development. The intelligent mammal begins its individual life as a pinhead-like cell, and for a long time it must be admitted that psychological methods or formulæ are quite inapplicable. The developing ovum of a rabbit (fide Brachet) can go on developing for some time outside of the maternal body,-it is a self-contained implicit organism. We do not understand how it is managed, but it has born with it the potentiality of the big brain and the intricate behaviour. There is a gradual emergence of reflexes, of tropisms, of spontaneous exertions, of experiments, of learning, of putting two and two together, of clever behaviour and, in man, of occasional wisdom. In our own case we are sure that as the minute structure of the cerebral cortcx increases in complexity, the child becomes more intelligent; as the child becomes more intelligent, the cerebral cortex increases in complexity. Not a single nerve-cell is added after birth, but the inter-relations between the cells increase in number, and the brain becomes' a labyrinth. There are no new nerve-cells, but there is normally no lack of new ideas in the growing boy.

(b) Our answer to the body and mind problem must be consistent with what we know of the historical facts. In the course of evolution the nervous system has become gradually more complex and behaviour gradually more masterly, wider in range, more fertile in resource. We do not wish to make too much of the nervous system, for the method of trial and error, for instance, is practised by animals with no nervous system at all, and a very den̉nite capacity for learning may be exhibited by an animal, like a starfish, without a single ganglion in its body. But when we have 
made this admission we must advance to the other fact that evolution of brains and evolution of behaviour have proceeded hand in hand, in intimate correlation.

(c) The theory we frame as to the mind and body relation must be consistent with the fact of their functional interdependence. We express one side of this inter-dependence when we say, "the spirit is willing, but the flesh is weak", which suggests the picture of a worn-out instrument unequal to the player's demands. We express another side of the inter-dependence when we say of our friend that "he died in his prime, of a broken heart, having lost interest in life", which suggests the picture of a strong organisation or society crumbling away because of the resignation of one who was its heart and soul.

A large and a complex brain among Vertebrates is correlated with a dominance of intelligent behaviour. The more convolutions the greater the fulness and freedom of life. An intricate brain among Arthropods is correlated with subtlety of instinctive behaviour. Thus an important part of the ant's brain is big in the worker, smaller in the queen, and almost absent in the drone. Retardation or warping of the development of the nervous system is associated with enfeeblement or disharmony of mental life. Fatigue, or poisoning, or degeneration of the nervous system has its mental correlate. Injury to particular areas of the brain may bring about specific changes in behaviour, e.g., disorders of speech. It seems, for instance, that an area at the base of the third convolution on the left side of the brain is the seat of the impressions and processes associated with remembrance of the movements of articulation; that an area affecting the first and second left temporal convolutions is similarly associated with memory of the sound of 
words; that an area at the posterior part of the second parietal convolution on the left side is similarly associated with visual images of words and letters (see Bergson's Creative Evolution).

The senescence of the worker hive-bees after their all too strenuous short life is correlated with observable fatiguechanges in their brains, and the influence on the human nervous system of degeneracy of the thyroid gland is correlated with the semi-idiocy of cretinism. There is no question-begging in giving these illustrations of the way in which our mind's activity and development are bound up with the health and development of the body, for it is quite open to any one to hold that the brain, for instance, is the instrument in and through which the mind realises its desires and ideals. "It may be held also," an expert psychologist writes, "that the gradual failure of powers with old age or the temporary failure with illness or fatigue -failure which, though primarily physical, seems to reach to the very core of the mind's being - is defect not of the player, but of the instrument on which he plays, and through which alone his genius ean find fitting expression " (J. L. McIntyre; Hastings' Cyclopadia, vol. x, p. 778). Our present point is simply that, whatever be our theoretical interpretation, it must do justice to the facts of correlation. For whatever theory we adopt, these facts remain.

\section{§3. What Must Be Recognised from the Humanist Side.}

In pondering over the body and mind problem we must never lose sight of the supreme reality of ' mind'. We need not dwell on the fact that we do not know anything of $\mathrm{Na}$ ture save in the selective mirror of our minds; it is more important to insist on the positive reality of the thought-life, 
the most real fact in the world. There must surely be some bungling with words when the distinguished physiologist Prof. Jacques Loeb speaks of our existence being "based on the play of blind forces and only a matter of chance", and of ourselves as " only chemical mechanisms". Ideas are not impalpable will-o'-the-wisps, they have hands and feet. "My mind to me a Kingdom is," not a dispensable emanation suspended tremulously over the physical, like the heathaze over the cornfields. The starry firmament on high is scarce more awe-inspiring than the spiritual edificescientific and ethical, artistic and religious-which man has built outside himself. Neither in peace nor in war can we ignore the larger values of the true, the beautiful, and the good without imperilling body as well as soul. Whatever theory we adopt about body and mind-monist or dualist, correlationist or interactionist, organicist or animistthese facts remain.

One of Darwin's services was to show man's solidarity with the rest of creation, his affiliation to a mammalian stock. That this was a very important contribution to human thought is recognised almost unanimously, and no one any. longer dreams that the dignity or value of a result is affected by the historical conditions of its becoming or evolution. Yet it seems fair to point out the risk, that focussing attention on the rock whence Man was hewn and the pit whence he was digged, may lead to an under-estimate of the apartness and uniqueness of Man as compared with the rest of creation. He is separated off by reason or the power of conceptual inference, by morality or the habit of controlling his conduct in reference to ideals, by the possession of true language or Logos. Man was the greatest of mutations -a new synthesis; and it is certain that in him organismal 
individuality finds a new and finer expression which we call Personality.

\section{§ 4. Various Theories of the Relation of 'Mind' and 'Body'.}

To the question how we are to think of our thought-life and our brain-life in relation to one another at least seven answers have been given, but we noed not give all of them the same amount of attention. Two of them fall if we conclude, as we have done, that mechanistic formulation does not give an adequate account of the world of organisms. These two are (I) thoroughgoing materialism, and its modern representative, (II) epiphenomenalism. (I) According to thoroughgoing materialism, mind is fictitious and the only realities are matter and motion. Sensation, according to Hobbes, is nothing but motion; and the brain, according to Cabanis, secretes thought as the liver secretes bile. To this it may suffice to answer that the mechanical theory of organisms breaks down; that we cannot satisfactorily explain our thinking in terms of laws of matter and motion which are the results of our thinking; and that we cannot think clearly to ourselves the proposition that mind is a function of the brain, or that the motion of particles produces the emotion of joy.

(II) According to Huxley's epiphenomenalism, the stream of consciousness is like the chain of foam-bells on the river, called into existence by the real physico-chemical processes in the brain, and ceasing as these cease. The real causal sequence is to be found in the neuroses which are assumed to admit of mechanical formulation; the sequence of psychoses is due to that of the neuroses, for the elements of consciousness have no influence either on one another or on the activities of the creature. The psychoses are the 
shadows cast by the vanes of the cerebral windmill, or the creakings of the machinery, or at the best the electrical sparks which accompany the friction. There may seem to be two watches, but only one is going (the brain); when the going watch ticks there is an echoing tick in the other; nay more, by induction the going watch may cause movements of the hands of the watch which only seems to go. Perhaps the most generous image is, that the elements of consciousness are the short-lived foam-bells on the wonderful current of cerebral processes.

We cannot accept this view because it is wrapped up with the mechanistic hypothesis, because it hands over the reins of life to matter and motion, becausc it denudes the thoughtlife of all reality. When biologists become preoccupied with the psychical concomitants of blots in the brain, or with the localisation of particular mental functions in particular areas in the cerebral cortex, they are apt to lean towards epiphenomenalism, but this has to be corrected by trying to see life whole.

The epiphenomenalist theory (which regards mentality as a negligible phosphorescence of life) is to be rejected on common-sense grounds because we are sure that in human life consciousness and awareness of meaning count for much. It is rejected by most biologists because they cannot evade the conviction, we can hardly say conclusion, that mentality is pervasive throughout.all creatures that exhibit genuine behaviour, associative memory, and profiting by experience; and because they find it difficult to believe in the elaboration and persistence of what is, on the epiphenomenalist theory, a useless by-play, counting for nought. And if it be asserted that the persistence and evolutionary elaboration may be accounted for because consciousness is the inevitable 


\section{8}

\section{THE PROBLEM OF BODY AND MIND}

by-product of the all-important inter-relations of nerve-cells, then we have slipped back again into the slough of materialism. And it does not seem unfair to put to those who say that thinking is only the phosphorescence of an exuberant cerebral metabolism, the question, "What, then, must the theory of epiphenomenalism be held to be? A will-o'-thewisp looking at itself?"

Against the theory that the mind does not count let us note the opinion of Professor Sherrington, one of the most distinguished investigators of the nervous system. In his important book The Integrative Action of the Nervous System, he says: "The concomitance between certain nervous reactions and psychosis seems an alliance that strengthens the restless striving of the individual animal which is the passport of its species to continuance of existence" (p. 333). . . " "Certain it is that if we study the process by which in ourselves this control over reflex action is acquired by an individual, psychical factors loom large, and more is known of them than of the purely physiological modus operandi involved in the attainment of the control" (p. 390).

Only in the analytic laboratory or systematic museum can we rest satisfied with a view of Animate Nature which maintains that mind does not count. By sympathy if not by science we are sure that to leave mind out is a travesty of the facts. Especially in its higher reaches, life is suffused with feeling and meaning.

In his Birds and Man Mr. Hudson tells of what his brother once saw on a lonely sheep-farm on the southern frontier of Buenos Ayres. "Immense numbers of upland geese in great flocks used to spend the cold months on the plains where he had his lonely hut; and one morning in 
August in the early spring of that southern country, some days after all the flocks had taken their departure to the south, he was out riding, and saw at a distance before him on the plain a pair of geese. They were male and female - a white and a brown bird. Their movements attracted his attention and he rode to them. The female was walking steadily on in a southerly direction, while the male, greatly excited, and calling loudly from time to time, walked at a distance ahead, and constantly turned back to see and call to his mate, and at intervals of a few minutes he would rise up and fly, screaming, to a distance of some hundreds of yards; then finding that he had not been followed he would return and alight at a distance of forty or fifty yards in advance of the other bird, and begin walking on as before. The female had one wing broken, and, unable to fly, had set out on her long journey to the Magellanic Islands on her feet; and her mate, though ealled to by that mysterious imperative voice in his breast, yet would not forsake her; but flying a little distance to show her the way, and returning again and again, and ealling to her with his wildest and most piercing cries, urged her still to spread her wings and fly with him to their distant home.

"And on that sad, anxious way they would journey on to the inevitable end, when a pair or family of carrion eagles would spy them from a great distance-the two travellers left far behind by their fellows, one flying, the other walking; and the first would be left to continue the journey alone" (Birds and Man. 2nd Ed., 1915, p. 214). The realm of animal life is crowded with this sort of thing.

(III) Also to be rejected is subjective idealism, which is the extreme antithesis of epiphenomenalism, and finds nothing real but the routine of personal conscious experience. 
This amounts to a denial of the existence of the physical world and of the possibility of science; it is the non-possumus of solipsism.

(IV) A fourth view-common as a working-hypothesis at least-goes by the name of psycho-physical parallelism. It admits the reality of both mental and cerebral processes, but regards them as concomitants merely, without interaction, two parallel causal chains, each complete in itself. We may think of two watches tied together, keeping perfect time, but constructed on different principles and using dif. ferent notations. This view was subjected to what seems to us destructive criticism in Professor Ward's first course of Gifford Lectures on "Naturalism and Agnosticism"; but it is still held by some psychologists of distinction, either simply as a convenient way of formulating the facts, or with a metaphysical theory behind it-namely, an idealistic view of material phenomena.

Besides psycho-physical parallelism there are in the field three possible theories. One is much favoured by philosophers-(V) the theory of psychical monism. Another view, (VI) the soul-theory or animism, does not seem to be favoured by many philosophers or by many scientific investigators, but may be true for all that. The remaining theory, much favoured by biologists, is (VII) the two-aspect or identity hypothesis. It seems to us that each of these theories has its particular advantages and its particular difficulties, and that a decision must at present be left with the individual according to his personal experience. In our judgment the biological facts mostly favour the two-aspect theory, but we have no assurance that it is the most valid.

(V) Psychical Monism. 'According to the doctrine of psychical monism, conscious process is the only reality, and 
though what we call physical objects and physical processes are also real, they owe their reality to being conscious processes or activities in disguise. We can formulate physical processes as if they consisted of the movements of bodies, but our formulation is purely symbolic. There are no things that move, nor things that have potential energy, there are no individualities outside the conscious stream. Things vanish away; things in themselves are regarded as mental in their nature. Needless to say, students of science are rarely attracted to this view. But it is to be suspected that the provocation to antipathy is in part due to confusing metaphysical and scientific language.

(VI) Animism. Of all the theories of the psycho-physical relation the oldest and perhaps the most attractive is animism, the soul-theory. In its clearest form it maintains the actuality of the soul as an embodied psychical being, which realises itself in interaction with the bodily organism. The soul is, apart from the bodily organisation, the ground of the unity of consciousness; it makes sensation, meaning, endeavour, and guidance possible. Its relation with the body is reciprocal, for while it controls the body, the bodily processes supply to it the content of consciousness. Interacting with the body, it develops into the centre of personality. It may conceivably attain to an existence independent of the life of its partner.

On Bergson's view, the brain is the medium between consciousness and the external conditions of life; it is "the organ of attention to life", keeping the mind in contact with reality. But thought, he maintains, is in great part independent of the brain, and "there is infinitely more in a human consciousness than in the corresponding brain". If the mental life thus transcends the cerebral life, if the 
brain serves simply to translate a small part of what goes on in mind, then personality is not permanently tethered to protoplasm.

The animist need not occupy the extreme position that the body is but an instrument on which the mind plays. Wiser and truer is the view that through the body the mind is educated, disciplined, and enriched. As Aliotta puts it, "The body is not something with which the mind can dispense, it is not the forbidding prison which the Platonists depicted in such gloomy colours, it is no torture-chamber in which mind is doomed to expiate some mysterious crime, but rather the fertile soil in which alone the plant of spirituality can develop and blossom."

Among the advantages of animism we recognise (1) its emphasis on the supremacy and efficiency of what we call mind or spirit; (2) that it nevertheless faces the fundamental and all-pervading fact of body; (3) that its idea of interaction or reciprocal influence, though perhaps inconceivable, is a good working hypothesis, fitting many familiar facts; and (4) that it is congruent with that attractive and optimistic view of the world which assures us of the conservation of values. A spirited and scholarly defence of Animism has been furnished by Dr. W. MacDougall in his book on Body and Mind.

Difficulties in the Way of Animism. All the statements that have been proposed of the body and mind puzzle have their particular difficulties, and they are not awanting in the case of animism.

(a) The whole trend of science is to emphasise the influence of the bodily life on the thought-life, and although we are told that this only means that the soul cannot realise itself except in co-operating with its partner the body, we 
are haunted by the knowledge that particular defects in the instrument are terribly perturbing to the player.

(b) The experiences of mathematicians and other thinkers at a high level lead us to attach considerable importance to unconscious cerebration, to actual achievements on the part of the personality when the partner whose task is with thinking appears to be in abeyance.

(c) The characteristic feature of the animalistic theory is the idea of interaction, and this raises several serious diffculties. For how can the mind act on metabolism or metabolism on the mind? How can there be interaction between two disparate series? As Professor Stout (Manual of Psychology, Chap. III.) puts it, "When we come to the direct connection between a nervous process, and a correlated conscious process, we find a complete solution of continuity. The two processes have no common factor. Their connection lies entirely outside of our total knowledge of physical nature on the one hand, and of conscious process on the other." It has been answered that the force of this difficulty is in the assumption that the two series are absolutely disparate, an assumption which the undeniable correspondence between the two series disproves. To positive vitalists there is no particular difficulty, for the non-material psychoid or entelechy which directs brain-processes will be readily susceptible to the influence of the mind; but this is a purely verbal relief, since it leaves us in face of the difficulty of the psychoid's or entelechy's capacity of acting on metabolism. We have admitted the difficulty of explaining what is meant by the "two-aspect theory" or "the double-faced unity", but we are not sure that the idea of interaction is any more intelligible. We suggest, however, to those who uphold the idea, that the difficulty will appear less if it be recognised 
that the vital activities of the organism, considered apart from its psychical activities, are not susceptible of satisfactory mechanical description. When we have abandoned a mechanistic view of the organism, we have made a step of importance towards understanding what Professor Ward calls the internal or inter-subjective relation that the subject bears to its organism.

It is often said that animism involves a breach with the principle of the conservation of energy. If mind really counts, it is argued, work is done which the antecedent energy-conditions do not fully account for. If the mind acts on the brain in a way that tells, then some energy disappears from the books, for the mind is outside the sphere of energytransformations. But to suppose that the mind acts on the material system without expending energy is, the critics of animism continue, to forsake scientific procedure, for the law of the conservation of energy cannot be broken.

Now we are not concerned in the defence of animism, but this criticism is not one that commends itself to us. The doctrine of the conservation of energy includes two propositions. In the first place, it suggests that the total amount of energy in the universe is a constant, but this is rather a pious opinion than an established fact. The less wo say regarding the universality of the conservation of energy the better, for we do not know. But in the second place it is a regulative principle, based on experimental evidence, which states that in any closed physical system at work the energy expended in one way must be gained in another. The organism and its environment are comparable to the change-office outside an exhibition; there are ceaseless transformations, but the amount of cash is not only the same in the evening as in the morning, it is the same all through 
the day. The question is whether, with this regulative principle in view, we can think of mind acting on body or of body acting on mind?

Various answers have been given, and we shall take the worst first. (1) It has been suggested that some physical energy may rise into mental energy and some mental energy may sink into physical energy. But mental energy is a mere metaphor. On this theory it is supposed that, if the physical energy is locally augmented by the influence of mind, e.g., of a strong will, a corresponding amount of physical energy in another part of the system disappears, say in engendering a feeling of self-approbation. When the resources of the change-office till are augmented by a remarkable operation in receiving cash they are automatically reduced to a corresponding amount by a remarkable operation in disbursing the same. This seems more like art than science and the preservation of the balance savours of the miraculous.

(2) We have already referred to Professor Poynting's suggestion that the will may act as a guiding power changing the direction of motion of the atoms and molecules of the brain, and that the amount of energy will not be changed, since a deflecting force does no work. "But the interposition of the guiding power does affect the transformation of energy; instead of the clash which the physicist would foretell there would be a new configuration as the molecules glided past each other in their new directions." This is an interesting position, but the difficulty of thinking of mind shunting material particles is surely hardly less than the difficulty of materialism that brain-motion causes consciousness. It is almost certain that this attempt to square animism and the doctrine of the conservation of energy is on quite 
the wrong line, for it pictures the mind acting mechanically on matter in motion. But if the mind can thus determine the direction of physical processes, say in the brain, the disparateness of mind and body is surely given up. Even Lotze spoke of " elements of mental life, intervening between the operation of the corporeal organs, and filling gaps between the single links of the chain of vital processes", but can we think of mind producing an impact or causing motion? What we call mind bulks largely in Animate Nature, but surely whatever be its mode of operation it is not that of a shunter. W. K. Clifford compared the belief in this kind of psychical influence upon material things to the belief that the wagons of a railway train are held together by the friendly feeling of the engine-driver for the guard.

(3) The animist is probably on firmer ground when be simply refuses to be tyrannised over by the principle of the conservation of energy. That principle was established in reference to inorganic systems which can be adequately summed up in dynamical terms, belonging to a domain without spontaneity or alternatives or endeavour. We need not allow a law of our own making to dogmatise as to what is possible or impossible in systems run on different lines. No doubt the life of the organism conforms on the whole to the principle of the conservation of energy, as calorimeter experiments prove; perhaps it corresponds absolutely; but what we are concerned to maintain is, that there is no reason grounded in the constitution of nature why a living material system should entirely correspond as regards energetics to a non-living material system.

In this connection it should also be noticed that just as a spark may cause an explosion, and cutting a tape may launch a liner, an emotion may intervene to considerable 
purpose in bodily affairs without it being possible to prove by calorimetric methods whether its interaction is accompanied by expenditure of energy or not.

It need hardly be said that the view of the soul as something extended in space is not the genuine animism, no matter how subtle that 'something' may be. Mr. Norman Pearson (1916) works with a soul which "has no resemblance to the ponderable matter of our senses . . . is finer even than the imponderable ether of our inference . . . is, in fact, the nearest conceivable approach to spirit." This may be a legitimate hypothesis, for one cannot dogmatically assert that the extended in space is exhausted by ordinary physical methods, but it is not pure animism.

(VII) The Two-Aspect Theory. There remains a view to which biological facts incline us, 'the two-aspect theory', or the 'Identity Hypothesis', or the 'correlation theory'. We think of the organism as one, as, while it lives, an indissoluble psycho-physical being. The mind and the body are both abstractions, very convenient for purposes of discourse; there is but one reality, the life of the organism, which has a subjective aspect known as psychosis and an objective aspect known as neurosis. The living creature gives an account of itself in two ways. It can know itself as something extended and intricately built up, burning away, moving, throbbing; it can also know itself as the seat of sensations, perceptions, feelings, wishes, thoughts. But there is not one process, thinking, and another process, cerebral metabolism; there is a psycho-physical life-a reality which we know under two aspects. This view may be associated with the names of Aristotle, Spinoza, Fechner, Ebbinghaus, Lloyd Morgan. Cerebral control and mental 
activity are, on this view, different aspects of one natural occurrence. What we have to do with is the unified life of a psycho-physical being, a body-mind or mind-body.

The advantages of the two-aspect theory, if it is tenable, are (1) that it does justice to the extraordinarily intimate inter-dependence of what we call 'mental processes' and 'brain-processes'. It regards them as two equally real aspects of the continuous life of the organism. There is not merely a material watch with a ticking which we call consciousness; there is not merely a thought-life with an illusion of associated things; there are not two watches which keep time without interacting, nor yet two watches which interact; there is one watch with two sides, which we call objective and subjective. The objective side is the body as a living whole; the subjective side in Man's case is the unity of mind. (2) The psycho-physical being is one, but its two aspects are not always equally clear to us. In thinking out a mathematical problem we may be quite unaware of anything but our thought-experiments, yet the evidence points to the possibility of these being continued by us (by the organism) without any conscious endeavour. In the application of an anæsthetic, one level after another of the conscious life is obliterated in precise relation to the degree of chloroforming, till by and by complete unconsciousness may result. It looks as if the uninterrupted life of the instrument kept the player in being, it looks as if the life were one. (3) It is extremely difficult to think of the mind in the ante-natal period; it is less difficult to think of a psycho-physical being, in whose one-cell phase the psychical aspect is as non-explicit as it is in the adult life during deep anæsthesia. (4) It is easier to think of evolution on this double-aspect view, for what has come 
about has always been simultaneous progress in the expression of both aspects-more intricate bodies with their counterpart in subtler behaviour, a growing mentality and its counterpart in a more complex brain-life.

Objections to the Two-Aspect Theory. (1) It has been objected that the phrase "two aspects of the same process" is unmeaning when forced upon the psycho-physical relation, where we have to deal with sequences of radically different orders, "apprehended in two radically different ways, the one by sense-perception, the other by reflective introspection". Fechner spoke of the view of a sphere from the inside and from the outside being two aspects of the same thing, but in that case the one gives us the other, whereas we cannot in the least degree deduce the nature of the psychical from an observation of the physical, or contrariwise. But this objection states a false case, for the postulate of the identity hypotheses is that there never are two events, but always only one. We must not think of two disparate series, one tcleological, implying a purposive selective unity, and the other mechanical, due to the refined and complicated organisation of the nervous system; we must think of one serics fundamentally purposive and in its higher reaches consciously purposeful. As Bain put it, "The line of causal sequence is not mind causing body, and body causing mind, but mind-body giving birth to mind-body." From a very different starting-point Samuel Butler said almost the same thing: "The idea of a soul, or of that unknown something for which the word 'soul' is our hieroglyphic, and the idea of living organism unite so spontaneously, and stick together so inseparably, that no matter how often we sunder them they will elude our vigilance and come together, like true lovers, in spite of us." 
(2) It is also objected to the identity hypothesis that there is lacking, except in the case of the introspecting psychologist, any observer occupying the inner-standpoint. But it is not in the least necessary to the theory that there should be any continuous observation of the subjective aspect. In ordinary daily life there is introspection only at intervals, when this miraculous power of self-awareness has a definite rôle to play. In animal life there is, of course, no demonstrable self-consciousness, but there is a mental life which cannot be interpreted in terms of the abstractions of tho physiology of the nervous system. According to the identity hypothesis this mental life is one aspect, hypothetically imagined by us, of the very highest reach of the organism's activity.

(3) It is objected that the two-aspect theory simply invents and glorifies an $X$, an unknown and unknowable entity. To make clearer what we do in some measure know, it postulates an indefinable reality of which we can know nothing. "The one substance," says Professor Stumpf, "which is supposed to manifest itself in the two attributes, the physical and the psychical, is nothing but a word which expresses the desire to escape from dualism, but which does not really bridge the gulf for our understanding." But the charge " nothing but a word" is readily made and as readily recoils. The identity hypothesis does not pretend that we know anything like all about that fraction of reality which we call a living creature, nor that we can explain its having two aspects. It maintains, however, that we know this about organisms, that they are agents that do things, unique individualities that express themselves in endeavour, psycho-physical beings that burn away and yet remember, that ripen and rot and yet work towards ends which transcend 
themselves. What the 'identity hypothesis' or correlation theory postulates is not an unknown $X$, but an imperfectly known organism, whose pre-awareness of meaning is as real as its flesh-and-blood metabolism, yet inseparable from it.

(4) Another objection to the 'double-aspect' interpretation is that we know ourselves as self-determining-for no one can get away from an immediate awareness of his personal agency-whereas the organism is determined from without, being part of the mechanical system of things. Can the same reality be determined from without and self-determining? But the objection must be disallowed, first because the organism has spontaneity, from the Amœba upwards, and is certainly not wholly determined from without; and, second, because when we examine ourselves carefully we find that our mental life is not wholly self-determined. It is an unnecessary difficulty to say that one aspect is teleological and the other mechanical; for we have given good reasons for believing that the organism is more than mechanical. 'Body' and ' mind' are both of the teleological or purposive type, for that is the nature of the creature from first to last.

§5. Monistic Speculation along the Line of the DoubleAspect or Correlation Theory.

On the Double-Aspect or Identity Hypothesis all animals are psycho-physical beings, and this is borne out by what is known of the behaviour of the very simplest, for we see Amœbæ going ahunting and Foraminifera working like selective artificers. But what of the plant world? Logically, we can make no halt, and there are curious phenomena which approach behaviour in earnivorous plants and climbing plants. In some cases, there is what looks like memory. 
But the continuity argument presses us further. Since it seems very likely that organisms arose upon this earth from not-living materials, in a manner at present obscure, are we to suppose that consciousness somehow entered $a b$ extra into the early organisms when they were as yet only beginning; or that it was interpolated later when they attained to some degree of complexity; or that the analogue of consciousness, which some have ealled infra-consciousness, was present even in the domain of the inorganic? The desire for continuity impels us to the speculation that even the inorganic raw materials were psycho-physical. For in no case can we think of consciousness arising out of motion, any more than we can think of atoms uniting for love.

There has been great progress in the course of evolution, but on the identity hypothesis we think rather of potencies being raised to higher powers than of the interpolation of new faculties. Instead of insinuating a principle of life $a b$ extra when a suitable mixture of proteins had been somehow synthesised, we suppose that a synthetic advance of materials, which were ever more than motions, made behaviour possible. Instead of insinuating mind $a b$ extra when the organism became complex enough, we suppose that the progressive differentiation and integration of what was from the outset a psycho-physical being, by and by disclosed another aspect of its inherent reality, and experimenting with ideas became possible. And similarly with man's rational diseourse and with the amazing phenomena of human society.

Biological monism has been characterised as a relapse to the old and crude metaphysics of hylozoism. Perhaps it is nearer the hylopsychism of some of the New Realists. "By hylopsychism I mean the theory that-The potentiality 
of the physical is the actuality of the psychical and the potentiality of the psychical is the actuality of the physical. Or, to put it in the form of a definition of consciousness: Consciousness is the potential or implicative presence of a thing at a space or time in which that thing is not actually present . . ." (W. P. Montague, p. 281). "By hylopsychism I wish to denote the theory that all matter is instinct with something of the cognitive function; that every objective event has that self-transcending implication of other events which when it occurs on the scale that it does in our brain processes we call consciousness" (p. 283).

Is there any difference between this and the monistic speculation of Prof. Lloyd Morgan? "Of simple awareness there can be no evidence by acquaintance, save in being aware. And since we cannot be an Amøba or an isolated neurone, an oak or an acorn, an attracting magnet or a shred of iron attracted thereto, we can never directly know whether in them some dim awareness is present or absent. None the less we may be permitted to suppose that awareness, as a specific mode of relation between terms, is ubiquitous throughout nature-basing this supposal on the principle of continuity. If here in us in high measure, then in the oak and the acorn, in the molecule and the atom, in their several measures and degrees" (1915, p. 10).

To demand of the biologist an explanation of the double aspect of the psycho-physical being is to demand the impossible. Organisms are unique facts; intelligent organisms are unique facts. But if the biologist is pressed hard and asked if there is no other unique fact beside which be can place his double-aspect organism, perhaps he may answer, "Why, there is only thought itself, which is subjective and objective at once." 
The 'Body and Mind' problem has served to stretch man's brains for moro than two thousand years, and there are many who would abandon it with the word 'Ignorabimus'. But Man will never leave it alone, and the resolute endeavour after greater clearness is likely to bring its own reward even if the riddle remain unread. For the inquiry patiently prosecuted is likely to lead to a deeper appreciation of what we call 'Body' and of what we call 'Mind'. And this deeper appreciation is the practically important result.

SUMMARY.

The approach to the difficult problem of the relation between 'body' and 'mind' has been cleared (a) by the argument that mechanical formulation is inadequate for the description of vital activities, and (b) by the recognition of the pervasive rôle of 'mentality' in Animate Nature.

In any consideration of the problem there must be borne in mind, from the biological side, how gradually mind develops in the individual, how gradually mind has evolved in the races of animals, and how intimately inter-dependent the psychical and neural processes are. Whatever theory is adopted, these facts remain.

In any consideration of the problem there must be borne in mind, from the humanist side, the reality of the thought-life, the reality of the external spiritual not-self which man has in the course of ages built up, and the potency of spiritual values in history and in everyday life. Whatever theory is adopted, these facts remain.

The question is how we are to think of our thought-life and of our brain-life in relation to one another, for we can at any rate talk of them as distinct actualities. At least seven answers have been given to this question. Two of these are only acceptable on the mechanistic hypothesis, namely (I) the throughgoing materialistic answer and (II) the theory of epiphenomenalism. The theory at the very opposite extreme-subjective idealism-(III) seems to deny the possibility of science. The theory of psycho-physical parallelism (IV) lands in apparently inextricable difficulties-so well exposed by Prof. James Ward. There remain in the field three possible theories:-(V) the theory of psychical monism, which few 
scientific investigators can entertain; (VI) the theory of animism or the soul-theory; and (VII) the identity hypothesis, or two-aspect theory, or correlation theory.

A case can be reasonably stated for the theory of psychical monism, for the soul-theory, and for the two-aspect theory, and a decision must be left with the individual according to his personal experience. Each theory has its awn advantages and its own difficulties. When the biological facts are dominant in the mind the balance will swing towards the 'two-aspect theory' or 'identity hypothesis,' which regards the living creature as a psycho-physical unity, psychosis and neurosis being two aspects of one and the same continuous life.

Perhaps, as in the case of vitalism, the most consistent scientific position is to keep firmly to the fact that just as the everyday functions of the organism, not to speak of its development, heredity, and evolution, cannot be adequately described in terms of chemico-physical concepts, so it appears that many of the forms of behaviour cannot be adequately described in terms of the concepts of biology. A new aspect of reality is expressed requiring new categories-psychological categories. This is but a pedantic way of expressing what was said of old: "Surely the life is more than food." 

LECTURE VIII.

THE FACT OF BEAUTY. 



\section{LECTURE VIII.}

\section{THE FACT OF BEAUTY.}

§1. A Synoptic View of Animate Nature Must Include the Fact of the Pervasiveness of Beauty. §2. General Characteristics of the Esthetic Emotion. §3. Beauty a General Quality of Animate Nature. \$4. Theoretical Objections to the Thesis. §5. Concrete Objections. §6. Factors in Esthetic Delight. §7. Aspects of Beauty in Animate Nature. §8. Biological Significance of Beauty to the Beautiful Organisms themselves. §9. Beauty of Animal Artifice. §10. Evolution of Esthetic Emotion. §11. The Significance of the Pervasive Beauty of Animate Nature.

§1. A Synoptic View of Animate Nature Must Include the Fact of the Pervasiveness of Beauty.

IN an inquiry into the significance of Animate Nature, there is no getting past the fact of Beauty. Whatever we make of it, the Beauty of Nature is a joy for ever to many, not only to the cultured, but to the unsophisticated who never heard of the æsthetic attitude. Man's contemplative and disinterested delight in the beautiful is well-nigh the best of him; and it is a reasonable and verified belief that we get at something in this way which can be reached by no other, certainly not by scientific analysis or by logic. There are curiously few general affirmations that we can make about Nature; one is that Nature is in great part intelligible or rationalisable, and another is that Nature is in greater part beautiful.

It is our object in these lectures to indicate what contri- 
butions Biological Science has to offer to a general view of the world, and it is impossible for biologists to pass over the pervasiveness of beauty in the realm of organisms. We cannot say that science is required to discover this beauty in its obvious expressions in bird and flower, but its luxuriance in the unobtrusive, in the well-concealed, in internal and microscopic structure, and among the unicellulars cannot be discerned without scientific investigation. If the popular impression be that beauty is the exception, the scientific impression is that beauty is the rule. For a long time, perhaps till the middle of the 19 th century, Beauty was very generally spoken of as a quality of the exotic-the orchid and the Bird of Paradise-now we feel it most at our doors. St. Peter's lesson has been learned, for we find nought common on the earth. As one of the pocts says, "Beauty crowds us all our life." Moreover, sound science tells us much that is very interesting regarding the beautiful and intensifies our appreciation of its significance.

\section{§2. General Characteristics of the Asthetic Emotion.}

We mean by the beautiful that which excites in us the particular kind of emotion which we call resthetic. This is experienced in many degrees of intensity and of purity, but it is distinctive. The rsthetic emotion is not excited by touch, taste, or smell. The rsthetic emotion is an end in itself, like intellectual contemplation, though it may liberate Man's formative impulse. It grips us as organisms, 'body and soul' at once, and abides with us incarnate. The thing of beauty is a joy for ever. Prof. B. Bosanquet points out (1915) that æsthetic feeling has qualities of permanence, relevance, and community. That is to say, it brings no satiety; it is annexed to particular qualities-not a feeling of general 
well-being; and it grows as we share it with others. In all but its simplest expressions, it strikes the chords of imagination, for, as Professor Bosanquet insists, "the æsthetic attitude is an attitude in which we imaginatively contemplate an object, being able in that way to live in it as an embodiment of our feeling. . . The æsthetic attitude so far as enjoyable" is "the pleasant awareness of a feeling embodied in an appearance presented to imagination or imaginative perception."

\section{§3. Beauty a General Quality of Animate Nature.}

Now, what seems to us to be a fact, and a very interesting fact, is that all natural, free-living, fully-formed, healthy living creatures, which we can contemplate without prejudice, are in their appropriate surroundings artistic harmonies, having that quality which we call beauty. That is to say they have qualities-objective qualities-which excite in us a particular kind of emotion, often of a very high order. To many of us - of the eye-minded type-the blotting out of the annual pageant, say of flowers and of birds, would be the extinguishing of one of the lights of life. But we must pause to inquire whether our proposition really expresses a fact.

\section{§4. Theoretical Objections to the Thesis.}

The first objection is, that beauty is in no sense a quality of things, but is wholly in our minds-purely subjective. Hegel, forgetful of Schelling and Goethe, remarked that it had never occurred to any one to emphasise the aspect of beauty in natural things, that in fact the beauty was not in the things but in the contemplating mind. Some other philosophers, such as Vaihinger,-the author of The Philos- 
ophy of the As If,-have maintained that the Beautiful is one of Man's self-preservative ' fictions'-whistlings to keep his courage up. But this is an extreme of subjectivism. No doubt the æsthetic emotion implies a racially and individually attuned mind, but this is not thrilled except in the presence of compositions of lines and combinations of colours which have a particular quality. There are other compositions and combinations-usually of our own makingwhich fail to please us, which have not the quality. Except in reminiscence, we do not have the rsthetic joy unless the thing of beauty is there, and in regard to animate objects there is remarkable congruence of emotion on the part of the observers, after certain readily intelligible difficulties have been overcome. Moreover, as a domesticated animal or cultivated plant degenerates under artificial conditions, becoming obese, or coarse, or scraggy, as the case may be, there is a correlated slackening in our pleasure in it. There is an objective basis of ugliness correlated with our subjective repulsion.

And again, it canrst be a mental fiction, this æsthetic delight, for if there is any corner of experience where the unity of body and mind is more forcibly illustrated than elsewhere, it is in connection with the æsthetic emotion. It is a body-and-mind reaction. "If we try," says Professor Bosanquet (1915), " to cut out the bodily side of our world, we shall find that we have reduced the mental side to a mere nothing."

Speaking of "the aspects of beauty and sublimity which we recognise in Nature, and the finer spirit of sense revealed by the insight of the poet and the artist ", Professor PringlePattison writes: "These things also are not subjective imaginings; they give us a deeper truth than ordinary vision, 
just as the more developed eye or ear carries us farther into Nature's refinements and beauties" (1917, p. 127). "Philosophy does not require us, then, to treat the beauty and sublimity of natural objects as subjective emotions in the bystander: we are entitled, on the principles I have been advocating, to treat them as qualities of the object just as much as the vaunted primary qualities" . . (p. 129). "Things are as they reveal themselves in their fullness to the knowing mind" (p. 130).

It is highly probable that our likes and dislikes, our standards and criteria, have been to some extent wrought out in the course of ages of familiarity with Nature. It is highly probable that certain arrangements of lines and colours please us greatly because of racial and even pre-human associations, for we are strange medleys of organic memories. But no one can say that he knows much about this. There are some cases of apparent æsthetic delight among animals, e.g., that of the Bower-birds which decorate their honeymoon bower with brightly coloured objects, apparently productive of pleasant excitement. But we do not wish to make much of the rather problematical æsthetic predispositions inherited from pre-human ancestry, especially since whatever was thus entailed had to pass muster with Man himself, had to be assimilated or eliminated, approved or rejected by an evolving rational being. Allowing something for hereditary associations, we have to face the fact that man has a great pleasure in the lines and colours of, say, flowers and birds; and our point is that these are not 'anyhow' lines and colours, but have a positive quality.

It is worth noting (1) that many quite unfamiliar living creatures - such as deep-sea animals-are recognised at first glance as triumphantly beautiful; (2) that it is among the 
domesticated and the cultivated, in favour of which man should be prejudiced, that we find the best examples of the ugly; and (3) that for many people the most beautiful things-that is to say, the things which evoke the keenest æsthetic delight-are not natural objects, but queer creations which bear no resemblance to anything in the heavens above, or in the earth beneath, or even in the waters under the earth where strange beings abound. Yet the beautiful thing - a decoration, a piece of pottery, a tile-thrills us through and through, and we never tire of it.

Another objection is based on the capriciousness of taste. In his well-known Romanes Lecture on "Criticism and Beauty", Mr. Arthur J. Balfour laid emplasis on the conspicuous absence of common agreement as to what is beautiful. There is no accepted body of æsthetic doctrine. Taste differs with race, age, and degree of culture. Greece had apparently in ancient days values very different from ours as to music, and in pictorial art what is one man's food is another man's poison. Even among the aristocracy of taste, what agreement is there among the various schools and crities? Mr. Balfour maintains that there is no standard of the beautiful to be found (a) by critical analysis, or (b) in the consensus of experts, or (c) in the general suffrage of pleased mankind. So he concludes that just as that is for every man most lovable which he most dearly loves, so that is for every man most beautiful which he most deeply admires.

Perhaps we may evade the force of this argument by remembering that Mr. Balfour was discussing art, while our theme is Nature, which makes a great difference. Moreover, while there is discrepancy of view among experts as regards the merits of subtle expressions of art, there is usu- 
ally agreement in appreciating straightforward æsthetic excellence and in rejecting the ugly.

In maintaining the objectivity of beauty we recognise to the full the subjective side, namely the æsthetic emotion, which is complex, not simple. The emotion is the subjective side, and, as every one knows, very personal, varying with age, health, state of mind, past experiences, and so forth: but certain qualities of form, colour, and movement in the objects of contemplation are objective and do not in any way depend on us. Against this position it does not seem particularly cogent to urge that the uneducated may see no beauty in a grass; that the sick man may find his old favourites intrusive and repugnant; that an analysis of our delight in the beautiful reveals subtle associations and selfprojections. For it must be remembered that all sensory alertness demands discipline; that there is, so to speak, easy beauty and difficult beauty-the latter often mistaken by the careless for ugliness; that health in subject and in animate object is the normal state with which we have primarily to reckon; and that a pleasedness directly induced by certain qualities of things may be enhanced and overwhelmed by secondary factors due much more to the world within than to the world without.

\section{$\S 5 . \quad$ Concrete Objections.}

But there is another series of objections, perhaps to the scientific mind more interesting. These consist in bringing forward evidence that the realm of organisms is spotted with ugliness. To meet these objections let us briefly explain the saving-clauses attached to our thesis.

(1) There are some creatures which the average man cannot contemplate without prejudice. He does not admire 
the jellyfish, beyond doubt a decorative masterpiece, because he was once stung; he cannot abide the handsome newt because of its clammy skin; he does not appreciate the snake's beauty because of the Garden of Eden. There is no use trying to get a fair verdict from a packed jury. In testing our thesis we must exclude cases where our impressions are more or less excusably warped by some unpleasant association-by something which is often at least quite extrinsic to the creature. It is difficult, even for a naturalist, to judge impartially of the artistic merits of parasites, though in some cases, like dodder and mistletoe, the beauty is too strong for our prejudice. In support of the view that Nature is spotted with ugliness, Prof. James Ward refers to creatures like the spinose lizard which has been ealled Moloch horridus. But bis examples are unfortunate. They are animals in regard to which a prejudiced association might readily arise; but they are delightful quaint creatures over which the artist is enthusiastic.

The other saving-clauses are slightly different. To get a clear issue we must exclude domesticated animals such as prize pigs, and cultivated plants such as the buxom cabbage, which are non-viable in a state of nature, and bear too obviously the marks of man's fingers. We may exclude also unfinished or embryonic stages, which are often, as a matter of fact, hidden away very carefully in Nature. We may exclude also all captive creatures which are distorted or crippled by parasites or by disease, and all the monsters of the teratological show which Nature would not have tolerated for a moment. These are ugly, and we shall see, later on, that there are several objective reasons for their being repulsive to us. Our thesis refers to wholesome wild nature.

Another saving-clause is significant. If we are to appraise 
rightly we must see the crcature in its native haunts,-in the environment to which it is adapted, which is in a sense its external heritage, which it has in some cases sought out. The hippopotamus at the Zoo may fail to excite æsthetic emotion, but that this is our misfortune and not Behemoth's fault is evident from the book of Job. We have to see him as the author of that poem saw him, with his ruddy hide in the shade of the lotuses, in the covert of the reeds and fens. "His strength is in his loins, his force in the sinews of his belly, the muscles of his thighs are knit together, his bones are pipes of brass, his limbs are like bars of iron, he is the chief of the ways of God." And we, purblind, call the hippopotamus an ugly creature!

This is a subtle subject which we venture to discussthe pervasiveness of a certain quality in living things and in the inorganic domain as well that makes life to the relatively unfettered a continuous delight. So we must be pardoned if we treat it gently, rather than with stern analysis. The science of æsthetics has not gone far yet, and we are not desirous of doing much more than pleading that our synoptic view of Nature must include a frank recognition of the fact of beauty.

\section{§6. Factors in Asthetic Delight.}

What is implied in our æsthetic emotion when we watch beautiful animals - the Shetland ponies racing in the field, the kingfisher darting up the stream like an arrow made of a piece of rainbow, the mayflies rising in a living cloud from a quiet stretch of the river, or the sea-anemones nestling like flowers in the niches of the shore-pool? What is implied in our thrill at finding in a corner of the rocks near the waterfall a stately Royal Fern- 
"Plant lovelier in its own recess Than Grecian naiad seen at earliest dawn Tending her font, or Lady of the lake Sole sitting by the shores of old romance."

In the first place, our enjoyment has a sensory or physiological factor. What we see sets up agreeable rhythmic processes in our eyes, and agreeable rhythmic messageswaves of chemical reaction if you will-pass to our brain, and the good news-the pleasedness-is echoed throughout the body, -in the pulse, for instance, and the beating of the heart. Wordsworth was a better physiologist than he knew when he said, "my heart leaps up when I behold a rainbow in the sky", or again, "And then my heart with pleasure fills, and dances with the daffodils". As with music, so with beautiful sights external rhythms are often echoed in internal rhythms, and rhythms are pleasant. It is easy enough to burlesque the idea of the physiological factor in æsthetic delight, but the sensory thrill is always there, and in simple cases, where perception is not wide awake, it may be predominant. We cannot enter into the difficult question of the precise relation of the bodily resonance to the æsthetic emotion, in connection with which three views have been held. They are thus stated by Sherrington:- $(a)$ that emotion is first aroused and that its nervous correlate excites bodily resonance; $(b)$ that the stimulus excites the mind and the nervous centres for visceral resonance concurrently; and $(c)$ that the stimulus acts on centres ruling the viscera, and that the visceral sensations, laden with affective quality, induce the emotion. We adhere to Sherrington's conclusion, that the visceral resonance is secondary to the cerebral excitement and the associated emotion, that it reinforces rather than initiates the joy. 
The second factor in our æsthetic delight is perceptual. The 'form' (in the widest sense) of what we contemplate is significant for us and satisfies our feeling. Beauty increases with significance of form, with the degree in which meaning is suffused into material, or with the degree in which the way is opened to us to give imaginative interpretation. The æsthetic attitude, Professor Bosanquet says, "is an attitude in which we imaginatively contemplate an object, being able in that way to live in it as an embodiment of our feeling ". We actively respond to what we enjoy looking at, projecting ourselves into it, reading ourselves or something else into it, in an æsthetic illusion, which has something in common with make-belicve forms of play, just as these in turn are linked on to art. It is because of the importance of this factor that many have been led to the idea, which seems to us mistaken, that the quality of beauty is altogether subjective.

If the beautiful form which moves us is truly excellent, it becomes more significant in all its details, in proportion to the intensity of our æsthetic contemplation. The form lends itself to more and more meaning. The imagination receires a succession of libcrating stimuli, one after the other, according to the depth of the beauty of the object; and the fact which secms to us to be outstanding is that the lines and patterns and colours of living creatures go to make up a 'form' which almost never disappoints.

In its highest reaches the imaginative perception rises into the poet's vision, of which Blake speaks:-

\section{"And before my way}

A frowning thistle implores my stay.

What to others a trifle appears

Fills me full of smiles or tears; 
For double the vision my eyes do see, And a double vision is always with me, With my inward eye, 'tis an old man grey, With my outward a thistle across my way."

While venturing to lay some emphasis on the objectivity of beauty and on the physiological as well as psychological side of the rsthetic emotion, we recognise that the higher factors may come to mean much more than the primary ones. As Professor Bosanquet says, "Man is not civilised, æsthetically, till he has learned to value the semblance above the reality. It is indeed, as we shall see, in one sense the higher reality."

A third factor in our asthetic delight is conceptual. Experts maintain that nothing which does not appear can count in the æsthetic impression, but it seems to us impossible to shut off the effect of associations and the influence of concepts on percepts. There is, for instance, the influence of the concept of adaptiveness which is always in the background of the naturalist's mind, as is, indeed, true of most of us. That thoughtful physiologist, Sir John Burdon Sanderson, was firmly persuaded that an appreciation of adaptiveness bulks very largely in our æsthetic enjoyment of animal form and structure. Canon Hannay speaks of the delight of watching the flight of birds:- "Above the rocks hovered the gulls with outstretched wings. Sometimes they slid down the wind till they almost touched the sea. Then with slow strong beatings of their wings they rose high again, slanted seaward against the breeze, swept in wide circles, lazily indifferent as it seemed to destination, but bent on satisfying themselves with exquisite smooth motion." As we watch this everyday sight we have purely æsthetic admiration of the grace of the creatures and of the music 
of their movements. There is sensory pleasure and there is imaginative sympathy. But the delight is subtly heightened by an appreciation of the fitness of the birds to this mastery of the air,- an appreciation that steals into the mind rather as an aroma than as a cold-blooded scientific reflection.

By the objectivity of the beauty of Animate Nature we mean that there is in the 'form' of plants and animals a positive quality which excites the æsthetic emotion. Speaking of tragic poetry, Mr. Bertrand Russell says: "it becomes possible at last so to transform and refashion the unconscious universe, so to transmute it in the crucible of imagination, that a new image of shining gold replaces the old idol of clay. In all the multiform facts of the world-in the visual shapes of trees and mountains and clouds, in the events of the life of man, even in the omnipotence of Death-the insight of creative idealism can find the reflection of a beauty which its own thoughts first made." This is splendidly said, and that man's mind should be able to assert "its subtle mastcry over the thoughtless forces of Nature" is something to ponder over, but our concern is with simpler things than the triumph of imaginative idealisation. We are pleading for the reality of a beauty which man's thoughts did not first make.

\section{§7. Aspects of Beauty in Animate Nature.}

Another question arises: Of what elements does the beauty of plants and animals consist? The general answer must be: In combinations and arrangements of lines and colours, and, in the case of animals, in movements as well.

It has been known for centuries that certain forms are much more pleasing than others. This has been borne out by experiments with children and other unsophisticated per- 
sons. Thus an ellipse with its axes in the proportion 5:3 has been recorded as very pleasing since 300 B.C.; it is the golden or divine section; it leads on to the mystic pentagram. But why it is moro pleasing than other ellipses, or than a rectangle, who can tell us? The eye registers certain forms with plcasure; there are lines that flow and shapes that sing. The approximate logarithmic spirals, so common throughout organic nature, for instance in horns and cones, in shells and buds, are peculiarly pleasing.

Perhaps this depends in part on racial education. For racially we were brought up in the country, and grew up more appreciative of rounded surfaces than of sharp corners. When we get beyond the domain of the inorganic, Nature is on the whole a world of curves. We were brought up on curves. Perhaps certain dominant associations of very early origin linked curves and pleasure together. Even our photographic plate- our retina-is a beautiful curved surface, and this may have something to do with our dislike of the angular.

Among organisms we like best those with flowing lines, which repeat one another rhythmically; which conspire, as Lessing said, to one effect; which are readily summed up; which compose. We are apt to be less pleased with asymmetrical animals (like snails), top-heavy animals (like hormbills), disproportionately lanky animals (like ostriches), not that any of these are to be artistically apologised for. We are least inclined to admire creatures whose architectural plan is difficult to grasp, which are distracting conundrums, or those which are too prolonged and monotonous in their repetition (like millipedes), or those which startle our perceptual conventionalities (like the Indian Ocean fish which has a window right through it). But our point is simply. 
that with a few exceptions (which are too difficult for us) the lines of living creatures are such that they give us asthetic pleasure. This is as true of the microscopic shells of Foraminifera and Radiolarians - which are joys for ever - as of the lines of the crane and of the cedar of Lebanon. It is as true of the carefully hidden down-feathers of the eagle as of the tail of the peacock. It is as true of the internal architecture of a sea-urchin's spine as of the external moulding of a tiger. It is as true of the minute chiselling of many a moth's egg-shell as of the sweeping lines of an Iguanodon. Is there no significance in the omnipresence of these pleasing lines?

The sccond element in organic beauty is colour, which so often emphasises and enhances the value of form. It seems that all wild animals and plants, living an independent and healthy life and in their natural surroundings, are beautiful in colour, that is to say, æsthetically pleasing. The combinations in parrots, humming-birds, birds of Paradise, coral-reef fishes, butterflies, orchids, and the like are often daring, but they are never wrong. That is to say, when we look at natural schemes of colour we are always pleased, which means, to begin with, that the chemieal processes set up in our retina are harmonious. It may be remarked that some skin-diseases involve vivid colours, and that they displease us,-partly perhaps because associations make us feel them uglier than they are, but partly because they are ugly, being expressions of disharmonious vital processes, non-viable failures which Nature scarce troubles to look at, but casts at once as rubbish to the void. The coloration of a scallop shell, of a peacock's feather, of a poppy's petal, and so forth, depends on the orderly chemical processes of a healthy life, and it is perhaps for this reason primarily 
that they never fail to set up pleasant changes in the human eye.

The third component of the beautiful in animals is movement. Just as we enjoy watching a waterfall, a fountain, the waves, or even the dance of motes in the sunlit air, so we are delighted with the jellyfishes throbbing in the tide, the flotilla of sepias all keeping time as they swim, the flyingfishes rising before the prow of the steamer like locusts before us as we walk in the meadow, the porpoises gambolling in the waves, the jerboas with their startling jumps, the flight of bat and bird and butterfly, and the way of the serpent on the rock. Let us watch the last. As Sir Richard Owen said, the snake can "outclimb the monkey, outswim the fish, outleap the zebra, outwrestle the athlete, and crush the tiger". The accurate zoologist cannot accept every word of Ruskin's famous description of the way of the serpent, but he will admit that it gets at the fact of beauty. "That rivulet of smooth silver-how does it flow, think you? It literally rows on the earth with every scale for an oar; it bites the dust with the ridges of its body. Watch it when it moves slowly-a wave, but without wind! a current, but with no fall! all the body moving at the same instant, yet some of it to one side, some to another, or some forward and the rest of the coil backwards, but all with the same calm will and equal way-no contraction, no extension; one soundless, causeless, march of sequent rings, and spectral procession of spotted dust, with dissolution in its fangs and dislocation in its coils. Startle it-the winding stream will become a twisted arrow; the wave of poisoned life will lash through the grass like a cast lance."

Spoil an animal-say by fattening-and the beauty of its movements vanishes,-we have the waddling duck and 


\section{THE FACT OF BEAUTY}

the wobbling pig. But the general fact unquestionably is that the movements of wild animals are eurhythmic. We like them primarily because they set up a pleasant internal mimicry of eurhythmic movements within ourselves. We admire the fitness of the structure to the movements; an accompanying song may increase the thrill; we add the imaginative touch; the lark is at heaven's gate and we with it.

\section{§8. Biological Significance of Beauty to the Beautiful} Organisms themselves.

The question now rises whether the combinations and arrangements of lines and colours in organisms-which mean so much to us-mean anything physiologically in their possessors. Is there any deep reason behind them? (a) In some cases the answer is easy, for the arrangements are obviously useful-in giving stability of architecture, in reducing friction, and in economising materials. Thus one of the most exquisite structures in the world is the flinty skeleton of Venus' Flower Basket (Euplectella); and the experts say that the architecture of this is very perfectly adapted to stand such strains as are put on it as it rises like a fairy palace from the floor of the deep sea. A spirally coiled tendril is a pleasing object, and we know that it is directly useful in its formation by drawing the climbing plant closer to its support and afterwards by forming a spring which yields to the wind but does not break. The green pigment of a leaf is well known to be the most useful non-living substance in the world, but though the greenness is somehow wrapped up with its chemical composition it might conceivably have worked just as well had it not been green. On the other hand, colour is often of direct external utility in giving the animal a garment of invisibility, or in 
giving the flower an advertisement which attracts useful insect visitors.

(b) Secondly there are arrangements of lines and colours which are not of direct use to their possessors, but have none the less a physiological significance, being expressions of rhythmic growth and orderly chemical processes. The pleasing parallel lines on many shells express periods of growths like the concentric rings inside the stem of a tree or the spine of a sea-urchin. The beautiful cross-bars on a hawk's feather are the expression of diurnal variations in the bloodpressure at the time when the feather was amaking. The subtlety of coloration is often due to its rhythmic distribution-its waxing and waning, its paling and flushing-so that it represents very literally the ripple-marks of growth.

(c) But, thirdly, in many cases, we cannot suggest for the beauty any utility whatsoever, either direct or indirect. Just as it is the way of water in certain circumstances to crystallise into very beautiful and very varied snow-crystals, so it is the way of individualised living matter to form the exquisitely beautiful shells of Foraminifera and Radiolarians. It may be that these relatively simple animals illustrate something that may be called organic crystallisation, though we shall afterwards find reason to suspect that this is not all; our present point is that their beauty is not useful. Just as it is the way of particles of water in the atmosphere to form a rainbow when the sun shines through, a beautiful thing that has no meaning at all except to us, so the "beauty for ashes" that transfigures the leaves of the forest in their dying has, so far as we know, no significance whatsoever to the plant. The withering leaves might as well be ugly, but they are not. Whence again rises the question, Is there any meaning in this pervasiveness of the beautiful? 
The main part of the answer which we would suggest is simple. Keeping to those combinations and arrangements of lines and colours which are the expression of development, growth, and activity, what strikes us as characteristic is their harmony. The expert in these matters is of course the artist, the producer of the beautiful and of more than beauty, and his verdict almost without exception is that every one of these wild creatures is an artistic unity. The simple reason for this is that the lines and the colours, in their arrangements and combinations, are the expression of unified viable individualities which have stood the test of time. Perhaps this is in agreement with Signor Croce's definition of beauty as "successful expression". In the age-long struggle for existence the unharmonious, the 'impossible', have been always weeded out before they took firm root and multiplied. The monster is a contradiction in terms. Meredith put it all in a nutshell when he said "Ugly is only half way to a thing". Nature pronounces her verdict on ugliness by eliminating it. Beauty is Nature's stamp of approval on harmonious viable individuality, and just as, objectively, the ugly is only halfway to a thing, a too incomplete expression, so is it subjectively. As Professor Bosanquet puts it (1915), the imagination is " at once excited in a particular direction and thwarted in it".

But there is another side to it. In the course of hundreds of thousands of years our senses have become attuned to the natural. We have unconscious or conscious standards of line and colour, of sound and movement. Just as a discord may break a precious glass vessel by setting up contradictory vibrations, so there are colour-schemes that almost literally jar, and muddy colours that are as painful as noises. The big result remains, that the combinations of lines and colours 
in natural individualities are such that they evoke in us an activity - a disinterested contemplative activity - which, as we have said, is almost the best of us. This is a noteworthy correspondence.

\section{§9. Beauty of Animal Artifice.}

When we pass from incorporated or incarnate beauty to that of artifice, we experience a delight in which there seems to be a deeper note than any that we have yet sounded. When we study the nests of birds, the webs of spiders, the architecture of the termitary, the combs of bees, the work of tube-building worms, the arenaceous encasements of some Foraminifera, we recognise skill in the use of materials, or selection of fit and congruent materials, or a triumphing over material difficulties, or an expression of individuality at a level almost reaching to art. Then in a new way deep calls to deep, we have a sympathetic joy in the creature's mastery of its materials, in its circumvention or solution of technical difficulties. We enjoy a vicarious victory of mind over matter. Let us consider once more the arenaceous Forminifera, organless, tissueless creatures, with little visible complexity. When a Technitella makes for itself an encasement of minute Echinoderm plates, when another species makes a two-layered warp and woof of sponge spicules, when a Reophax makes a chain-armour of mica platelets cemented at their margin with chitin, when a Marsipella twists its borrowed sponge spicules in a spiralprobably anticipating the prehistoric genius who invented string, we venture to think that in such moments of endeavour and adventure in dealing with inorganic materials, artistic consciousness finds its first glimmering expression. We have argued that organisms are psycho-physical individ- 
ualities, and perhaps we are nearer the truth in saying that Technitella thompsoni says to itself, in a quiet way of its own, "Anch' io sono pittore "- "I also am an artist", than in supposing that its beautiful architecture is describable in terms of surface-tension. Perhaps an intermediate view is truer still.

The artist knows of the emotion that rewards formative achievement, and we have ventured the suggestion that part of the ordinary man's enjoyment in a beautiful work of animal artifice (or, sccondarily, in a beautiful organism itself) is a sympathetic sharing in the triumphant mastery of materials. The same general idea we have found in more developed expression in a lecture by Dr. P. Chalmers Mitchell entitled "Science and Life". From this we would quote a few sentences. Speaking not of Nature but of art, he says: "I do not doubt but that the creative artist is a supreme example of the exuberant will of conscious life to absorb, comprehend, transform the universe into itself, and that the emotion he conveys to us is an all-powerful stimulus. The form that he has created is significant, not because it is a vision of abstract relations, or of reality, or of truth, but because it has laid hold of more of the external world, recast it in categories of human mind and the human senses" (p. 18). "Asthetic emotion is the responsive thrill to creation realised, and life, seeing the image of its own power, knows that it is beautiful" (p. 21).

\section{§10. Evolution of Esthetic Emotion.}

In his Gifford Lectures (1915) Mr. Balfour has spoken of the absence of any pedigree for æsthetic emotions, and has suggested that all that evolutionists can do is to regard them as chance by-products. Esthetic emotions have opened 
to Man at his best something conveying not knowledge, but an intuition that was greater than knowledge. How can this be if the æsthetic emotions are but the refined outcome of primeval distributions of matter and energy? We have tried in our consideration of the organism to take the edge off such arguments. There are few active evolutionists of the present day who are committed to such materialism. From the physical abstractions 'matter' and 'energy' it is impossible to account for emotion, yet emotion may have evolved in psycho-physical beings such as it seems quite legitimate to postulate as the first organisms.

Esthetic emotion is a very subtle feeling, and is possibly peculiar to mankind, yet it is not inconceivable that its raw materials - up to the level perhaps of a pleased awareness of specific arrangements of certain lines and colours as distinguished from others-may be detected far below the human plane of being. Bower-birds are not, of course, among man's ancestors, but it is interesting to know how the males decorate their sometimes elaborate courting bowers with brightly coloured pods and flowers and shells. We must remember that low down in the kingdom of the unicellulars, as we have seen, animals select material to work with and handle it without hands dexterously, and it does not seem far-fetched to suppose that the creature has a dim pleasure in its work. We find similar artificers at various levels in the animal hierarchy, and the thrill accompanying successful formative endeavour will probably strengthen and deepen with the degree of general differentiation and integration. From enjoyment of one's own achievement it is possible to pass to an appreciation of that of others, and in the fact that some birds will appropriate characteristic phrases of song from others we have a hint of admiration. It is too 
soon to elose the door on inquiry into the evolution of æsthetic emotion.

Wo have to remember also that from time to time value has bcen given to the beautiful by linking it to love. Shapes, patterns, colours, lights, fragrance, movements, perhaps originating for constitutional reasons, as decorative exuberances arise even in complete darkness, come to be seized upon by sclection and brought into the service of preferential mating. To this difficult subject we shall return in Chapter XIV. We simply refer to it now because it suggests one of the ways in which interest in the beautiful might have been cultivated historically in pre-human days.

Another point worthy perhaps of consideration is that asthetic emotion is its own evolutionary reward, since the feeling has a quite noteworthy unifying value in the development of personality, and in its communicability has been, espeeially in music, an important socialising factor. This idea has been elaborated in the work of Guyau-that enthusiastic evolutionist philosopher-who recognised the importance of the Beautiful and of Art in adding social sympathy to social synergy. A common admiration and delight helps to produce a community of feeling and sentiment.

To speak of the evolutionary value of being pleased with beautiful things does not involve the heresy of suggesting that we like beautiful things because of an ulterior reward. The delight is its own reward. But there is no real difficulty here, for an activity, like play, which is exercised for its own sake, may none the less have survival value. Beyond and deeper than this utilitarian interpretation, however, there is the idea-difficult, we confess, to state-that just as a beautiful organic ornament seems often of no use to its possessor, but is an expression of a harmonious life, so 
man's joyous drawing towards the beautiful, when we trace it back far enough, may be an expression of the same, or of a harmony further back still.

$\S 11$. The Significance of the Pervasive Beauty of Animate Nature.

The recognition of the pervasiveness of beauty in the realm of organisms is important. First, because its enjoyment may mean much to man-part of the salt of life. And though its enjoyment may not be brought nearer by any cold-blooded assertions on the subject, man is susceptible to indirect education in reference to the beautiful as well as in relation to the true and the good. Various influenees which may be typified by Gilbert White, Wordsworth, Ruskin, Whitman, and Meredith have done much to increase appreciation. Second, to those who agree with our position that the scientific view of the realm of organisms is not exhaustive, it will not seem far-fetched that we are inelined to dwell on the fact of beauty, regarding asthetic emotion as another right-of-way path towards reality. It is thus that the beautiful has been thought of by many philosophers, such as Schiller and Schelling, "not as a casual and fanciful attribute of certain things or mental states, but as an independent revelation of the essence of reality of the truly real" (Merz, 1914, p. 25). Their suggestion is that the beautiful in Nature may be a key to her deeper significance. As Lotze put it, "It was of high value to look upon beauty, not as a stranger in the world, not as a casual aspect afforded by some phenomena under accidental conditions, but as the fortunate revelation of that principle which permeates all reality with its living activity" (quoted by Merz, 1914, p. 25). Third, in reference to the triad of human ideals- 
the True, the Beautiful, and the Good-is there not signifcance in the correspondence that obtains between these and what we find in nature? To the ideal of the true there corresponds, perhaps, the rational orderliness and harmonious consistency of Nature, but rather, we should say, the reward of those organisms which face the facts effectively with the clear-headedness of vigorous health. To the ideal of the good there corresponds the extraordinary subordination of self to species which is so characteristic of organisms. To the ideal of the beautiful there corresponds the richness of the realm of organisms where ugliness is banned.

\section{SUMMARY.}

In an endeavour to indicate what contribution Natural Science has to make to our general view of the world, it is impossible to pass over the pervasiveness of beauty in the realm of organisms. Scientific investigation bas disclosed it in the microseopically minute, in internal structure, in the well-concealed-everywhere.

We mean by the beautiful that which excites in us the distinctive kind of emotion called asthetic, the characteristic qualities of which, such as duration without satiety, communicability, and detachedness from utility, have been much discussed by experts. What concerns us in this study is the interesting fact that all natural, free-living, fully-formed, bealthy living creatures, which we can contemplate without prejudice, are in their appropriate surroundings artistic harmonies-a joy to behold.

This thesis may be objected to on various grounds-that beauty is wholly in our minds, that our likes and dislikes are wholly due to individual and racial nurture, that there is no agreement as to what is beautiful; but it seems possible to meet these objections. Another series of objections, however, consists of evidence that the realm of organisms is spotted with ugliness; and to meet these it is necessary to emphasise the saving-clauses of our thesis, that it does not apply to the domesticated and cultivated, the diseased or crippled, the unfinished, the parasitic, and the freakish. Moreover, the artistic harmony is often obscure till the creature is seen in its native haunts-a fact of special importance when these are of its own choosing. 
In our xsthetic emotion there is a pbysiological factor of sensory thrill. Pleasant eurhythmic processes are set up within us, - a hodily resonance. But it is a thoroughly mind-and-body or organismal fceling. There is a psychological factor or perceptual response. We project ourselves into the object whose 'form' (in the widest sense) is significant for us and embodies our feeling. We cannot, except abstractly, separate off 'mere sensation' or 'pure perception'-it is the whole organism's concern-and it secms very difficult to dissociate from our æsthetie delight the influenee of certain concepts. Thus the physiologist, Sir John Burdon Sanderson, maintained that an appreciation of adaptiveness bulks largely in our æstbetic enjoyment of animal form and structure. Sımilarly, symbolism may contribute its inextricable influence; or we may discern the touch of the Divine Artist.

The elements that make up the impression we call visual beauty are arrangements and combinations of lines and colours, and a pre-condition of the beautiful is some quality of satisfactoriness in this pattern. In the case of animals, and somewhat apart, pleasing movements may be added to the presentation. But the big fact is that the stamp or halo of heauty is on every free individuality, and if the straight lines and the curves, the patterns, the colours, and the apportionment of the colours be expressions of normal vital processes, and so with rhythmic movements, it becomes easier to understand why they should appeal in a pleasant way to wholesome sensoria with the requisite freedom of response.

The question inevitably arises whether these combinations of lines and colours-which mean so much to us-mean anything to their possessors.

(a) There is no doubt that the 'beauty' bas in some cases direct utility to the organism. For beauty of pattern often spells stable architecture, beauty of line is often the expression of strength and agility, and beauty of eolouring often means a life-saving garment of invisibility. And there are other uses.

(b) In many cases the 'beauty' has vital significance though it cannot be called in itself useful. Thus a pleasing succession of concentric lines may represent the ripple-marks of orderly rhythmic growtb.

(c) In many cases, however, the beautiful seems to be accessory, without utility either direct or indirect. The lines and colours are harmonious, probably because they are the expressions of unified viable individualities which have stood the test of time. The 
monster is a contradiction in terms and is forthwith eliminated. "Ugly is only half way to a thing."

Passing from incarnate beauty to that of animal artificers-in encasement and web, in bower and nest-we recognise precise selection of material, effective use of it, and, it may be, a circumventing or mastery of technical difficulties. There is in varying degrees an external expression of the individuality, the creature creative.

The difficulty of scientifically accounting for man's 'sense of beauty' is doubtless great, as Mr. Balfour has emphasised; but this kind of inquiry is young. (1) The raw materials of æsthetic emotion may have been associated with successful formative endeavour. (2) It is well known that interest in the visually and audibly beautiful has been from time to time closely linked to 'love'. (3) Joyous feeling has a notable unifying influence on the development both. of personality and of society. And there are other considerations.

Perhaps deepest of all in our æsthetic emotion is a sympathetic sharing in every triumph of 'life' over 'matter', in every abiding expression and extension of individuality. Thus Animate $\mathrm{Na}$ ture is to many minds much more significant than Scenery and Precious Stones,-commanding as their beauty is. In any case, there is for man great value in the beauty of the world without. There may be theoretical exaggeration in Goethe's saying: "Sympathy and enjoyment in what we see is in fact the only reality"and it is very satisfying in itself, as reality should be; but there is no risk of practical exaggeration, for the consistent discernment and enjoyment of the heautiful cannot be attained on any easier terms than consistent discernment and enjoyment of the True and the Good. 

LECTURE IX.

THE ISSUES OF LIFE. 



\section{LECTURE IX.}

\section{THE ISSUES OF LIFE.}

§1. The Tactics of Animate Nature. §2. The Twofold Business of Life. §3. The Struggle for Existence. §4. Correction of Some Misconceptions of the Struggle for Existence. §5. The Welfare of the Species. $\$ 6$. As regards Warfare.

\section{$\S 1$. The Tactics of Animate Nature.}

IF we share Bacon's belief that the footprints of the Creator are imprinted on His creatures, we cannot but be interested in inquiring into the general trend of organic activities. What is all the bustle about? What are living creatures, as they are, immediately working towards? If they have an end in any sense in view, as some of them have, what is it and by what means do they accomplish it? Reality has been spoken of as "a totality of striving and willing existence", we have in the realm of organisms a portion of this reality, and we are bound to inquire into the fundamental motives of the striving and crying that surround us.

Some students of the tactics of Animate Nature have discerned in them little to admire and less to imitate. To Huxley, for instance, it seemed that Nature's tactics are so disappointing that Man's best rule for his own conduct is to try to do the direct opposite of what Nature does. Others, such as Prof. Patrick Geddes, have discerned in Animate Nature a materialised ethical process worthy of our closest attention and imitation. Which is right in this case, master or pupil? Others, again, while making no 
pronouncement, have deprecated further inquiry, reminding one of people who are nervous as to the manners of their poor relations. The inquiry is interesting, for if we have made the great assumption that the system of lives which we call Animate Nature is an expression of something more spiritual and abiding than itself a difficulty will arise if the tactics are those of "a dismal cockpit".

Those who believe that Nature is (as Prof. William James phrased it) "the external staging of a many-storied universe, in which spiritual forces have the last word", will have to face a great difficulty if what is often reported about Nature be even approximately true,-that her only word to man is "Each for himself, and extinction take the hindmost". We turn again therefore to our task of justifying the ways of Nature to man by the method of accurate description.

In inquiring into the general tacties of Animate Nature, which we have seen to be pervaded with vitality, with mentality, and with beauty, we must avoid two extremes. The one focusses attention on 'love', the other on 'hunger'; the one emphasises race-preserving, the other self-preserving activities. On the one hand, there is a wealth of illustrations of parental care, of conjugal devotion, of mutual aid, of loyalty to $\mathrm{kin}$, of subordination of the individual to the life of the herd or hive,- - in short, of ' altruistic behaviour', if we can use the term in inverted commas to indicate that it is below the level of strictly ethical conduet.

The other extreme is appalled by the dæmonic element in Nature, the non-moral callousness, the wastefulness, the ruthlessness, the egoism, the mere 'weather'. It is well expressed in William James's famous essay Is Life Worth Living? "Visible nature," he says, "is all plasticity and 
indifference, - a moral multiverse, as one might call it, and not a moral universe. To such a harlot we owe no allegiance; with her as a whole we can establish no moral communion" (1905, p. 43). "Beauty and hideousness, love and cruelty, life and death keep house together in indissoluble partnership; and there gradually steals over us, instead of the old warm notion of a man-loving Deity, that of an awful power that neither hates nor loves, but rolls all things together meaninglessly to a common doom" (1905, p. 41).

Now there is a via media between these two extreme views, and it is the path of accuracy. On the one hand, we must not pick and choose our facts, selecting those which suit our thesis and ignoring the discordant. On the other hand, we must not be gratuitously anthropomorphic, projecting upon Nature concepts drawn from human society which very imperfectly fit. We must also guard against allowing human sentiments, as to supposed cruelty and the like, to lead us astray in domains where they are irrelevant. We must be restrained and critical in the degree to which we read ethical content into animal behaviour,-especially when it is of the instinctive type.

\section{§ 2. The Twofold Business of Life.}

As we contemplate the drama of life among plants and animals, both as we can see it around us with our eyes, and as we can see it with the help of telephotic apparatus (such as the microscope and the palæontological museum!), we discern one perennial problem and endeavour, namely to adjust relations between the active, self-assertive, insistent, insurgent organism and the environment. The inorganic environment is callous, irresponsive, heavy-handed, yet remarkably amenable to life's purposes; the organic environ- 
ment is capricious, unpredictable, combative. On the one hand, we see the Environment acting upon the organism, burning it and stoking it, heating it and cooling it, quickening it and slowing it, moistening it and drying it, provoking it and quieting it, nurturing it and killing it, cradling it and burying it. On the other hand, we see the Organism responding to the environment, operating on it, changing it; thrusting as well as parrying; defying it, mastering it, and using it; even selecting it. Now the business of life is the continual adjustment of this twofold relation. But when we look more closely into the cffective, regulated, self-assertive, self-expressive, insurgent activity which we call 'life', we see that it takes two main directions-caring for self and caring for others. That is the twofold business of life which all pursue,- - the half-awake plant, the dreamy coral, the instinctive ant, the intelligent beaver, and rational man. The imperious primal impulses are 'Hunger' and 'Love', the subject and counter-subject of the great fugue of life. "Why do the people strive and cry?" the poet asked, and gave the lasting answer: "They will have food and they will have children, and they will bring them up as best they can." So is it through the realm of organisms. Of course the words 'hunger' and 'love' must not be used woodenly; they correspond to self-preservation and race-continuance, to self-regarding and other-regarding, to feeding and flowering, to nutrition and reproduction, to self-increase and self-multiplication. We may not be inclined to speak as Erasmus Darwin did of the "Loves of the Plants", but it is sound science to emphasise the fact that, rich as plants are in adaptations which secure food, they are not less rich in adaptations which secure the nurture and dispersal and development of their offspring. 
In their endeavours to secure self-preservation and racecontinuance, organisms exhibit an effectiveness, a persistence, a resourcefulness, and a finesse that is worthy of all admiration. But the shadow on the picture is the supposed Ishmaelitish charaeter of the struggle for existence,- the shadow of what Huxley ealled " the huge gladiatorial show". Sometimes, too, there is an occurrence of what looks like sheer devilry.

\section{§ 3. The Struggle for Existence.}

One of the great facts of life, beyond all doubt, is that summed up by Darwin as "the struggle for existence". Nothing is more familiar, and yet the concept lacks precise definition and is the subject of lamentable misunderstanding. The phrase, as Darwin said, was to be used "in a large and metaphorical sense, including dependence of one being on another, and including (which is more important) not only the life of the individual, but success in leaving progeny" (Origin of Species, p. 50). This does not coincide with the view of some naturalists that the struggle for existence means nothing more nor less than life-and-death competition between individuals of the same kith and kin. If that had been Darwin's meaning, he would not have spoken of using the term "in a large and metaphorical sense", nor would he have spoken of the difficulty he felt in constantly bearing the conclusion in mind. We have to be especially careful since the idea of the struggle for existence was confessedly taken over from human life. It was consciously suggested to Darwin by reading Malthus; it was subconsciously suggested by the keen industrial competition, more striking, because more novel and less regulated, in Darwin's day than ours. 
It is clearest to start with the familiar fact of observation that the life of organisms is seldom an easy affair. The living creature is by its very nature insurgent and it finds itself encompassed by limitations and difficulties. As Spinoza maintained, every individual thing, so far as in it lies, endeavours to persist in its own being. How much more a living agent, that eats into its environment, that grows and stores and multiplies its kind! The vigorous creature is ever hustling and jostling in its will to live. Now, as every one knows, this insurgence of life meets three main difficulties, and the struggle for existence in the strict sense is the reacting clash.

The first difficulty is in the tendency to over-population. One weed could cover the earth in three years, one codfish could soon fill up the vastness of the sea, and one fly could soon shut out the sun. This tendency to overwhelming abundance limits the foothold and food-supply of the prolific organisms and of others in the same area; there are individual reactions against the limitations, and these constitute the struggle for existence which soon counteracts one of its own causes. A second difficulty follows from the pattern of the web of life, that is to say, from the nutritive inter-relations that have in the course of time been established. Plants have banked for animals, which draw on them. The higher animals devour the lower, and Nature is run on a plan of successive reincarnations. This conjugation of the verb to eat involves difficulties, and leads to the struggle for existence. A third limitation is the irregular changefulness of the physical environment.

None of the reasons which we have just recalled can be said to necessitate the struggle for existence. (1) There might have been a flood-bed for the teeming river of life, 
and we know in point of fact that incalculable myriads of minute creatures flourish in the open sea without overcrowding. Moreover, the length of an organism's life is adjustable, and can be regulated in relation to the rate of inerease. (2) It is conceivable that all animals might have been vegetarian and débris-eaters. To a much greater degree than was previously supposed the animals of the sea-floor depend upon detritus, the crumbs of the littoral table. Or much more might have been made of symbiotic partnerships between animals and plants, - so extraordinarily successful in cases like Radiolarians, of which some authorities say that there are five thousand species. (3) There is no necessity that life should be continually vexed by environmental vicissitudes, for there are monotonous conditions in which it flourishes bravely. We know, for instance, of the rich fauna of the great oceanic abysses-that strange, dark, cold, calm, silent, plantless world where there is neither day nor night, neither summer nor winter, but eternal monotony. We see, then, that the struggle for existence is not an inevitable consequence of the conditions of life. In fact, it is often evaded. Reduction of the number of offspring is an evasion of the difficulty of finding foothold in crowded areas; change of diet, e.g., to vegetarianism, evades the necessity for cannibalism; and migration often evades the thrusts and arrows of an unfriendly environment. The true inwardness of the struggle for existence is discerned when we fix our attention not only on the limitations and difficulties, but on the self-assertiveness and insurgence of the ereature, which insists on having its own way.

A second point is that the struggle for existence is not synonymous with great mortality. That may be a problem in itself, but it is not the problem of the struggle for exist- 
ence. When an avalanche or a landslip, on any scale we please, or a sudden fall of temperature, or a great drought, or any eatastrophe wipes out whole regiments of living creatures, the struggle for existence is not illustrated, for the essential idea in the concept of struggle is that the living individual answers back. When on the summer evening the mayflies rise like a living mist from the quiet reaches of the river, and in some cases end their ephemeral aërial life before the twilight is past, there is assuredly great mortality, but there is not in the dying any struggle for existence. They die off in the crisis of giving origin to the next generation, and as they may have spent two or three years of larval sub-aquatic life they may be at their death quite old as insects count age. Similarly, when the baleen whale rushing through the waves engulfs myriads of sea-butterflies in the buge cavern of its mouth, there is great mortality, but no struggle for existence. Nor is there when the squirrel has a meal of beech-nuts, each of them a young life.

The essential idea, often missed, is that the struggle for existence is the clash between life and its limitations, when life insists on its rights and answers back. When organisms react to their limitations and difficulties, when they do not meet these passively, but thrust and parry, experiment and actively evade, and in a hundred ways say "We will live", -there is the struggle for existence. The essence of the struggle is the endeavour after well-being.

Another point, somewhat difficult at first sight, is that inter-specific struggle for existence is not illustrated when all the members of a species meet a difficulty by the same adaptive response, the capacity for which is now ingrained in their constitution. Thus many species offer interesting 
solutions of the problem of meeting the winter; the brown stoats, for instance, by becoming white ermine. But nowadays the stoats cannot help changing their robe; in the same locality they all do it equally well; the ingrained capacity is the indirect outcome of the struggle for existence in the distant past; the stoat's present-day struggle for existence is to be found elsewhere. Inter-specific struggle for existence implies individual and novel reactions and responses to environing difficulties and limitations. As we understand it, inter-specific struggle for existence cannot be illustrated in regard to adaptations shared equally by all the members, but it may be illustrated if there are inequalities in these adaptations, or in the way they are used, or in individual adjustments.

It should also be noted that it is a confusion of thought to identify the struggle for existence with Natural Selection. The concept of struggle is wider than that of selection. The struggle for existence is to be found in the reactions between organisms and their environing limitations, which may include, of course, the presence or antagonism of other organisms. When inequalities or idiosyncrasies in the reactions or responses are of life-saving importance the result is discriminate elimination and the survival of the relatively fitter to the given conditions. But in many cases the result of the struggle for existence is not discriminate elimination. There may be nothing more than a lessening of populationpressure by a large reduction of numbers. And even when discriminate elimination does occur, it may work as slowly as the mills of God. Some writers speak as if a decision was always given there and then. But that is a misunderstanding. The elimination may take the form of gently handicapping those who lack what others have,-handicap- 
ping them so that they have a rather shorter life or a rather less numerous or less successful family. This is precisely what eugenists of the gentler persuasion wish to see in operation in mankind-the replacement rather than the destruc tion of the baser sort.

As is well known, the struggle for existence takes three main forms:- $(a)$ between fellow-organisms of the same kith and kin, (b) between foes of entirely different kinds, and $(c)$ between living creatures and the physical fates.

In regard to the first, Darwin headed a paragraph " Struggle for Life Most Severe Between Individuals and Varieties of the Same Species", and that paragraph, along with a subconscious desire to get a theoretical backing for individualistic human practices, has given rise to the widespread idea that what is most characteristic of Nature is an internecine competition of near kin for food and foothold.

But it is very profitable to examine Darwin's evidence for his momentous conclusion. Not that we doubt that keen competition between fellows is one mode of the struggle for existence; the point is to what extent it obtains. The gladiatorial show conception of Animate Nature is illustrated by the supposed internecine competition between brown rat and black rat, and might almost be called the rat theory of life. The story of this internecine competition, for which Darwin is largely responsible, is well known, but it suffers from the demerit of not being quite true. Long ago Britain had only the Black Rat (Mus rattus) which probably came from Asia through Mediterranean ports. It seems to have been introduced into Western Europe by the ships of the Crusaders. The Brown Rat (Mus decumanus), also of Eastern origin, was a later arrival, becoming common in the early part of the eighteenth century. 
Now the story which had till recently all the expert authority behind it, is that the larger, stronger, fiercer Brown Rat killed off the Black Rat everywhere, and by competition to the death took its place. But the account of the matter given by Dr. Chalmers Mitchell is very different. The Black Rat is far from being extinct in Britain; it is wild and shy, much more active than the Brown Rat; it is the typical barn and granary rat. The Brown Rat is more of an outdoor creature, though the haunter of sewers and drains, to the great extension of which it probably owes a considerable part of its success.

Let us allow that the ranks of the Black Rat have been increased by fresh imports; let us allow that it once was the 'common rat' and is so no longer; let us even allow that if representatives of the two species are shut up in a cage together (a condition of which there are few counterparts in nature!) the brown rats will kill the blacks; yet the edge has been taken off Darwin's famous illustration,the best piece of evidence he adduced in support of his thesis. As Dr. Chalmers Mitchell says, "In this story of the rats, which has been very carefully investigated, there is no trace of a process comparable with the German theory of war as an instance of the struggle for existence. . . . Each species has its different aptitudes, capacities, and preferences, and each insinuates itself into the most suitable environment" (1915, p. 30). The internecine competition has not taken place. A compromise was effected.

The second form of the struggle for existence is between animate foes of entirely different kinds, between herbivore and carnivore, between birds of prey and small mammals, between the grass and the other plants of the meadow, between the thorns and the seedlings in the stony ground. 
Here the competition is sometimes keen, but sometimes a very one-sided affair.

The third form of the struggle for existence is between living creatures and the callous and changeful physical environment. Thus Darwin spoke of the struggle of the plant at the edge of the desert, and one thinks of reactions of animals against the winter's cold, and so on. This is obviously non-competitive; it is crossing swords with Fate.

So we see that in the struggle for existence between organisms and the inorganic environment, the element of direct competition is always absent; in that between organisms of entirely different kinds whose interests conflict it is often absent; and even in the struggle between members of the same kith and kin the supposed state of internecine warfare is often conspicuous by its absence. The furious battles between different kinds of ants, and between disorganised hives of bees, and between true ants and white ants, are among the few phenomena in the animal world that suggest human warfare.

It may be said that this is surely cutting at the roots of Darwinism (Natural Selectionism) to deny that fellows of the same kith and kin are sifted inter se, but we make no such denial. Our doubt is as to whether the sifting is often effected by internecine intra-specific competition. Individuals possessing an advantageous variation which enables them to meet difficulties successfully are favoured by Natural Selection, as the phrase has it; our point is that their success does not necessarily depend on any warfare or competition with their fellows. When a plague enters a household and only one member survives, he does so because his constitution successfully parried the microbe, not by any competition with his brothers and sisters. When the last 
rabbit in the scamper towards the warren is caught by the fox, his elimination is not the result of there being others of his kind who are more alert and agile. The barbarous proverb Lupus lupo lupus was invented by Man as an excuse for his own unnatural behaviour, and there is much better biology in Kipling's Jungle Books.

\section{\$4. Correction of Some Misconceptions of the Struggle for Existence.}

A number of attempts have been made to correct the idea which has taken such firm hold of men's minds that Nature is in a state of ceascless warfare and that there is especially frightful competition for food and foothold among the members of the same species. Thus Herbert Spencer was clearly of opinion that the purely self-sceking animal is a fiction. "Self-sacrifice is no less primordial than self-preservation." "From the dawn of life, altruism has been no less essential than egoism."

Darwin himself in The Descent of Man showed that in many animal societies the struggle between individuals disappears, being replaced by co-operation. Survival is not restricted to the strongest, but may reward those that give the best send-off to their offspring or excel in self-subordination and mutual support. "Those communities," he wrote (Descent of Man, 2nd Ed., p. 163), "which included the greatest number of the most sympathetic members would flourish best, and rear the greatest number of offspring." It should be remembered, too, that one of the tasks which Darwin proposed for himself, but did not accomplish, was an inquiry into the natural checks to over-multiplication.

Kessler, a Russian zoologist, brought forward evidence in support of the thesis that " in the evolution of the organic 
world-in the progressive modification of organic beingsmutual support among individuals plays a much more important part than thcir mutual struggle". Prof. Patrick Geddes also argued that the popular version of the Darwinian picture had become distorted into falseness, and advanced illustrations of the evolutionary rôle of other-regarding as opposed to self-gratifying activities, and of the survivalvalue of subordinating the self to the species. Prof. Henry Drummond in his Lowell Lcctures gave an eloquent exposition of the importance of the struggle for others as contrasted with the struggle for self. Best of all, because most concrete, were Prince Kropotkin's essays on Mutual Aid. With a wealth of illustration he showed the pervasiveness of mutual aid and mutual support in the Animal Kingdom. To him it seemed as much a law of life as mutual struggle, and "of the greatest importance for the maintenance of life, the preservation of each species, and its further evolution".

Now while it is useful to hold over against aggressive competition the fact of mutual aid, there is a more radical way of stating the case. The idea of two struggles, one for self, and one for others, is artificial, and it must be borne in mind that there is much self-expression and much self-subordination which has no direct connection with struggle in the technical sense; witness, for instance, the expression of a well-adapted parental nature that is not meeting with any particular difficulties or limitations. How is the case to be stated? By going back to Darwin's position. Self-assertive organisms, whose inmost nature is endeavour, find themselves faced with baffling difficulties, hemmed in by thwarting limitations. Whenever the creature answers back in an individual way, girding up its loins against these difficulties and hurling itself against these limitations, there 
is the struggle for existence. But there are many different ways of answering back; there are many different cards that the organism can play. One creature uses its weapons with increased skill, another finds discretion the better part of valour; both are reacting in the struggle for existence. One creature intensifies its competitive efforts, another seeks to ensure the safety and success of its offspring; both are reacting in the struggle for existence. In the egg-capsules of the whelk some of the larvæ devour the rest-a grim cannibalism in the cradle - this is the one extreme, of which there are few illustrations. As nestling birds are only in process of becoming warm-blooded, it is of great importance in many eases that they should be surrounded by non-conducting materials. When we see an individual bird taking particular care to add feather to feather till there are over two thousand, we know that it is unmistakably strengthening its own and its family's foothold in the struggle for existence, but its reaction to environing difficulties does not hurt any other bird. This is at the opposite pole, and similar illustrations abound.

The race is not always to the swift nor the battle to the strong. The concept of struggle includes self-assertive competition, but it also includes a gentle endeavour after wellbeing. One creature asserts itself by sharpening its claws and whetting its teeth, another finds a place where it is invisible. One intensifies competition with its kin around the platter of subsistence-though this is much less frequent than is supposed; another expresses itself in more elaborate parental care. Nor can we forget that evasive change of habit and habitat known as parasitism-the door to which is always open. The organism has many a thrust and parry, -all of which are logically included in the conception of 
reactions and responses to environing difficulties and limitations.

Thus the nightmare picture of the Struggle for Existence as "a dismal cockpit" gives place to a more accurate one. It is often an Endeavour after Well-being on a noncompetitive basis. We see reason to regard as inaccurate the conception of Animate Nature as "all weather".

We must not allow interests other than those of accuracy and consistency to intrude in scientific inquiry, but the fact must be pointed out that vague views of what obtains in Nature have had a deplorable influence in human affairs. What was at first said almost in jest, "The struggle for existence-laissez faire-the survival of the fittest", has become to some a philosophy of life. There has been a sinister effect of careless Darwinism. As has been well said, "It has given the seeming sanction of science at one time to a soulless commercialism, at another to an overweening pride of race and the lust of dominion. By one of the paradoxes to which the history of thought is prone, the theory of progress has been in the main a weapon in the hands of intellectual and moral reaction. But every new theory has to go through its infantile diseases. The worst of these arises from that distemper of the mind, peculiarly prevalent in the half-educated world of modern thought, which prompts men to pick up ideas which specialists have elaborated for their own purposes in their own departments and apply them indiscriminately as catchwords to settle questions arising in another sphere."

What is fallacious in the careless Darwinism alluded to? There is: (1) a narrow and wooden conception of the Struggle for Existence which includes many endearours that are not directly competitive at all; (2) a failure to perceive 
that the survival of the fittest means only the survival of those relatively best adapted to particular conditions, which may be parasitism or (in some ants) slave-keeping; (3) a forgetfulness of the apartness of human society from the animal world with which it is nevertheless solidary-an apartness which forbids any uncriticised transference of a purely biological induction to social affairs; and (4) an ignoring of the historical fact, which we dare mention even after years of carnage, that the trend of civilisation has been away from the harsher forms of Nature's régime.

\section{§5. The Welfare of the Species.}

When we pass from the struggle for existence in its many forms to consider old-established activities which secure the welfare of the species, we arrive at a result which colours our whole view of Animate Nature, and is of great interest to philosophy,- to that philosophy at least which has one hand on Human History and the other on Natural History, and is as a daysman between them. Postponing the difficult question as to where we should draw the line which delimits set purpose, we find that a very large part of the time and energy of living creatures is given over to activities which do not make for self-increase or self-stability or selfpreservation, but make for the welfare of the family, the kin, and the species.

To a degree which has not been adequately realised by naturalists, organisms are adapted to, and give themselves up to securing the welfare of their race. In their multiplication, in their reproductive processes, in their parental care, individuals spend themselves in activities which are often not to their own advantage. Their personal interests have been subordinated to those of the species. They are borne 
on by impulses and instincts which are as compelling as hunger and thirst, but the satisfaction of these rarely makes for individual advantage. Indeed it is often fatal. Reproduction is often not merely the distant beginning of the individual's death, but has death as its immediate nemesis. In some higher animals love is its own reward and the parental life is enriched by the family, but this is true only of a minority. Even sexual gratification is as often absent as present. According to Goethe, Nature holds that for the pains of a lifetime it is fair payment to get a couple of draughts from the tankard of love. But many animals have only one draught and many none at all. How many insects there are, with a parental solicitude and an elaborateness of care that strikes one dumb, who have not even the psychic reward of seeing the offspring for the good of which they more or less unwittingly spend themselves.

Professor Cresson (1913) has done a notable service in illustrating with accuracy and learning the extent to which there is subordination of the individual to the species. There is the physiological cost of producing germ-cells, so obvious in some fishes; of nourishing the young before birth-familiarly great in most mammals; of feeding the offspring after they are hatched or born-as in many insects and almost all birds and mammals. There is the danger and exhaustion of reproduction, for many female organisms die of it, and the drone-bees are far from being the only males that are sacrificed on the altar of sex.

Taking birds, for instance, we are all more or less familiar with the work of nest-making (MacGillivray counted over two thousand feathers in the nest of the Long-tailed Tit), with the patience of brooding (sometimes involving fatal exposure), with the prodigious industry exhibited in feeding 
the family (the parent bird wearing itself to a skeleton), with the self-forgetfulness shown in guarding, cleaning, and educating the young. But have we sufficiently weighed the general fact that although it is the birds' meat and drink to do all this, it is not self-preservation at any rate that results? Many adult insects spend by far the greater part of their time and energy in securing the safety of their eggs and the nourishment of the young. It is hardly an exaggeration to say with Cresson: "Everything for the species; everything by the individual; nothing for the individual."

What difficulties often lie in the way of the fertilisation of the egg-cell! How many tens of thousands of years, how many variations, how much vital energy, how much searching elimination have gone to the establishment of the adaptations which secure this end,- the fragrance, the flags of colour, and the strategically placed nectaries in flowering plants, the imperious desires, the intricate attractions, and the subtle psychical embroidery in the case of animals. There are parallel adaptations of structure and habit, which secure the welfare of the young.

The fact which must be included in our conception of organic life is the amount of energy that is expended towards the maintenance of the species rather than towards self-preserration and self-gratification. Animals have become organically interested in working for the species, and even though they know it not, their individuality completes itself in the larger life of their race. What it seems to mean, according to current evolution-theory, is that variations (probably altogether germinal to begin with) in directions which made for the welfare of offspring, family, society, or species, have been established in the course of selection no less securely than those which made for self-preservation. Meta- 
phorically speaking, we may say that this has been Nature's way of setting the seal of her approval on altruistic behaviour, even when the animal's left hand does not know what its right hand doeth.

\section{$\S 6$. As regards Warfare.}

The position here defended has an obvious practical interest,-in reference to war, for some have seriously maintained that human warfare has what is called 'Nature's sanction', that it is consonant with what goes on throughout Animate Nature, which is believed to be in a state of universal Hobbesian warfare, each against all, and no discharge for any. Moreover, human warfare is declared to be a continuation of a natural process which necessarily leads to the survival of the relatively more fit. In the words of von Bernhardi: "Wherever we look in nature, we find that war is a fundamental law of evolution. This great verity, which has been recognised in past ages, has been convincingly demonstrated in modern times by Charles Darwin."

Prof. Karl Pearson has given strong expression to the view that a nation should be "kept up to a high pitch of internal efficiency by insuring that its numbers are substantially recruited from the better stocks, and kept up to a high pitch of external efficiency by contest, chiefly by way of war with inferior races, and with equal races by the struggle for trade-routes and for the sources of food supply" . . . (1901, p. 44). "When the struggle for existence between races is suspended, the solution of great problems may be unnaturally postponed; instead of the slow stern processes of evolution, cataclysmal solutions are prepared for the future." . . . (1901, p. 20). "There will be nothing to check the fertility of inferior stock; the relentless law 
of heredity will not be controlled and guided by natural selection. Man will stagnate" .-. (1901, p. 24). Thus imperialism and militarism find theoretical justification,even from one who is quite clear that "the safety of a gregarious animal-and man is essentially such-depends upon the intensity with which the social instinct has been developed". "The stability of a race depends entirely on the extent to which the social feelings have got a real hold on it" (1901, p. 47).

We need not raise the question of the wisdom of appealing to Nature for ethical guidance, nor dwell on the danger involved in the fact that the Darwinian concept of struggle arose historically from a consideration of human problems; there are more important things to say. First, as we have seen, internecine competition among near kin is only one mode of the struggle for existence. Especially among the finer forms of life do we find that the answer-back which is given to the environing limitations is less and less frequently an intensification of competition, is more and more frequently something subtler, some modification of parental sacrifice, some co-operative device, some experiment in sociality. Dr. Chalmers Mitchell goes the length of saying (too strongly, we think) that "the struggle for existence as propounded by Charles Darwin, and as it can be followed in Nature, has no resemblance with human warfare" (1915, p. 108). And again, as entirely independent confirmation of what we have maintained in Darwinism and Human Life (1909) and elsewhere, we may quote this interesting passage: "Looking through the Animal Kingdom as a whole, and remembering that the Vegetable Kingdom is as much subject and responsive to whatsoever may be the law of organic evolution, I find no grounds for interpreting 
Darwin's 'metaphorical phrase', the struggle for existence, in any sense that would make it a justification of war between nations. It is my business just now to refute a mis. conception of the struggle rather than to explain what it is. But, if the latter were my task, I could adduco from the writings of Darwin himself, and from those of later naturalists, a thousand instances taken from the Animal Kingdom in which success has come about by means analogous with the cultivation of all the peaceful arts, the raising of the intelligence, and the heightening of the emotions of love and pity" (1915, p. 41).

Second, in spite of the one hundred and fifty definitions of war, we may venture to regard the essence of it as an organised flesh and blood struggle between communities or nationalities, and if this be so its analogue is to be looked for in the quite exceptional group-competition which sometimes occurs among some social insects, notably among ants, and not in the competitive forms of the struggle which may occur between individual animals of the same species.

Third, as Dr. Chalmers Mitchell points out, the fallacious comparison between human warfare and the struggle for existence breaks down because "modern nations are not units of the same order as the units of the animal and vegetable kingdom" (p. 108). Nationalities “differ from the units of zoology and botany in that the individuals composing them are not united by blood-relationship. Even if the struggle for existence were the sole law that had shaped and trimmed the tree of life, it does not necessarily apply to the political communities of men, for these cohere not because of common descent but because of bonds that are peculiar to the human race" (p. 64).

The appeal to human history, which the militarists make 
confidently, has seemed to many to show that civilisation was born out of war. Even Maine spoke of the "Universal belligerency of primitive mankind". But scientific inquiry does not confirm this conclusion. In a valuable article Mr. Havelock Ellis (1919) makes the following points: (1) Chellean man, who first used permanent and indubitably human tools, may have lived about 27,000 years ago, so that our 'historical' period does not cover a large part of our history. But what Palæolithic weapons and art suggest is in the main hunting not fighting. (2) If the culture of the primitive Mousterians survives among the Australians, that of the Aurignacians among the Bushmen, and that of the Magdalenians among the Eskimo, what the study of these contemporary ancestors of ours secms to show is that war, apart from regulated punishment and blood-vengeance, is almost unknown. 'Savages' are on the whole not warlike. (3) "War probably began late in the history of mankind, it developed slowly out of animal hunting by way of a regulated attempt to secure justice as well as the gratification of revenge, it was immensely stimulated by the discoveries of the metals, and especially iron; above all, it owed its expansion to two great forces, the attractive force of booty and commercial gain in front, and the propulsive force of a confined population with a high birth-rate behind. . . ." "War was a result, and not a cause, of social organisation."

We think that there is a risk of exaggerating the importance of a high birth-rate as a factor in the evolution of warfare, for primitive peoples had their. own rough ways of keeping a population balance. Perhaps, again, Mr. Ellis underrates the importance of variation-especially social variation-as a cause of war. Therefore while it is with 
conviction that he looks forward to the control of the birthrate and to the regularisation of industrialism as likely to bring wars to an end, we should add as a more positive pacific factor an increase of inter-relations which will promote tolerance for, and intelligent appreciation of those who are very different from ourselves.

But the immediate point is that the militarists' appeal to history is not any more convincing than their appeal to biology. The facts are against them in both fields.

The third appeal of the militarists is to ethics, and may be illustrated by Moltke's famous letter of 1880- "Eternal peace is a dream, and not even a beautiful dream, and war is a part of God's world-order. In war are developed the noblest virtues of mankind; courage and sacrifice, fidelity and the willingness to sacrifice life itself. Without war the world would be swallowed up in materialism." There are two half-truths here. The first is that war does evoke noble virtues; the missing half is that there are other endeavours outside of war that may evoke these virtues not less well, and much less wastefully. Moreover, no one can forget that war evokes other qualities than virtues. The second half-truth is that struggle and sifting seem to be needed for the welfare of humanity; the missing half is that war is only one of the many forms of struggle. As Havelock Ellis tersely puts it, "Conflict is a genus with many species, of which war is only one"-and one of violence, from which at every level it is the effort of civilisation to deliver us. Struggle we can never do without, but of war the world has had more than enough.

Let us state the case more generally. Endeavour and sifting are surely conditions of progress, but war between races is only one mode and it seems very doubtful that it 
makes for real superiority. If the energy misdirected by the facile acceptance of bad biology were turned to practicable eugenics, to hygienic reform, to inter-national adventure, if men looked out for the "moral equivalents of war", there might be a way out of the impasse which Prof. Karl Pearson pictures as inevitable if there is cessation in the struggle of race against race. Are we not beginning (to use Prof. Lovejoy's words) "to recognise that the effort to cram the moral ideas of civilised man into the rigid mould of the natural selection hypothesis is an artificial and not very promising enterprise" (1909, p. 99)?

Furthermore, when Man has recourse to internecine competition among fellows, - to what is, let us say, remotely analogous to a primitive and crude form of the struggle for existence-exhibited by amœbæ, if not by rats-he cannot console himself with the belief that this must result in the survival of the fittest in any desirable human sense. For the struggle for existence need not result in the survival of the strongest, cleverest, or best. It never results in more than the survival of those relatively more fit to the given conditions, and these may be on the downgrade, not on the upgrade. As a matter of fact, there is considerable reason to believe that, as regards the members of either side, war acts on the whole dysgenically, by sifting out those whom the race can least afford to lose.

\section{IN CONCLUSION.}

It is not maintained that there are no shadows in Nature - wildness', wastefulness, parasitism, and even, at times, positive disharmony-but, postponing a discussion of some of these difficulties, we are concerned here to point out that although there is in the routine of Animate Nature much 
hunting and being hunted, much devouring and being devoured, that is only one side of the picture.

Outside the struggle for existence in the strict sense there is undeniably a large amount of established self-preservative routine, but there is at least an equally large amount of established race-preservative routine. Our total impression must do justice to both sets of facts. And within the bounds of the struggle for existence in the strict sense there are many modes, some not strictly competitive at all. The struggle which Nietzsche saw in Nature and condescended to approve of, was not a scramble of starvelings around the platter of subsistence, but the elbowing and jostling of masterful individualities; and we maintain that much of this quality of insurgence is familiar to the field naturalist. But apart from elbowing and jostling, and apart from internecine competition and sanguinary combats, there is much of the struggle for existence which might often be quite accurately called the endeavour after well-being, and much, as Darwin emphasised, which may be described as self-subordinating experiment and effort to secure the success of the offspring.

\section{SUMMARY.}

Some students of the tactics of Animate Nature have discerned in them little to admire and less to imitate. Huxley and James are here in agreement. Others, such as Geddes and Kropotkin, have discerned a materialised ethical process. The discrepancy is partly due to focussing attention now on 'hunger' and again on 'love', now on 'egoistic' and again on 'altruistic' activities, now on selfpreservation and self-increase and again on race-continuance and eugenic success. Both sets of facts must be kept in view.

The twofold business of living creatures is caring for self and caring for others. Hunger and love, in the widest sense, form the subject and the counter-subject of the great fugue of life. In satisfying these imperious primal impulses the organism encounters 
obstacles, and the inmost secret of life, from first to last, is endeavour. The perennial problem is to adjust relations between the self-expression of the organism and the indifference, or hostility, or conflicting interests in its environment.

All the fresh reactions and responses which living creatures make to environing difficulties and limitations are summed up in the Darwinian concept of the Struggle for Existence which has suffered from widespread misunderstanding. As is well known, the three main difficulties are those involved in the tendency to over-population, in the nutritive dependence of one creature upon another, and in the changefulness of the environment. As is also well known, the struggle takes three main forms,--between fellows of the same kith and kin, between foes of entirely different kinds, and between organisms and their inorganic surroundings. But what is less clearly recognised is that the struggle need not be directly competitive, need not be sanguinary, need not lead to elimination there and then, and that it is often more accurately described as an endeavour after well-being. The race is not always to the swift, nor the battle to the strong, for, as Darwin elearly recognised, survival may be the reward of those who give the best send-off to their offspring, or to those who vary most in the direction of self-subordination.

Corrections of the idea that the struggle for existence is necessarily an internecine competition between kin around the margin of subsistence (of which there are remarkably few good illustrations) have been offered by Spencer, Kessler, Geddes, Drummond, Kropotkin, and others. And Darwin safeguarded himself carefully. Instead of opposing "Struggle for Self" and "Struggle for Others", or "Mutual Struggle" and "Mutual Aid", it is scientifically clearer to recognise that the concept of Struggle includes all the reactions and responses which individual organisms make in face of difficulties. Intensifying competition is one mode, an elaboration of parental care is another, an experiment in parasitism is another, a new departure in sociality another, and there are many more-all of which pay. Thus the nightmare picture of the Struggle for Existence as "a dismal cockpit" gives place to a more accurate one, which is more conformable with the assumption that Nature is not "all weather" or "a moral multiverse".

The competitive form of the struggle for existence is not illustrated when all the members of a species meet a familiar difficulty with equal effectiveness, the capacity for the response being ingrained in the constitution. But it is interesting to turn to these 
securely established ways, to see how large a proportion of the energy and time at the disposal of living ereatures is spent in activities which make not for self-increase, self-stability, or self-preservation, but for the welfare of the family, the kin, and the species. Neither naturalists nor philosophers have adequately realised the extent to which there is throughout Animate Nature a subordination of the individual to the species. Survival is often the reward of the individualistic competitor, but not less frequently of those with a capacity for self-forgetfulness.

There is little in common between the Darwinian struggle for existence and human warfare. Modern nationalities are not comparable to individual organisms. Even if the analogy were closer it would afford no biological justification for war, for natural selection in the struggle for existence results only in the survival of the relatively more fit to given conditions. 
LECTURE $\mathrm{X}$.

ADAPTIVENESS AND PURPOSIVENESS. 



\section{LECTURE $\mathrm{X}$.}

\section{ADAPTIVENESS AND PURPOSIVENESS.}

§1. Animate Nature Abounds in Adaptations. §2. Their Origin neither by Design nor Mechanical. §3. Is There 'Purpose' in the Inorganic Domain? $\$ 4$. Purposefulness and Purposiveness in II uman Behaviour. §5. Purposiveness and Purposefulness in Animal Behaviour. \$6. The Purposelikeness of the Ordinary Functioning of the Body is Covered bi the Concept of Adaptation. § 7. Provisional Conclusion and Anticipation.

Our survey of the Realm of Organisms as it is affords evidence in support of the following propositions: (1) that living creatures are individualities standing apart from things in general and not exhaustively described in mechanistic terms; (2) that their lives abound in behaviour with a psychical aspect; (3) that there is in Animate Nature a prevalence of orderly systematisation, balance, and smooth working; (4) that there is a pervasive beauty both hidden and revealed; and (5) that a very large proportion of the timo and energy at the disposal of organisms is devoted to activities which make not for self-maintenance and selfaggrandisement, but for the continuance and welfare of the race. In fact, we find in Animate Nature far-reaching correspondence to the ideals of the True, the Beautiful, and the Good-correspondences which may suggest to some a possible line of development for Natural Theology.

§1. Animate Nature Abounds in Adaptations.

A survey of the realm of organisms affords another great impression and that is the prevalence of adaptations. "The 
narrowest hinge in my hand puts to scorn all machinery"; the hand as a whole is the subject of a Bridgewater Treatise. The Vertebrate eye is extraordinarily well adapted, in spite of the instrumental imperfections which Helmholtz discovered. The functional correlations of internal organs such as heart and lungs are as effective as they are delicate. The flat-fish is so adaptable in its coloration to the pattern of the sea-floor on which it rests that it has practically a Gyges ring, making itself invisible, sometimes almost instantaneously. Flowers and their welcome insect-visitors are suited to one another as glove to hand. The realm of organisms abounds in adaptations, some extraordinarily perfect, some in process of becoming perfect.

First there are the structural adaptations of the organism -some with internal and some with external reference, some static, some dynamic. The internal structure of a long bone or of the stem of a plant is suited in detail to stand the strains and stresses to which it is exposed. The same quality of architectural stability may be seen everywhere from the scaffolding of a siliceous sponge like $\nabla$ enus's Flower Basket to the spine of a sea-urchin, from the spirally twisted encasement of an arenaceous Foraminifer to the prismatic structure of the enamel of our teeth.

Less static are the adaptations of parts that move and work. The adaptations of a bird's skeleton for flight and for bipedal progression are many and thorough. The heart is a masterpiece of fitness, and in many cases, as in the antelope on the plains or in the ptarmigan on the high mountains, there are interesting special adaptations of the heart to stand special strain. The delicacy and complexity of the mouth-parts of such insects as mosquitoes may well evoke the artificer's admiration. 


\section{ADAP'TIVENESS AND PURPOSIVENESS}

Of great interest are the co-ordinating functional adjustments which secure smooth working. A fine example is the heat-regulating arrangement or thermotaxis of birds and mammals, which adjusts the production of animal heat so as to meet the loss. Superimposed on this, as it were, are the special adjustments which bring about winter-sleep in hibernating mammals. And there is no internal regulation more worthy of our admiration than the manner in which the mother-mammal is functionally prepared for the antenatal development of the offspring and its nurture after birth. The adaptive regulatory rôle of the internal secretions is one of the most fascinating chapters in modern physiology.

Inexhaustible, again, are the illustrations of the manner in which living creatures are adapted to the particular conditions of their life. The mole, living underground, is adapted in its short vertical fur and in the absence of an ear-trumpet to the reduction of friction in burrowing; its hand has become an extraordinary shovel and its shouldergirdle and associated musculature are powerfully developed; the minute, imperfectly developed eye is good enough for what is required of it, and it is hidden by hair so that it does not get rubbed and become a source of weakness; and so the zoologist goes on.

We may also refer to the theoretically very interesting inter-organismal adaptations. These may be between organisms of the same kind, between parent and offspring, between male and female. Even the male parent may be adapted to the offspring as we see in the pouch of the sea-horse, and in the still more striking case of the New Guinea fresh-water fish called Kurtus, where a hooked bony process grows from the top of the male's head at the breeding season and serves for the suspension of the bunch of 
eggs. The young marsupials are born prematurely and cannot even suck; tho mother places them in her external pocket of skin and has a special arrangement for forcing the milk into their mouth. They meet this, so to speak, with a special adaptation that prevents the milk going down the wrong way.

There are also inter-organismal adaptations between creatures of different kinds, of which the crowning examples are to be found in the way certain flowers and certain insects are suited for making the best of one another. Very striking also are the numerous mutually belpful associations which have been established-partnerships, commensalism, and symbiosis, in which there is sometimes two-sided adaptation. The case is repulsive, but the parasite is often adapted to its drifting life of ease and to making much of its host, which, in turn, is often adapted so that it hardly suffers at all from its guest. In the mimetic resemblance of one creature to another there is again adaptation, often of almost incredible subtlety.

In Indo-Pacific crabs of the genus Melia a delicate seaanemone is often carried on the forceps, and probably serves to paralyse the crab's prey with its batteries of stinging cells. It is quaintly suggestive of a tool, and its occasional absence shows that it is not vitally necessary. But the partnership or commensalism is probably of very old standing, since the denticles of the forceps are elongated into needles which are adaptively suited to keeping a firm grip of the 'tool'.

We are accustomed to the idea of adaptations, but perhaps we are not sufficiently appreciative of their nicety. When winter sets in, the North American ruffed grouse puts on snow-shoes-a row of projecting plates on each side of each toe so that the bird can tread on the loose snow without 
sinking in. The African egg-eating snake, Dasypeltis, has very few teeth and it would not be profitable to crack the eggs in its mouth; the egg slips intact into the gullet, where it is met by the sharp points of the inferior spines of a number of vertebræ. These project into the gullet and cut the egg-shells, so that none of the precious food is wasted. The spines are said to be actually tipped with enamel, the hardest of all tissues. The empty broken egg-shells are always returned.

An adaptation that gives us pause is the 'egg-tooth' found at the tip of the bill in many young birds, and used by them to break a way through the imprisoning egg-shell. It is a hard thickening of horn and lime at the tip of the bill, and since it develops before the horny ensheathment of the beak it may be a residue of a very ancient scaly armature in Reptilian ancestors of birds. Be this as it may, the instrument is an effective one and it is used only once! What happens is this: the young bird ready to be hatched thrusts its beak into the air-chamber that forms at the broad end of the egg; air rushes down the nostrils and fills the lungs for the first time; in the exhilaration of this first breath the unhatched bird knocks vigorously at the shell and breaks open the prison doors. After a few days, in most cases, the egg-tooth, having done its work, falls off,-a well-adapted instrument that functions only once.

But there is a further detail which is of much interest. The bill and its egg-tooth are only the instruments; what about the musculature which works these? Prof. Franz Keibel has inquired into this in the case of the unhatched chick and duckling. He finds that the work is done by a muscle called the musculus complexus, and that this is very markedly hypertrophied for some time before hatching. On 


\section{ADAPTIVENESS AND PURPOSIVENESS}

the tenth day after hatching, it shows no peculiarity. Here, then, we have a simple instance of the way in which development proceeds as if it were working with a purpose. How comes that musculus complexus to be temporarily exaggerated in strength, in relation to the breaking of the eggshell, - an action which only occurs once in each generation?

The idea of adaptation is sometimes held far too narrowly, and a needless difficulty is made over the fact that some specific characters are not known to be adaptive to any particular condition of life. But, in the first place, some characters supposed at first to be quite indifferent have been shown, after closer acquaintance with the creature, to be finely adaptive. And, in the sceond place, an organism is not a system of pegs on which a hundred 'characters' are hung, it is a harmonious unity, viable and persisting in virtue of its subtle internal equilibrium as well as in virtue of the adjustment of its tout ensemble to the conditions of life. Adaptation may have an internal as well as an external reference.

Beyond particular instances of organismal adaptation, we have the broad fact that in a given association of organisms a balanced modus vivendi is arrived at, a compromise be tween competing interests, so that the system persists and works smoothly. The balance of nature is the largest of all adaptations. Just as the Systema Naturæ of the taxonomist-the orderly classification of the classifier-speaks of rationality; so the vital systema naturæ which the naturalist discloses is also a cosmos. There is a systematisation or co-ordination of lives, world-wide in its scope, and becoming ever more subtle in its accomplishment. 


\section{ADAPTIVENESS AND PURPOSIVENESS}

\section{§2. Their Origin neither by Design nor Mechanical.}

Opposite the title-page of Darwin's Origin of Species, there is a quotation from one of the Bridgewater Treatises. A judicious quotation it is, but, as Professor Lovejoy points out, there is a historic irony in finding it at the outset of a book which was the death-sentence of the kind of argument most characteristic of the treatises in question. Darwin sought to show that, if copious variability be granted and abundance of time $b_{3}$ allowed, then Nature's sifting-the process of Natural Selection-will account for all the striking adaptations from which many thoughtful observers had been wont to argue directly to theism. He says himself: "The old argument from design in nature .. . which once seemed to me so conclusive, fails, now that the law of natural selection has been discovered. We can no longer argue that, for instance, the beautiful hinge of a bivalve shell must have been made by an intelligent being, like the hinge of a door by man. There seems to be no more design in the variability of organic beings, and in the action of natural selection, than in the eourse which the wind blows."

Now we cannot return to any crude form of the old idea that the thousand and one adaptations of organisms, which gratify our sense of fitness, are the direct outcome of the design of a divine artificer. It is agreed that they have been more or less gradually evolved by the operation of natural factors. They have been wrought out in what is often called Nature's workshop.

On the other hand, we cannot accept Darwin's statement that the evolution of adaptations is comparable to the work of the wind among the snow-drifts. The inadequacy of the statement is fourfold. 
(1) The raw materials of adaptations are variations or mutations - the precious idiosyncrasies of structure and function that are continually cropping up, that keep the realm of organisms on the move. Some of these variations may be accidental and some necessitated, but of many, especially those which may be called 'new departures', all we can say is that they arise,-apparently from within the arcana of the germ-cells. They look like expressions of inherent creative spontaneity, like experiments in self-expression. And it must be remembered that a germ-cell is not an ordinary cell, but a condensed implicit individuality, rich in the gains of the past, rich in possibilities for the future, - a psycho-physical being telescoped down. In any case, while our ignorance of the origin of variations remains, as in Darwin's day, profound, there is no reason why the argumentum ad ignorantiam should favour mechanistic interpretation. The fact is that we cannot at present give a mechanical account of the origin of the crop of variations from which Nature's weeding removes the tares. We always reckon without our host in Biology when we leave life out.

(2) An important idea, which we cannot at present elaborate, is that the variations or new departures which take hold must not be inconsistent with the already established organic architecture. Just as the architect or the crystal must build congruently, so the varying organism must not contradict itself. The novelty must be in keeping or harmony with what has preceded, with what has already justified itself as fit. There are very few monsters to be seen in wild Nature, for they express a contradiction in terms and cannot live in natural conditions. Nay more, very few monsters ever appear in wild Nature, for the germ-cell must be a viable unity, and even in its experiments it is 


\section{ADAPTIVENESS AND PURPOSIVENESS}

controlled by the past to hold fast to that which is good. It is a very interesting fact that some monsters have been experimentally produced by disharmonious mongrel fertilisation of egg-cells.

(3) It is admitted that one of the characteristics of ' $\mathrm{Na}$ ture's workshop' is the number of automatic arrangements. In making a machine an artificer literally selects; in establishing a breed of animals Man literally selects; but Natural Selection is a metaphorical term,-the sifting is very largely automatic. The survivors survive automatically in virtue of the possession of certain advantageous qualities; the eliminated disappear automatically because of the absence of certain advantageous qualities or the presence of others that are fatal. But this is not the whole truth.

The selection that occurs is not haphazard; it bears some relation to the previously established external systematisation which we call the web of life, just as social criticism which makes it difficult for the unreliable to get on is not haphazard, but bears some relation to previously established traditions and standards. The elimination in either case is remote from fortuity or capriciousness. It always has, of course, an immediate reference to the present and not to the future; but the present has been determined by a past selection of the fit and embodies that selection in an objective siere of great subtlety. Since the sieve is a systematisation of fitness, it tends to sift towards fitness in the future as well as in the present-unless, indeed, the conditions of the future should greatly change.

Let us repeat this argument. There is in each case a line of evolution that pays; it has been reached by past variations; new variations that are congruent with the past are on the whole most likely to appear and to eatch on; there- 


\section{8

fore a variation may have a prospective value. Moreover, the external systematisation which forms the sieve is the embodiment of the results of ages of sifting. Therefore fortuitousness dwindles away. Sir Ray Lankester is inaccurate in speaking of evolution as a "chapter of accidents".

(4) Again, we must bear in mind that in addition to varying, organisms often take an active part in their own evolution. They are anything but passive in a game Fate plays. They may select the environment that suits them, and play the cards with which variability supplies them. And this is not automatic. If a change in instinctive behaviour (e.g., that exhibited in fashioning a wasp's nest) be the outcrop of a germinal mutation, it is not likely to persist unless it is congruent with the previously established routine, and it is not likely to come to stay unless it pass muster in the individual apprenticeship when novelties are tested, an apprenticeship in which, according to some careful students of behaviour, the slender rill of intelligence is sometimes to be detected even in those creatures most thoroughly dominated by instinctive equipment.

We see, then, that it is not legitimate to say that a mechanistic description has been given of the establishment of adaptations, or even to say, without qualification, that they have been turned out automatically in the workshop of $\mathrm{Na}$ ture. Darwin's comparison of the process to the work of the wind expressed an error of judgment, for the blowing of the wind is altogether mechanically necessitated, and we cannot admit that this is true of organic evolution where individuality exists and counts.

But let us suppose that we have made some mistake in cur argument, and that evolution is more, not less, automatic than Darwin believed. What then? We look with great 
satisfaction at a contrivance like a linotype printing machine, or a monorail engine with its equilibrating gyroscope, or at a watch (had not Bridgewaterism made us tired of it); they all show much skill on the part of the artificer-the original artificer at least. If we were told, however, that the contrivance we admire was not made by an artificer at all, but was turned out by an automatic machine, our admiration would simply be shifted to the designer or artificer of the original automatic machine, and we should admire all the more if the original device was very simple. So in Biology, the basal fact remains that organisms have had, and still have, the capacity of evolving adaptively. They have it in virtue of certain intrinsic qualities, previously discussed, which are much more striking than readymade fitnesses. It is because living creatures are irritable, persistent, registrative, variable, and so on, that they have been able to evolve in a consummately adaptive way. This was, of course, what Charles Kingsley had in mind in his immortal child's-story when he put into the mouth of Mother Carey the words: "I make things make themselves." This is a very different view, it must be remarked, from that of an infinite regress of automatic machines, with no original designer at all; for this does not seem to us to be a clearly conceivable idea.

Time was when the multitudinous fitnesses of Animate Nature were the subject of admiring wonder, but this has shrivelled. Surely, however, the loss of wonder is not altogether creditable. If an adaptation is wrought out gradually by a co-operation of factors, that is just as wonderful as a special creation at the hands of a divine artificer; and it is more intelligible. And even if the process of evolving adaptations should turn out to be more automatic than it 
seems to us to have been, it remains very wonderful that living creatures should be so adaptable, should have so rich a capacity of supplying the raw materials for adaptations.

\section{§ 3. Is There 'Purpose' in the Inorganic Domain?}

Leaving in the meantime the fact of almost universal adaptiveness in the realm of organisms, let us turn to the difficult problem of purpose. In the inorganic domain we see the river earving its course in the rock, the wind blowing the snow into beautiful wreaths, the various weathering processes making scenery, but these results are not adaptive to a future, and keeping to things as they are, we feel no reason to speak of purpose. The eoncept of purpose is irrelevant in the domain of the inorganic where there are no individualities and no alternatives, but rigorous concatenation and mechanical necessitation everywhere.

The hylozoist beholding the stream, flowing like an endless snake, may point to its enduring purpose. It sweeps some obstacles away and patiently undermines others; it bides its time with patience and overflows what it cannot circumvent; it consents to sinuous meanderings, and then, on a day of flood, cuts off a huge salient; it will even submit to an apparent death, becoming an underground current, if it may thereby accomplish its end of reaching the sea. But this remains fanciful and unconvincing: the stream is not a very long snake nor an individuality in any sense, it has no alternative in anything it does; it is not in the true sense an agent.

Two saving clauses are necessary. It is obvious that the inorganic domain is not chaotic, nor incoherent, nor ineffective. But it is without endearour. It is orderly and stable, made to last, able to assume forms of great beauty, with 
an interesting tendency to complexify under certain conditions, but it does not reveal any resident operative purpose. It will be understood that by 'purpose' in this discussion we mean intention, conative endeavour, anticipation of an end. We are not taking account of the employment of the word to denote use or efficieney, as when people say that the purpose of the elephant's trunk is to be a hand, or that a man worked to good purpose.

The other saving clause is, that we are not at present raising the question of the part that the inorganic has played in the world-wide genetic process in making organisms possible, and still plays in affording a basis for, and an opposition to the activities of organisms and personalities. The way in which a cradle and a home for organisms was made "when as yet there was none of them" is very remarkable (see Henderson, The Order of Nature, 1917), and will engage our attention later on. This may point to there having been a purpose in the institution of Nature, but not to there being a resident operative purpose in inorganic transformations.

\section{§4. Purposefulness and Purposiveness in Human}

Behaviour.

The other pole is to be found in human affairs, where purposefulness dominates. When we give time and energy to some scheme or eause, we know that what we do is actuated by a clearly conceived purpose. No one can make sense of our life who does not recognise this, even if he eall it the method in our madness. An anticipation, an ideal, with an associated tension of endeavour and glow of feeling, does as a matter of fact rule our will on many occasions. If this conceived purpose is not real, "with hands and feet", 


\section{ADAPTIVENESS AND PURPOSIVENESS}

we may abandon the possibility of either philosophy or science. Our life is at its highest efficiency when it is most dominated by purpose, when there is least of "the unlit lamp and the ungirt loin".

At a slightly lower level, however, we recognise analogous facts. We prepare for months to build a rockery in our garden, collecting stones and tree-roots and such like in a way that perplexes our next-door neighbour, who is not in the secret, who shakes his head at the absence of purpose in our behaviour. But all that we do is actuated by a purpose, so simple that we may call it perceptual, to form in the outer world an actual counterpart of a pleasing picture which had formed itself, as we say, in our mind. If this pereeived purpose is not real, nothing is real. A mental anticipation with its associated desire determines our behaviour.

We feel no difficulty in the fact that the curious can give, if he will, a tolerably complete physiological account of our various activities in making the rockery-the collecting, the carrying, the digging, and the building. For we know that however complete such an account may be either at the chemico-physical level, or at the physiological level, it never comes near being a complete scientific account until it recognises the end which serves "as a point of connection for a plurality of causes", something which cannot be measured or weighed-the vision of the rockery as desirable. Not only may a teleological interpretation be put upon our behaviour; it must be put upon it, if we are to give a scientific description.

There are many difficulties in our way when we begin to draw conclusions as to the purposes of others, but there is certainty in regard to our own. We have direct experi- 
ence of a clear outlook towards the future, of making plans, of desiring ends, of deliberately willing to realise an idea, of bending a multitude of means, often with some difficulty, towards a definite result, and so on. We cannot think of it without the concept of purpose. It is not merely that we put this finalistic interpretation on our conduct; we know that our purpose actuates our conduct. Among the conditions of our conduct we recognise ideal anticipations as dominant. As Lloyd Morgan puts it, there are psychological factors which we name " prospective significance and interest". "Pre-perceptive relationships have been established and highly developed. And such conseious relationships count, really count, every whit as much as any other natural relationship. They are not merely epiphenomenal phosphorescence; they are real conditions of the course of the process, both mental and bodily."

We must admit, then, the reality of purposeful self-determination. It is not that a psychical entity, called a purpose, functions; it is rather that our whole organism bends its bow in a particular dircetion and that we know this on the experiencing side as our conscious purpose and strengthen it in knowing it. We see, then, that in the human realm of ends the concept of purpose is essential; that in the inorganic domain, considered in itself, it is irrelevant; the question is as to the intermediate realm, and here the diffculties of interpretation are great.

This question of purpose is more or less clear when we are dealing with ourselves, but it becomes much more diffcult when we pass to our neighbours. One of our neighbours behaves as we were doing and we eredit him with the purpose of making a rockery. But it may be that he has some other purpose in view, or it may be that he is simply imitat- 


\section{ADAPTIVENESS AND PURPOSIVENESS}

ing us with a confidence that the result will be worth having. If there is this possibility of misinterpreting purpose within our own species, how careful must we be when we pass to animal behaviour.

We see a crofter making, year after year, a long line of the stones he has gathered from his field. We infer that he is arranging them so as to be least inconvenient. But one day he digs a trench beside the line and begins to lay the biggest blocks solidly within it. We know that he is going to build a wall. Now it is quite possible that this purpose was not in his mind when he began, and did not arise until the line of stones reached eertain dimensions or until his clearance gave him a little leisure to think of a further improsement. This idea of an inereasing purpose seems to be of great importance in Natural History, where a secondary end often appears to grow out of a primary one.

We inferred that the crofter was building a wall because we could not make sense of his activity on any other assumption; we argued by analogy from our own experience; and if we knew his language we could verify our interpretation by asking him what he was working towards. He would tell us that he had been working intermittently for years because he had the purpose of building a wall. The thought . of the future wall was something actual which moved the crofter to will and to do. The thought and the will were in a real sense the ground of necessity of the wall, not less real than the stones.

But the convincingness of our interpretation of the crofter's actions as the outcome of his purpose rests, we must admit, on our recognition of him as a fellow-countryman, on his own assurance, and on parallels between his behaviour and 


\section{ADAPTIVENESS AND PURPOSIVENESS}

endeavours within our own experience. How careful we must be in regard to the purposefulness of animals who are very distantly related, whose language-if they have anywe do not know, whose behaviour is cast on different lines from ours.

When we see a blacksmith take a twisted shoe from a horse's foot, heat it in the fire, hammer it, cool it, file it, and so on, we know from the very first what his purpose is, and we understand more or less every step in relation to the obvious end. But if we watch a potter or a glass blower or the like for the first time we find it more difficult from what we see to prove that he is not amusing himself; he does things that we do not see the meaning of; he ends just at the last moment by turning out something which we did not expect. There is here the warning that a sequence may be actuated by purpose through and through although we do not recognise the domination-not even when we know the end.

§5. Purposiveness and Purposefulness in Animal Behaviour.

Let us pass to animal behaviour. When a dog hides an unfinished bone in a very unusual place; when Lord Avebury's dog Van goes to its box and brings out and arranges the letters T-E-A; when rooks take fresh-water mussels to a great height and let them fall on the shingle beneath so that they are broken; when a mother weasel, accompanied by one of her offspring, about to be overtaken on the links, seizes the youngster in her mouth, dashes on ahead, and lays it in a sandy hole; when beavers cut a eanal right through a large island in a river; when mares, some past foaling, unite to lift up between them a number of foals on the 


\section{ADAPTIVENESS AND PURPOSIVENESS}

occasion of a great flood, and so on, we say, with probable accuracy, that the creature was actuated by a definite purpose, by some sort of intention, by some anticipation of an end. The validity of this undemonstrable conclusion depends (1) on the need of assuming some degree of purpose as the connecting thread which binds together the series of acts, and (2) on what we know in other ways of the creature's psychological analogy with ourselves. If the acts composing the chain are discontinuous, the need for postulating a bond of purpose is particularly evident. If the creature has a fine brain at a high structural level, as we know to be the case with dogs, horses, clephants, and the like, the legitimacy of inferring an actuating purpose is the more probable. It may well be that the purpose is not of the same nature as our purpose when we begin a day with the intention of economising our energies at every turn for a difficult task to-morrow, or of converting as many people as possible to an acceptance of methodological vitalism. It may be that the animal's 'purpose' is only a concrete picture with an associated desire,-a cognitive disposition at a perceptual level and an associated conative disposition. So it is sometimes in mankind, especially in childhood. But it will still be legitimate to describe the behaviour as purposeful, though the purpose was not a conceived purpose. For we mean by purpose an intention of the organism, involving a perceptual or conceptual anticipation of a desired end.

Difficulties in making sure that an actuating purpose is at work begin whenever we pass from ourselves to our neighbours; they increase when we pass to big-brained higher animals; they go on increasing when we pass to cases like that of a bird building a nest. The bird goes through a certain routine of collecting and interweaving materials, 
of lining the interior with feathers-there may be over two thousand of them, - of covering the outside with lichens which make the nest almost invisible on the bough. There is no doubt as to the adaptiveness of the chain of acts; it seems clear that the work is without justification until it is finished; we cannot make sense of the prolonged activity unless we sce the whole in the light of the final result which is of great value to the individual bird, to the nestlings, and to the species in question. But we are no longer so certain that the bird's behaviour is actuated by perceived purpose. We may know, for instance, that the bird never made a nest or laid an egg before; we know that there is a remarkable rigidity in the routine which sometimes detracts from its effectiveness; and that there arc occasional aberrations which suggest that the bird is not quite on the spot. In other words, we are watching an instinctive routine with a spice of intelligence. How far are we warranted in saying that it is actuated by purpose? Can there be purpose which is not clearly perceived? We propose to rank all such cases under the rubric 'purposiveness'. It implies in the bird's case a determined endeavour, obedience to an inborn inspiration modified by intelligence, but we are not sure how far the end is in view.

Returning to the observations of Prof. J. B. Watson and Dr. K. S. Lashley on homing terns, we have to interpret such facts as these. A number of brooding terns are conveyed in hooded cages on board ship for over four hundred miles from the nesting island; they are liberated in the middle of the sea beyond all hint of land; they set off at once for home against a head wind; some of them reach home safely. How they succeeded we do not know; whether they are influenced by magnetic currents and the like we do not know; 


\section{ADAPTIVENESS AND PURPOSIVENESS}

but this we do know, that they are going back to their nests. The nesting impulse remains strong for two or three weeks, and this gives an illuminating significance to the homing of these sea-swallows. They are returning to activities in which their life reaches its climax, to the continuance of which they are urged by a deep organic impulse, by an irresistible will which is not readily baulked.

But difficulties increase when we pass to the field of purely or predominantly instinetive behaviour among animals ' of the little brain type', such as ants and bees. We see numerous acts dovetailed in a series, correlated in a definite sequence which leads to a useful result. We cannot make the bchaviour intelligible without saying: "Somehow or other these several acts have been concatenated in relation to an end." But in what senso can we say that a bee on its first honey-collecting expedition is actuated by a purpose? We dare not suppose a conceived purpose and we cannot clearly think in this ease of a perceived purpose, for the beo is operating effectively in a world previously unknown to it. What kind of purpose can there be? We shall speak of instinctive purposiveness, differing from perceptual purposefulness in the probable absence of any clear vision of the end.

. Here we have to include the extraordinary cases where the individual works resolutely towards a goal which it never experiences. Many Digger-wasps, for instance, make elaborate preparations for offspring which they never survive to see. Since social wasps are geologically ancient it is reasonable to suppose that their behaviour originated in the distant past when the ancestors of our present-day species did survive to see their progeny. Originally, on this supposition, whether the primitive behaviour arose as an intelligent new de- 
parture (as some would say) which was hereditarily added on to the instinctive patrimony of the race, or arose as a germinal mutation (as we would say) which was intelligently tested and approved of in the individual lifetime, it is not far-fetched to suppose that it was justified to the individual in some measure of satisfaction. The mothers saw their children, which is more than they do now.

The difficulty is to understand the present-day implicit obedience to the voice of the distant past, to see how an elaborate piece of instinctive routine which does not justify itself to its possessor can retain its imperious inertia through the ages. Probably some sop unknown to us is given to the individual's interests and satisfactions. It may be, for instance, that parental instincts have become in some cases linked on to conjugal instincts, reverberations of which continue to give meaning and interest to parental care whose reward is nowadays never experienced. But the problem of making for an unseen goal is a very difficult one.

Since this was written our suggestion of an individual 'sop' has been strikingly confirmed by the observations of Roubaud and of Wheeler. For certain tropical wasps Roubaud has shown that the queens and workers receive from the grubs, which they assiduously tend and feed, small quantities of a secreted elixir of which they are extraordinarily fond. For certain kinds of ants Wheeler has shown that there is a similar give and take (trophallaxis) between the workers and the grubs. The workers feed the grubs with chewed flesh, but they receive from their charges a douceur of secretion which seems to keep them in good heart.

But we cannot draw a line at instinctive creatures like ants and bees, where the complexity of the brain gives us some warrant for postulating ideational processes. There 
is hardly less effective purposelike behaviour in animals with no nerve-ganglia at all. Our typical case, already described, is the struggle between the brainless starfish and the brainless sea-urehin. Here we have a long series of difficult operations, not in the line of least resistance, not habitual, not a sequence of tropisms or reflexes, but a correlated behaviour-chain. Can we avoid saying that the starfish shows endeavour? We do not dream of calling it purposeful, but is it in any way purposive? We have to remember that the starfish has no nerve-ganglia. It has diffusely scattered neurons, a line of them up each arm, and a pentagon uniting these lines around the mouth. But there is no concentration into ganglia, and therefore we must be very parsimonious in our use of mental terms. We propose to speak of this sort of purposelike behaviour as illustrating organic purposiveness, organised endeavour.

Summing up to this point, we find that a modicum of purpose or intention is to be recognised over a very wide range, that it is a vera causa that counts, that we are not at liberty to take it or leave it, that it must enter into the scientific description. It probably represents in all eases an organismal summarising of past experiences in such a way that a definite endeavour is engendered, and behaviour is effectively dominated. But it tends to elearness to distinguish conceptual purposefulness in man's conduct, perceptual purposefulness in the intelligent behaviour of man and some animals, instinctive purposiveness in the routine behaviour of ants and bees, and organic purposiveness in the controlled and experimental endeavours of brainless animals,-even in the architectural achievements of the arenaceous Foraminifera.

We began with deliberate purposefulness and worked 


\section{ADAPTIVENESS AND PURPOSIVENESS 341}

downwards; but deliberate purposefulness is a lofty specialisation of organic purposiveness. Without implying too hard and fast boundary lines, we suggest that the word purposeful be kept for actions in which there is conscious anticipation of the constraining end. The common note in purposeful or purposive behaviour is that of the individuality or total reaction of the organism. When the organism as a whole works towards a future result which is not immediate, there is purpose in some form or other. Where the concept of purpose or intention is applied beyond the category of individuality there is bound to be confusion of thought, and care must be taken not to use it to denote the end which a particular collocation subserves or the utility which any particular collocation may have in the economy of Nature.

\$6. The Purposelikeness of the Ordinary Functioning of the Body is Covered by the Concept of Adaptation.

The organism's behaviour as a whole is fundamentally purposelike. It makes for self-preservation and racepreservation in the widest sense. It may, on occasions, exhibit self-determination, selection, and control with reference to a distant result. In higher animals, purpose probably operates, as in man, as a cognitive anticipation of the future; in lower animals the nervous system is so different that we dare not argue from analogy as to the degree of awareness with which the conative bow is bent.

It appears probable that activities originally dominated by clearly perceived purpose, may, by individual habituation or by germinal variation, sink to a lower level of organised purposiveness. Not only the bending of the conative bow, but the hitting of the mark, becomes part of the organisation, it may be part of the inheritance, part of the 


\section{ADAP'TIVENESS AND PURPOSIVENESS}

organism's ready-made self. The organism as a whole hardly requires to keep its hand on the reins, purpose has become implicit. There are disadvantages in this, for the fixity sometimes leads to quaint mistakes, but it spells cconomy and allows more freedom for direct or individual purposive or purposeful endeavours and experiments. Just as we need the uniformity of the inorganic domain as a reliable fulcrum for our efforts, so the uniformity of organised or implicit purposiveness, besides saving organismal energy, may serve as a trustworthy stepping-stone to higher things.

When we observe an intricate machine with many regulative adjustments, such as safety-valves, we are impressed with its efficiency and purposelikeness. But we credit its maker with purpose, not itself; the concept does not grip. It is a confusion of thought to speak of a torpedo or a solar system being actuated by purpose. Only an organism or a higher form of Being can have a purpose.

Similarly in regard to the smooth working of the organs of a complex animal and even the orderly development of the same we are inclined to say that the appropriate term is adaptive not purposive. The concept of adaptation suffices for the fact that in ordinary functioning "the whole and the parts are, as it were, reciprocally ends to each other". The harmonious functioning and development are the outcome of an organisation gradually wrought out through ages and are exhibited whenever suitable liberating stimuli are present. We need not here introduce the concept of actuating purpose in any form.

But it seems legitimate to lay emphasis on the view which we have tried to substantiate that the adaptive organisation did not come about mechanically, that it has behind it a long history in which germinal variability and organic pur- 
posiveness have played an important part, and that even when it may be said that variability shuffles the cards blindly, it is incumbent on the individual to play the game intelligently if it means to win.

Moreover, in the regulatory self-adjustment of the organism when functioning or development has been badly disturbed, in the activity, within the body, of independent mobile elements like phagocytes, in the regeneration of a lost lens from a tissue which does not normally give rise to one, we get just a glimpse of a residual organic purposiveness, though that has been as a whole resigned in favour of very perfect and thoroughgoing organisation.

What is meant by saying that the organism is essentially purposive, or that it has an essentially teleological or finalist aspect? This is meant, that the whole life "expresses a tendency to persist, that the whole life is adapted towards selfpreservation and self-expression. And if it be said that this adaptedness is the outcome of ages of mechanical variation and selection, the answer is that neither variation nor selection can be adequately described as mechanical.

\section{§7. Provisional Conclusion and Anticipation.}

We have been necessarily much concerned with the outworks, and there remain many imperfectly answered questions. What, in the world-becoming as a whole, is the significance in the largest sense of the inorganic domain in its intricacy and splendour, of the myriads of invisible Protists, of the hundreds of thousands of plants, of the struggle for existence, of the prodigious mortality, of the age-long genetic process with all its groaning and travailing? To such questions we shall return in our study of Organic Evolution, conscious that behind them there loom others-If Nature be Nature 


\section{ADAPTIVENESS AND PURPOSIVENESS}

for a purpose, what is that purpose? If there be design what does it promise?

The general outcome of the present discussion is an appreciation not only of the pervasiveness of mentality in the realm of organisms, but of all-penetrating purpose as well. Looking back imaginatively on the course of evolution, we have seen the emergence of an aspect of reality which we call Life, and another aspect of reality which we eall Mind, now we are getting glimpses of the emergence of another aspect of reality which we eall Purpose. Of this we shall get a larger view when we eome to consider the evolutionary process as a whole.

In the meantime, however, we have gained something. For while thero may be difference of opinion as to terms and coneepts, it has become increasingly clear that animals, and plants too, are creatures with purposeful or purposive lives, and are not to be banished from the Realm of Ends. This enriches our conception of life. It is a contribution towards a Philosophy of Nature. It makes our view of Nature and our view of Human Life moro conformable.

In any case we trust that our study so far may have contributed to a deeper appreciation of the Realm of Organisms, in which we are, to say the least, no aliens. We have sought to envisage the variety of life-hundreds of thousands of distinct individualities or species; the abundance of life,like a river always tending to overflow its banks; the diffusion of life,--exploring and exploiting every corner of land and sea; the insurgence of life,-self-assertive, persistent, defiant, continually achieving the apparently impossible; the cyclical development of life,-ever passing from birth, through love, to death; the intricacy of life,-every cell a microcosm; the subtlety of life,-every drop of blood an 
index of idiosynerasies; the inter-relatedness of life,-with myriad threads woven in a patterned web; the drama of life, -plot within plot, age after age, with every conceivable illustration of the twin motives of hunger and love; the flux of life,-even under our short-lived eyes; the progress of life,-slowly creeping upwards through unthinkable time, expressing itself in ever nobler forms; the beauty of life,every finished organism an artistic harmony; the morality of life,-spending itself to the death for other than individual ends; tho mentality of life,-sometimes quietly dreaming, sometimes sleep-walking, sometimes widely-awake; and the victory of life,-subduing material things to its will, and in its highest reaches controlling itself towards an increasing purpose.

It is something to have found warrant for regarding the Realm of Organisms as pervaded with active purposiveness. At a later stage in the argument we shall show that there is at least a presumption in farour of the view that Nature is Nature for a purpose-an increasing and transcendent purpose. At this stage it seems as if part of that purpose were the emergence of individuality, mind, freedom, purpose. This thrilling word purpose, expressing the most real fact in our personal experience, brings us at this half-way house to our provisional conclusion which is, we confess, too large for the premises, that individualities with mind, with freedom, and with purpose, eannot be accounted for in terms of a ground of reality without mind, without freedom, without purpose. Therefore let us humbly seek after, if haply we may find, more than the footprints of the Creator, who beholding all the works of His hands found them good for His purpose. 


\section{SUMMARY.}

Our consideration of the realm of organisms has shown us the apartness of living creatures and how they transcend mechanical and dynamical formulation, the important rôle played by behaviour with a definitely mental aspect, the pervasiveness of beauty, and the large proportion of time and energy devoted to activities which make not for self-preservation but for race-welfare. We find, in fact, in Animate Nature far-reaching correspondences to our ideals of the True, the Beautiful, and the Good,-which suggest a rehabilitation of Natural Theology.

Taking a wide sweep we gain another great impression-that of almost universal adaptiveness. Every living creature is a bundle of adaptations. It matters comparatively little that we are to some extent able to describe the process by which these adaptations have arisen (the imperfections of this description to be considered later), for the basal fact remains that living ereatures have had the capacity of evolving thus adaptively. The adaptiveness depends on intrinsic qualities, previously discussed, which are more striking than readymade fitnesses.

Adaptations may be classified as:-(1) structural arrangements with internal or external reference, (2) co-ordinating functional adjustments of a special sort, including regulatory integrations, and (3) inter-organismal adaptations. The result of the last is a systematisation or co-ordination of lives, world-wide in its scope, and often extraordinarily subtle in its accomplishment.

In the inorganic domain we find rigorous concatenation, a dominance of mechanical necessitation. There are no unique individualities, no alternatives; and the concept of purpose is irrelevant (except when we are thinking of the significance of the evolutionary trend as a whole). On the other hand, in the human realm of ends, ideal anticipations are dominant. Our conduct implies purposeful selfdetermination. There is no difficulty until we begin to consider the realm of organisms,--between the inorganic and the buman.

It may be said that the organism as a whole is characteristically purposive,- " a unity in which the whole and the parts are reciprocally ends to each other". It shows some measure of self-determination; its behaviour is regulatory, selective, controlled; the activities of its parts are correlated in reference to the preservation and continuance of the individual and the race. The development 
is also purposive through and through. And if it be said that in all this the organism is merely obeying its bereditary constitution adapted to react to an appropriate environment, it must be observed that this hereditary constitution is determined by the selection of variations, many of which seem like experiments in self-expression, and that all the innate variations are, so to speak, cards which have to be played by organismal endeavour. This endeavour is ipso facto purposive and is along the lines of previous play in some measure seleeted by the organism.

Passing above what may be called organised purposiveness, we may recognise instinctive purposiveness, often with its paradoxical quality of making towards a goal which the individual never experiences. At a higher level, among intelligent animals, it beeomes possible to speak of a perceived purpose-an imaging of the end which has compelling force. Thus we are led to an appreeiation not only of the pervasiveness of mentality in the realm of organisms, but of the all-penetrating purposiveness as well. 


.

$-$

4
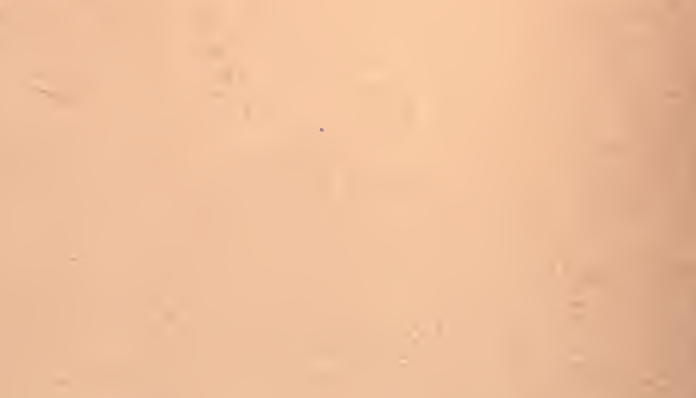

$$
\begin{aligned}
& \text { - n- } \\
& \text { - }
\end{aligned}
$$$$
=
$$

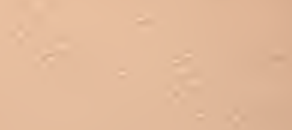




\section{DATE DUE}

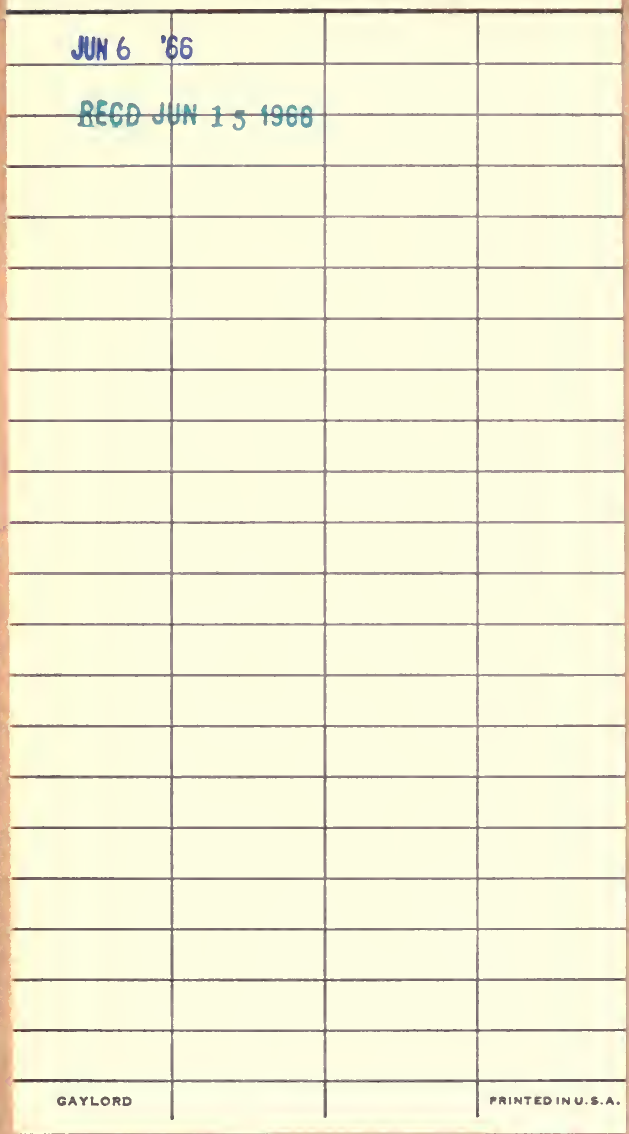


UC SOUTHERN REGIONAL. LBRAAY FACLITY

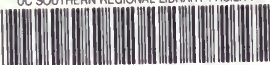

A $000433397 \quad 7$ 


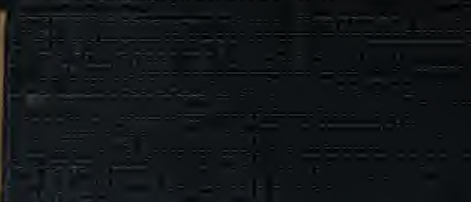

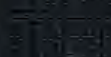

$7=$

$\frac{3}{3}:=$

(1)

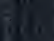

$x-2=-2$.

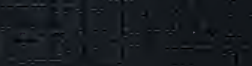

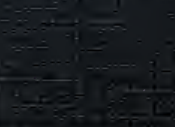

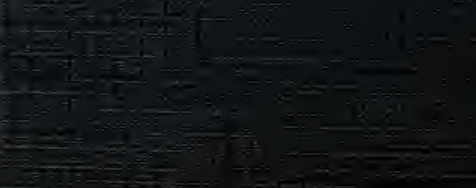

